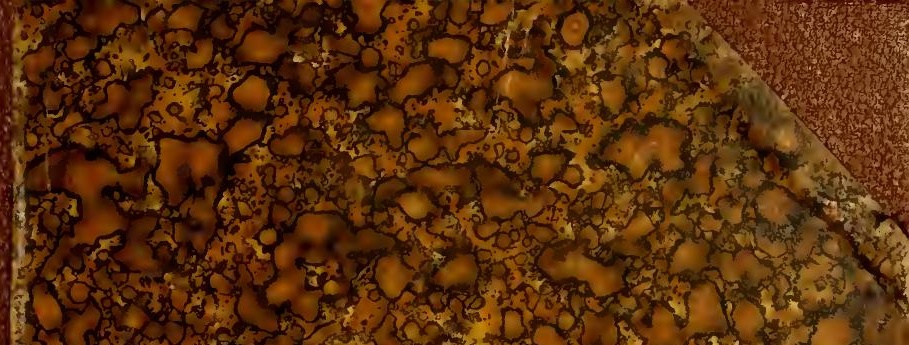
2) 2 min

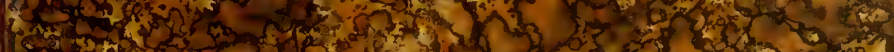
6 3 a

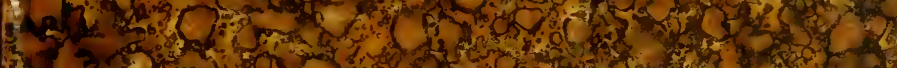
4. 350 .

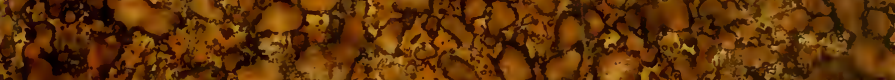

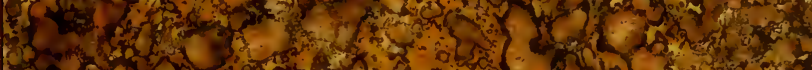

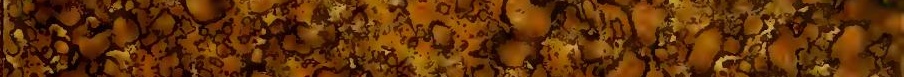

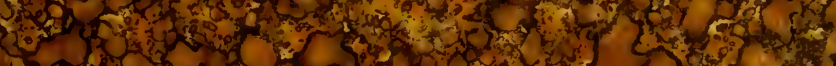

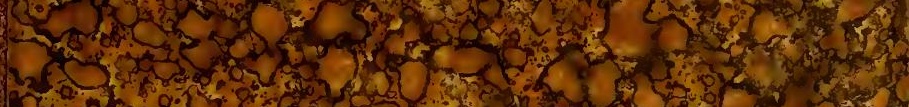

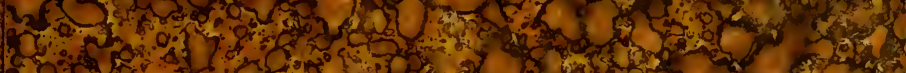

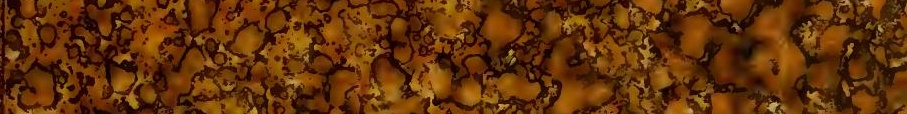
C.

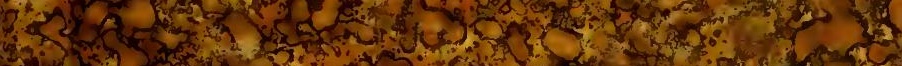

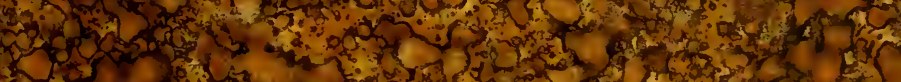

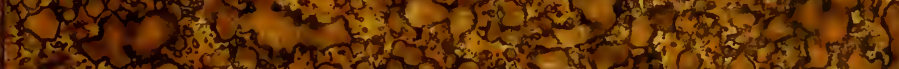

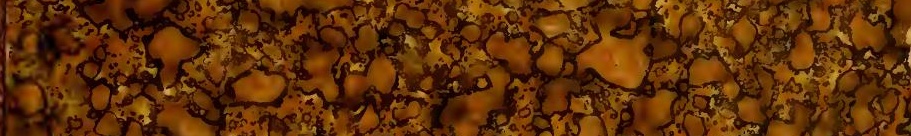

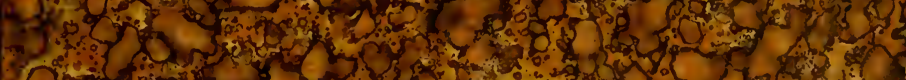

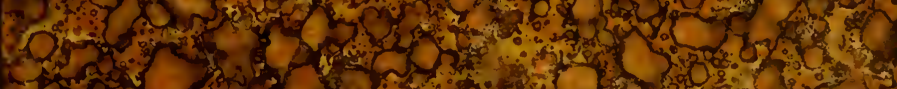

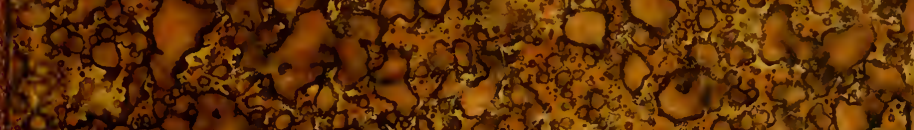

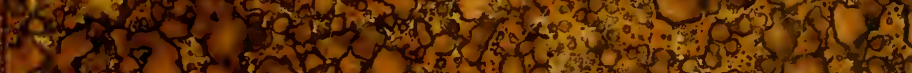

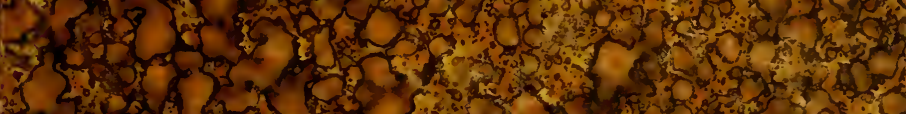

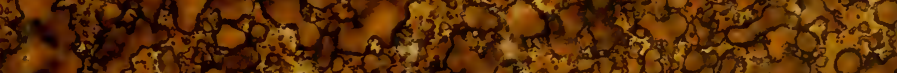

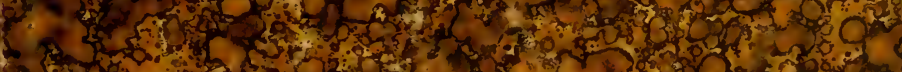

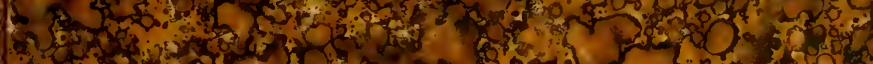

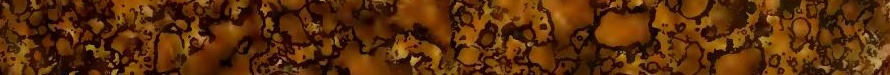

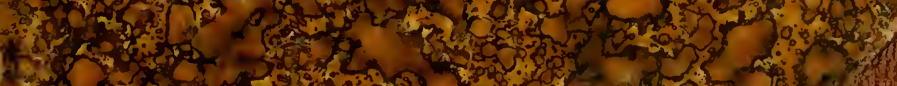

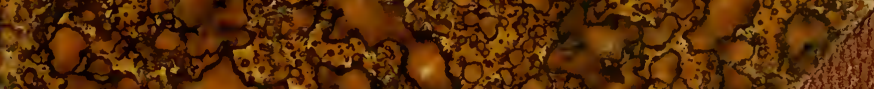

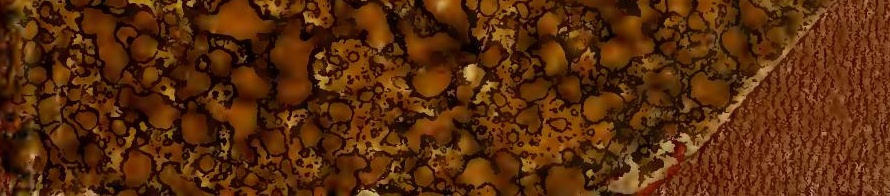





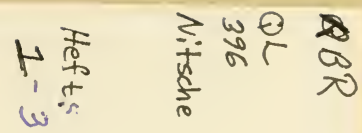

हें

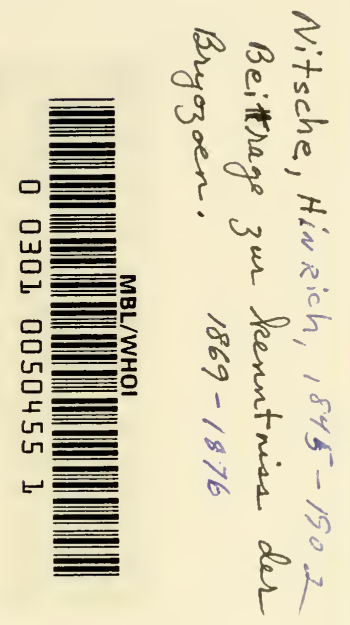





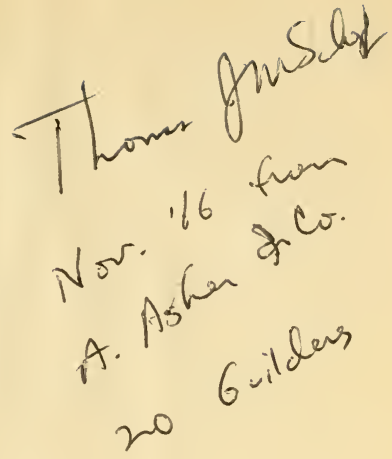





\title{
BEITRÄGE
}

\author{
ZUR
}

\section{KENNTNISS DER BRYOZOEN}

VON

\section{$\mathrm{D}^{\mathrm{R}}$. HINRICH NITSCHE.}

\section{HEFT.}

MIT DREI TAFELN.

1. Beobachtungen iiber die Entwicklungsgeschichte einiger chilostomen Bryozoen. Mit Taf. I.

II. Ueher die Anatomie von Pedicellina echinata SARS. Mit Taf. II. III.

\section{LEIPZIG,}

VERLAG VON WILHELM ENGELMANN.

1569 . 
Abdruck ans der Zeitschrift für wissensch. Zool. XX. Bd. 1. Heft. 
I.

Beobachtungen uber die Entwicklungsgeschichle einiger chilostomen Bryozoen.

(Hierzu Tafel I.)

Eine geschlechtliche Fortpflanzung ist meines Wissens bei den chilostomen Bryozoen nur von HixLex') und Smitr ${ }^{2}$ ) beobachtet worden. Bis zum Erscheinen der leider nur sebr kurzen Arbeit des ersteren glauble man, die Eier, welche zu gewissen Jabreszeiten in den sogenannten Ovicellen gefunden werden und welche in ihnen zu bewimperten Larven sich entwickeln,entständen innerhalb der Ovicellen. Die Beobachtungen von Huxuer widerlegen diese Annahme; er hat nämlich gesehen, dass sich innerhalb der jüngeren Zooecien ${ }^{3}$ ) von $\mathrm{Bugula}$ avicularis, B. plumosa, B. flabellata und Scrupocellaria scruposa Eier und Spermatozoen bilden und zwar zu gleicher Zeit in denselben Zooecien. Die Spermatozoen entstehen stets am unteren Ende jedes Zooecium, die Eier dagegen bei den verschiedenen Species an verschiedenen Stellen. Jede Ovicelle ist ursprünglich leer, plötzlich findet man aber ein grosses $\mathrm{Ei}$ in ihr, während zugleich das fruher in der Leibeshöhle"des betreffenden Thieres befindliche Ei verschwunden ist. Er schliesst hieraus, dass das in der Leibeshöhle befruchtete $\mathrm{Ei}$ in die Ovicelle ubertritt. Die Ovicellen sind nach ihm also nur eine

1) Quarterly Journ. Micr. Sc. Vol. IV. 1856, p. 191.

2) Oefvers. af. K. Vet.- Akad. Förhandl. 1865, p. 33.

3) Der Ausdruck "Zooecium" ist von Suıтt sehr passender Weise anstatt des bis dahin gebräuchlichen "Zelle" vorgeschlagen worden. Ebenso rührt der Ausdruck wMündungsarea" von diesem Forscher ber. 
Art Bruttasche (marsupial pouch). Für Scrupocellaria scruposa sind diese Angaben durch Surt, welcher ausserdem noch eine geschlechtliche Fortpflanzung bei Flustra membranacea beobachtet hat, bestätigt worden. Hrvcks $\left.{ }^{1}\right)$ dagegen leugnet ihre Richtigkeit und behauptet bei Bugula flabellata, B. turbinata und Bicellaria cilia ta entständen die Eier wirklich innerhalb der Ovicellen und entwickelten sich daselbst. ohne Befruchtung zu bewimperten Larven, Angaben, welche auch von Surт ${ }^{2}$ ) wieder citirt werden.

Im Sommer 1868 hatte ich Gelegenheit auf Helgoland Bugula flabellata Tномгs., B. plumosa Pall. und Bicellaria ciliata Lis. genauer zu untersuchen. Die Resultate dieser Beobachtungen, soweit sie sich auf die Entwicklungsgeschichte beziehen, sind im Folgenden zusammengestellt.

Wir wollen uns zunächst zu Bi cellaria cilia ta wenden.

Bei diesem Thiere sind wie bekannt die Zooecien zweizeilig angeordnet, und zwar alterniren die Zooecien beider Reihen mit einander, ihre Form ist füllhornartig und die Mündungsarea der Zooecien liegt beinahe parallel mit der Längsaxe derselben. Wir werden der Einfachheit wegen diejenige Seite des Thierstockes, auf welcher die Mündungsareen der Zooecien liegen, die Vorderseite, die entgegengesetzte die Rückseite, den Theil eines jeden Zooecium, mit welchem es von dem älteren Zooecium entspringt, den unteren, die Gegend der Mündung aber den oberen Theil nennen, eine Nomenclatur, welche lediglich den wirklichen Verhältnissen des Thierstockes in seiner natürlichen Lage entspricht, ohne Rücksicht auf die Frage, was man als Dorsaloder Ventralseite anzusehen habe.

Ein jedes ausgewachsenes Zooecium besteht aus einem oberen und einem unteren Theile, welcher letzterer durch eine schräg von innen nach aussen laufende Einschnürung von dem oberen abgegrenzt ist und mit einer zweischenkeligen Verbreiterung von dem oberen Theile der Rückseite des nächst älteren Zooecium derselben Reihe entspringt (Taf. I. Fig. 14). Die Zooecien, welche sich an der Spitze eines jeden Astes befinden, sind stets unausgewachsen, indem der Stock fortwährend knospt. Diese Knospung an den Astspitzen und ein mit ihr parallel gehendes Absterben der Polypide der älteren Zooecien des Stockes scheint das ganze Jahr hindurch stattzufinden, während eine geschlechtliche Fortpllanzung nur am Ende des Sommers und im Herbste auftritt. $\mathrm{Zu}$ dieser Zeil bilden sich in jedem Zooecium, sobald nur das Polypid seine Ausbildung erreicht hat, Eier und Spermatozoen.

1) Quart. Journ: of Mier. Sc. 1861, p. 278.

2) Oefvers. af. K. Vet.-Akad. Förhandl. 1865, p. 19. 
Die Ei er entstehen nicht in besonderen Eierstöcken, sondern einfach durch Knospung an der Innenfläche der Endocyste; gewöhnlich sind es zwei oder auch drei, welche von einer gemeinsamen feinen Membran umbüllt und durch sie an der Endocyste hefestigt sind. Sie bestehen aus einer gelblichen, stark lichthrechenden Dottersubstanz, und man kann an ihnen stets deutlich die Keimblase unterscheiden, meistens auch den Keimfleck; an Spiritusexemplaren ist letzterer jedoch manchmal verschwunden. Zwei solcher Eier (Taf. I. Fig. 1ä) finden wir z. B. bereits in dem dritten Zooecium - von der Spitze des Zweiges aus gerechnet - des auf Taf. I. Fig. 14 abgebildeten Exemplares. Die Eier finden sich stets an demselben Orte, nämlich in der Mitte derjenigen Seite der oberen Abtheilung jedes Zooecium, mit welcher es der anderen Reihe anliegt (Taf. I. Fig. $14 v v$ ). Wegen ihrer anfänglich sehr geringen Grösse sind diese Eier schwer aufzufinden, zumal der Darmtractus meist hindernd im Wege liegt.

Die Spermatoz oen sind als solche nicht so zeitig zu erkennen, als die Eier. In den unteren Abtheilungen der obersten, ausgebildeten Zooecien des Thierstockes bemerkt man anfänglich (Taf. I. Fig. 14t) nur eine aus hellen Körnern bestehende Masse. Betrachtet man aber Zooecien, welche ein wenig weiter abwärts am Zweige liegen, so sieht man aus dieser körnigen Masse eine grosse Anzahl ungemein feiner, sich schlängelnder Fäden hervorragen und in noch älteren Zooecien hat sich die ganze Körnermasse zu Spermatozoen umgewandelt, welche theilweise schon nit' lebhaften, schlängelnden Bewegungen frei in der perigastrischen Flüssigkeit umherschwimmen. Sie sind einfach fadenförmig und stark lichtbrechend. In solchen älteren Zooecien sind die an der bekannten Stelle gelegenen Eier inzwischen bedeutend gewachsen; endlich findet man dann ein noch älteres Zooecium, in welchem ein Ei sich losgelöst hat und frei in der Leibeshöhle liegt. In diesem losgelösten Eie, dessen Inhalt dunkler und körniger geworden, ist die Keimblase nicht mehr sichtbar und man darf daher wohl annelsmen, dass es bereits befruchtet worden ist. Diese Lier entwickeln sich aber nicht innerhalb des Zooeciums des Mutterthieres zu Larven, vielmehr müssen sie zu diesem $Z$ wecke in die Ovicellen übertreten.

An jedem Zooecium, in welchem sich Genitalproducte zu bilden beginnen, entsteht durch Knospung nach aussen am inneren Seitenrande der Mündungsarea eine 0 vicelle. Zunächst zeigt sich hier eine kleine Anschwellung (Taf. I. Fig. 14 ovic.), bald können wir zwei verschiedene Theile an dieser Anschwellung unterscheiden, eine von dem kalkigen Rande der Area entspringende, l öf felfö rmige, hohle A u ftreibung (Taf. I. Fig. 13 b), deren concave Fläche der Mündungsarea 
zugekehrt ist, und eine runde etwas kleinere Blase, welche an der Basis der ersteren entsteht und der concaven Seite derselben anliegt (Taf. I Fig 13 c). Die löffelförmige Anschwellung zeigt an ihrer convexen Seite bereits eine feste kalkige Schicht, ihre concave Seite dagegen, ebenso wie die runde Blase, ist membranös. An ihren Basen hängen beide fest zusammen.

Allmählich wachsen nun beide Blasen, die löffelförmige aber stärker als die runde, sodass die runde allmählich auf der einen Seite von der löffelförmigen wie von einem Schirme umschlossen wird und sich ein Raum bildet zwischen der concaven membranösen Wandung der loffelförmigen und der runden Blase (Taf. I. Fig. 12). Zugleich streckt sich auch die Basis der Blasen zu einer Art Stiel, mit welchem sie nun am Rande der Mundungsarea befestigt erscheinen. Der Rand der löffelförmigen Blase wächst mehr und mehr, bis sie die sogenannte helmartige Form erhalten hat, in welcher die Eizellen von Bicellaria gewöhnlich beschrieben werden (Taf. 1. Fig. 10). Genau genommen stellt sie alsdann eine an der Unterseite mit einem grossen Loche versehene Hohlkugel mit doppelten Wänden dar. Die beiden Wände der Hohlkugel gehen am Rande der Oeffnung ineinander uber und vom Rande der Oeffnung entspringt ein kurzer Stiel, mit welchem die Ovicelle an den Rand der Mündungsarea befestigt ist. Die äussere Wand der Ovicelle ist mit einer kalkigen Schicht bedeckt, welche eine punktirte Structur zeigt; die innere Wand ist membranös. An dem Stiele hängt die helmförmige Blase fest zusammen mit der runden Blase, welche die Oeffunng der ersteren wie eine Art von Deckel verschliesst, inden sie sich dicht an die Ränder der Oeffnung anlegt. Es hat sich inzwischen bereits in einem etwas jüngeren Stadium innerhalb der rundlichen Blase ein aus stark lichtbrechenden Fasern bestehender Strang gebildet, welcher von der Verbindungsstelle beider Blasen entspringend, dieselbe quer der Länge nach durchsetzt (Taf. I. Fig. 11 d). Späte zweigen sich einige Fasern ab und befestigen sich zunächst an der Unterfläche der runden Blase, um dann aber an dem Anheftungspunkt der ubrigen Fasern zu endigen $\left(d^{\prime}\right)$. Es bilden daher sämmtliche Fasern ein Dreieck mit sehr stumpfen Scheitelwinkeln (Taf. I. Fig. $10 d$ ). Ausserdem strablen von dem Ausgangspunkte sämmtlicher Fasern an dem Stiele noch einige viel feinere Fäden aus, welche sich an der Oberseite der runden Blase festheften (Taf. I. Fig. $\left.10 d^{\prime \prime}\right)$; diese letztere hat sich inzwischen auf der oberen Hälfte ihrer Innenfläche mit einem deutlichen Epithel aus flachen polygonalen Zellen mit Kernen bestehend uberzogen.

Die Ovicelle hat nun ihre definitive Form erhalten, sie ist aber noch leer, kein Ei, noch auch eine Anlage zu einem Ei findet sich in 
ihr; dagegen enthalten diejenigen Zooecien, welche soweit entwickelte Ovicellen tragen, stets weit entwickelte Eier und Spermatozoen, meist sogar ein befruchtetes, frei in der Leibeshöhle liegendes Ei. In den nächst älteren Zooecien aber finden wir, dass das befruchtete Ei aus der Leibeshöhle verschwunden ist, dass dagegen in dem Raume zwischen der helmförmigen und der runden Blase ihrer Ovicelle ein Ei liegt, welches in Grösse und Gestalt gänzlich mit dem beschriebenen befruchteten Eie übereinstimmt (Taf. I. Fig. 10).

Auf diese Beobachtung gestutzt, glaube ich mich $z u$ dem Schlusse berechtigt, dass das in der Leibeshöhle befruchtete $\mathrm{Ei}$ in die Ovicelle übergetreten ist, wenngleich es mir nie gelang den Uebertritt selbst zu beobachten. Auf welche Weise derselbe erfolgt, kann ich daher auch nicht angeben; wahrscheinlich zwängt sich das Ei durch den hohlen Stiel der Ovicelle und tritt durch eine Oeffnung, welche ich an der Stelle, wo die beiden Blasen zusammenhängen (Taf. I. Fig. $10 x$ ), gelegen vermuthe, in den Raum zwischen den beiden Blasen; es wird innerhalb der Concavität der helmförmigen Blase, der eigentlichen Ovicelle der bisherigen Beschreiber, durch die rundliche, die Oeffnung verschliessende Blase festgehalten, liegt dicht an der membranösen Innenfläche der helmförmigen Blase an und klebt mitunter an derselben sogar fest. In dieser Lage entwickelt es sich nun weiter, es furcht sich, erreicht die Maulbeerform, erhält dann bei fortwährendem Wachsthum eine feste äussere Membran und wenn es so weit gewachsen ist, dass es beinahe die ganze Höhlung der helmförmigen Blase ausfullt, hat es auf seiner Aussenfläche Wimpern bekommen und sich überhaupt bereits vollständig zu der später $z u$ beschreibenden Larve ausgebildet.

Die rundliche Blase ist durch sein Wachstbum inzwischen stark abgeplattet und beinahe gänzlich aus dem Inneren der helmförmigen Blase verdrängt worden, deren Oeffnurıg sie aber noch immer verschliesst.

Die Larve ist nun durch die Thätigkeit ihrer Wimpern in einer steten, rotirenden Bewegung; endlich schlüft sie aus der Ovicelle heraus und schwimmt in rascher aber gleichmässiger Bewegung umber. REID ${ }^{1)}$ - der einzige Forscher, welcher eine annähernd genaue Beschreibung der Ovicellen und zwar von Bugula fl a bellata giebt - hat beobachtet, dass die rundliche Blase, welche er als eine Duplicatur der Endocyste der Ovicelle betrachtet, an Ovicellen, welche reife Larven enthalten, rhythmische Contractionen macht. Es rüren diese wahrscheinlich her von Contractionen ähnlicher Faserstränge, wie diejenigen, 
welche ich soeben beschrieben habe. Da diese auch in ihrem ganzen Habitus grosse Aehnlichkeit zeigen mit den übrigen Muskeln von Bicellaria, so möchte ich nicht anstehen, diese Stränge für Muskeln zu halten, deren Aufgabe es ist, den Rand der rundlichen Blase von dem Rande der Oeffnung der helmartigen Blase hinwegzuziehen und so das Ausschlüpfen der Larve zu ermöglichen, eine Vermuthung, die um so wahrscheinlicher wird durch den Umstand, dass die Ovicellen, aus denen die Larve bereits ausgeschlüpft ist, keine Perforation oder Ruptur der Deckelblase zeigen.

Auch bei Bugula plumosa gelang es mir, im Septemher Eier und Spermatozoen zu beobachten. Die Spermatozoen bilden sich in gleicher Weise, wie bei Bicellaria ciliata im unteren Theile des Zooecium. Die Eier kann man nur dann erkennen, wenn man den Stock von der Rückseite betrachtet. Bei dieser Species entspringen die jüngeren Zooecien von dem oberen Theile der Rückseite der älteren ebenfalls mit einem zweischenkligen Fortsatze und dicht unterhalb dieses Fortsatzes bilden sich die Eier in der Mitte der Rückseite des Zooecium durch Knospung der Endocyste nach Innen; sie sind von einer feinen Membran umgeben; Keimblase und Keimfleck sind stets deutlich zu erkennen. Auch bei Bugula flabellata beobachtete ich die Bildung von Eiern und Spermatozoen. Letztere bilden sich am unteren Theile des Zooecium, die Eier dagegen an der Rückseite desselben in der Mitte zwischen seinem oberen und unteren Ende.

Wir sehen also, dass meine Beobachtungen genau übereinstimmen mit denen von Huxuex, ein Umstand, der um so gewichtiger ist, als mir der Huxuey'sche Aufsatz erst nach meiner Rückkehr aus Helgoland bekannt wurde. Die abweichenden Angaben von Hıкскs, welcher in der Ovicelle eine körnige, formlose Masse bemerkt haben will, aus welcher das Ei sich bilden soll, lassen sich vielleicht dadurch erklären, dass häufig ein Ei nach seinem Uebertritt in die Ovicelle abstirht und anstatt sich weiter zu entwickeln, zu einem Häufchen körniger Substanz ohne bestimmte Umrisse zerfällt. Die wirklichen Eier hat er offenbar vollkommın ühersehen, denn diejenigen Eier, welche er beobachtet haben will und welche nach ihm stets in solchen Zooecien sich finden, aus deren Ovicellen die Larve hereits ausgeschlüpft ist und welche nach dem gänzlichen Verschwinden des Polypids noch in den Zooecien liegen, sind keine wirklichen Eier, sondern vielmehr diejenigen Körper, welche Suirt 》g rod dka pslar" nennt und welche nach den Beobachtungen dieses Forschers, welche ich vollkommen bestätigen kann, aus dem Polypid selbst durch eine regressive Metamorphose hervorgehen. Dass diese Körper nicht in die Ovicellen übertreten, ist allerdings voll- 
kommen richtig, dieser Umstand liefert aber nạtürlich nicht den geringsten Beweis gegen die Beobachtungen von Huxley.

Wenden wir uns nun zur Betrachtung der Larven selbst.

Die Larve von Bicellaria ciliata (Taf. I. Fig. 9) hat eine ungemein characteristische Form. Denken wir uns eine Pfirsiche mit der Kerbe nach unten und vorn gelegt und von oben nach unten stark abgeplattet und zwar vorn stärker als hinten, so haben wir ein annäherndes Bild ihrer Gestalt. In der Längsrichtung der Kerbe und am vorderen Ende derselben liegt eine ungefähr bisquitförmige Oeffnung, welche ich als Mund deuten möchte (Taf. I. Fig. 9 b). Dicht oberhalb derselben befindet sich ein Büschel langer, starker, lanzettförmiger Flagellen, welche stets in heftig schlagender Bewegung sind (Taf. I. Fig 9 c). Auf der Oberseite des Thieres liegt eine scharf abgegrenzte, runde Vertiefung, aus welcher ein ihr Lumen völlig ausfullender, kurzer c ylinderförmiger For ts a $\mathrm{z}$ hervorragt, welcher vollständig zuruckgezogen werden kann. Der obere Rand dieses Fortsatzes ist mit einem Kranze un beweglicher Borsten besetzt (Taf. 1. Fig. 9 a). Mit Ausnahme des Fortsatzes, welchen man vielleicht als eine Art Saugnapf deuten könnte, ist die ganze Larve mit kurzen Wimpern dicht besetzt. Betrachtet man die Mitte des einziehbaren Fortsatzes und den Mund als Pole, so schlagen die sämmtlichen Wimpern in meridionaler Richtung nach dem. Munde zu.

Die Larven von Bugula plumosa (Taf. I. Fig. 8) sind bedeutend grösser als die eben beschriebenen und weniger abgeplattet, im allgemeinen Baue denselben aber vollkommen gleich; indessen sind sie von ersteren durch eine characteristische $Z$ e ichnung leicht zu unterscheiden. Oberhalb der langen Flagellen haben sie nämlich zwei kirschrothe, runde Flecken, welche dicht neben einander stehen und mit einem helleren, stärker lichtbrechenden Punkte in der Mitte versehen sind (Taf. I. Fig 8 é). Rechts und links von diesen Punkten, auf der Mitte der Seiten, aber ein Wenig weiter nach dem einziehbaren Fortsatze hinauf haben sie noch je einen solchen Pigmentfleck, also in Ganzen vier (Taf. I. Fig. 8 e). Nitunter scheint es, als trügen diese Flecken, welche vielleicht als Augen zu deuten sind, kurze Wimpern, welche langsamer schlagen, als die Bewimperung des übrigen Körpers. Der Rand der Scheide des zurückziehbaren Fortsatzes ist mit einer Reihe deutlicher Zellen umgeben (Taf. I. Fig. 8. $f$ ).

Schon innerhalb der Ovicellen kann man deutlich die characteristischen Flecken an den Larven erkennen, und so leicht die Zugehörigkeit der frei umherschwimmenden Larven zu der Species feststellen.

Am auffallendsten ist die Larve von $\mathrm{Bugula}$ flabellata ge- 
zeichnet $^{\text {) }}$ (Taf. I. Fig. 1. In Gestalt und Grosse stimmt sie genau mit der Larve von Bugula plumosa uberein. Nur ist die Kerbe, in welcher der Mund liegt, ein wenig weiter von der Unterseite nach der Vorderseite des Körpers gerückt und mit ihr der Mund. Während aber die Grundfarbe der beiden vorher beschriebenen Larven rein weiss ist, ist die ihrige gelblich. Die sie characterisirende $\mathrm{Zeichnung}$ besteht aus zehn mennigrothen, lanzettförmigen Flecken, welche in einer äquatorialen Zone angeordnet stehen, deren unterer Rand in der Höhe der Flagellen beginnt. Der längere Durchmesser eines jeden Fleckes ist meridional orientirt. Zwei Flecken liegen zunächst rechts und links oberhalb der Flagellen (Fig. 1. $\dot{e})$; uber diesen, aber ein Wenig weiter auseinanderstehend liegen zwei weitere Flecken, und in demselben Parallelkreise mit diesen vier weitere, welche so geordnet sind, dass, wenn man die beiden erst erwähnten Flecke dieses Kreises als 1 bezeichnet und nun nach rechts und links fortzählt, die Zwischenräume zwischen dem zweiten und dritten Flecken jederseits am grössesten sind (Taf. I. Fig. 1. ee). In diesen grossen $\mathrm{Zwischenräumen}$ aber in demselben Parallel - Kreise mit den beiden zuerst beschriebenen supraoralen Flecken liegen zwei weitere Flecke (Fig. 1. $e^{\prime \prime}$ ), welche an Grösse alle vorhergehenden unter sich gleichen Flecke bedeutend ubertreffen. Sämmtliche Flecken sind mit stärkeren, aber kurzen sehr langsam schlagenden, oder vielmehr nur undulirenden Wimpern besetzt, welche sich deutlich von den stets in heftiger Bewegung befindlichen feineren Wimpern des übrigen Körpers unterscheiden. Mitunter glauhte ich auch in diesen Pigmentflecken einen stärker lichtbrechenden Körper unterscheiden zu können. Der Rand der Scheide des zuruckziehbaren Fortsatzes ist auch hier von einer Reihe grosser Zellen besetzt. Unterhalb der Mundöffnung, am Ende der Kerbe und symmetrisch rechts und links von ibr gelegen zeigt sich eine grosse, rosettenförmige Zeichnung, deren Bedeutung mir aber völlig unklar geblieben ist (Taf. I. Fig. 1 d.).

Die Larven von Bugula flahellata und Bugula plumosa unterscheiden sich so constant durch die eben beschriebene Zeichnung, dass mir die Berechtigung der Zusammenziehung dieser beiden Species

1) Es existirt bereits eine, wenn auch nur unvollkomınene Beschreibung und Abbildung dieser Larve. Reıd beobachtete sie bei Gelegenheit der Untersuchung der Ovicellen und beschreibt sie als einen runden bewimperten körper, dessen Vorderende verlängert und durchsichtiger als der übrige Theil ist. Der Rand des Vorderendes wird von einem Kranze unbeweglicher Haare umgeben und ist offenbar der von ihm richtig beobachtete vorstreckbare Fortsatz (Ann. and Magaz. of Nat. Hist. 1845. Vol. XVI. p. 398. Tab. XII. Fig. 13). 
zu einer einzigen, wie sie von Surt ${ }^{1}$ ) vorgeschlagen worden ist, zweifelhaft zu sein scheint.

Auch die Larve ron Scrupocellaria scruposa habe ich einige Male beobachtet. Im Allgemeinen gleicht sie den eben beschriebenen; dagegen hat sie eine andere Zeichnung. Die wie bei Bugula plumosa angeordneten Pigmentflecke sind dunkelbraunroth, die supraoralen Flecke sind dreieckig und stossen oberhalb der Flagellen mit einer Ecke zusammen. Die beiden seitlichen Flecken dagegen sind viereckig, nach oben nicht ganz scharf begrenzt und zeigen einen deutlichen lichtbrechenden Fleck. Zwischen ihnen an der hinteren Seite der Larve kann man mitunter noch zwei feine braune Linien unterscheiden, welche meridional gerichtet sind. Die Oberseite des ausstülpbaren Fortsatzes zeigt häufig eine vom Mittelpunkt ausgehende, sternformige Zeichnung, welche man ubrigens manchmal auch an den Larven von Bugula flabellata sehen kann.

Alle diese Larven besitzen das Vermögen ihre Gestalt bedeutend zu verändern; fast beständig contrahiren sie sich und dehnen sich wieder aus, besonders können sie ihre Ruckseite vorstrecken, sodass sie dann von oben gesehen eine birnförmige Gestalt annehmen. Es scheint, als ob sämmtliche eine Art von Fäces auszuscheiden im Stande wären; häufig sieht man $\mathrm{z}$. B. dass eine Larve von $\mathrm{Bugula}$ flabellat a beim Schwimmen einen braunen Streifen fein körniger Masse hinter sich zurücklässt. Alle sind von einer deutlichen, festen Membran umgeben, auf welcher die Wimpern sitzen und welche sich bei Zusatz von Essigsäure von dem Inhalt abhebt. Die Pigmentflecken, welche durch farbige Fettröpfchen gebildet scheinen, liegen unterhalb dieser Membran; der Mund scheint in eine centrale Höhle zu führen. Der Ortswechsel der Larven wird lediglich durch die kurzen Wimpern der Körperoberfläche vermittelt, die Flagellen tragen zu demselben nichts bei.

Nur bei Bugula flabellata war es mir möglich die Entwicklung der Larven zun primären Zooecium zu beobachten.

Die Larven dieses Thieres schwimmen lustig in dem Glase umber, meist dicht an der Oberfläche des Wassers; mitunter bleiben sie lange an demselhen Punkte stehen, indem sie lediglich eine schnelle Drehung um ihre eigene Achse vollfuhren. Dies geschieht hesonders an der Wand des Glases, oder an irgend einem im Wasser befindlichen festen Körper. Nach wenigen Stunden schon setzen sie sich dicht unterbalb der Wasserfläche an der dem Lichte zugewendeten Seite des Glases fest;

1) Oevfers. af. K. Vet.- Akad. Förhandl. 1867 p. 289 
ob dies vielleicht mit Hülfe des vorstreckbaren Fortsatzes geschieht, wie eine Beobachtung von ReID vermuthen lässt, ist mir zweifelhaft geblieben. Die Wimperbewegung wird langsamer, hört endlich auf, die Wimpern fallen ab, die Membran beginnt sich etwas abzuheben von dem Körperinhalte und das ganze Thier streckt sich ein Wenig in die Länge, sodass es am erste n Tag e die auf Taf. I. Fig. 2 abgebildete Form angenommen hat. In diesem Stadium hat die Larve ihre fruhere Organisation also gänzlich verloren und bildet nur ein Häufchen Bildungsmasse, umgeben von e in er festen Membran. Dieser Vorgang ist vollkommen analog demjenigen, welchen A. Schxeıder ${ }^{1}$ ) bei der Entwicklung des Cyphonautes zur Membranipora pilos a nachgewiesen hat. Bei Anwendung von Druck kann man innerhalb der Bildungsmasse die mennigrothen Pigmentkörner noch erkennen.

Bald hebt sich der obere Theil des Thieres von der Wand des Glases ab und streckt sich frei in die Höhe, die Bildungsmasse zieht sich aus dem unteren zur Befestigung an der Unterlage dienenden Basaltheile zuruck und formt sich in der Mitte des Thieres zu einem bräunlichen Körnerhaufen (Taf. I. Fig. $3 b$ ), an dessen oberem Ende sich ein elliptischer Wulst mit einer centralen Depression gebildet hat. Dieser letztere ist gelblich (Taf. I. Fig. $3 a$ ). In diesem Stadium befindet sich die Larve bereits am $\mathrm{z}$ weiten Tage; aber auch schon während des ersten Tages kann man die Stelle erkennen, an welcher dieser Wulst sich bilden wird. Er erscheint als ein hellerer Fleck (Taf. I. Fig. $2 a)$.

A m dritten Tage hat sich das ganze Thier bedeutend gestreckt, die ganze Wandung ist durchsichtig geworden. An seinem oberen Ende zeigt es eine Einstülpung (Taf. I. Fig. 4). Der elliptische Wulst hat sich zur Anlage der Tentakelkrone umgestaltet, man erkennt bereits die zwölf kurzen Tentakel, deren Längsachse aber noch schräg steht gegen die Längsachse des ganzen Thieres (Taf. I. Fig. 4 a). An diese Anlage der Tentakelkrone schliesst sich nach unten ein kurzer, dicker Fortsatz an $(d)$, die Anlage des Darmtractus; nach oben ist die Tentakelkrone bereits von der sehr langen Anlage der Tentakel$\mathrm{scheide}(e)$ umgeben, welche sich nach oben zu verjungt und sich ansetzt an den Grund der erwähnten Depression an dem oberen Ende des Thieres. Die Bildungsmasse ist braun geworden und hängt einerseits an der Anlage des Darmtractus, andererseits ist sie durch einen Sarcodestrang $(c)$ mit der Basis des Thieres verbun-

1) Sitzungs-Bericht der Gesell schaft Naturforschender Freunde zu Berlin vom 20. Octuber 1868 . 
den. Auf der Oberfläche des Thieres beginnt bereits eine Schicht von . Kalksalz sich abzulagern.

A m vierten Tage hat die Tentakelkrone bereits ihre definitive Lage eingenommen (Taf. I. Fig. 5), d. h. sie hat eine Drehung gemacht, in der Art, dass die Längsachsen der Tentakeln parallel laufen der Längsachse des ganzen Thieres. Oe s o phagus, Magen und Rectum sind schon deutlich zu erkennen, auch die Retractoren beginnen sich zu bilden, das ganze Polypid ist aber weiter hinaufgerückt nach dem oberen Ende des Thieres, indem die Tentakelscheide sich verkürzt, die Tentakeln aber sich verlängern. Das untere Ende des Magens hängt jetzt mit der stark verminderten Bildungsmasse $(b)$ nur durch einige Sarcodesıränge zusammen. Das untere Ende der Bildungsmasse ist ebenfalls durch einen Sarcodestrang $(c)$ mit dem unteren Ende des Thieres verbunden.

A m fünften Tage hat das bedeutend gewachsene Thier beinahe gänzlich seine definitive Form angenommen (Taf. I. Fig. 6). Die hintere Seite des Thieres ist in die Höhe gewachsen, während die vordere zurückblieb und es hat sich nun die definitive Mündungsarea gebildet, an deren Rand sich die Stacheln anzulegen beginnen. Dieselbe wird von einer unverkalkten Membran verschlossen, in welche die Tentakelscheide übergeht. Die Bildungsmasse hat sich zu einem längeren Wulst ausgezogen, welcher den Sarcodestrang umhüllt, der den Magen mit der Basis des Zooecium verbindet. Auf dem oberen Ende der Rückseite des Zooecium erscheint ein hufeisenförmiger Wulst ( $f$ ), die Anlage des secundären, Zooecium. Die Oeffnung des Hufeisens ist nach unten gekehrt. Es beginnt nun innerhalb des Magens sich Wimperung zu zeigen, die Tentakelscheide öffnet sich nach aussen, die noch vorhandene braune Bildungsmasse schwindet gänzlich, die Stacheln am Rande der Mündungsarea bilden sich aus, die Muskeln beginnen zu wirken und das nun reife junge Thier streckt seine zierliche Tentakelkrone hervor, entfaltet sie und beginnt Nahrung aufzunehmen.

Wir sehen also, dass das primäre Zooecium aus dem Klumpen Bildungsmasse, in welchen die Larve sich verwandelt, genau in derselben weise entsteht, wie ein beliebiges anderes $\mathrm{Z}$ ooecium aus einer Knospe und besonders, dass das Polypid durch innere Knospung sich bildet, ein Vorgang, der z. B. an Knospen von Flustra membranacea von Smitr ${ }^{1}$ ) genau verfolgt worden ist.

1) Oefvers af. K. Vet. - Akad. Förhandl. 1865. pag. 5. Taf. I. Fig. 1-10. 
Auf Tafel I. Fig. 7. sehen wir das primäre Zooecium eines älteren Stockes und die beiden nächst älteren Zooecien abgebildet. Das primäre Zooecium zeichnet sich hier durch seine bedeutende Länge aus. Seine Mündungsarea ist nicht so langgestreckt, wie bei den folgenden und stärker gegen die Längsachse des ganzen Zooecium geneigt; sie ist von 7 Stacheln umgeben und besitzt bereits an dem einen Seitenrande ein kleines Avicularium. Indessen ist die Form des primären Zooecium nicht immer constant, die Zahl der Stacheln variirt von sieben bis neun und die Länge des Zooecium ist ebenfalls sehr verschieden.

Von dem primären Zooecium können nun entweder ein oder zwei jungere Zooecien knospen. Bildet sich an ihm nur eine einzige Knospe, so entspringt dieselbe mit einer hufeisenförmigen Basis, wie bereits beschrieben, vom oberen Theile seiner Rückseite.

Knospen hingegen an ihm zwei Zooecien, so entsteht das eine in der eben beschriebenen Weise, das andere hingegen entspringt seitlich neben diesem mit einer einfach zugespitzten Basis, welche tiefer herabreicht als die bufeisenförmige Basis des anderen 7.ooecium und ein Wenig auf die Seitenfläche des primären Zooecium herumgreift. Es scheint, als ob sich das Polypid der zuletzt beschriebenen Knospe mit keilförmiger Basis etwas früher entwickle als das der anderen Knospe. Auch scheint nur dann ein Avicularium an dem primären Zooecium vorzukommen, wenn zwei Knospen an ihm entstehen.

Wenn der Thierstock zu einer gewissen Höhe emporgewachsen ist und die Polypide der ältesten Zooecien hereits abgestorben sind, beginnen diese letzteren Wurzelfäden zu treiben. Diese Wurzelfäden sind hoble, hornige Röhren, in welchen man mitunter ein Wenig Protoplasma erkennt (Taf. I. Fig. 7. r). An der Stelle eines Zooecium, von welchem ein solcher Wurzelfaden entstehen soll, zeigt sich zunächst ein heller, lanzettförmiger Fleck, dessen längerer Durchmesser parallel läuft der Längsachse des ganzen Zooecium und es scheint, als ob sich hier die Endocyste ein Wenig ablöse von der kalkigen Ectocyste (Taf. I. Fig. $7 x$ ). Zunächst ist es das primäre Zooecium, welches solche Wurzelfiden aussendet, und zwar in unbestimmter Anzahl. Dieselben breiten sich auf der Unterlage aus und tragen zur Befestigung des Stockes an derselben bei. Auch von den zunächst älteren Zooecien können nocb mehrere Wurzelfäden entstehen, sämmtliche übrigen Zooecien des Stockes hingegen können nur je einen Wurzelfaden aussenden und zwar entspringt dieser von der Mitte der Ruckseite. Die Wurzelfäden ragen aber nicht frei nach allen Seiten hinaus, wie wir dies z. B. bei $\mathrm{C}$ a nda reptans sehen, sondern sie laufen am Thierstocke herab, denselben nit einem dichten Gewebe umbullend, sodass man an seinem unteren 
Theile die Zooecien gar nicht mehr erkennen kann und letztere also von den Wurzelfäden in derselben Weise umhüllt werden, wie der Stamm der Baumfarne von den Luftwurzeln. Dieser Vorgang wurde ubrigens bereits von Surrt erkannt und beschrieben ${ }^{1}$ ) und ist von mir nur deshalb erwähnt worden, weil die schöne Surrs'sche Arbeit in Deutschland noch keine hinreichende Verbreitung gefunden hat.

Die mitgetheilten Beobachtungen lassen sich kurz in folgende Sätze zusammenfassen.

1. Einige chilostome Bryozoen sind Zwitter.

2. Die Eier und Spermatozoen bilden sich in der Leibeshöhle des Mutterthieres.

3. Das befruchtete Ei tritt in die Ovicelle über, welche als eine Art Bruttasche $\mathrm{zu}$ betrachten ist.

4. Die aus ihm hervorgehende bewimperte, ziemlich hoch organisirte Larve setzt sich fest und verwandelt sich in einen Haufen Bildungsmasse, ohne erkennbare Organisation, umgeben von einer festen Membran.

5. Das Polypid entsteht in diesem Gebilde durch innere Knospung genau in derselben Weise, wie es sich innerhalb der Knospen an den Spitzen des Stockes bildet.

II.

Ueber die Anatomie von Pedicellina echinata Sans.

(Hierzu Taf, II. u. III.)

Im Jahre 1833 gründete Michael Sars ${ }^{2}$ ) die Gattung Pedicellin a für zwei von ihm an der norwegischen Küste gefundene Thierarten, welchen er die Speciesnamen e chinata und gracil is beilegte. VAN Beneden zeigte späterhin, dass bereits vor SARs diese Thiere an der englischen Küste von Ellis, Bosk, Listrir, Sharpey und Anderen beobachtet waren, aber erst von $\mathrm{S}_{\mathrm{ARS}}$ her datirt sich eine genauere Kenntniss ihres Baues. Sars stellte diese Thiere zu den Polypen, und zwar als einen Uebergang von diesen zu den Vorticellen und erst Gervals war es, der im Jahre 1837 sie auf Grund der Sars'schen Beobachtungen mit seinen "Polypes infundibuliformes« vereinigte und so den ersten Schritt that, ihnen den Platz zu sichern, welchen sie noch jetzt im System einnehmen. 1841 beschreibt Hassall ${ }^{3}$ ) in seinem Catalog der Zoo-

1) Oefvers. af. K. Vet. - Akad. Förh. 1867. pag. 332.

2) Bescrivelser og Jagttagelser u. s. w. Bergen 1835 p. 4. Taf. I. Fig 1 и. $\mathbf{~}$

3) Ann. and Magaz. of Nat. History Vol. VII. 1841 p. 365. 
phyten der irischen Kuste Ped. echinata ziemlich gut. Im September 184 fand VAN $_{\star}$ BENEDEN ein Thier an der belgischen Küste, welches er für neu hielt und welchem er den Namen Crinomorpha gab; er erkannte aber bald die Zugehörigkeit seines Thieres zu der Gattung Pedicellina, zog daher seinen früheren Namen selbst zuruck und begnügte sich dasselbe unter dem Namen Ped. belg i ca zu beschreiben. In den »Mémoires de l'Academie de Bruxelles 1845 Vol. XIX. giebt er eine weitläufige Darstellung der Anatomie und Entwicklungsgeschichte seines Thieres, und es ist dies die Hauptarbeit, welche wir über Pedicellina besitzen. In demselben Jahre gab ReID ${ }^{1}$ ) eine gute Beschreibung von Ped. echinata und berichtet besonders genau uber ihre Lebensweise. Seit dieser Zeit haben nur noch Gosse ${ }^{2}$ ) (1853) und LEwes ${ }^{3}$ ) (1858) kurze Notizen über die Entwicklungsgeschichte dieses Thieres gegeben, welche jedoch den Beobachtungen von van BeNEDEN nichts Wesentliches hinzufugen. Ausserdem berichtet Alcman ${ }^{4}$ ) (4856 und 1857) kurz uber seine Untersuchungen dieser Gattung und versucht es mit grossem Scharfsinn den abweichenden Bau derselben zurückzuführen auf den Typus der Phylactolaemen Bryozoen. Ihm gebührt das Verdienst zuerst den Unterschied der Pedicellina von den übrigen Bryozoen mit rundem Lophophor nachgewiesen zu haben. Keine neuen Untersuchungen sind seither über diesen Gegenstand publicirt worden, dagegen haben sich gelegentlich Hratт ${ }^{5}$ ) und Surtr ${ }^{6}$ ) gegen die Allмav'sche Ansicht ausgesprochen. Sмıтт betont hierbei die Aehnlichkeit von Pedicellina mit Urnatella Lerdy und sieht beide als die niedrigsten Bryozoenformen an. Unter diesen Umständen war es mir sehr interessant in Helgoland mit Pedicellina echinata bekannt zu werden. Man findet dieses Thier manchmal auf Sertularien oder Austerschalen, welche mit dem Schleppnetz an der Westküste der Insel heraufgebracht werden. Indessen zogen mich bald andere Arbeiten von dem Studium seines Baues ab und erst $z u$ Hause fand ich Musse, mich wieder mit ihm zu beschäftigen. Den grössten Theil der gesammelten Exemplare hatte ich aber unglücklicherweise in Chromsäure aufbewahrt und diese zeigten sich zur Beobachtung gänzlich ungeeignet. Nur wenige Spiritus-Exemplare sind es daher, an welchen ich meine Untersuchungen

1) Ann. and Magaz. of Nat. Hist. Vol. XI. 1845 p. 390 pl. XII. Fig. 8.

2) A Naturalist's ramble on the Devonshire coast. London 1853. p. 208 pl. XII.

3) Naturstudien am Seestrande übers. von I. Freese. 1859. p. 239.

4) A Monograph of the fresh-water Polyzoa. London 1856 p. 19 und Edinburgh New Philosophical Journal New Series. Vol. VI. 1857 p. 155.

5) Proceedings of the Essex Institute. Vol. V. 1868 p. 215.

6) Oefvers. af. K. Vet.-Akad.-Förh. 1867 p. 486. 
anstellen konnte, und es möge dieser Umstand mir zur Entschuldigung dienen, wenn sich in meiner Darstellung Lücken vorfinden; indessen, Dank dem Umstand, dass die grösste Art der Gattung mir zu Gebote stand, ist es mir dennoch gelungen, einige so sehr von allen bisher bei Bryozoen bekannt gewordenen Verhältnissen abweichende Thatsachen aufzufinden, dass es mir nicht ungerechtfertigt erscheint, schon jetzt meine Beobachtungen der Oeffentlichkeit zu übergeben.

Schon hei schwacher Vergrösserung gewährt P edicell in a e c h inat a einen höchst eigenthümlichen Anblick (Taf. II. Fig. 1). Von einem kriechenden runden Stamme erhebt sich senkrecht gegen die Unterlage ein langer drehrunder, sich nach oben ein Wenig verjüngender, mit kurzen Stacheln besetzter Stiel, welcher den eigentlichen, sämmtliche Eingeweide umschliessenden und oben von einem Tentakelkranze umgebenen Leib des Thieres trägt. Von einem eigentlichen Unterschiede zwischen Zooecium und Polypid kann man hier nicht sprechen, da der Darmtractus und die Tentakelkrone nicht frei beweglich sind gegen den von der Leibeswand gebildeten Sack. Der Leib ist kelchförmig jedoch seitlich etwas zusammengedruckt, sodass sein horizontaler Querschnitt oval ist. Eine Ebene gelegt durch die längere Achse eines solchen Querschnittes und durch die Längsachse des Stieles theilt das ganze Thier in zwei symmetrische Hälften und geht durch Mund und After. Oesophagus und Rectum verlaufen also längs der schmalen Seiten des Leibes, welche ich durch die Bezeichnungen »o rale« und nan a le Seite unterscheiden werde. Wenn das Thier sich entfaltet, ist der obere Rand des Leibes ein Wenig nach aussen umgeschlagen, wie bei einem wirklichen Kelche und bildet eine vorspringende Kante, bevor er in die Tentakeln ausläuft, deren Aussenfläche mit der äusseren Kelchwand continuirlich ist, deren Innenfläche aber in denjenigen Theil der Leibeswand übergeht, welcher innerhalb des Tentakelkranzes den Körper begrenzt und welchen ich als die intratentakuläre Leibes wa d bezeichnen werde (Taf. Il. Fig. 2. A. B. C.). Sie wird von dem Munde, dem After und wahrscheinlich auch von der Genitalöffnung durchbohrt und ist ausserdem auch noch mit verschiedenen Falten und Einstülpungen verseben, welche später besprochen werden sollen.

Die auffallendste Lebenserscheinung, welche man an diesem Thier beobachten kann, ist die ungemeine Beweglichkeit des Stieles; derselbe neigt sich frei nach allen Seiten mit bedeutender Kraft und Schnelligkeit, und zwar mitunter so stark, dass der Becher die Unterlage, auf 
welcher der Stamm kriecht, berührt. Ich wende mich nun zunächst zur Beschreibung der einzelnen Organe.

\section{Der Stiel.}

Die Wand des Stieles besteht, wenn man von seinem obersten Ende absieht, aus zwei gesonderten Schichten: aus einer äusseren festen, zähen, durchsichtigen Cuticula und einer der Innenfläche der ersteren dicht anliegenden Längs muskelschicht (Taf. II. Fig. 3). Diese Thatsache ist in ersten Augenblicke sehr auffallend, da die Cuticula durchaus structurlos ist, als der Ectocyste der ubrigen Bryozoen homolog d. h. als ein erhärtetes Sekret, angesehen werden muss, eine Gewebsschicht jedoch, welche man als Matrix derselben deuten könnte, durchaus zu fehlen scheint. Die Lösung dieser Schwierigkeit bietet eine Untersuchung des Stieles jungerer unausgewachsener Thiere, sowie des obersten Endes eines jeden Stieles (Taf. II. Fig. 4). Hier finden wir nämlich zwischen Ectocyste und Muskelschicht eine deutliche Zellschicht (Taf. Il. Fig. \& en) eingeschoben, welche der Endocyste der ubrigen Bryozoen vollkommen homolog ist. Dieselbe besteht aus dicken langen polygonalen Zellen, welche ein Wenig von einander abzustehen scheinen und in welchen man deutlich den Kern erkennen kann. Wenn das Thier ausgewachsen ist und die Cuticula ihre definitive Dicke erhalten hat, verschwindet diese Zellschicht an dem grössten Theile des Stieles und bleibt nur an seinen obersten Ende bestehen; sie hört nach unten zu aber nicht plötzlich auf, sondern verschwindet durch allmähliche Verdünnung. Diese Zellschicht giebt auch die Matrix ab zur Bildung der Stacheln, welche dem Thiere den Speciesnamen we chinata eingetragen haben. Am ausgewachsenen Thiere sind dieselben jedoch hohle Ausstülpungen der Cuticula, die Matrix ist gänzlich aus ihnen verschwunden (Taf. II. Fig. 3.).

Die Längsmuskelschicht (Taf. II. Fig. 3 und $4 m$ und Fig. 5) besteht ausschliesslich aus langen, spindelförmigen, seitlich abgeplatteten Muskelfasern, dieselben sind mit ihren flachen Seiten dicht aneinandergedrängt und mit ihren Spitzen zwischeneinander eingekeilt; sie bilden aber kein Muskelnetz. An der dicksten Stelle einer jeden Faser kann man einen runden Kern nit Kernkörperchen entdecken; die durch die Kerne hervorgebrachten Anschwellungen ragen tiber die Innenfläche der Muskelschicht hervor. An dem unteren Theil der Stiele sind die Fasern in der Mitte bedeutend stärker und nehmen dann nach den Enden zu schneller an Dicke ab. Die Kerne ragen hier noch weit stärker hervor, indem sie die Mitte der Muskelfasern beinahe blasenartig auftreiben. Altmax, welcher diese Schicht richtig beschreibt, 
will ausserdem noch Ringmuskeln an dem Stiele bemerkt haben, und allerdings kann man häufig eine dichte Querringelung besonders an seinem unteren Ende wahrnehmen. Indessen habe ich mich überzeugt, dass diese Zeichnung nicht von Muskelfasern, sondern von einer Art Sculptur der Ectocyste herruhrt, welche vielleicht als eine Runzelung derselben, hervorgebracht durch die Contraction der Längsfasern, angesehen werden muss.

Der Stiel bildet aber keine hohle Röhre, wie man bei oberflächlicher Betrachtung desselben vermuthen könnte, er ist vielmehr von einer Art parenchymatischen Gewebes ausgefült. Dieses besteht aus $\mathrm{Z}$ ellen und In tercellularsubstanz.

Die Zellen (Taf. II. Fig. 3. und Fig. $4 p$ ) sind spindelförmig mit ovalem Kern und Kernkörperchen; von ihren spitzen Enden entspringen verzweigte Ausläufer, durch welche sie untereinander zusammenhängen. Der Zwischenraum zwischen ihnen wird von einer farblosen ziemlich stark lichtbrechenden, durchsichtigen, mitunter kleine Körnchen enthaltenden Intercellularsubstanz erfüllt.

An dem unteren Ende des Stieles stehen diese Zellen wirr durcheinander, seine Höhle ohne jede planmässige Anordnung durchsetzend; am oberen Ende hingegen sind sie auf den peripherischen Theil der Höhlung beschränkt, das Centrum wird blos von Intercellularsubstanz erfültt; zugleich sind hier die Zellen in ziemlich regelmässige Längşreihen angeordnet und haben dem entsprechend meist nur unverzweigte Ausläufer, die einzelnen Längsreihen anastomosiren nur selten miteinander. Dieses Parenchym ist um so interessanter als es bei den nach dem gewöhnlichen Bauplane gebauten Bryozoen, soweit manbis jetzt weiss, durchweg fehlt, dagegen hat $\mathrm{Kow}$ a l ews k y ein ganz ähnliches Parenchym in der Leibeshöhle des von ihm entdeckten Lox osoma Neapolitanum beschrieben oder vielmehr abgebildet.

An der Grenze zwischen Stiel und Kelch endet die Muskelschicht. Hier bildet die Ectocyste ein horizontales Diaphragma mit einem kleinen centralen Loche (Taf. Il. Fig $4 d$ ). Dieses Diaphragma ist auf beiden Seiten von der Endocyste überzogen, welche auf diese Weise in den Kelch übergeht, um an der Bildung der Leibeswand Theil zu nehmen; die auf der oberen Fläche des Diaphragma den Rand des Loches umgebenden Zellen sind sehr verlängert und bilden eine Art Wall um dasselbe $(v)$, welcher von der Seite gesehen als ein Knopf erscheint, mit welchem der Stiel des Thieres in das Innere des Kelches vorragt. Nach oben ist dieser Knopf mit einer durchsichtigen Wölbung $(f)$ gegen die eigentliche Körperhöhle des Thieres geschlossen, uber deren 
Bedeutung ich mir aber keine ganz genaue Rechenschaft zu geben vernag.

\section{Die Leibeswand.}

Ectocyste und Endocyste des Stieles setzen sich direct in die Wand des Kelches fort, dieselbe besteht also aus einer starken, zähen $\mathrm{Gu}$ ticula, der Ectocyste, und e iner S chicht Zellen, welche der Innenfläche dieser Cuticula dicht anliegen (Tab. III. Fig. 3). Die Zellen sind polygonal und ganz flach, mit stark lichtbrechenden, scharf begrenzten, ovalen Kernen; letztere ragen nach innen zu ein Wenig uber die Fläche der Zellschicht vor und sie sind es, welche bei Untersuchung der Leibeswand zunächst in die Augen fallen. Erst eine genauere Beobachtung lässt die Zellgreuzen erkennen. An der intratentakulären Leibeswand sind die Kerne weniger deutlich; mitunter gelingt es aber doch die polygonale Zeichnung, welche durch die Zellgrenzen hervorgebracht wird, zu sehen. Auch die Ectocyste ist hier nur in seltenen Fällen deutlich zu erkennen. Im Allgemeinen macht daher die intratentakuläre Leibeswand den Eindruck einer einfachen Membran. Muskelfasern habe ich niemals in der Leibeswand zu erkennen vermocht, dieselbe ist also viel einfacher zusammengesetzt als die Leibeswand der phylactolämen Bryozoen; dagegen complicirter als die Leibeswand der chilostomen Bryozoen, bei denen man in der Endocyste, des erwachsenen Thieres wenigstens, keinerlei Formelemente unterscheiden kann.

\section{Die Organe der Verdaung.}

Der Darmtractus fullt nahezu die ganze Leibeshöhle aus; man kann an ibm unterscheiden den Oesophagus, den Magen und den Darm, und zwar zerfällt dieser letztere wiederum in ein In te sti n u m und ein Rectum.

Der O es ophagus durchbohrt mit einer ziemlich weiten runden, excentrisch liegenden Mundöflinung die intratentakuläre Leibeswand, (Taf. II. Fig. $2 C$ und $D, O$.) läuft dann der weniger gewölbten, schmalen Seite des Kelches parallel bis ziemlich auf den Grund des Kelches herab, wird allmählich enger und mündet endlich mit einer engen Oeffnung in den Magen.

Der $\mathrm{M}$ a g e n (Taf. II. Fig. $2 A$ und $C, V$ ), bildet einen ovalen, von oben nach unten etwas abgeplatteten Sack, welcher den Grund des Kelches ausfültt; die Cardia liegt ohngefähr in der Mitte seiner oralen Seite und über derselben bildet er eine Art kurzen Blindsackes. Der Pylorus liegt der 'ardia grade gegenüber, ihm schliesst sich das kurze Intestinum (Taf. II. Fig. $2 B$ und $C, I$ ) an, welches sich oben wie- 
der ein Wenig zusammenschnürt und dann in das Kectum (Taf. II. Fig. $2 C, R$ ) ubergeht, welches nit seinem oberen Ende die intratentakuläre Leibeswand zu einer Art grossen Papille oder Schornste in - so nennt KefErstein dieses Organ bei Loxosoma - auftreibt, an dessen Spitze dann die Analöffnung liegt. Das Ende des Rectum steckt also in einer Art Scheide, welche von der Leibeswand gebildet wird. Der ganze Darm verläuft längs der gewölbteren schmalen Seite des Kelches und der Analschornstein liegt mit seiner Aussenfläche der Basis der Tentakeln dicht an.

Wir sehen also, dass bei den geschlechtsreifen erwachsenen Thieren Mund und After weit von einander getrennt liegen, bei den jungen Thieren, in denen die Genitalien noch nicht vollständig entwickelt sind, gestaltet sich dies Verhältniss anders, indem bei diesen das Rectum nicht aufrecht steht, sondern nach innen umgeschlagen ist, mit dem Intestinum einen spitzen Winkel bildet und beinahe horizontal zu liegen kommt. Hierdurch wird der After dem Munde bedeutend genähert. Allman beschreibt Mund und After als dicht nebeneinanderliegend und es ist mir daher wahrscheinlich, dass seine Beschreibung von Pedicellina nach jungen, noch nicht geschlechtsreifen Thieren entworfen ist.

Der Oesophagus, dessen Wandung nach Aussen zu von einer homogenen Membran gebildet wird, ist innen ausgekleidet nit einem Wimperepithel, bestehend aus ziemlich grossen polygonalen Zellen, welche deutliche ovale Kerne mit Kernkörperchen besitzen (Taf. III. Fig. 2 g). Die Wimpern dieser Zellen sind ziemlich lang und stets in lebhafter Bewegung.

Mitunter hat es den Anschein, als ständen die Wimpern nicht direct auf den Zellen, sondern auf einer Membran, welche die Zellen uberzieht; indessen kann man sich hierin leicht täuschen. Der Oesophagus ist der einzige Theil des Darmtractus, an welchem Rein schwache Contractionen zu bemerken vermochte. Eine eigentliche Muskulatur habe ich aber in seiner Wandung eben so wenig zu entdecken vermocht, als in derjenigen des übrigen Darmtractus; dagegen scheint es oftmals, wenn man ein Thier von der Seite betrachtet, als lägen der analen Aussenfläche des Oesophagus einige runde Fasern an, in derselben Richtung, welche die Fasern einer Quermuskelschicht einnehmen würden; ob es wirklich Muskeln sind, muss ich unentschieden lassen.

Der Magen ist ebenfalls mit einer Zellschicht ausgekleidet, in welcher man aber drei verschiedene Arten von Zellen unterscheiden kann.

Die ganze obere Hälfte des Magens, welche durch einen Querschnitt des Thieres, horizontal durch Cardia und Pylorus gelegt, abgetrennt werden würde, ist ausgekleidet mit langen dicht aneinander ge- 
drängten polygonalen Zellen, an denen man einen Kern nur schwer unterscheiden kann (Taf. III. Fig. 6). Diese Zellen tragen keine Wimpern, ihre gewölbten Enden geben der Innenfläche des Magens ein warziges Aussehen. Sie sind es, welche im lebenden, wohlgenährten Thiere das bekannte braune Pigment enthalten und welche man als Leberzellen gedeutet hat (Taf. II. Fig. 1).

Die untere Hälfte des Magens wird von zwei verschiedenen Zellarten ausgekleidet. Der Cardialtheil des Magens, welcher sich dem Oesophagus anschliesst, ist bedeckt mit flachen sehr durchsichtigen polygonalen Wimperepithelzellen; man kann an ihnen deutlich den hellen Kern nebst Kernkörper von dem feinkörnigen Inhalt unterscheiden (Taf. III. Fig. 8). Die Zone dieser Zellen wird auf jeder Seite des Magens scharf begrenzt von einer Linie, welche etwas gebogen von dem oberen Rande der Cardia nach der Mitte der Unterseite des Magens sich hinzieht. Auf Tafel II. Fig. $2 C$ ist diese Grenze durch die punktirte Linie $v^{\prime}$ bezeichnet.

Der ubrige Theil des Magens wird ausgekleidet von grossen $\mathrm{Z}$ ellen mit stark lichtbrechendem Inhalte, welche eben so lang sind als die Leberzellen, dagegen einen bedeutend grösseren Querschnitt haben. Kern und Kernkörperchen sind an ihnen meist deutlich zu unterscheiden (Taf. III. Fig. 7). Ihre oberen Enden sind gewölbt und stehen ein wenig von einander ab. Der Zone ihrer Verbreitung ist auf Taf. I. Fig $2 C$ durch die punktirten Linien $v^{\prime}$ und $v^{\prime \prime}$ angedeutet; ob sie ebenfalls Wimpern tragen, ist bei der Undurchsichtigkeit dieses Theiles des Magens an Spiritusexemplaren schwer zu bestimmen.

Das Inte stinum wird von einem Wimperepithel ausgekleidet, welches dem des Oesophagus in allen Stucken gleicht; das Rectum dagegen scheint auf seiner Innenfläche nicht zu wimpern, mit Ausnahme der nächsten Umgebung des Afters; seine Zellschicht ist ein Wenig dünner, wie die des Intestinum.

\section{Die Tentakelkrone.}

Die Tentakelkrone besteht aus 14 bis 24 Tentakeln 1 ), deren Form, Anordnung und histologische Beschaffenheit sehr eigenthumlich sind. Während bei den meisten übrigen Bryozoen die Tentakeln mehr oder weniger seitlich zusammengedrückt Cylinder darstellen, ihr Querschnitt also oval oder rund ist, bilden sie bei unserem Thiere, wenn man sie sich ganz gerade ausgestreckt denkt, vierseitige Pyramiden, deren Querschnitt ein gleichschenkliges Trapez mit schwach abgerundeten

1) Das Minimum dieser Anzahl wurde von ReID, das Maximum von SArs beobachtet. 
Ecken ist (Taf. III. Fig. 11). Die Schenkel des Trapezes, welche länger sind als seine Basis, entsprechen den Seitenflächen des Tentakels, die Basis, d. h. die längere der parallelen Seiten, der Aussenfläche, die kürzere der parallelen Seiten aber der Innenfläche; diese letztere zeigt in ihrer Mitte eine ziemlich tiefe Längsfurche. Die Tentakeln sind aber niemals so gerade ausgestreckt, wie wir dies bei den übrigen Bryozoen wahrnehmen können, sondern stets ein wenig nach Innen gekrummt; LEwEs. vergleicht ihre Krümmung sehr treffend mit der eines jungen Farrenkrautwedels.

Behufs vollkommenen Verständnisses der eigenthümlichen Art, in welcher die Tentakeln dem Rande des Leibes entspringen, wollen wir einen Kelch in einem.mittleren Zustande der Entfaltung betrachten Taf. II. Fig. $2 A$ zeigt den Durchschnitt eines solchen - uns zunächst aber die Tentakeln als nicht vorhanden denken. Die Wandungen des Kelches, äussere sowohl als intratentakuläre, bilden dann einen Becher mit doppelten Wänden, die beiden Wände gehen am oberen Rande ineinander uber und der obere Boden, welcher der intratentakulären Leibeswand entspricht, liegt ungefähr in der Mitte zwischen dem Rande und dem Grunde des Kelches. Die Tentakeln sind nun Ausstülpungen der obersten Randzone der inneren Kelchwandung, und zwar steht, abgesehen von der Krümmung, ihre Längsaxe senkrecht gegen die Leibeswand, im Allgemeinen also horizontal. Ihre äussere, bezüglich in diesem Falle obere Fläche, liegt dann in derselben Ebene, wie der Rand des Kelches, und geht ununterbrochen in die äussere Leibeswand über. Sollen diese Tentakeln nun entfaltet werden, so wird der Rand des Kelches nach aussen umgeschlagen und dadurch die Längsaxe der Tentakeln aufgerichtet, aber auch dann noch bleiben dieselben meist noch ein Wenig nach innen geneigt, sodass ihre Spitzen convergiren (Taf. I. Fig. $2 C$ ).

Diese so gestalteten Tentakeln stehen um den Rand des Leibes bilateral-symmetrisch angeordnet und zwar so, dass die Symmetrieebene des Thieres durch zwei Intertentakularräume geht, welche also unpaarig, alle übrigen dagegen paarig sind; diese beiden unpaaren Intertentakularräume sind weit grösser als alle übrigen.

Die innere Fläche der Tentakeln geht nicht direct in die intratentakuläre Leibeswand uber; letztere bildet vielmehr ringsherum an der Basis der Tentakeln eine starke Falte; durch diese wird eine Rinne gebildet, welche ich die Tentakelrinne nennen werde (Taf. Il. Fig. $2 a a^{\prime}$ ). Diese Rinne ist am breitesten an der oralen Seite des Thieres, wo sie den Mund in sich fasst, indem die Falte an dessen analer Seite vorbeigeht und also hier weit von der Basis der Tentakeln absteht. 
Nach rechts und links verschmälert sich die Rinne aber bald, indem die Fálte an die Basis der Tentakeln herantritt; sie wird aber zugleich auch etwas niedriger und verschwindet schliesslich beinahe ganz, wenn sie die analen Tentakeln erreicht hat. Diese Tentakelrinne hat also die Form eines Hufeisens, dessen zugespitzte Schenkel gegeneinander gebogen sind. Da die Mundöffnung tiefer liegt nicht allein als der After, sondern auch als die Basis des beschriebenen Analschornsteins, so steigt die intratentakuläre Leibeswand von der oralen nach der analen Seite des Thieres schräg aufwärts und nit ihr natürlich die Tentakelrinne.

Diese letztere wird von einer directen Fortsetzung des Wimperepithels des Oesophagus ausgekleidet, welches sich von hier aus auch auf die Innenseite der Tentakeln fortsetzt.

Es hat diese Vorrichtung offenbar den Zweck, die durch die Bewegung der Wimpern an der Innenfläche der Tentakel herabgeführten Nahrungstheilchen direct dem excentrisch gelegenen Munde zuzuführen und dieselben nicht auf die eigentliche intratentakuläre Leibeswand gelangen zu lassen, wo sie die, wie wir später sehen werden, dort sich öffnende Bruttasche nur verunreinigen wirden.

In dem Epithel der Tentakelrinne kann man zwei Arten von Zellen unterscheiden :

1. die gewöhnlichen dunkelen und ziemlich dicken Wimperepithelzellen, wie sie auch den Oesophagus auskleiden,

2. hellere, flachere und gestrecktere viereckige oder polygonale Epithelzellen.

Die ersteren tragen immer starke und stets deutlich erkennbare Wimpern; ob aber die letzteren nur kurze Wimpern tragen oder unbewimpert sind, war mir zu entscheiden nicht möglich, da die langen Wimpern der benachbarten Zellen der ersten Art sich stets uber die Zone der Zellen der zweiten Art hinweglegen und so die Untersuchung erschweren.

Die hellen Zellen bilden in der Mitte jedes Schenkels der Tentakelrinne eine Längszone. Diese beiden Längszonen beginnen getrennt von einander an dem oberen Theile der Aussenflaiche des Oesophagus, setzen sich dann eine jede auf die betreffende Seitenwand desselben und von dort auf die Tentakelrinne fort. Von diesen Längszonen zweigen sich nach Aussen Aeste ab, welche aus je einer Zellreihe bestehen; einem jeden Tentakel entspricht ein solcher Ast. Im Allgemeinen ist die Gestalt dieser Zone also einseitig gefiedert. Ihre Bänder werden eingefasst durch Zellen der ersten Art. Diese Verhältnisse sind schematisch angedeutet durch punktirte Linien auf Taf. II. Fig. $2 C$. Genau 
nach der Natur mit der Camera lucida gezeichnet sind die Abbildungen Taf. IIl. Fig. 1 und 2.

Taf. III. Fig. 2 stellt den Zellbelag der rechten Hälfte der Aussenwand des Oesophagus und der Innenseite der beiden ersten Tentakeln der rechten Seite des Thieres dar. Die Wimpern sind der Klarheit wegen weggelassen, ebenso auch auf Fig. 1. $c d$ bezeichnet die rechte Hälfte des unpaaren oralen Intertentakularraumes und wir sehen die Zone $e$ e der flachen Zellen, welche für jeden der beiden Tentakeln eine Reihe Zellen abgiebt $(f f)$. Diese Zellen sind oblong und liegen mit ihren langen Seiten aneinander, sie haben gewöhnlich nur einen schwach angedeuteten Kern, mitunter aber auch zwei. Die Zellreihe fur Tentakel I. wendet sich ein Wenig ruckwärts, um die Basis ihres Tentakels zu erreichen; da, wo sie auf ihn ubergeht und dabei einen Winkel macht, wird die einreihige Anordnung ihrer Zellen ein Wenig gestört, um aber bald darauf wiederhergestellt zu werden. Aehnlich verhält es sich mit der Zellreihe für Tentakel II. Die Zwischenräume zwischen den flachen Zellreihen werden ausgefullt durch gewöhnliche Wimperepithelzellen $g g$. Da diese aber dicker sind als die eben beschriebenen Zellreihen, bilden letztere eine Art von Furche. Die Wimperepithelzellen sind besonders hervortretend an dem Rande der Intertentakularräume.

Tafel III. Fig. I stellt den analen Theil der T'entakelfurche dar. $a b$ zeigt die Lage der Symmetrieebene, $c c$ die Lage des Analschornsteines an, $x x$ bezeichnet die Grenzfalte der Tentakelrinne, welche kurz vor dem zehnten Tentakel jederseits sich verliert und nicht mit der Falte der anderen Seite zusammenhängt. Wir sehen die Hauptzonen der flachen Zellen $(e e)$ die Zellreihen $f f$ abschicken für einen jeden einzelnen Tentakel; ihre $\mathrm{Z}$ wischenräume sind ausgefullt durch dunkle Wimperzellen $(g g)$, der Rand der Intertentakularräume ist durch einige besonders grosse Zellen ausgezeichnet. Die hellen Zellen hören nicht auf, wenn sie die Zellreihe fur den zehnten Tentakel jederseits ausgesendet haben, reichen vielmehr uber die Falten hinaus und es gehen die beiden Zonen hinter dem Analschornstein in einander über, wenngleich sie in der Medianebene des Thieres sehr schwach werden. Die dunklen Wimperzellen, welche die der Medianlinie zugekehrte Seite der hellen Zellreihe fur die beiden Tentakel X. bekleiden, stossen aber nicht zusammen.

Die Innenseite der T entakeln wird, wie bereits gesagt, von der Fortsetzung des Epithels der Tentakelrinne bekleidet (Taf. III. Fig. 11). An ihrer Basis kann man die Vertheilung der Zellen deutlich wahrnehmen. Die Mitte, d. h. den Grund der Furche, nimmt die Reihe 
der hellen Zellen ein (Taf. III. Fig. 2). Die Ränder der Furche werden bekleidet von je zwei Reihen von dunklen Epithelzellen, welche lange Wimpern tragen; die äussere Zellreihe jederseits besteht aus viereckigen, die innere Reihe aus langgestreckten Zellen. Da sich die Tentakeln nach oben zuspitzen, ihre Innenfläche also sich verschmälert, werden diese Verhältnisse an den Spitzen der Tentakeln viel undeutlicher, und da ausserdem die Wimpern sich meist so umklappen, dass man in die Tiefe der mittleren Furche nicht hineinblicken kann, so ist es mir unmöglich anzugeben, aus wie viel Längsreihen von Zellen das Epithel hier besteht.

Die Aussen- und Seitenwände der Tentakeln tragen keinen ăusseren Zellbelag, sie bestehen vielmehr wie die äussere Leibeswand, in welche die Aussenfläche auch direct übergeht, aus einer dünnen Ectocyste und einer Endocyste. In dieser letzteren kann man zwar Kerne erkennen, entsprechend den Zellkernen der Endocyste der Leibeswand, dagegen aber keine Zellgrenzen.

Die Tentakeln sind nicht hohl, sondern es finden sich in ibnen verschiedene $\mathrm{Z}$ ellgebilde, diese sollen aber erst bei der Besprechung des allgemeinen Körperparenchyms erwähnt werden. Die Tentakeln rollen sich nach Innen häufig zusammen und es bilden sich dabei Querfalten auf ihren Seitenflächen (Taf. III. Fig. 11). Zunächst war ich geneigt, diese für Muskeln zu halten, glaube mich aher jetzt überzeugt zu haben, dass es wirklich blos Falten sind.

Die einzigen deutlichen M uske If a s ern, welche ich in der Nähe der Tentakeln wahrgenommen habe, bilden den schon längst bekannten Sphincter. Derselbe besteht aus einem breiten Gürtel abgeplatteter, an beiden Enden zugespitzter Ringmuskelfasern, welche sich untereinander verbinden, mitunter auch sich überkreuzen und so ein Muskelnetz darstellen (Taf. II. Fig. 6). Auf dem Querschnitt hat es manchmal den Anschein, als könne man in ihnen eine centrale innere und eine peripherische Schicht unterscheiden. Kerne habe ich an ihnen nicht zu entdecken vermocht, meist haben sie aber ein längsgestreiftes faseriges Ansehen. Am besten wird man die Lage dieses Gürtels im Thiere verstehen bei Betrachtung von Taf. II. Fig. $2 A, B, C$, wo sph den Querschnitt desselben bezeichnet. Der obere Rand des Gürtels liegt in gleicher Höhe mit dem oberen Rande des Kelches und die Fläche desselben läuft parallel der Aussenwand des Kelches an der Basalfläche der Tentakeln hin, dieselben also von dem allgemeinen Leibesraum durch eine Art Netz abtrennend.

Die Bewegungen, welche die Tentakeln ausfuhren, kann man allerdings nicht vollständig durch die Thätigkeit dieses Sphincters er- 
klären, die Einrollung derselben wird wahrscheinlich durch Muskelfäden bewirkt werden, welche in ihrer Längsrichtung verlaufen; beobachtet habe ich diese Muskeln jedoch nicht. Die Neigung der Tentakeln gegen einander und die Wiederaufrichtung derselben sind aher sehr gut zu erklären durch die Thätigkeit des Sphincters unter der Voraussetzung, dass der Kelch dann in seinem normalen Zustande ist, d. h. in demjenigen Zustande, den er durch seine eigene Elasticität immer wieder herzustellen bemüht ist, wenn sein Rand nach Aussen in der beschriebenen Weise ungeschlagen, die Längsaxe der Tentakeln also aufgerichtet ist. Es ist leicht einzusehen, dass alsdann die Contraction der oberen Fasern genügt, um die Tentakeln aus der auf Taf. II. Fig. $2 C$ dargestellten Lage in die Fig. $2 B$ gezeichnete zu bringen. Eine starke Contraction sämmtlicher Fasern schnürt dann den oberen Rand des Leibes bis auf eine kleine Ocffnung zusammen, sodass die Tentakeln dann gänzlich innerhalb des Kelches geborgen und der Leib des Thieres eine nach oben zugespitzte Gestalt angenommen hat. Diesen Zustand kann man sehr häufig beobachten, wenn das Thier durch irgend welche Erschütterung erschreckt worden ist, und es verbleibt oft sehr lange in demselben, ehe es durch einfaches Nachlassen des Sphincter die Tentakeln wieder entfaltet.

Es wird hier der passende Platz sein, den Unterschied der AlLMax'schen Auffassung des Baues unseres Thieres von der meinigen darzustellen. Alluan giebt an, dass der obere Rand des Kelches gebildet werde von einer Duplicatur der Leibeswand, welche er als den ncalyx bezeichnet, und dass in dem Grunde des von diesem calyx eingeschlossenen Raume ein hufeisenförmiger Lophophor läge, welcher aber nur an seinem äusseren Rande Tentakeln trage; das untere Drittel der Rückseite dieser Tentakel werde durch den calyx verbunden, die Anordnung der Tentakel sei also hufeisenförmig und gewinne nur durch den calyx das Ansehen eines geschlossenen Kreises. An der analen Seite des Mundes beschreibt er dann ein Epistom, welches aber unbeweglich ist. Er vergleicht nun unser Thier mit einem halb eingestulpten Thiere einer gewöhnlichen phylactolämen Bryozoe, parallelisirt seinen calyx mit der halb ausgestülpten Tentakelscheide der letzteren und kommt schliesslich zu der Ansicht, Pedicellina sei nach dem Typus der phylactolämen Bryozoe wenn auch mit einigen Modificationen gebaut. Ich glaube diese Auffassung von Allman kommt daher, dass er das Thier in einem halb entfalteten Zustande beobachtet hat, wie derselbe dargestellt ist auf Taf. II. Fig. $2 B$. Betrachtet man ein vollständiges Thier alsdann von der Seite, so kann man die sehr dünnen und durchsichtigen Aussen- und Seitenwände der Tentakel nicht erkennen, dagegen 
aber sehr gut den dunklen Zellbelag der Innenfläche; diesen kann man nun leicht für den ganzen Tentakel selbst ansehen und der obere Rand des Kelches (Taf. II. Fig. 2 B habe ich dieses Stúck durch die punktirten Linien $x$ bezeichnet) erscheint dann wirklich als eine durchsichtige Duplicatur der Leibeswand, an deren Innenfläche der Sphincter verläuft. Die ebenfalls dunkel bervortretende Tentakelrinne scheint dann die Tentakeln auszusenden und sie ist es offenbar, welche Allman als hufeisenförmigen Lophophor beschreibt; die auf der analen Seite des Mundes verlaufende Grenzfalte der Tentakelrinne erscheint bei dieser Seitenansicht im optischen Querschnitt als eine Art Epistom.

\section{Die Organe der Fortpflanzung.}

Pedicellina echinata ist ein Zwitter; man kann am geschlechtsreifen Thiere innere und äussere Organe der Fortpflanzung unterscheiden; erstere bestehen aus den Eier und Spermatozoen bereitenden Drusen mit ihren accessorischen Organen, letztere aus einer Bruttasche, in welcher sich die Eier zu bewiuperten Larven entwickeln. Wenden wir uns zunächst zu der letzteren.

Betrachten wir ein geschlechtsreifes Thier von Aussen, so sehen wir den Raum zwischen dem Pylortheile des Magens und dem Rectum eingenommen von einer dunklen zelligen Masse, welche nach oben gradlinig begrenzt ist, nach unten aber einen mebrfach ausgebuchteten Umriss zeigt (Taf. II. Fig | b); wenden wir nun das Thier so, dass es auf seine Oralseite zu liegen kommt, so sehen wir, dass die Masse symmetrisch rechts und links vertheilt ist. Dieselbe ist vielfach beobachtet und meistens fur den Eierstock gehalten worden, da man bemerkte, dass bei Druck aus dem oberen Ende Eier oder Larven hervortraten. Durch viele Querschnitte habe ich mich uberzeugt, dass es keine compacte Zellmasse ist, sondern eine Tasche mit dicken zellbelegten Wänden, welche als eine Einstulpung der analen Hälfte der intratentakulären Leibeswand aufzufassen ist. Auf Taf. Il. Fig. $2 D$ wird der obere Rand dieser Tasche durch die Linie $b^{\prime \prime}$ bezeichnet; ihre Oeffnung nimmt also den grössten Theil der analen Hälfte der intratentakulären Leibeswand ein und erstreckt sich, von der Basis des Analschornsteines ausgehend, seitlich bis dicht an die Tentakelrinne heran; ihr Grund und ihre anale Fläche liegt dem Darmtractus dicht auf, sie ist also in der Mittelebene des Thieres weniger tief und hat rechts und links von dieser je eine taschenartige Ausstulpung (Taf. II. Fig. $2 \quad B \quad b)$. Ihre oralen und ihre seitliche Wandungen zeigen vielfache Falten, sodass sie von oben betrachtet die auf Taf. II. Fig. $2 D$ 
durch die punktirten Linien $b b$ angedeuteten Umrisse zeigt; in der Mitte der oralen Seite springt eine unpaare Falte $\left(b^{\prime}\right)$ papillenartig vor.

Der $\mathrm{Z}$ ellbe la g ihrer Wandung ist dünner an denjenigen Stellen, wo sie dem Eingeweidetractus aufliegt. Im Allgemeinen besteht derselbe aus unregelmässig polygonalen, scharf abgegrenzten Zellen mit ziemlich undurchsichtigem stark lichtbrechendem Inhalte, in welchen man den Kern meist erkennen kann (Taf. Ill. Fig. 9).

Die eigentlicben Genitalien liegen einerseits zwischen der oberen Fläche des Magens und der intratentakulären Leibeswand, andererseits zwischen dem oralen Rande der Bruttasche und der analen Seite des Mundes, und zwar näher an dem ersteren; sie bestehen aus zwei Hoden und zwei Eierstöcken, welche symmetrisch rechts und links von der Mittelebene des Thieres liegen, und zwar die Hoden zunächst der Bruttasche, auf ihrer oralen Seite aber die Eierstöcke (Taf. II. Fig. $2 D, t, o v)$. Beide Organe sind birnförmige Blasen. Die kurzen Aus führungsgänge des Hodens und des Eierstockes derselben Seite vereinigen sich kurz bevor sie die Mittellinie des Thieres erreichen, zu einem $\mathrm{Z}$ wittergange, welcher dann in der Mittellinie mit dem der anderen Seite verschmilzt; rechtwinklig gegen ihre bisherige Richtung setzen sie sich dann, zu einem einzigen Ausführungsgange verschmolzen, in der Symmetrieebene des Thieres in der Richtung nach der unpaaren an der Oralseite der Bruttasche gelegenen papillenartigen Falte fort. Der Punkt, wo die paarigen Zwittergänge beider Seiten zu dem unpaaren medianen Ausführungsgang verschmelzen, ist umgeben von einem rundlichen Aggregate von Zellen mit körnigem Inhalte, welches nach Aussen hin von keiner besonderen Membran begrenzt wird (Taf. III. Fig. $5 \mathrm{gl}$ ). Ich möchte dieses Gebilde für eine Art Druse ansehen. Die Structur der Ausführungsgänge ist sehr zart, und es ist mir daher nicht gelungen, direct eine Oeffinung des unpaaren Ausführungsganges auf der Spitze der beschriebenen Papille zu beobachten, dagegen habe ich bei günstiger Beleuchtung den Ausführungsgang bis in die Papillen hinein verfolgt und zu wiederholten Malen gesehen, dass die Zellen auf der Oberfläche der Papille eine von der gewöhnlichen Anordnung der Zellen des Bruttaschenbelages abweichende, ich möchte sagen sternförmige Anordnung zeigten, und ich glaube daher nicht fehl zu schliessen, wenn ich eine Mündung des Ausführungsganges auf der Oberseite der Papille annehme.

Die Eierstöcke sowohl, wie die Hoden sind von einer festen durchsichtigen Membran umgeben, welche in die Wandung der Ausführungsgänge übergeht. In den Eierstöcken (Taf. III. Fig. 5 ov) erkennt man deutlich Eier von sebr verschiedener Grösse; an diesen kann man den 
dunkleren feinkörnigen Dotter deutlich unterscheiden von der helleren Keimblase, in welcher excentrisch der scharf begrenzte kleine Keimfleck liegt. Die grössten Eier liegen merkwürdiger Weise meist an dem geschlossenen Ende des Eierstockes und sind von einer helleren Zone umgeben. Ein Epithel kann man an der mnenwand der Eierstöcke nicht unterscheiden, mitunter hat es jedoch den Anschein, als wären die Ausführungsgänge derselben von einem solchen ausgekleidet.

Die Hoden sind je nach dem Entwicklungszustande der Spermatozoen bald von einer Masse runder, stark lichtbrechender, scharf begrenzter Körner, bald von einem Gewirr feiner fadenförmiger Spermatozoen, bald von beiden zugleich erfült.

In der Bruttasche finden wir die Eier stets von einer birnförmigen Eischale umgeben; mit den spitzen Enden hängen oftmals mehrere Eier, wie schon vas BENEDEN es beschreibt, zusammen und sind mit ihnen an der Wand der Bruttasche so fest angeheftet, dass es Mühe kostet, sie von derselben loszulösen; ausserdem liegen in der Bruttasche oft eine Anzahl bereits bewimperter Larven. An Spiritusexemplaren sind dieselben jedoch nicht gut genug erhalten, um eine genauere Untersuchung ihres Baues vorzunehmen. Indessen vermuthe ich, dass dieselben höher organisirt sind, als die von van Beneden bei Pedicellin a Belgi ca beschriebenen.

Betrachtet man ein Thier, dessen Bruttaschen mit solchen Larven erfültt ist, von der Seite, so ragen häufig die Larven über den Rand der Bruttasche hervor. Die Pedicellina echinata wird erst dann geschlechtsreif, wenn alle ubrigen Organe sich vollkommen entwickelt haben und man trifft daher mitunter ziemlich ausgebildete Individuen, bei welchen man von den beschriebenen Genitalorganen noch Nichts entdecken kann und welche statt derselben Nichts weiter als einen an der oralen Seite des Darmes gelegenen Klumpen von Bildungsmasse besitzen; bei diesen ist stets das Rectum in der oben beschriebenen Weise auf das Intestinum zurückgebogen.

\section{Das Nervensystem.}

Das Centralorgan des Nervensystems wird gebildet von einem ovalen abgeplatteten Gangli on (Taf. III. Fig. 4). Dasselbe liegt in der Mittelebene des Thieres oberhalb des Magens, einerseits zwischen diesem und der intratentakulären Leibeswand, andererseits zwischen der analen Seite des Oesophagus und den Genitalien (Taf. II. Fig. 2 D. $n$ ). Sein längerer Durchmesser steht senkrecht gegen die Symmetrieebene; man kann an ihm unterscheiden eine äussere feste membranöse Hülle und einen Inhalt. Der Inbalt zeigt an den Rändern keine Differenzirung 
in besondere Formelemente, in der Mitte besteht er jedoch aus grősseren Zellen mit feinkörnigem Inhalte, welche mitunter einen Kern zeigen. Diese muss man wohl als Ganglien z ell en auffassen. Von der Oberfläche des Ganglion entspringen die peripherischen Nerven und zwar ein Wenig nach Innen von dem Aussenrande gerade da, wo die Ganglienzellen aufhören. Es sind dies jederseits drei Nervenstämme (Taf. III. Fig. $4 n$ ), welche aber nicht immer ganz symmetrisch sind; bald ist der eine ein Wenig stärker, bald der andere. Sie verlaufen an der Innenseite der intratentakulären Leibeswand nach der Peripherie derselben, spalten sich dort und versorgen die Tentakeln und zwar so, dass die am weitesten nach der oralen Seite des Ganglion zu entspringenden Nerven die oralen Tentakeln versorgen u. s. w.

Eine besondere Hülle kann man an ihnen nicht wahrnehmen, sie sind sehr schwach lichtbrechend und zeigen eine feine Längsfaserung.

Von der analen Seite des Ganglion entspringen mitunter noch zwei schwächere Nervenstämme, welche in der Richtung der Genitalien verlaufen; diese scheinen nicht ganz constant zu sein. An dem Präparate, nach welchem die Abbildung Taf. III. Fig. 4 gemacht wurde, fehlten sie, und ihre Lage ist daher blos durch punktirte Linien angedeutet.

Von dem Rande der Oralseite des Ganglion scheint ausserdem noch ein starker unpa arer Strang zu entspringen, welcher sich aber sofort in zwei einen stumpfen Winkel miteinander bildende Aeste theilt (Taf. III. Fig. $4 \mathrm{~m}$ ). Diese treten dann jederseits an den Oesophagus heran, ihren weiteren Verlauf habe ich nicht zu beobachten vermocht. Anfänglich hielt ich sie für das Aequivalent des Schlundringes, indessen sind mir später Zweifel aufgestossen, ob dieses Organ wirklich von dem Ganglion entspringt oder ihm blos auflagert; sollte dies Letztere der Fall sein, so würde ich mir über seine Bedeutung durchaus keine Rechenschaft zu geben im Stande sein.

Die Structur dieser Stränge weicht bedeutend ab von der der ubrigen Nerven. Sie sind viel dicker und gerundeter und man kann häufig an ihnen eine hellere Hülle und eine dunklere Centralmasse unterscheiden. Ich will noch erwähnen, dass es mitunter den Anschein hat, als verliefen von dem Punkte der intratentakulären Membran, welche gerade oberhalb der Gabelungsstelle der Aeste dieses Organes liegt, nach dem Rande der Tentakelrinne zu ein kleiner Streifen polygonaler Zellen.

Das Körperparenchym und die Bänder.

Während bei den ubrigen Bryozoen die Leibeshöhle von einer Flüssigkeit erfüllt ist, welche die Vertheilung der vom Darmtractus 
bereiteten Nahrungssäfte besorgt, ist bei Pedicellina der allerdings nur geringe $\mathbf{Z}$ wischen raum zwischen den Wänden des Darmtractus und der Leibeswand, sowie auch die Höhlung der Tentakeln erfullt mit einem parenchymatösen Gewebe. Dasselbe besteht aus sehr verschieden gestalteten $\mathrm{Z}$ ellen, welche lange oftmals verästelte Fortsätze haben, mit denen sie sich unter einander verbinden und an den Darmtractus oder die Leibeswand ansetzen. Ihr Inhalt ist meist feinkörnig und sie sind mit einem ovalen Kern nebst Kernkörperchen versehen (Taf. III. Fig. 10 b). Diese Zellen sind vollkommen homolog den Zellen des parenchymatösen Gewebes im Stiele, und ich vermuthe, dass ihre Zwischenräume ebenfalls von einer durchsichtigen Intercellularmasse ausgefült sind.

An der Unterfläche des Magens bilden dieselben eine Art von Strängen, durch welche der Magen mit dem oben beschriebenen Knopfe des Stieles zusammenhängt (Taf. II. Fig. \& $p$ ). Rechts und links verlaufen stärkere Stränge von diesem Knopfe an den Seitenflächen des Magens aufwärts nach der Gegend des Blindsackes zu, also ziemlich genau auf der Grenze der hellen, dünnen und durchsichtigen Wimperepithelzellen am Cardialtheile des Magens. Diese Stränge sind es offenbar, welche von van Beneden und Allman als die Retractoren beschrieben worden sind; indessen kann ich mich dieser Deutung nicht anschliessen. Ihr Ansehen weicht gänzlich ab von dem Habitus der Muskeln der übrigen Bryozoen. Wegen ihrer ungemeinen Zartheit sind sie sehr schwer zu untersuchen und von einer Isolirung derselben kann erst recht nicht die Rede sein, da die Wände des Magens durch das parenchymatöse Gewebe so fest mit der Leibeswand verbunden sind, dass eine Trennung ohne Zerstörung kaum vorzunehmen ist. Ich halte diese Stränge für weiter Nichts als für stärker entwickeltes Körperparenchym.

Ausserdem findet man noch eine zweite Art von Zellen zwischen die eben beschriebenen eingestreut (Taf. III. Fig. 10 a). Dies sind ziemlich runde, scharfbegrenzte und meist mit einem körnigen Inhalte versehene Zellen, welche mitunter auch einen feinen Ausläufer zeigen, besonders häufig finden sie sich an dem peripherischen Theile der intratentakulären Leibeswand und sind dort mitunter in Reihen geordnet.

Beide bis jetzt beschriebenen Zellarten finden sich auch innerhalb der Tentakeln. Ausserdem liegen in diesen letzteren aber noch deutliche Zellen von anderer Beschaffenheit, welche indessen nur dem vollkommen entwickelten Thiere zuzukommen scheinen. Es sind dies grosse, runde, scharf begrenzte Zellen mit vollkonmen wasserhellem 
Inbalte und einem sehr kleinen, aber ebenfalls scharf begrenzten, stark lichtbrechenden Kerne (Taf. III. Fig. 11); sie bilden gewöhnlich zwei Lăngsreihen in jedem Tentakel, sind schon am lebenden Thiere sehr deutlich, werden aber merkwürdiger Weise nur von SARS erwähnt, wenn man nicht etwa die Angabe von Reıd, dass die Aussenfläche der Tentakeln von einer Zellschicht bedeckt ist, hierauf beziehen will.

Ausserdem finden sich dicht unterhalb der intratentakulären Leibeswand noch verschiedene Bänderz Uge (Taf. Ill. Fig. 12); dieselben entspringen von den Seitenrändern der Bruttasche, laufen dann in flachen Bogen nach der Oralseite hin, verästeln sich dichotom und kreuzen sich theilweise in der Mittelebene des Thieres kurz ehe sie unter den undurchsichtigen breiten Oraltheil der Tentakelrinne treten. Hier zeigen sie häufig starke Verbreiterungen an ihren Gabelungsstellen und anastomosiren miteinander. Einige von ihnen lösen sich schliesslich in ganz feine runde Zweige auf, welche an den Seitenflichen des Oesophagus entlang laufen und sicb rechts und links von der Mittellinie des Thieres an der oralen Seite der Leibeswand festheften.

Andere Bänder, welche breiter und kürer sind, entspringen mit mehrschenkeligen Basen von der Leibeswand ohngefähr in derselben Höhe mil der unteren Grenze der Zone der Leberzellen und verlaufen schräg nach innen und oben, um sich an der intratentakulären Leibeswand anzusetzen; diese sind jedoch sehr schwer zu beobachten (Taf. II. Fig. $2 A, l$ ) .

Diese sämmtlichen Bänder zeigen eine faserige Structur, ähnlich wie die der Muskelfasern des Sphincter, und ich würde nicht anstehen, dieselben auch für Muskelfasern zu halten, wenn am lebenden Thiere Bewegungen wahrzunehmen wären, welche man ihrer Thätigkeit zuschreiben könnte.

Aus der bisherigen Darstellung ersieht man leicht, dass die Structur von Pedicellina bedeutend abweicht von dem gewöhnlichen Bauplane der Bryozoen. Die einzigen Gattungen, welche sich mit ihr vergleichen lassen, sind Loxosoma Kefrest. und Urnatella Lexdy.

Lox o s o ma besonders, dessen nahe Verwandtschaft mil unserem Thiere schon von den Entdeckern vollkommen gewürdigt wurde, soweit es nach den damals vorhandenen Publicationen möglich war, ist sogar einer Pedicellina so ähnlich, dass ich nicht anstehen würde, z. B. L. singulare Keferst. fur eine junge Pedicellina zu halten, wenn nicht Genitalorgane bei diesem Thiere nachgewiesen worden wären. 
Ein Blick auf die Keperstein'sche Figur ${ }^{1}$ ) zeigt diese Aehnlichkeit auf das schlagendste. Hier sehen wir deutlich, wie der Kreis der zehn mit zwei Reihen starker Wimpern auf der Innenseite besetzten Tentakeln Mund und After einschliesst. Der bewimperte Saum an der Basis der Innenseite der Tentakeln, welchen Kefersteiv als Diaphragma bezeichnet, ist ein genaues Aequivalent der Tentakelrinne bei Pedicellina und wird von dem Munde durchbohrt ${ }^{2}$ ). Der After liegt hier ebenfalls an der Spitze einer Art Papille, welche Kefrerstein als Schornstein bezeichnet. Eine Zurückziehung der Tentakeln nebst Invagination des vordersten Theiles der Leibeswand findet nicht Statt. Die Tentakeln werden einfach nach Innen eingeschlagen und zugleich eingerollt, und aus der Beschreibung der Zeichnung, welche Glaparède ${ }^{3}$ ) von L. KeFERSTEIN aus Neapel giebt, geht hervor, dass der Kelchrand sich nach Einschlagung der Tentakeln ebenso stark contrahiren kann, wie bei Pedicellina, was wohl auf das Vorhandensein eines Sphincter schliessen lässt. Auch ist der bei dieser letzteren Species längere Stiel mit Muskeln versehen.

Die obere Wand des Magens ist auch bei Loxosoma der Sitz der Leberzellen und die Genitalien scheinen nach der Darstellung von GLAPAREDE sich ebenfalls symmetrisch oberhalb des Magens zu entwickeln, wenngleich der von ihm beschriebene Eierstock (?) sich mit keinem Organ bei Pedicellina genau vergleichen lässt.

Als dritte Species ist der Gattung Loxosoma durch Kowalewskx hinzugefügt worden L. Neapolitanum ${ }^{4}$, wenngleich derselbe bemerkt, dass dieses Thier wohl als eine besondere Gattung angesehen werden könnte.

Diese Art zeigt einerseits eine grössere Abweichung von dem Bau von Pedicellina als die beiden vorhergehenden, andererseits aber auch wieder Uebereinstimmungen, welche bei jenen noch nicht nachgewiesen werden konnten.

Nach Kowalewsky besteht seine grösste Eigenthümlichkeit in dem Mangel einer besonderen Mundöffnung und er hält den Schornstein, der aus dem Innern des Tentakelkranzes herausragt und der genau dem Analschornsteine von Pedicellina entspricht, für Mund- und Afteröffnung zugleich. Sollte diese Ansicht sich wirklich bestätigen, so würden

1) Zeitschrift für wissenschaftliche Zoologie Vol. XII. Taf. XI. Fig. 29.

2) Dies geht übrigens aus den Abbildungen von ClAPARĖDE in seinen "Beobachtungen u. s. w. an der Küste der Normandie 1863. Taf. II. Fig. 6 und 7. pag 105 bis 107 " nicht hervor, sondern nur aus der Keferstein'schen Figur und Beschreibung.

3) Annales des Sciences nat. 5 e Série Zool. Tome 8 p. 28 Tab. 6 Fig. 1-3.

4) Mém. de l'Ac. imp. des Sc. de St. Petersbourg. VII. Sér. Tome X. Nr. 2. 1866. 
wir hier eine der merkwürdigsten Modificationen des Bryozoentypus haben; indessen glaube ich Herrn Kowalewsкy nicht zu nahe zu treten, wenn ich die Vermuthung ausspreche, eine nachträgliche Untersuchung dürfte doch wohl noch eine gesonderte Mundöffnung erkennen lassen. Claparéde übersah ja anfänglich ebenfalls die Mundöffnung bei Loxosoma singulare. In diesem Falle bliebe alsdann ein typischer Unterschied dieses Thieres von dem den Gattungen Pedicellina und Loxosoma gemeinsamen Bauplane nicht übrig, wenngleich das Vorhandensein der Fussdrüse sehr wohl eine generische Trennung dieses Thieres von Loxosoma rechtfertigen würde.

Auch bei diesen Thiere haben wir im Uebrigen zehn Tentakeln, welche den oberen Körperrand umgeben, deren Basen durch einen sehr breiten Bord von wimpernden Zellen verbunden sind, welche der Tentakelrinne entsprechen. Der von diesem Wimperborde eingeschlossene vertiefte Raum, welcher mit unbewimperten Zellen bedeckt ist, würde dann der intratentakulären Leibeswand bei Pedicellina entsprechen, vielleicht auch der Bruttasche, da ja Kowalewsky sagt, odie Eier würden durch einen der Tentakeln so lange an die Scheibe (so nennt er die intratentakuläre Leibeswand) angepresst und hier gehalten, bis daraus eine flimmernde Larve ausschwimmt. Muskelfäden, welche in ihrer Lagerung viel Aehnlichkeit haben mit dem Sphincter bei Pedicellina, werden ebenfalls beschrieben. Die Leberzellen finden sich an der gewohnten Stelle. Besonders hervorzuheben ist aber der Umstand, dass Kowalewsky berichtet, der Zwischenraum zwischen Magen- und Leibeswand werde ausgefüllt von einem aus Zellen und Intercellularsubstanz bestehenden Parenchym, welches, soweit sich aus seiner Abbildung ersehen lässt, durchaus übereinstimmt mit dem eben bei Pedicellina beschriebenen. Beiliufig möchte ich noch aufmerksan machen auf die grosse Aeholichkeit, welche zwischen der am weitesten entwickelten Larve von L. Neapolitanum (Fig. 10 , und dem von Buscr ${ }^{1}$ ) in Triest beobachteten C y c I opelma longociliat um besteht.

Was Lrnatella betrifft, so ist diese interessante amerikanische Süsswasser-Bryozoe noch $\mathrm{zu}$ wenig bekannt, als dass eine genaue Vergleichung mit Pedicellina sich durchführen liesse; indessen genügt ein Blick auf eine der beiden Figuren, welche bis jetzt von diesem Thiere existiren ${ }^{2}$, um die grosse Aehnlichkeit von Pedicellina und Urantella erkennen zu lassen.

1) Beobachtungen über Anatomie und Entwicklung einiger wirbelloser Seethiere. 1851. pag. 132. Taf. XVI. Fig. 12-16.

2) Allmax, Monogr. of the Fresch-Water Polyzoa, 1856. pag. 118. und Proceedings of the Essex Institute. Salem. 1868. Tab. XV. Fig $\mathbf{5 .}$ 
Auch bei Urnatella mïnden Mund und After innerhalb des Tentakelkranzes; eine Leibeshöhle, geräumig genug, um ein Zurückweichen des Darmkanales zu erlauben in der Art und Weise, welche nothwendig wird bei einer Invagination des vorderen Theiles der Leibeswand, fehlt, sodass der Schluss wohl gerechtfertigt erscheint, dass auch bei diesem Thiere die Tentakeln nur nach Innen eingeschlagen, aber nicht zurückgezogen werden. Aus der von Alumax gegebenen Abbildung scheint sich ferner zu ergeben, dass ein Sphincter vorhanden ist in gleicher Lage wie bei Pedicellina.

Wir sehen also, dass die Genera Pedicellina, Loxosoma und Urnatella eine Summe von gemeinsamen Merkmalen besitzen, welche sie von allen übrigen bekannten Bryozoen scharf trennen, und ich bin daher zu der Ansicht gelangt, dass diese drei Genera eine natürliche Gruppe bilden. Wenn man eine systematische Eintheilung der Bryozoen in der Form einer Clavis geben wollte, so müsste man diese Gruppe bei dem jetzigen Stande unserer Kenntniss der Anatomie der Bryo\%en als gleichwerthig der Summe sïmmtlicher übrigen Bryozoen hinstellen; indessen sind die anatomischen Arbeiten noch lange nicht weit genug gediehen, um eine solche Behauptung bedingungslos auszusprechen; ich begnüge mich daher, die erwähnten drei Gattungen zusammenzufassen als eine Familie, für welche ich den Namen »Entoprocta (') vorschlage und die Diagnose derselben würde dann sein:

Mund und After liegen innerhalb des Tentakelkranzes, der vordere Theil der Leibeswạnd isı nicht einstülphar, daher keine Tentakelscheide vorhanden: die Tentakeln sind bilateral symmetrisch angeordnet, nicht zurückziebbar, sondern nur nach Innen einschlaghar und einrollbar."

Sollte es sich jedoch erweisen, diss die Entoprocta wirklich simmtlichen übrigen Bryozoen als gleichwerthig gegenübergestellt werden müssen, so könnte man diese letzteren alsdann passender Weise als "Ectoprocta bezeichnen ${ }^{2}$;

1) Eirós und $\pi$ owstós.

2) Eine vorläufige Mittheilung uber diese beiden Aufsätze findel sich in dem sitzungsbericht der Gesellschaft der naturforschenden Freunde vom 16. März 1869.

Kurz nach Ostern 1869, als mein Aufsatz bereits unter der Presse war, erfuhr ich durch die Güle des Herrn Professor Letckant, dass einer seiner Schüler, Herr OtLlanixe im Frühjahr 1868 zu Neapel Untersuchungen angestellt hat über die Anatomie und Entwickelungsgeschichte von 2 Species von Pedicellina, welche wahrscheinlicher Weise in russischer Sprache bereits publicirt sind. Derselbe theilte mir ferner init, dass er in seinem Jahresberichte lïr 1866 und 1867. (Trosché's Archiv für Naturgeschichte 1868. Vol. II. p. 340 auf die Identität des Cyclopelma longociliatum Busch mit der Larve von Loxosoma Neapolitanum Kow aufmerksam gemacht habe 


\section{Erklärung der Abbildungen.}

Tafel I.

Fig. 1-7. Bugula flabella ta Thомps.

Fig. 1. Die Larve. $A$ von der Seite, $B$ von oben; $a$ ausstülpbarer Fortsatz, $b$ Mund, $c$ Flagellen, $d$ die rosettenförmige Zeichnung, $e$ Pigmentflecke ${ }^{145} / 1$.

Fig. 2-6. Die Entwicklung der Larve zum primären Zooecium. a Anlage der Tentakelkrone, $b$ Bildungsmasse, $c$ Sarcodestränge, $d$ Anlage des Darmtractus, $e$ Tentakelscheide $145 / 1$.

Fig. 7. Die drei ersten Zooecien eines älteren Stockes. $r$ Wurzelfäden, av Avicularium $40 \%$.

Fig. 8. Die Larve von Bugula plumosa Pall. $A$ von der Seile, $B$ von unten. Die Bedeulung der kleinen Buchstaben ist wie bei Fig. 1 145/1.

Fig. 9-15. Bicella ria ciliata Lin.

Fig. 9. Die Larve. $A$ von der Seite, $B$ von unten. Die kleinen Buchstaben wie bei Fig. 1 und 8 145/1.

Fig. 10-13. Verschiedene Stadien einer Ovicelle. $m$ Rand der Mündungsarea, $a$ ein befruchtetes Ei, $b$ die löffelförmige, resp. helmförmige Blase, $c$ die rundliche Blase (Deckelblase), $d$ Muskelfasern innerhalb der letzteren 145/1.

Fig. 14. Eine Astspitze. ov Lage der Eier innerhalb des Zooecium, $t$ untere Abtheilung des Zooecium, in welcher die Spermatozoen entstehen, ovic Anlage der Ovicelle, av Avicularium 40/1.

Fị. 15. Zwei Eier mit der sie umhüllenden Membran 57\% 1 .

Tafel II.

Pedicellina eclıinata SARs.

Fig. 1. Ein geschlechtsreifes Thier nebst einer ganz jungen Knospe, $b$ Brultasche $5 \pi / 1$.

Fig. 2. Schematische Darstellung des allgemeinen Baues. A Querschnitt des lielches senkrecht gegen die Symmetrieehene und parallel der Längsaxe des Sticles, $B$ desgleichen, aber weiter nach der Analseite zu, $C$ Querschnitt parallel der Symmetrieebene, aber ein Wenig links von derselhen (ein Querschnitt in der Symmetrieehene selbst würde nicht durch zwei Tentakel, sondern durch zwei liftertenlakularräume gehen). $D$ ein Blick in den Kelch von oben nach Entfernung der Tentakeln. Die geraden punktirten und mil $A-D$ bezeichneten Linien auf den Figuren $C$ und $D$ zeigen die Stellen an, in welchen die mit denselben Buchstaben bezeichnelen Schnitte diese Figuren treffen. $O$ der Mund, $R$ Rectum, $V$ Magen, $I$ Intestinum; $a$ Tentakelrinne, $c$ Zonen der flachen Zellen, $b$ Bruttasche, $b^{i}$ unpaare Falte in derselben, $b^{\prime \prime}$ ihr oberer Rand, $n$ Ganglion, ov Eierstock, $t$ Hoden, $g$ Drüse, sph Sphincter, ec Ectocyste, en Endocyste, $m$ Nuskelschicht des stieles, $l$ Bänder."

Fig. 3. Querschnitt des mittleren Theiles des Stieles. $m$ Muskelschicht, ec Ectocyste, $p$ Parencliymzellen 570/1. 
Fig. 4. Längsschnitt des obersten Theiles des Stieles. ec Ectocyste, en Endocyste, $m$ Muskelschicht, $p$ Parenchymzellen, $d$ Diaphragma, $v$ wallartige Zellen, $f$ durchsichtige Wölbung, $p$ Parenchymstränge nach der Unterseite des Magens 200/1.

Fig. 5. Muskelschicht des Stieles von der Innenfläche gesehen $570 / 1$.

\section{Tafel III.}

Pedicellina e chinata Sars.

Fig. 1. Analer Theil der Tentakelrinne. Die Erklärung der Buchstaben dieser und der folgenden Figur sind im Texte pag. 23 570/1.

Fig. 2. Zellbelag der rechten Hälfte der Aussenseite des Oesophagus und der Basis der beiden ersten Tentakeln rechter Seits $570 / 1$.

Fig. 3. Zellen der Endocyste 57\%/1.

Fig. 4. Ganglion $570 / 1$.

Fig. 5. Die inneren Genitalien nebst dem Ganglion. $n$ Ganglion, ov Eierstock, $t$ Hoden, $g l$ Drüsen, $d$ unpaarer Ausführungsgang 200/1.

Fig. 6. Flächenansicht der Leberzellen des Magens von Aussen 570/1.

Fig. 7. Flächenansicht der grossen Zellen der unteren Hälfte der Magenwand 570/1.

Fig. 8. Flächenansicht der hellen Wimperepithelzellen des Cardialtheiles des Magens $570 / 1$.

Fig. 9. Zellbelag der Bruttasche 570/1.

Fig. 10. Parenchymzellen $570 / 1$.

Fig. 11. Ein Stück eines Tentakels von der Seite gesehen $200 / 1$.

Fig. 12. Die unterhalb der intratentakulären Leibeswand verlaufenden Bänder. $a b$ Mittellinie des Thieres, $m$ Grenzfalte des oralen Theiles der Tentakelrinne $380 / 1$. 


\title{
BEITRÄGE
}

\author{
ZUR
}

\section{KENNINISS DER BRYOZOEN}

\author{
VON
}

\section{$D^{R}$. HINRICH NITSCHE.}

\section{HEFT.}

MIT DREI HOLZSCHNITTEN UND DREI TAFELN.

III. Ueber die Anatomie und Entwicklungsgeschiehte von Flustra membranaeea. Mit Taf. IV. V. VI. und 1 Figur in Holzsehnitt.

IV. Ueber die Morphologie der Bryozoen. Mit 2 Figuren in Holzsehnitt.

\section{LEIPZIG,}

VERLAG VON WILHELM ENGELMANN. 
Abdruck aus der Zeitschrift fiir wissensch. Zool. XXI. Bd. 4. Heft 
III.

Ueber die Anatomie und Entwicklungsgeschichte von Flustra membranacea.

(Hierzu Tafel IV - VI.)

Eine monographische Darstellung des Baues einer chilostomen Bryozoc fehlt noch gïnlich in der zoologischen Literatur; auf den folgenden Seiten soll der Versuch gemacht werden, diese Lücke einigermaassen auszufüllen; dieselben sind getvidmet einer Besprechung der Anatomie und der Knospungsverhältnisse von

Flustra membranacea Lin. Sol. Die verhälnissmässig bedeutende Grösse der einzelnen Zoöcien, sowie die geringe Ausdehnung der Kalkeinlagerungen der Ectocyste liessen gerade diese Species für eine anatomische Untersuchung besonders geeignet erscheinen. Die geschlechtliche Fortpflanzung mit in den Bereich der Untersuchungen zu ziehen, war unmöglich, da die kriegerischen Ereignisse des Jahres 1870 den Verfasser von der Meeresküste entfernt hielten.

Die untersuchten Exemplare wurden in Helgoland gesammelt, und sofort in ziemlich starken Spiritus gesetzt; sie gehören, wie ich mich leicht durch Vergleichung derselben mit den vorhandenen Abbildungen überzeugen konnte, zwar wirklich zu der eben genannten Species, ich habe

Anmerkung. Einige Hauptresultate der in den folgenden beiden Aufsätzen niedergelegten Untersuchungen sind bereits in einer vorläufigen Mittheilung kurz dargelegt worden, in dem Journal of microscopical Science, New series. Vol. XI, p. 155. In dieser vorläufigen Mittheilung ist ibrigens ein sinnentstellender Druckfehler vorhanden. Auf p. 161, Zeile 16 von oben muss es anstatt Bryozoa entoprocta heissen: Br. ectoprocta. Auch ist die eigentlich zu dem Holzschnitt bestimmte Erklärung der Buehstaben weggelassen und ein Stück Text fälsehlicher Weise als solche benutzt und so aus dem Zusammenhange gerissen. 
aber auch erkannt, dass die Diagnose dieser Species einer kleinen Veränderung bedarf. Surt diagnosticirt sie in seinen ausgezeichneten kritischen Untersuchungen uber die skandinavischen Meeresbryozoen folgendermaassen : Colonia in crustae formam expansa zooecia (rectangularia) ad angulos distales (i. e. juniores, exteriores) seta brevi mucronata praebet; avicularia et ooecia desunt. $\left.{ }^{1}\right)$ Surre sieht also mit allen ührigen Schriftstellern die beiden Stacheln, welche sich finden an den Enden der Scheidewand, durch welche ein bestimmtes Zoöcium einer Längsreihe von den nächstjüngeren abgegrenzt wird, als dem Vordertheile des älteren Zöocium zugehörig an. Die anatomische Untersuchung hat aber gelehrt, dass diese beiden Stacheln vielmehr dem Hinterende des jüngeren Zoöcium angehören. Die Diagnose der Species gestaltet sich also folgenderinaassen :

Flustra membranacea (Liv. Sol.)

Char. Colonia in crustae formam expansa zooecia (rectangularia) ad angulos proximales (i. e. seniores, interiores) seta brevi mucronata praebet. Avicularia et ooecia desunt.

In Betreff der Synonyme unserer Species verweise ich auf die ungemein vollständige Zusammenstellung derselben, welche Surт am angefürten Orte gegeben hat.

\section{Anatomie des ausgebildeten Thieres.}

Die Thierstöcke von Flustra membranacea bilden einen dünnen netzartigen Ueberzug verschiedener submariner Gegenstände, besondere Vorliebe scheint jedoch das Thier für die langen Laminarien zu haben, deren Flächen es mitunter auf fusslange Sirecken hin uberzieht. Ist der Stock noch jung, so sind die ihn zusammensetzenden Zoöcien in mehr oder weniger regelmässigen Radien un das primäre Zoöcium angeordnet, in den älteren Stöcken dagegen sind sie meist in ziemlich parallele Längsreihen geordnet, und zwar liegen die Zoöcien zweier neben einander herlaufender Längsreihen alternirend, so dass die Vorder- und Hinterenden der Zellen einer bestimmten Reihe in gleicher Linie liegen mit der Mitte der Zoöcien der beiden anliegenden Reihen (Taf. IV, Fig. 6). Die Grösse und Form der einzelnen Zoöcien variirt ziemlich stark; diese Verhältnisse sollen jedoch vorläufig unberucksichtigı blieben: ich halte mich hier an die am häufigsten vorkommende, ich möchte sagen normale oder typische Form des ausgewachsenen

1) Öfversigt af Kongl. Vetensk.-Akad. Förhandl. 1867; p. 357. 
Zoöcium; die aberranten Zoöcienformen sollen erst bei der Darstellung der Knospungsweise besprochen werden.

Das Gebilde, welches man gewöhnlich als das Einzelindividuum in dem Bryozoenthierstocke zu bezeichnen pflegt, besteht aus zwei Hauptbestandtheilen, dem $\mathrm{Z}$ oöcium und dem Polypid. Letzteres liegt im Zustande der Ruhe, innerhalb des bis auf eine kleine Oeffnung, die Mündung, durch welche ein Theil des Polypids mit der Aussenwelt in Berührung treten kann, ringsum geschlossenen Zoöcium. Es steht in directer Verbindung mit dem Zoöcium, am Rande der Mündung durch die hier sich inserirende Tentakelscheide, durch die grossen ReIractoren und das sogenannte "Colonialnervensystem" oder - wie ich dies Gebilde zu nennen vorschlage - die »Funicularplatter. Ich wende mich zunächst zur Beschreibung des Zoöcium.

\section{D a s $\mathrm{Z}$ o ö c i u m.}

Das normale Zoöcium (Taf. IV, Fig. $6 f$ ) hat im Allgemeinen die Form eines hohlen Parallelopipeds; dasselbe liegt der Unterlage mit einer seiner beiden grössten Flächen auf; die kleinsten Flïchen bilden die Vorder- und Hinterwand, und stehen nicht ganz senkrecht gegen die Unterlage, neigen sich vielmehr ein wenig (ohngefähr in einem Winkèl von $\left.75^{0}\right)$ nach vorn; die Seitenflächen bilden daher keine Rechtecke, sondern langgestreckte Rhomboide. Die oberen und hinteren Ecken eines jeden Zoöcium ziehen sich aus in zwei starke kegelförmige, ein wenig nach hinten geneigte Stacheln (Taf. IV, Fig. 1 u. 2).

Die Wandung des Zoöcium besteht wie bei allen Bryozoen aus zwei Schichten, aus der Endoc yste und der Ect oc yste, d. h. aus einer weichen Gewebsschicht und einer ihr nach aussen aufliegenden, von ihr secernirten Cuticula. In dem normalen ausgewachsenen Zoöcium uberwiegt die letztere so ungemein, dass die Gewebsschicht, deren Secret sie ist, die Matrix der Cuticula, nur als ein feines der Innenfläche der Eclocyste anliegendes Häutchen erscheint. Ich wende mich zunächst zur Beschreibung der Ectocyste.

Die Ectocyste bildet nach aussen zu die Begrenzung des gesammten Zoöcium, dessen Form durch sie bestimmt wird. Ursprünglich besteht die Ectocyste an allen Stellen aus einer einfachen Chitinmembran ohne jede erkennbare innere Structur. Bei den ausgewachsenen Zoöcien ist dieses Verhältniss nur auf der Ober- und Unterseite erhalten. Hier bleibt die Ectocyste stets eine schmiegsame, vollkommen durchsichtige Cuticula. Die Cuticula der Unterfliche ist am dünnsten. 
Die vier kleineren Flächen des Parallelopipeds zeigen dagegen Kalkeinlagerungen innerhalb der hier stark verdickten Guticula. Auch der untere Theil der Stacheln verkalkı stets.

Die sehr eigenthümliche Form dieser Kalkeinlagerungen, die übrigens ziemlich constant ist, kann man am besten an Zoöcien erkennen, welche in concentrirter Kalilauge gekocht worden, aus denen also alle Weichtheile verschwunden sind.

Auf Taf. VI, Fig. $3 A$ ist das Kalkgerüst eines normalen Zoöcium dargestellt. Dasselbe besteht aus 4 getrennten, nur durch die Chitincuticula verbundenen Stücken $\left(a, a^{\prime}, b, c\right)$.

In der Mitte jeder Seitenfläche liegt eine ohngefähr viereckige Platte feinkörnigen Kalkes $\left(a, a^{\prime}\right)$, welche etwas unterhalb ihres oberen, längeren Randes eine in den Innenraum des Zoöcium vorspringende Verdickung zeigt, gebildet von einigen Reihen stumpfconischer dichtgedrängter Wärzchen; der nach oben von dieser Warzenreihe liegende glatte Rand erscheint gleichfalls etwas dicker, als die unteren Theile der Platte. Wenn man ein Zoöcium von oben betrachtet, so erkennt man zunächst bei oberflächlicher Einstellung diesen oberen Rand, und erst bei Senkung der Linse tritt die von den Warzen gebildete, weiter nach innen liegende gezackte Linie hervor. In der unteren Hälfte dieser Platten finden sich zwei rundliche, sehr verdünnte Stellen $(r s p l)$, eingefasst von einem schwach wulstigen Rande, der eine weniger körnige Beschaffenheit zeigt als der Rest der Platte. Mitunter ist eine dieser verdünnten Stellen durch zwei ihr ähnliche, kleinere vertreten; so z. B. an dem Hinterrande der Platte $a$ in Fig. $3 A$. Jede solche verdünnte Stelle wird durchbohrt von einer Anzahl sehr kleiner, scharf begrenzter, runder Löchelchen, welche selbst wieder von einem gewulsteten Rande umgeben werden (Taf. VI, Fig. 4 a). Durch diese Poren, denen, wie wir sehen werden, Poren in den Wandungen der anliegenden Zoöcien entsprechen, stehen die Elemente der Endocyste zweier Zoöcien in directer Verbindung. SuIt hat diese runden verdünnten Stellen zuerst bei Flustra foliacea gesehen. Er scheint aber die ganze verdünnte Stelle als Oeffnung anzusehen und die kleinen Poren innerhalb der Platte übersehen zu haben. Es nennt das ganze Gebilde daher "Communicationsporea. ")

Reicherт beschreibt ferner ganz gleiche Gebilde, in welchen aber die kleinen Perforationen regelmässiger angeordnet sind in der allerdings nicht verkalkten Eclocyste der Stammglieder von Zoobotryon 
pellucidus. ') Dieselben finden sich je eine an der Stelle, wo ein Zoöcium dem Stamme aufsitzt, und die Poren lassen Fäden der Substanz der Endocyste durchtreten. Reichert bezeichnet sie als Rosettenplatten. Auch Claparéde hat bei Bugula und Scrupocellaria ähnliche Gebilde gefunden. Er beschreibt sie als uhrglasförmige Vertiefungen der Ectocyste, welche in der Mitte von einem winzigen Loche durchbohrt werden, und so die Verbindungen der benachbarten Zoöcien derselben Lüngsreihe vermitteln. ${ }^{2}$ ) Ausser diesen finden sich bei Scrupocellaria aber auch noch grosse weite Oeffnungen, welche eine Communication zwischen den Zoöcien der beiden neben einander laufenden Längsreihen herstellen und zwar steht jedes einzelne Zoöcium mil den $\mathrm{zw}$ ei benachbarten Zoöcien der anderen Längsreihe in Verbindung. 3) Ich will die Reichert'sche Bezeichnung annehmen, da der Surт'sche Name Communicationspore für das ganze Gebilde nicht zutreffend erscheint.

Die beiden Seitemplatten des Kalkgerüstes werden nun durch nicht verkalkte Räume getrennt von den Kalkeinlagerungen der hinteren und vorderen Theile der Seitenflächen; diese letzteren hängen direct zusammen und gehen continuirlich über in die Kalkeinlagerungen der Hinter-, resp. der Vorderwand.

Die Kalkeinlagerungen der Vorderwand des Zoöcium bilden daher mit denen der Vordertheile der beiden Seitenwände einen zwei Mal rechtwinkelig geknickten Schirm mit einem Mittelstuck - Vorderwand - und zwei seitlichen Flügeln, den Seitenwänden (Taf. Vl, Fig. $3 A, c$ u. C.)

Einen ganz ähnlichen Schirm bilden die Kalkeinlagerungen der Hinterwand des Zoöcium mit denen der hinteren Theile der Seitenwände (Fig. $3 A, b$ u. B). Nur sind die oberen Enden der Platten, da wo sie in den Winkeln zusammenstossen, ausgezogen in zwei conische, oben abgestutzte offene Duten, die Kalkeinlagerungen der Stacheln.

Auch die beiden eben beschriebenen schirmförmigen Kalkeinlagerungen haben eine nach der Höhlung des Zoöcium zu durch Warzenreihen verdickte Zone längs ihres oberen Randes, nur liegt diese Zone an der Vorderwand etwas tiefer wie an der Hinterwand. Auch Rosettenplatten vermisst man weder an den Vorder- und Hintertheilen der Seitenwände, noch auch an den Vorder- und Hinterwänden selbst. In den letzteren finden sich je zwei birnförmige Rosettenplatten, in

1) Reichert, Vergleichende anatomische Untersuchungen über Zoobotryon pellucidus (Енrenв.). Aus d. Abhandl. d. Königl. Akad. der Wissensch. zu Berlin, 1869, p. 267 , Tab. III, Fig. 7.

2) Zeitschr. für wissensch. Zoologie. Vol. XXI, p. 160. Tab. VIII, Fig. 1 A. a.

3) loc. cit. p. 156, Taf. VIII, Fig. 1 C, $c, c^{\prime}, c^{\prime \prime}$ etc. 
den ersteren je eine runde. Im Allgemeinen hat also jodes Zoöcium normaler Weise 12 Rosettenplatten.

Die Rosettenplatten eines jeden Zoöcium correspondiren nun mit den Rosettenplatten der umliegenden Zoöcien auf das genaueste.

Zunächst passen natürlich die
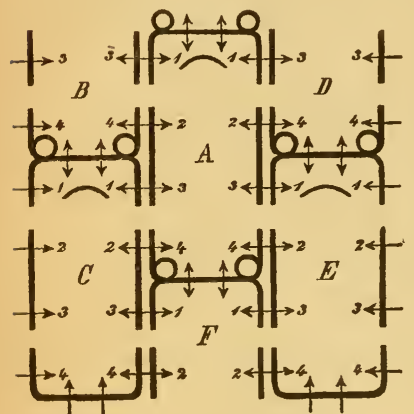

Fig. 1. Rosettenplatten der Ilinterwand eines jeden Zoöcium auf die Rosettenplatten der Vorderwand des nächstälteren Zoöcium derselben Längsreihe. Durch die quincunxartige Anordnung der Zoöcien der neben einander liegenden Längsreihen wird ferner bewirkt, dass die Rosettenplatten der Mittelplatte einer Seitenwand passen auf die Rosettenplatten der Seitentheile der Kalkschirme der Vorder- und Hinterenden zweier Zoöcien in der nebenliegenden Längsreihe (Taf. VI, Fig. $3 A$ u. D). In dem beigedruckten Schema sind die Rosettenplatten durch Pfeile bezeichnet. Es passt also dic Rosettenplatte 1 der rechten Seitenwand des Zoöcium $A$ auf die Rosettenplatte 3 der linken Seitenwand des Zoöcium $D$ der nebenliegenden Reihe und die Rosettenplatte 4 der linken Seitenwand des Zoöcium $A$ auf die Rosettenplatte 2 der rechten Seitenwand des Zoöcium $C$ u. s. w.

Ich hahe dieses Kalkgerüste als eine Ein lag er ung der Cuticula bezeichnet, und dies ist auch wirklich der Fall: nicht die ganze Ectocyste verkalkt, sondern nur die mittlere Schicht derselben. An den Seitenwänden des Zoöcium sind die beiden unverkalkten äusseren Blätter der Ectocyste ziemlich dünn, bedeutend stärker dagegen in den Stacheln. Wie wir übrigens später schen werden, besteht der Process der Verkalkung vicht darin, dass zwei Lamellen der Endoeyste getrennt werden durch sich dazwischen schichende Kalkpartikeln, sondern in der Imprägnirung einer präformirten mittleren Chitinschicht mit Kalksalzen.

Die Gliederung des starren Gerüstes unseres Thieres durch 4 stets biegsam bleibende, nicht verkalkende Zwischenräume erscheint als eine Anpassung desselben an seinen gewöhnlichen Wohnsitz, die Tange und insbesondere die Laminarien. Das ganze Zoöcium wird durch dieselbe in einer gewissen Wcise biegsam, und wird viel weniger als ein mit einem ganz starren Gerüste ausgestattetes Zoöcium einer 
Zerbrechung ausgesetzt sein, wenn die langen Laminarien durch den Wellenschlag hin und her bewegt, gekrümmt und geschlängelt werden. In functioneller Hinsicht kann man daher diese unverkalkten Zwischenräume vergleichen mit den unverkalkt bleibenden Stellen in den Aesten der Salicomariaden und Cellulariaden, durch welche dieselben in einzelne, aus mehreren Zoöcien bestehende und durch unverkalkte falsche Gelenke getrennte Glieder zertheilt werden. Die bekanntesten Beispiele sind Scrupocellaria und Canda.

Nicht weit von dem vorderen Ende des Zoöcium befindet sich in seiner oberen Wand die Mündung, d. h. die Oeffnung, durch welche das Polypid, resp. die Tentakelkrone desselben herausgestulpt werden kann. Dieselbe erscheint als eine quere schlitzartige Einstulpung der Ectocyste und natürlich auch der Endocyste (Taf. IV, Fig. 2 Md). Der hintere Rand der Einstülpung springt faltenartig von hinten uber die Oeffnung vor und schliesst sie von oben; dieser deckende Rand wird gewöhnlich als der Deckel, „die Lippe« des Zoöcium bezeichnet. Ein solcher Deckel findet sich nur bei der Abtheilung der Bryozoen, zu welcher unser Thier gehört: daher ihr Name Chilostomata.

Der Deckel ist also kein selbständiges Gebilde, sondern nur eine locale Verdickung der Cuticula (Taf. IV, Fig. 1 u. 2 op. Taf. V, Fig. 2 u. 4 op und Fig. 11). Der Rand der deckenden Falte ist nach vorn convex und ziemlich stark stabartig verdickt. Das obere Blatt der Falte, welche nach vorn von diesem verdickten Rande, nach hinten von einer Verbindungslinie der beiden Endpunkte des verdickten Randes begrenzt wird, ist etwas stärker als der Rest der Ectocyste der oberen Wand. Die Enden der erwähnten Verbindungslinie sind beinahe eben so stark verdickt, wie der Vorderrand der Falte (Fig. 11). Diese verdickte halbmondförmige Platte ist nun in ihrer Fläche von rechts nach links stark gebogen und zwar derartig, dass die zugespitzten Seitentheile ziemlich stark nach unten gekrümmt sind; liegt also der mittlere Theil des Deckels in der Ebene der ubrigen Endocyste, wie dies stets der Fall, wenn die Mündung mässig geschlossen ist, so ragen die Seitentheile in das Innere des Zoöcium hinein; da der ganze Deckel aber an allen seinen Rändern in Continuität steht mit der übrigen Ectocyste, so werden durch die Seitentheile des Deckels enge, spitze, dütenartige Einstülpungen der Endocyste gebildet, deren blinde Enden in das Innere des Zoöcium vorragen. Diese dienen als Ansatzpunkte für die Opercularmusculatur.

Dicht hinter dem Deckel befindet sich bei den meisten Zoöcien noch jederseits eine kleine warzenartige Auftreibung der Ectocyste nach aussen (Taf. V, Fig. $4 y$ ). Diese Auftreibungen sind 
ungemein leicht zu ubersehen, da unter ihnen in der Endocyste stets ein kleiner Zellhaufen liegt; die Unrisse der Auftreibung werden dadurch undeutlich und man verwechselt das ganze Gelbilde anfänglich leicht mit den der Innenfliiche der Endocyste anliegenden, durch die Ectocyste hindurch deutlich erkennbaren Körnerhaufen (Fig. 4. k). Im Profil kann man es aber stets leicht als eine Hervorragung erkennen. lch glaube diese Gebilde als rudimentäre Stacheln ansprechen zu dürfen.

Bekleidet ist die Innenfläche der Ectocyste, wie schon gesagt, rings herum von der End oc yste. Dieselbe ist aber an der Unterseite des Zoöcium loser mit der Ectocyste verbunden, als an den fünf übrigen Flächen.

Der in der Literatur vorhandenen Angaben uber die histologische Beschaffenheit der Endocyste giebt es sehr wenige, nur Suitr und Glaparède haben darüber für die Chilostomen Angaben gemacht.

Surt 1) beschrieb dieselbe anfänglich bei Menbranipora pilosa als eine durchsichtige, von einem netzartigen Canalsysteme durchzogene Membran. Dort, wo mehrere Canäle zusammenstiessen, sollten dieselben sich zu einer kleinen Lacune erweitern, welche durch ein * trichterförmiges Röhrchen nach aussen mündete. Diese Angaben hat Suitr nachher selbst auf Grund fernerer an Vesiculariaden gemachten Beobachtungen angezweifelt. ${ }^{2}$ )

CLaparède ${ }^{3}$ ), wenngleich er die Möglichkeit der Smitt'schen Angaben nicht gänzlich von der Hand weist, - er hat ubersehen, dass SMIт bereits selbst dieselben zurüekgenommen hat, - ist weit mehr geneigt, das erwähnte netzartige Ansehen, welches die Endocyste der meisten fertig gebildeten Chilostomenzoöcien unstreitig zeigl, zu deuten als dadurch hervorgebracht, dass eine grosse Anzahl von Zellen, welche uber die ganze Endocyste verstreut sind, zusammenhängen durch fadenartige anastomosirende Ausläufer.

lch selbst habe ferner einmal beiläufig bemerkt, man könne keinerlei Formelemente in der Endocyste der Chilostomen unterscheiden. ${ }^{4}$ )

Diese letztere Aeusserung war, wie ClaparÉde sehr richtig bcmerkt, zu weit gehend. Neuere Untersuchungen erlauben mir die Smitt-Claparède'sche Ansicht im Allgemeinen zu bestatigen, bei dem hier zu besprechenden Thier wenigstens für die Endocyste der Oberund Seitenwände des Zoöcium.

1) Öfvers. Vet. Akad. Förh. 1865, p. 16. Taf. II, Fig. 3-4.

2) Ebendaselbst 1866, p. 519, Tab. XIII, Fig. 28.

3) Zeitschr. f. wissensch. Zoologie. XXI, p. 142.

4) Zeitschr. f. wissensch. Zoologie. XX, p. 18. 
Die Endocyste der Oberseite eines ausgewachsenen Zoöcium von Flustra membranacea besteht aus einer ungemein zarten, wasserhellen, mitunter an Spiritusexemplaren eine, wenngleich schwache, doch erkennbare feinkörnige Structur zeigenden Membran; dieselbe liegt der Ectocyste ziemlich fest an. In ihr sind eingebettet grosse r'unde und etwas kleinere ovale Zellkerne, beide zeigen deutliche Kernkörperchen. Umgeben ist jeder solcher Zellkern von einem kleinen Hofe protoplasmatischer Substanz, welcher unregelmässige Ausläufer nach verschiedenen Seiten hin ausschickt. Die Ausläufer der benachbarten Zellterritorien anastomosiren mit einander. Mitunter nehmen die, die einzelnen Zellterritorien verbindenden Ausläufer die Gestalt feiner, sich kreuzender Fasern an. An der Innenfläche dieser Endocyste haften und ragen frei in das Innere des Zoöcium hinein runde Haufen ungemein stark lichtbrechender, scharf begrenzter Körner, in denen man keinen Kern unterscheiden kann (Taf. VI, Fig. 16 und Fig. 6).

An frischen Exemplaren sind die Kerne als solche nicht erkennbar; erst bei Zusatz von Essigsäure kann man sie, aber alsdann auch mit grosser Sicherheit erkennen. Die die Kerne umgebenden Zellterritorien und deren Ausläufer sind aber schon an frischen Ghilostomen sehr deutlich zu sehen.

Die Beschaffenheit der Endocyste der Seitenwände ist in Allgemeinen eine ganz ähnliche, nur finden sich hier dic Körnerhaufen mitunter in grösserer Anzahl. An den Stellen nur, wo die Endocyste uber die Rosettenplatten weggeht, zeigt sie cine etwas andere Beschaffenheit. Hier besteht sie nämlich aus grossen, Kerne führenden Cylinderepithelzellen, welche der Rosettenplatte als eine Art Pfropf aufsitzen. Sehr wahrscheinlich senden diese Zellen Ausläufer durch dic Poren der Rosettenplatte hindurch, um sich mit dem Zellpfropf der correspondirenden Rosettenplatte des benachbarten anliegenden Zoöcium zu verbinden (Taf. V, Fig. 9, rspl).

Die Endocyste der Unterseite des Zoöcium ist nur lose verbunden mit der Ectocyste, sie erscheint ebenfalls als eine feine durchsichtige Membran von mitunter etwas feinkörniger Beschaffenheit mit vielen, über ihre Fläche nach aussen ein wenig vorangenden runden Zellkernen mit Zellterritorien. Dieselben sind aber meist viel dichter gedrängt, als an der Oberseite des Zoöcium; mitunter ist die Membran hier lacunenartig durchbrochen, wahrscheinlich in Folge von Vacuolenbildung. Der Innenfläche dieser Membran sind zwei deutliche Züge spindelförmiger Fasern aufgelagert. Diese Züge laufen parallel den Seitenkanten des Zoöcium und verbinden die Rosettenplatten der Vorderund Hinterwand mit einander; sie anastomosiren auch mitunter und 
verbinden sich durch Ausläufer mit den Rosettenplatten, an denen sie vorbeilaufen. Ihre Elemente zeigen deutliche ovale Kerne mit Kernkörperchen.

Der Endocyste der Unterseite liegen ferner auch noch Gebilde auf, welche ich als Seitensträng e - funiculi laterales - zu bezeichnen vorschlage, weil durch eine solche Bezeichnung durchaus kein Präjudiz ausgesprochen wird über die physiologische Bedeutung derselben. Es sind dies (Taf. IV, Fig. $2 f l$. Taf. V, Fig. $9 f l$.) röhrige Gebilde, welche von den Rosettenplatten ihren Ursprung nehmen. Von jeder Rosettenplatte entspringen mit gemeinsamer etwas verdickter Wurzel zwei solche Seitenstränge, welche in entgegengesetzter Richtung, dicht an der Unterfläche des Zoöcium hinlaufend sich an den nach vorn und hinten zunächst gelegenen Rosettenplatten, resp. an deren Zellpfröpfell, inseriren. Wird das Zoöcium sehr schmal, und rücken daher die beiden Rosettenplatten der Vorderseite und ebenso die der Hinterseite nahe an einander, so verkürzt sich natülich der zwischen ihnen ausgespannte Strang ungemein und die von den erwähnten Rosettenplatten nach den benachbarten Rosettenplatten der Seitenwände verlaufenden Seitenstränge scheinen mit einer gemeinsamen verbreiterten Wurzel von der Vorder-, resp. Ilinterwand des Zoöcium zu entspringen. Die histologische Structur dieser Gebilde zeigt in verschiedenen Fällen zwei verschiedene Modificationen. Mitunter sind es (Taf. VI, Fig. 19) rundliche Röhren, deren Wandung gebildet wird von spindelförmigen Zellelementen mit deutlichem ovalen Kerne, und deren Lumen erfullt ist von einer körnigen stark lichtbrechenden Substanz; in anderen Fällen scheint die äussere Wandung der Röhre bis auf geringe Spuren verschwunden zu sein, und der körnige Inhalt ist viel solider und zusammenhängender geworden. Der nach dem Innern des Zoöcium gelegene Rand des Gebildes (Taf. VI, Fig. 20) zeigt dann eine helle, homogene, sehr stark lichtbrechende, ungemein scharf begrenzte, bogige oder gerade Contour. Das Gebilde ist dann ungemein resistent gegen die Einwirkung selbst concentrirt angewendeter Reagentien. Es scheint der Inhalt der Röhre chitinisirt zu sein.

Ein ganz ähnliches Gebilde wird übrigens von CLAPARÉ \&1) bei Bugula avicularia beschrieben und der Hauptstamm des "communalen Bewegungsorganes " bei Zoobotryon pellucidus scheint nach der $\mathrm{Be}-$ schreibung von Reichert ${ }^{2}$ ) ebenfalls hiermit verwandt zu sein. Vielleicht. lässt sich auch die "chitinous rod", welche Allmanx 3) in den

1) Zeitschr. f. wiss. Zoolog. XXI, p. 159. Tab. VIII, Fig. 1. $c b$.

2) loco citato pag. 282 .

3) Quarterly Journal of Micr. Science Vol. IX. 1869 p. 57. pl. VIII. 
Coenoecien von Rhabdopleura beschreibt, an welche die Funiculi der cinzelnen Polypide sich ansetzen, zum Vergleich heranziehen.

Genetisch sicherlich mit der Endocyste zusammenhängend ist auch das Gebilde, was ich als "Funicularplatte "zu bezeichnen vorschlage. Da dasselbe aber zwischen dem Polypide, besonders dem tractus intestinalis und den Wandungen des Zoöcium ausgespannt ist, so kann dasselbe erst besprochen werden, wenn auch der Polypid geschildert worden ist.

Der Innenraum des Zoöcium kann verengert werden dadurch, dass die obere, wie wir sahen geschmeidig gebliebene Fläche des Zoöcium der Unterfläche angenähert wird. Dies geschieht durch die Contraction der sogenannten Pa rietalmuskeln.

Die Parietalmusculatur ist keine flächenhaft ausgebreitete in der Endocyste selbst gelagerte tunica muscularis, wie dies bei den Phylactolaemen der Fall ist; sie besteht aus einer Anzahl von Muskelbündeln, welche von dem unteren Theile der Endocyste der Seitenwände entspringen, quer durch die Höhlung der Zoöcium verlaufen und sich an die Endocyste der Oberseite ansetzen. Die von derselben Seitenwand entspringenden Muskelbündel setzen sich in einer und derselben dem oberen Seitenrande des Zoöcium parallel laufenden Linie an. Die Ansätze der einzelnen Muskelbündel sind auf dieser mitunter in der Ectocyste als eine ganz kleine Verdickung markirten Linie ziemlich weit von einander entfernt. (Taf. IV, Fig. 1 u. 2, und Taf. V, Fig. 4 $p m$ und $x$ ). Jedes Parietalmuskelbuindel besteht aus 2, 4 od. 5, kurz aus ciner ganz beschränkten Anzahl gesondert neben einander herlaufender Muskelfasern, welche genau so gebaut sind, wie die vorderen Parietovaginalmuskeln der phylactolaemen Bryozoen. Es sind dünne, wasserbelle, cylindrische oder etwas abgeplattete Fasern, an denen man einen durch ein feines Sarcolemma an der eigentlichen Faser befestigten Kern erkennen kann. Sie setzen sich mit verbreiterten Enden der Endocyste an. Dieselben sind functionell meiner Ansicht nach vollkommen homolog den Parietalmuskeln der Vesiculariaden, welche Reıchert bekanntlich zu chitinösen Spannbändern $\mathrm{zu}$ degradiren versucht.

Die gemeinsame Action dieser Parietalmuskeln deprimirt also die ganze Oberfläche des Zoöcium, welche bei unserer Species in ihrer ganzen Ausdehnung dasjenige darstellt, was Surt bei den Chilostomen als "Mündungsarea " bezeichnet. Der hierdurch verursachte Druck pflanzt sich durch die Vermittelung der incompressiblen Leibeshöhlentlüssigkeit auf das Polypid fort und bewirkt dessen Evagination.

Für die Depression des Deckelapparates sind gesonderte Muskeln, 
die Deckelmuskeln vorhanden Taf. IV, Fig. I 1 . $20 \mathrm{p}$. Taf. V, Fig. 1 o $p \mathrm{~m}$ ). Dieselben werden gebildet von zwei Muskelbündeln, welche ein wenig nach hinten von der Mündung rechts und links von dem untcren Drittheile der Seitenwände der Zoöcien entspringen und nach innen und oben (juer durch die Höhlung des Zoöcium verlaufen, um sich an dic zugespitzten, in die Höhle des Zoöcium vorragenden, oben geschilderten Seitentheile des Deckels, resp. an dic sie bekleidende Endocyste festzusetzen. Die einzelnen, dic Bündel zusammensetzenden Muskelfasern sind den die Parietalmuskeln zusammensetzenden Fasern völlig gleich. Eine mässige Contraction der Deckelmuskeln schliesst die Mündung des Zoöcium, eine starke Contraction deprimirt die ganze Umgebung des Deckelapparates, welcher dann in die Tiefe einer Art von trichterförmiger Einsenkung der Ectocyste zu liegen kommt.

\section{Das Polypid.}

Innerhalb des Zoöcium ist das Polypid gelegen; dasselbe besteht aus \& Haupttheilen. 1) Dem Darmtractus; 2) der Tentakelkrone; 3) dem Nervencentrum; 4) der Tentakelscheide.

Der Darmtractus (Taf. IV, Fig. 1 u. 2 und Taf. V, Fig. 1) besteht aus 3 gesonderten Abtheilungen: a) dem Oesophagus; b) dem Magen und c) dem Rectum.

Der Oesophagus (Oes) bildet den vordersten kurzen, verkehrt kegelförmigen Abschnitt des Darmtractus. Sein vorderer Rand ist wulstig verdickt und umschliesst die zirkelrunde Mundöffnung. Eine durch die Ränder der Mundöffnung gelegte Ebene steht aber nicht senkrecht gegen die Achse des Kegels, die abanale Seite des Oesophagus ist nämlich ein wenig kürzer als die anale. Ein Querschnitt durch den Oesophagus zeigt, dass seine Innenwandung Längsfurchen aufzuweisen hat. (Tab. VI, Fig. 9.)

Durch ein kreisrundes Diaphragma setzt sich der Oesophagus ab gegen den langen schlauchförmigen Cardialtheil des Magens (C), welcher, wenn das Polypid hervorgestreckt ist, in der Symmetrieebene liegt, sonst aber eine grosse seitliche, nach vorn offene Schleife bildet.

Der Cardialtheil mündet direct ohne scharfe Abgrenzung in den eigentlichen Magen $(S t)$, der einen wurstförmigen, der Längsachse des Zoöcium parallel liegenden Sack darstellt.

Die Einmündung des Cardialtheiles befindet sich in der Mitte der Längserstreckung des Magens, und das hinter ihr liegende, sich nach hinten etwas verengende Stuck des letzteren crscheint daher als Blind- 
sack. Das vordere Ende des Magens bildet den Pylortheil desselben. Hier steht der Magen mit dem bald kugelförmigen, bald mehr gestreckten kurzen Rectum durch eine runde Oeffnung in Verbindung. Das Rectum $(R)$ inserirt sich in der Symmetrieebene ohngefähr der Mitte der Tentakelscheide, welche also von der Analöffnung durchbohrt wird. Der Anus liegt bei den Chilostomen überhaupt und insbesondere bei den hier beschriebenen Species entfernter von dem Nunde, als dies z. B. bei den Phylactolaemen der Fall ist: Die Tentakelscheide bildet um die Afteröffnung herum eine Art von Einstülpung, welche als ein bedeutend in seinen Wandungen verdünntes Endstück des Rectum $\left(R^{\prime}\right)$ er'scheint.

Genetisch muss, wie wir später sehen werden, der ganze Darmcanal betrachtet werden als ein schleifenförmig gebogener Schlauch, dessen Beugungsstelle in einen Blindsack nach hinten sich verlängert.

Der histologische Bau des Darmcanals ist bei Fl. membranacea sehr ähnlich dem bei den Phylactolaemen vorkommenden.

Die Form des ganzen Darmtractus wird bestimmt durch eine feine homogene Lamelle; diese bildet die Stütze der gesammten Wandung. Nur am Oesophagus ist derselben eine Schicht deutlicher Ringmuskelfasern aufgelagert, welche man besonders im optischen Querschnitte leicht erkennen kann. Auf ihrer, der Höhle des Zoöcium zugewendeten Fläche ist die homogene Lamelle bedeckt mit einer feinkörnigen Epithellage mit deutlichen runden Kernen. Die einzelnen Zellterritorien gehen ohne scharfe Grenze in einander über; die äussere Epithellage setzt sich continuirlich fort in die Funicularplatte, : ihnlich wie die :iussere Epithellage des Darmes der Phylactolaemen, ja auch auf den Funiculus übergeht.

Die Höllung des Darmcanales wird ausgekleidet von einer einfachen Zellschicht. Die sie zusammensetzenden Zellen sind in den einzelnen Abtheilungen des Darmtractus sehr verschieden geformt.

Der vorderste Theil des Oesophagus, der den Tentakeln zunächst liegt, wird ausgekleidet von einem einfachen polygonalen Wimperepithel, welches sich direct über die Ränder der Mundöffnung auf die Tentakeln fortsetzt; sein Verbreitungsbezirk bildet aber keine überall glcichmässig breite Ringzone, dieselbe ist an der abanalen Seite des Oesophagus viel brciter, als an seiner analen. Da die Wimperepithelzellen ein wenig länger sind als die Zellelemente der Auskleidung des übrigen Theiles des Oesophagus, so setzt sich die bewimperte Zone scharf gegen die unbewimperte ab. (Taf. IV, Fig. 1 u. 2 w.)

Der Rest des Oesophagus wird bekleidet von einer Zellschicht, welche sehr viel Aehnlichkeit hat mit der an der gleichen Stelle von 
mir bei den Phylactolaemen beschriebenen. 1) Die Zellen bilden hier eine Art Cylinderepithel, der Querschnitt der einzelnen Zellen wird durch ihre dichte Aneinanderdrängung polygonal; dieselben scheinen aber keine gesonderten IVandungen mehr zu besitzen: die Zellwände der benachbarten Zellen verschmelzen mit einander und die ganze Zellschicht erschein dadurch einer Bieneuwabe ähnlich gebildet. Die der Höhlung des Oesophagus zugekehrten Zellflächen erscheinen ungemein scharf begrenzt. Der Inhalt der Zellen ist wasserhell und man kann in ihm, abweichend von dem, was bei den Phylactolaemen beobachtet wurde, keine Kerne mehr entdecken; bei den jungen Polypiden unterscheidet sich aber die Zellenlage des Oesophagus noch keineswegs von dem des übrigen Darmes. Erst ziemlich später findet die Umwandlung des einfachen polygonalen Epithels in das wabenartige Gewebe statt.

Der Cardialtheil des Magens sowie überhaupt der ganze Magen mit Ausnahme seines Pylortheiles zeigt eine polygonale Zellschicht, welche ein drüsiges Epithel darstellt. Die stets erkennbaren Grenzen der einzelnen Zellen sind nicht sehr scharf markirt. Immer erkennt man in dem meist körnigen Inhalı einen deutlichen runden Kern eingelagert. Die dem Lumen des Magens zugewandten Zellenden sind kuppelartig gewölbt. Am dicksten ist diese Zellschicht in dem Blindsacke. Zwischen die im Allgemeinen sehr hell erscheinenden Zellen sind häufig weniger durchsichtige mit stark lichtbrechendem Inhalte eingestreut. (Taf. VI, Fig. 8.)

Der Pylortheil des Magens ist ausgekleidet von einem polygonalen Wimperepithel. Der Querschnitt der einzelnen Zellen desselben ist ist viel kleiner als der der Epithelzellen des ubrigen Magens. (Taf. VI, Fig. ז.) Die Wimpern tragenden Zellflächen sind sehr scharf begrenzl, so dass man mitunter geneigt ist, zu glauben, die Wimpern sässen auf einer besonderen, über die Zellen weglaufenden Membran.

Die Zellauskleidung des Rectum ist sehr ähnlich der des Cardialtheiles des Magens.

Die Zellen des Magens mit Ausnahme der wimpertragenden enthalten im Leben häufig braunes Pigment, ein Umstand, der die Vermuthung, dass sie als Leberzellen functioniren, stützt.

Im Umkreis der Mundöffnung erheben sich die T en $\mathbf{t}$ akeln. Gewöhnlich sind es 18 Stück, welche die im entfalteten Zustande glockenförmige Tentakelkrone zusammensetzen. (Taf. IV, Fig. 1.) Mitunter konnte ich aber nur 17 Stück zählen.

1) Beiträge z. Anat. u. Entwickelungsgesch. d. phylactolacm. Süssw. Bryoz. Archiv. f. Anat. u. Physiol. 1868. Sep. Abdr. p. 19. 
Die Tentakeln stellen hohle röhrenförmige Gebilde dar. Sie werden gestutzt von einem ihren Hohlraum begrenzenden Schlauche, gebildet aus einer homogenen Membran, welche zusammenhängt mit der in die Zusammensetzung der Magenwände eingehenden homogenen Lamelle. Nach aussen wird dieser Schlauch bekleidet von einem Wimperepithel, welches sich unmittelbar fortsetzt in die Zellbekleidung des Oesophagus. Der Querschnitt der Tentakeln ist an der Basis abgerundet dreieckig, die Basis des gleichschenkeligen Dreieckes nach aussen zu gewendet; weiter oben ist derselbe mehr rundlich. Eine genaue Einsicht in die Vertheilung der einzelnen Zellen auf der Oberfläche der Tentakeln zu gewinnen, ist bei der ungemeinen Kleinheit der zu untersuchenden Objecte ungemein schwer. Indessen glaube ich mich doch überzeugt zu haben, dass die Innenfläche der Tentakeln, d. h. diejenige, deren Zellbelag sich direct fortsetzt in die Epithelialauskleidung des Oesophagus, besetzt ist mit längeren Wimperepithelzellen, welche 2 oder 3 Längsreihen zu bilden scheinen (Taf. VI, Fig. 10, a). Die Wand des homogenen Schlauches, dem sie aufsitzen, erscheint hier etwas verdickt. Die Seitenflächen der Tentakeln erscheinen dagegen bekleidet jederseits mit 3 Längsreihen deutlicher kernführender Zellen (Fig. 10,b,,$d$ ). Die auf einem Querschnitt jederseits den langen Epithelzellen zunächst liegende Zelle $b$ erscheint als die grösste. In Winkel, welcher sich zwischen ihr, den Cylinderepithelzellen $a$ und der homogenen Lamelle $l$ findet, kann man mitunter noch jederseits einen deutlichen Kern (resp. vielleicht eine kleine Zelle) finden (Fig. 10,e).

Ilöchst wahrscheinlich wird eine spätere Untersuchung frischer Exemplare zeigen, dass auch die Tentakeln dieser Species mit einzelnen langen borstenartigen Haaren (wahrscheinlich Fühlhaaren) besetzt sind, wie dies von Mem. branipora pilosa und Alcyonella fungosa fruher von Farne und mir ${ }^{1}$ ) nachgewiesen wurde.

Der Innenwand des homogenen Schlauches angelagert kann man mitunter noch strang- oder faserähnliche Gebilde erkennen. Wenigstens erhält man auf Querschnitten Bilder, welche sich wohl nur so deuten lassen.

Die Höhlungen der einzelnen Tentakeln münden nach unten zu sämmtlich in einen hohlen ringförmigen Raum, der nach innen zu von der Wand des Oesophagus, nach aussen von der Tentakelscheide begrenzt wird. Derselbe umgiebt also als ein Ringcanal die Mundöffnung.

1) Philosophical Transactions, London 1837. p. 412. Beiträge z. Analomie u. Entwickelungsgesch. der phylactolaemen Süsswasser bryozoen. Sep.-Abdr. p. 27. 
Gegenüber der Vermuthung Rircnert's, die Höhlungen der Tentakeln communicirten durch kleine Oeffnungen mit dem Lumen des Oesophagus, muss ich ausdrücklich constatiren, dass dem wenigstens bei Fl. membranacea nicht so ist.

Innerhalh des Lumen dieses Ringes und zwar in der Symmetrieebene auf der Analseite des Oesophagus liegt auch das Gebilde, welches ich als das Nervencentrum unserer Thiere ansprechen möchte. Taf. IV, Fig. 1 u. 2; Taf. V, Fig. 1, $A$; Taf. VI, Fig. 1, $N$.) 'Es ist dies ein rundliches, etwas quergezogenes scharf begrenztes, von einer membranösen Hülle umgebenes Gebilde, welches mitunter an jungen Exemplaren in seinem Innern deutliche Zellen erkennen lässt. Mitunter hat es den Anschein als entspringen nach rechts und links von seinem der Basis der Tentakeln zugekehrten Rande zwei kurze Ausläufer. Dieselben aber weiter zu verfolgen, war mir nie möglich. Ob die helle linienartige Zeichnung, welche man stets auf der Analseite des Oesophagus in der Medianlinie verlaufen sieht, in irgend welchem $\mathrm{Zu}-$ sammenhange mit dem eben beschriebenen Gebilde steht, ist mir sehr zweifelhaft geblieben (Taf. V, Fig. $2 \Lambda, n$ ).

Der Unstand, dass wir es hier mit einem Gebilde zu thun haben, welches genau die Stelle einnimmt, wie das sicher constatirte Ganglion bei den Phylactolaemen, scheint mir ungemein für die Deutung desselben als Centrum des Nervensystems zu sprechen. Dieses Ganglion steht übrigens, soweit ich gesehen habe, in keinerlei Zusammenhang mit denjenigen Gebilden, welche als »Colonialnervensystem« von Sитт angesprochen worden sind.

Auch hat es nichts zu thun mit demjenigen, welches Surt bei Lepralia nitida als das Specialganglion des betreffenden Thierhauses bezeichnet. ${ }^{1}$ ) Es ist dies letztere Ding ein Gebilde, welches zugleich mit einer sogenannten » Keimkapsel " vorhanden ist, in cinem Zoöcium, welches bereits sein Polypid verloren hat. Das, was ich eben beschrieb, ist dagegen ein integrirender Theil des Polypids und geht mit diesem zugleich unter.

Die Tentakelscheide bildet, wenn das Polypid in das Zoöcium ganz zurückgezogen ist, einen cylindrischen Sack, etwas länger als die Tentakeln, welche er dicht unschliesst. Sie setzt sich mit ihrer Basis fest an die Basis der Tentakeln und den Anfangstheil des Oesophagus, die Höhlung des Ringcanales wie gesagt nach aussen abschliessend. Mit ihrem andern Ende geht sie über in die Endocyste des Zoöcium im Umkreise der Mündung. Sie erscheint also als eine schlauchförmige

1) Öfvers. af K. Vet. Akad. Förhandl. 186.5. Taf. VI, Fig. 1. p. 32. 
Einstulpung der Endocyste, die sich durch einen Spalt der Ectocyste nach aussen öffnet. Eine solche Auffassung ist aber, wie wir später sehen werden, genetisch nicht zu begründen (Taf. IV, Fig. 2, Tsch).

Ihrer histologischen Structur nach besteht die Tentakelscheide aus einer anscheinend ziemlich homogenen Lamelle, in welche hie und da deutliche Kerne eingestreut sind. Dieselbe ist aufzufassen als hervorgegangen aus der Verschmelzung einer Zelllage. In ihr sind eingebettet (oder aufgelagert?) Lïngs- und Querfasern, welche als Muskelfasern zu deuten ich keinen Anstand nehme. Die Quermuskelfasern bilden ziemlich nahe an der Basis der Tentakeln, von diesen aber durch einen Zwischenraum getrennt, einen deutlichen breiten Sphinkter (Taf. V, Fig. 1, A. $m$ ). Wenn man den Rand der Tentakelscheide auf dem optischen Durchschnitt betrachtet, so kann man sich leicht überzeugen, dass man es hier wirklich mit Ringfasern und nicht mit einer Runzelung der Tentakelscheide zu thun hat. Auch ist die Stelle, an welcher sich dies Bild zeigt, viel zu constant und stets zu scharf begrenzt, als dass man eine blosse Runzelung annehmen dürfte. Die Längsfasern entspringen an der Basis der Tentakelscheide als dünne, helle, scharf contourirte Fasern, welche anfänglich in dem ganzen Umfange der Tentakelscheide gleichmässig vertheilt sind. Kurz vor dem anderen Ende derselben ordnen sie sich aber in 4 Bündel (Taf. V, Fig. 1, B. $m^{\prime}$ ), von denen zwei der analen und zwei der abanalen Fläche der Tentakelscheide angehören.

Dicht vor der Spitze der in ihr eingeschlossenen Tentakeln wird die Ilöhlung der Tentakelscheide abgeschlossen durch ein Diaphragma (Taf. IV, Fig. 1, $d$; Taf. V, Fig. 1, B. d). Dasselbe besteht aus einem kurzen, hohlen, an der Spitze offenen Kegel. Sein unterer Rand inserirt sich an der Tentakelscheide, seine Aussenfläche ist also dem Deckelapparat, die Innenfläche'dagegen den Tentakeln zugekehrt. Es wird gebildet von einer Lamelle, welche mit der Substanz der Tentakelscheide direct zusammenhängt und in der deutliche Ringfasern eingebettet sind, welche einen kräftigen Sphinkter bilden, der die Tentakelscheidenhöhle vollkommen abschliessen kann. Die dem Deckel zugewendete Fläche des Kegels ist mit einem deutlichen Gylinderepithel belegt. Betrachtet man ein Zoöcium mit stark eingezogenem Polypide von oben oder unten (Taf. V, Fig. $1, B, d$ ), so erscheint der Diaphragmakegel als eine runde, in der Mitte durchbohrte, mit Zellen bekleidete Stelle kurz hinter dem halbmondförmigen verdickten Deckelrande.

Von dem vorderen Ende der Tentakelscheide verlaufen nach den Wänden des Zoöcium die Parietovaginalbänder und die Parietovaginalmuskeln. 
Diejenigen Gebilde, welche ich als Parietovag in al bänder bezeichne (Taf. IV, Fig. 1 u. 2; Taf. V, Fig. 1, $A$ u. $B$, lig. $p v$ ), entsprechen durchaus den sogenannten hinteren Parietovaginalmuskeln der Phylactolaemen, welche ja, wie ich gezeigt habe ${ }^{1}$ ), ebenfalls in ihrem Bau von den übrigen Muskeln scharf unterschieden sind. Es sind stets zwei Paar Parietovaginalbänder vorhanden, ein oberes und ein unteres Paar. Die Bänder des unteren Paares entspringen von der Analseite der Tentakelscheide ziemlich weit vorn und laufen nach vorn, aussen und unten gegen die Wand des Zoöcium, auf dessen Unterfläche sie sich nicht weit von den vorderen Ecken an die Endocyste inseriren. Die Bänder des oberen Paares entspringen von der abanalen Seite der Tentakelscheide in derselben Ringzone wie die unteren und laufen (das Polypid stets müssig zurückgezogen gedacht) nach aussen, oben und hinten (Taf. IV, Fig. 2) an die obere Wand des Zoöcium, wo sie sich ebenfalls der Endocyste inseriren.

Was den histologischen Bau der Parietovaginalbänder betrifft, so bestehen sie aus breiten, dünnen Bändern einer homogenen Substanz. In jedes Parietovaginalband tritt eines der 4 Bündel von Muskelfasern, welche wir oben an der Tentakelscheide beschrieben haben. Die einzelnen Muskelfasern liegen parallel nebeneinander, durch regelmässige Zwischenräume getrennt und geben den Bändern ein fein längsgestreiftes Aussehen. Diese Gebilde waren bisher völlig úbersehen worden.

Die Parie tova gina $\mathrm{mu}$ sk el $\mathrm{n}$ werden gebildet von zwei Muskelbündeln, welche dicht hinter den Ursprungsstellen der Deckelmuskeln von den Seitenflächen des Zoöcium entspringen und sich jederseits ein wenig hinter den Ursprungsstellen der Parietovaginalbänder seitlich der Tentakelscheide inseriren (Taf. IV, Fig. 1 u. 2, pvm; Taf.V, Fig. 1, $A$ u. $B, p v m)$. Wenn sie sich contrahiren, so ziehen sie öfters die Tentakelscheide nach beiden Seiten in zwei kleine ohrartige Blindsäcke aus. Sie bestehen aus einer Anzahl lose nebeneinander herlaufender Muskelfasern, welche genau denen gleichen, welche die Deckelund Parietalmuskeln bilden.

Nur noch ein Muskel bleibt zu beschreiben übrig. Es ist dies der grosse Retractor des Polypids. Der grosse Retractor besteht aus einer grossen Menge langer, dünner, cylindrischer Fasern, deren Querschnitt variirt je nach dem Contractionszustande, in dem sic sich gerade befinden. In der Mitte ihrer Längsausdehnung erkennt man, an ihnen festgehalten durch ein dünnes Sarcolemma, einen deutlichen ovalen 
Kern mit Kernkörperchen. Mitunter, aber nicht immer, und unabhängig davon, ob sie gerade contrahirt oder erschlafit sind, kann man an ihnen eine deutliche Querstreifung wahrnehmen, welche ihren Grund hat nicht in einer Querrunzelung des Sarcolemma, sondern in inneren Structurverhältnissen der Fasersubstanz (Taf. VI, Fig. 11).

Diese Fasern entspringen von einer gemeinsamen rundlichen $\mathrm{Ur}$ sprungsstelle in der Mitte der IInterwand des Zoöcium, laufen frei durch die Höhlung des Zoöeium nach vorn und selzen sich grösstentheils an dem Vorderrande des Oesophagus und der Basis der Tentakeln an, mit Ausnahme der analen Seite dieser Zone. Dagegen inseriren sich einzelne Fïden stets an dem Anfange des Cardialtheils des Magens (Taf. IV, Fig. 1 u. 2; Taf. V, Fig. 1, A).

Ich wende mich nun zur Beschreibung der Funicularplatte, welche, genetisch betrachtet, wie bereits oben gesagt, zu der Endocyste gehört, deren Besprechung aber aus Opportunitätsgründen bis jetzt verschoben wurde. Dieselbe ist eine dünne Platte mit vielfachen, mehr oder minder unregelmässigen und verzweigten flachen Auslïufern, welche horizontal, der Unterfläche mehr angenähert als der Oberseite, den Hohlraum des Zoöcium durchsetzt (Taf. V, Fig. 9, $(p l)$. Ihr Centraltheil setzt sich als eine Art horizontalen Bordes an den Magen (mit Ausnahıne des Cardialtheiles) an, ihr am wenigsten durchbrochener Theil an das Ende des Blindsackes. Die peripherischen, zerschlitzten Ausläufer verbinden sich theils mit den Funiculi laterales und zwar am häufigsten dort, wo letztere von den Zellpfröpfen der Rosettenplatten ihren Ursprung nehmen, theils inseriren sie sich und zwar is dies besonders am Hinterrande des Zoöcium der Fall, auch an der Endocyste der Unterseite. Ilistologisch betrachtet ist die Funicularplatte eine flïchenhafte Aneinanderreihung spindelförmiger Zellen mit deutlichen Kernen (Taf. VI, Fig. 12) zu einer einzigen Lage.

Die Funicularplatte ist ein ungemein dauerhaftes Gebilde. Sie bleibt erhalten auch dann, wenn der Darm nebst Tentakelkrone abstirbt und sich, wie wir später sehen werden, zu einem sogenannten "braunen Körper« umwandelt. Sie ist es, welche dann diesen »braunen Körper", mit dem sie noch in Verbindung steht, an einer bestimmten Stelle im Zoöcium fixirt.

Das was Surt als das Colonialnervensystem von Fl. membranacea beschreibt und abbildet ${ }^{1}$ ), besteht theils aus dieser Funicularplatte, theils aus den Spindelzellsträngen der Endocyste der Unterfliiche des

1) Om Hafslıryozoernas utveckling och fellkroppar. Öfvers. af $\mathbf{k}$. Vet.-Akad. Forh. 1865 . No. 1. p. 32. Taf. VI. Fig. 2 u. Taf. VII, lig. 3. 
Zoöcium. An Zoöcien, welche ihr Polypid verloren haben, ist es oftmals schwer, diese beiden Gebilden auseinander zu halten, da bei diesen die Funicularplatte sich dicht an die Endocyste anlegt. Die Funiculi laterales und die Zellpfröpfe der Rosettenplatten hat Sirt bei dieser Species nicht gesehen, sonst würde er die letzteren wahrscheinlich als Colonialganglien angesprochen haben; wenigstens scheinen mir die Gebilde, die er bei anderen Species als Colonialganglien beschreibt, genau den Zellpfröpfen bei Fl. membranacea zu entsprechen.

Der Umstand, dass man das » Colonialnervensystem « der Bryozoen und besonders der Ghilostomen hauptsächlich an solchen Zoöcien untersucht hat, welche ihr Polypid verloren hatten, hat offenbar verhindert, dass man die Verbindung der Funicularplatte mit dem Epithelium der Aussenfliiche des Darmcanals erkannte. Das Bild eines frei das Zoöcium durchziehenden Geflechtes von verschiedenen anastomosirenden Strängen erhält man wirklich nur dann. Bei Bugula plumosa und auch bei anderen Chilostomen habe ich mich aber uberzeugt, dass das Colonialnervensystem eines Zoöcium mit abgestorbenem Polypid wirklich nichts weiter ist, als der Rest einer Anzahl mehr oder weniger flichenhafter Stränge, welche den Darmcanal des Polypids zu der Zeil als letzteres noch auf der Höhe seiner Ausbildung stand, mit der Endocyste und zwar hauptsächlich mit den die Rosettenplatten überziehenden Theilen der Endocyste verband.

Ich muss daher offen bekennen, dass mir in keiner Beziehung ein hinreichender Grund vorzuliegen scheint, das fragliche Gebilde als wirklich nervöser Natur anzusehen. Es ist ja durchaus nicht zu leugnen, dass vielleicht einzelne Elemente desselben zur Fortleitung von Reizen geeignet sein mögen, das ganze Gebilde ist, als meiner Ansicht nach, nicht ein Nervengeflecht. Schon der Umstand, dass es bei jeder Lagenveränderung des Darmcanales gezerrt und gedehnt wird, lässt dies höchst zweifelhaft erscheinen. Betrachten wir aber gar das Zoöcium und das Polypid als zwei Individuen, von denen das eine in dem anderen, seinem Multerthiere, definitiv eingeschachtelt bleibt, so erscheint die Annahme, dass ein nervöses Organ es ist, welches die Befestigung des einen Individuum in anderen theilweise bewirkt, als völlig unzulässig.

Auch eine physiologische Nothwendigkeit für das Vorhandensein eines » Colonialnervensystems « scheint mir durchaus nicht zu existiren. Schon das blosse Fehlen eines jeden als Leitungsweg für Reizungen von einem Individuum des Thierstockes zum anderen zu deutenden Apparates bei den Phylatolaemen (denn dass der Funiculus hier nicht so gedeutet werden darf, leuchtet leicht ein, er steht ja in gar keiner 
Verbindung mit dem bei diesen Thieren unzweifelhaft erwiesenen Nervencentrum), spricht ungemein gegen die $A$ nnahme, dass ein solches Organ ein nothweniges Postulat sei für das Colonialleben.

Ich kann mir ferner die Thatsache, dass alle Polypide eines Stockes sich zurückziehen; wenn nur ein einziges Polypid gereizt oder injuriirt wird, sehr wohl erklären, ohne ein Colonialnervensystem anzunehmen. Ein Bryozoenstock, z. B. unsre Fl. membranacea, kann aufgefassi werden als ein Aggregat von ringsgeschlossenen Säcken, welche mit Flüssigkeit prall erfullt sind; durch Weichtheile verschlossene Poren verbinden die Höhlungen der einzelnen Säcke. In jedem Sacke, dem Zoöcium, liegt eingeschachtelt ein Polypid. Dic Bewegung eines jeden solchen Polypides muss nun nothwendig eine Erschütterung der das Zoöcium erfüllenden Flüssigkeit hervorbringen und diese Erschütterung kann sich sicherlich durch die Poren oder vielleicht auch durch Schwingungen der dünnen Rosettenplatten auf den flüssigen Inhalt der benachbarten Zoöcien in weitem Umkreise fortpflanzen. Die Erschütterungen der Flüssigkeit werden sich direct auf die in der Flüssigkeit schwimmenden Polypide fortpflanzen und diese somit benachrichtigt werden, dass in einem Zoöcium des Stockes eine Bewegung des Polypids stattgefunden hat.

Ich glaube, dass wir nur auf die sich uns darbietenden Homologien Rücksicht nehmien dürfen, wenn wir die Natur des fraglichen Gebildes und seine Bedeutung für das Leben unseres Thieres bestimmen vvollen. Das einzige homologe Gebilde ist der Funiculus bei den Phylactolaemen. Ich sehe die Funicularplatte genau so wie den Funiculus als ein Organ an, welches dazu dient, das Polypid, besonders den Nagen desselben in einer bestimmten Lage zum Zoöcium zu fixiren, namentlich wenn dasselbe hervorgestulpt ist.

Betrachten wir nun noch kurz, nachdem wir den Bau des Thieres in seinen Einzelheiten kennen gelernt haben, wie die Verschiebungen des Polypids gegen das Zoöcium, besonders die Hervorstulpung des ersteren, vor sich geht.

Wir nehmen an, das Polypid läge zurückgezogen wie in Fig. 2 auf Taf. IV. Soll die Evagination beginnen, so erschlaffen zunächst die Deckelmuskeln, die Parietalmuskeln contrahiren sich, die Oberfläche des Zoöcium, die Mündungsarea, wird herabgezogen, die Flüssigkeit in der Zoöciumhöhle comprimirt und ein Druck auf das Polypid ausgeübt; dieses letztere weicht nun dem Drucke aus und zwar nach dem locus minoris resistentiae $\mathrm{zu}, \mathrm{d} . \mathrm{h}$. die Spitzen der Tentakeln drängen gegen das Diaphragma an, der Sphinkter des letzteren erschlafft und die Tentakeln treten allmälig aus der Mündung hervor; zugleich wird nach und nach 
die Tentakelscheide ausgestülpt, so dass ihre frühere Innenfläche nun nach aussen zu liegen kommt und der After nicht mehr in das Innere derselben, sondern frei nach aussen mündet. Nur die dem Diaphragma zunächst gelegene Zone der Tentakelscheide bleibt permanent als invaginirte Falte im Innern des Zoöcium zurück, festgehalten von den 4 Parietovaginalbändern. Die Falte wird aber eine doppelte dadurch, dass auch der Diaphragmakegel aueh aussen gedrängt wird und nun als eine Art Ringwall nach innen von dem Rande der weit geöffneten Mündung die Tentakelscheide umgiebt (Taf. IV, Fig. $1 d$ ).

Die Zurüekziehung wird dadureh eingeleitet, dass zunächst die Parietovaginalmuskeln die Tentakelscheide ein wenig zurückziehen; die durch dic llervorstülpung des Polypids ungemein stark gedehnten Fasern des grossen Retraetors vollenden dann die Zurückziehung, während die Parietalmuskeln erschlaffen. Eine Contraction der Diaphragmasphinkters und der Deckelmuskeln bewirkt endlich den definitiven Verschluss des Zoöcium.

Im Allgemeinen scheinen die Polypide sieh nur dann zurüekzuzichen, wenn Gefahr von aussen droht, der Rand des Diaphragmakegels ist also gewöhnlieh nach aussen zu vorgestülpt, und dient sehr häufig 2 oder 3 klcinen Vaginicolen als Befestigungspunkt; wird das Polypid bei drohender Gefahr nun zurückgezogen, so، kommen diese kleinen Parasiten mit dem Deckelkegel unter die halbmondförnige Deckelfalte $\mathrm{zu}$ liegen und sind gleichfalls in Sicherheit.

\section{Die Knospungsvorgänge.}

Eine der auffallendsten Eigenthümlichkeiten der Knospung bei den Bryozoen besteht darin, dass durch dic Knospung eines bestimmten Zoöcium nach aussen anfänglich ein Gebilde orzeugt wird, welches einem Zoöcium ohne Polypid äquivalent ist, und dass das Polypid, also nach der Auffassung vieler Forscher die Verdauungs- und Respirationsorgane nicht durch Differenzirung des Inhaltes, des Gewebes der Knospe, sondern durch eine secundäre Knospung der Wandung des primär entstandenen Zoöcium - der Lẻibeswand - nach innen erzeugt wird.

Ganz gleiche Vorgänge zeigen sich auch bei der geschlechtlichen Fortpflanzung: die aus dem Ei hervorgegangene Larve, mag sie auch noch so hoch organisirt sein und z. B. wie Gyphonautes einen eigenen Darm besitzen, ist homolog einem Zoöcium, nicht einem Zoöeium + Polypid. Die Larve verwandelt sich durch directe Metamorphose in das 
primare Zoöcium, dieses erzeugt nachträglich, durch innere Knospung das Polypid. 1)

1) Metschnıкоf scheint die hier ausgesprochene Auffassung der Vorgänge, durch welche eine Bryzoenlarve sich in das primäre Zoöcium mit dem primäreu Polypiden verwandelt, nicht $\mathrm{zu}$ theilen. Dieselbe wurde zuncichst von Schneiden (M. Schultze, Archiv. Bd. 5, p. 260) für die Verwandlung eines Cyphonautes in das primäre Zoöcium von Membranipora pilosa und nachträglich von mir für die Entwicklung der Larve von Bugula flabellata darzulegen gesucht (Zeitschr. f. wiss. Zoolog. Bd.20. p. 9.). Wie weit eigentlich Metschnikoff von dieser Ansicht abweicht, ist allerdings aus seiner kurzen Notiz (Nachrichten d. Göttinger Universität, 1869. No. 12) nicht ganz klar zu ersehen. Er sagt nur: "Ich kann überlaupt die Ansicht über das totale Verschwinden der Larvenorgane bei Cyphonautes, resp. die vollkommene Neubildung der Organe des definitiven Thieres nicht theilen." Sollte nun MетschnккоF dies so gedeutet haben wollen, dass damit ausgesprochen wird, irgend ein Theil des Cyphonautes gehe als solcher in die Zusammensetzung des fertigen Zoöcium mit seinem Polypiden ein, dass z. B. der Darmcanal von Cyphonautes sich in den Darmeanal des Polypids verwandele, etwa in derselhen Weise, wie der Darmcanal eines Pilidium zum Darmcanal der definitiven Nemertine wird, so muss ich mich' gegen eine solche Auffassung verwahren, und zwar abgesehen davon, dass ich mich von dem Gegentheile durch directe Beobachtung überzeugt zu haben glaube, auch aus theoretischen Gründen. Bei der Knospung entsteht, wie weiterhin ganz ausführlich gezeigt werden soll, zunächst nur das Zoöcium, und erst nachträglich iı diesem durch Knospung nach innen das Polypid. Kein Theil des Polypids ist als solcher in der ursprünglichen Knospe angelegt. Nehmen wir nun an, ein Theil des Polypids des primären Zoöcium sei in der Larve präformirt, so nehmen wir zugleich an, es bestehe ein durchgreifender Unterschied zwischen der Art und Weise, wie das Polypid des primären Zoöcium sich bildet, und der Entstehungsweise der Polypiden aller folgenden, von dem primären Zoöcium geknospten Zoöcien. Eine solche Annalıme sclieint mir unstatthaft. Der einzige Unterschied, welcher zwischen diesen beiden Vorgängen besteht, ist der, dass das Material zur Entwicklung des primären Polypids innerhalb des primären Zoöcium geliefert wird durch einen Haufen Bildungsmaterial, welcher herstammt aus dem Zerfalle der Larvenorgane, dass hingegen das Material zur Erzeugung der Polypide in den auf das primäre Zoöcium folgenden Zoöcien der Knospe zugeführt wird aus dem Mutterzoöcium. Dies hat bereits Claparède auf das deutlichste ausgesprochen. (Zeitschr. f. wiss. Zool, Vol, XXI. p. 169.) Dagegen stimmt auch Claparède mit meiner Auffassung der Vorgänge der Entwicklung der Larve von Bugula flabellata zum primären Zoöcium mit seinem $\mathrm{P}_{0}$ Iypide nicht ganz überein; und zwar stösst er sich, wie mir scheint, hauptsächlich daran, dass iclı den Ausdruck gebraucht habe: die Larve verwandle sich in ein Häufchen Bildungsmasse, umgeben von einer festen Membran. Ich muss zugeben, dass ich mit diesem Ausspruche zu weit gegangen bin. Ich habe damit nur sagen wollen, kein Organ der Larve gehe als solches in,den Bau des definitiven Thieres mit seinem Polypide ein, und will durchaus nicht behaupten, dass z. B. alle Zellen, welche die Leibeswand der Larve bilden, nun in eine protoplasmatische Nasse sich verwandeln, etwa in der Art, wie RATzeL den Zerfall der aus der Furchung des Lumbricuseies hervorgegangenen Dotterelemente in die "Dotterruinen" 
Eine weitere Eigenthumlichkeit derjenigen Bryozoen, bei welchen die einzelnen Zoöcien durch Scheidewände scharf gegen einander $a b-$ gegrenzt sind und charakteristische, scharf ausgeprägte Formen zeigen, ist die, dass das aus der Larve entstehende primäre Zoöcium in seiner Gestalt und Grösse abweicht von der normalen Form der späteren durch Knospung entstandenen Zoöcien, welche die Mehrzahl der den Stock bildenden Elemente ausmachen.

Man muss daher bei der Darstellung des Knospungsprocesses ausgehen von dem primären Zoöcium, und kann zunächst nur die Entwicklung der Zoöcien in Betracht ziehen, die Besprechung der Entstehung der Polypide muss dagegen auf später verspart bleiben.

Die Larve von Fl. membranacea ist, wenigstens als solche, noch nicht beobachtet worden. Der Umstand aber, dass unsere Species keine Zoöcien besitzt, und dass ihre Spermatozoen die so sehr eigenthümliche büschelartige Gestalt besitzen ${ }^{1}$ ), zusammengehalten mit dem Umstande, dass diese beiden Eigenthümlichkeiten auch Membranipora pilosa zukonmen - dass die Spermatozoen dieser letzteren Species die gleiche Gestalt haben, davon habe ich mich durch Beobachtung uberzeugt - macht es wahrscheinlich, dass auch die Larvenform unserer Species ubereinstimmt mit der von Membr. pilosa, d. h. dass sie cin Cyphonautes ist. Vielleicht ist die zweite grössere von Schneider ${ }^{2)}$ beschriebene und abgebildete Cyphonautesform als zu Fl. membranacea gehörig zu betrachten.

An grossen, alten Thierstöcken sind die ältesten Theile oft vollkommen zerstört, und mil ihnen natürlich das primäre Zoöcium; dieses ist daher nur an jüngeren Therstöcken zu finden. Unter dem mir zu Gebote stehenden Material befanden sich nur zwei derartige junge Exemplare. Der grösste Theil des einen ist auf Taf. IV, Fig. 3 abgebildet. Die durch einen rothen Punkt ausgezeichneten beiden Zoöcien sind die primären, d. h. diejenigen, von denen, als von Mutterthieren die sänımtlichen übrigen Zoöcien des Stockes sich ableiten lassen. Welches von diesen beiden Zoöcien das eigentliche primäre ist, für cine solche Entscheidung habe ich keine Anhaltspunkte gefunden. Vielleicht sind sie beide aus der Larve entstanden, $d$. h. die sich festsetzende Larve ist durch Theilung in zwei gesonderte Zoöcien zerfallon. Ein solcher Vor-

schildert. Ich muss nur daran festhalten, und zwar auch für Cyphonautes, dass kein Theil der Polypids des primären Zoöcium präformirt ist in einem Organe der Larve. Auf Grund dieser Erläuterungen wird sich, so glaube ich fest, eine Vereinignng der Ansichten von ClaparÈde und mir sehr leicht herbeiführen lassen.

1) Sмiтr, Öfvers. af Kg. Vet.-Akad. Förhandl. 1865 Taf. VII, Fig. 4.

2) M. Schultze, Archiv, Bd. 5, 1869, Taf. XVI, Fig. 9. 
gang ware ja auch durehaus nicht einzelstehend. Für Alcyonella fungosa ist $\%$. B. nachgewiesen, dass in der ursprünglichen bewimperten Larve gleichzeitig zwei Polypide auftreten; dieselbe ist also zwei Zoöcien aquivalent, und dass sie nicht wirklich in zwei differente Zoöcien zerfällt, können wir nur dem Umstande zuschreiben, dass bei dieser Species eine Trennung der einzelnen Zoöcien überhaupt nur selten stattfindet.

Die primären Z oöcien haben eine von der Gestalt des Normalzoöcium ungemein abweichende Form. Ihre Umrisse bilden zusammen eine kartenherzähnliche Figur. Eine von der Spitze des Herzens zu dem Grunde des einspringenden Winkels hinlaufende Scheidewand trennt die beiden Einzelzoöcien. Ihr proximaler Theil ist der die Herzspitze ausmachende. Ihre Nündungsarea ist oval und liegt an dem distalen Ende eines jeden Zoöcium. Jedes für sich ähnelt daher ungemein einem Zoöcium von Membranipora pilosa. Sie zeigen aber nicht die unverkalkten runden Stellen, die sogenannten Poren, welche sich an der Ectocyste der letztern Species vorfinden, sie haben nur zwei Stachehn an ihrem proximalen Mündungsarearande und diese sind bedeutend kürzer und stumpfer als bei M. pilosa.

Dic weiteren Vorgänge der Knospung an den primären Zoöcien sind denjenigen, welche Scuneiner an dem primären Zoöcium von Membranipora pilosa beschrieb, ungemein ahnlich; während inı Allgemeinen jedes jüngere Zoöcium von Fl. membranacea nur eine Knospe an seinem distalen Ende erzeugt und meistens schon ehe seine Wandungen zu verkalken beginnen, so treten an den primären Zoöcien eine ganze Reihe von Knospen auf und zwar nimmt hier jede Knospe ihren Ursprung von einem ovalen Raume der Wandung aus, dessen Ectocyste unverkalkt geblieben: so sind aus den primären Zoöcien des auf Fig. 3 abgebildeten Stockes, aus dem unteren 5, aus dem oberen 3 Knospen cntstanden. Die ovalen Knospungspunkte an der Leibeswand des priInären Zoöcium sind besser auf Taf. IV, Fig. 7 zu erkennen. An dem rechter Hand gelegenen primären Zoöcium entspringen die 3 durch punktirte Linien angedeuteten Knospen $b^{\prime \prime} b^{\prime \prime \prime} b^{\prime \prime \prime \prime}$ von derartigen ovalen Knospungspunkten. Auch an dem distalen Ende der beiden primären Zoöcien entstehen Knospen, dieselben sind also umgeben von einer einfachen geschlossenen Reihe junger Knospen, deren Wachsthumsrichtungen von den primären Zoöcien als Mittelpunkt radial divergiren.

Die Ausbildung dieses kleinen Stockes zu einem grossen scheibenartig ausgebreiteten geht nun aber nicht einfach dadurch vor sich, dass alle jungen, von den primären Zoöcien erzeugten Knospen gleichmässig sich ausbilden und durch Knospung nun ihrerseits wiederum Zoöcienreihen erzeugen, welche in Radien von den primären Zoöcien nach allen 
Richtungen auslaufen. Vichehr abortiren die dem proximalen Ende der beiden primären Zoöcien zunäehst entstandenen Knospen, indem sie gegeneinander wachsen, keilförmig sich aneinander legen und keine weiteren Kuospen erzeugen (Taf. IV, Fig. $3 g$ u. $f$ ). Die weiter nach den distalen Ende der primïren Zoöcien entstandenen Knospen erzeugen dagegen Zoöeicnreihen, diese ändern aber ihre Wachsthumsrichtung, dichotomiren dureh Einschaltungen neuer Zellreihen, biegen sich nach dem proximalen Ende der primären Zoöcien herum, legen sich den abortirten Knospen $g \mathrm{u}$. $f$ an, wachsen nun ein wenig gegeneinander, die zunächst auf einander stossenden Zoöcien ( $h$ u. $i$ ) abortiren wieder und werden keilförmig, ebenso das Zoöeium $k$, dann aber legen sich die aus dem oberen und die aus dem unteren primären Zoöeium entstandenen umgebogenen Zoöeienreihen aneinander und wachsen parallel in einer der Wachsthumsrichtung der primären Zoöcien entgegengesetzten Richtung gleichmässig fort.

Die über der schwarzen punktirten Linie $A$ gelegenen Knospen des rechten geraden Randes des Stockes sind also Abkömmlinge des obcren primären Zoöcium, die unterhalb gelegenen Deseendenten des unteren primärcn Zoöcium.

Diese Verhältnisse lassen sich schlecht beschreiben; ein Blick auf die Figur 3 ; in weleher dureh die punktirten rothen Linien der Stammbaum des Stockes angegeben ist, wird klar machen, wie die einzelnen Zoöcien auseinander entstanden sind.

Die abortirten Zoöcien $f g h i k$ zeichnen sich nicht nur durch ihre am distalen Ende kcilförmig zugespitzte Gestalt, sondern auch dadurch aus, dass sie keinen Deckelapparat besitzen, also kein Polypid in ihrem Innern erzeugt haben.

Dic aus dem distalen Ende der primären Zoöcien durch Knospung hervorgegangenen Zoöcien zeichnen sich ebenfalls durch abweichende Gestalt aus. Ihr Umriss ist noch durchaus nicht rectangulär wie bei dem normalen Zoöeium, das wir bei der Beschreibung der Anatomic von Fl. membranacea zu Grunde legten, derselbe ist vielmehr abgerundet polygonal, sic haben mehr den Habitus von Membraniporenzoöcien als den von Flustrenzoöeien. Auch sind sie bedeutend kleiner als die normalen Zoöcien es durchsehnittlich zu sein pflegen. Die den umgcbogenen Zoöcienreihen angehörenden Zoöcien nehmen aber in dem jungen Stocke bereits sehr früh die gewöhnliche rectanguläre Gestalt an.

Bei weiterer Knospung treten auch in den von dem distalen Ende der primären Zoöcien ausgehenden Zoöcienreihen Zoöcien von typischer Form auf und die rectanguläre Zoöcienform wird die herrschende in allen jüngeren Theilen des Stockes. Die membranipora-ähnliche Form 
der Zoöcien ist aul die directe Umgebung der primären Zoöcien beschränkt. Die einzelnen Zoöcienreihen, deren Zoöcien genetisch miteinander zusammenhängen, d. h. die sogenannten Längsreihen, liegen in den älteren Theilen des Stockes ziemlich parallel nebeneinander, eine Anordnung, die gewölnnlich nur dann gestört wird, wenn auf die oben angedeutete Weise eine neue Zoöcienreihe eingeschaltet wird. Die Zoöcien der nebeneinander liegenden Längsreihen liegen alternirend, wie in dem ersten Abschnitte ausführlich dargelegt wurde, daher in Allgemeinen ihre quincunxähnliche Anordnung.

Die Aussenränder des wachsenden Stockes bilden eine gleichmässig gekrümmte oder auch stellenweis gerade Linie, über welche die einzelnen jungen Zoöcien nicht hervorragen. Aus diesem Umstand zusammengehalten mit der quincunxartigen Anordnung der Zellen folgt, dass am Rande immer eine grössere Knospe von zwei kleineren seitlich begrenzt sein muss (Taf. IV, Fig. 5). In einem stark wachsenden Stocke sind die Zoöcien der Randzone immer blosse Knospen, d. h. ohne jede Spur von Polypiden, die weiter nach innen liegende Zone zeigt schon weiter entwickelte Zoöcien. Diese lassen bereits die Anlage der hintcren Stacheln erkennen, und haben beinahe ihre definitive Grösse erreicht. Erst in einer weit mehr centripetal gelegenen Zone finden wir vollkommen entwickelte typisch verkalkte Zoöcien mit völlig ausgebildetem Polypiden. Kommt aber ein Stock im Verlaufe seines Wachsthumes an den Rand des Laminarienblattes, so geht er nur in seltenen Fällen üher die scharfe Kante herüber auf die andere Seite desselben, vielmehr stellt er dann gewöhnlich sein Wachsthum hier ein, alle bereits angelegten Zoöcien entwickeln sich aber normal bis auf die der äussersten Randreihe. Diese bleiben blosse Knospen, welche kein Polypid in sich erzeugen, keinen Deckelapparat entwickeln, dagegen crhalten auch sie an ihrem proximalen Ende die charakteristischen Stacheln und ihre Hinter- und Seitenwand verkalkt (Taf. IV, Fig. 6).

Gewöhnlich wächst, wie gesagt, der ganze Rand eines Stockes gleichıässig fort, d. h. alle Zoöcienlängsreihen knospen so gleichmässig, dass die Randcontour nicht verändert wird. Mitunter aber beginnen an zwei etwas von einander entfernten Randstellen zwei Randzoöciengruppen stärker zu wuchern, sich stärker zu entwickeln als die zwischen ihnen liegende Zoöciengruppe. Es wölben sich dann diese beiden Stellen über die gewöhnliche Randcontour vor. Es werden öfters neue Zoöcienreihen eingeschaltet. Die Zoöcienlängsreihen divergiren alsclann fïcherartig, die Zoöcienreihen der einander zugewendeten Sciten der wuchernden Randstellen wachsen gegen einander und stossen schliesslich zusammen, indem sie die zwischenliegenden, nicht 
wuchernden Zoöeienlängsreihen voll dem Aussenrande des Stockes verdrängen. Die anı Ende der verdrängten Zoöcienreihen gelegenen Zoöcien nebmen gewöhnlich eine abweichende, meist keilförmig zugespitzte Gestalt an und bleiben steril. So sind z. B. die drei Zoöcienlängsreihen $A$ (Taf. IV, Fig. 4) von dem Aussenrande des Stockes verdrängt worden, indem die rechts und links von ihnen liegenden Längsreihen vor ihnen sich zusammenschlossen. Auch die Zoöcien der den ausgeschalteten Zoöcienreihen zunächst liegenden Längsreihen werden aber durch das Zusammenschliessen der beiden ursprünglich von cinander getrennten Zoöciengruppen in ihrer Form beeinträchtigt, und haben in diesem Falle z. B. theils ebenfalls eine Umänderung in die Keilform erfahren, theils sind sie ungewöhnlich langgestreckt und schmal geworden.

Sterile keilförmige Zoöcien kommen also nicht nur in der Nähe der primären Zoöcien, sondern auch in den später entstehenden Theilen des Stockes vor. In Bezug auf ihre histologische Structur bleiben dieselben meist lange auf dem Knospenzustande stehen, d. h. ihre Endocyste behält ihren deutlich zelligen Bau, und da die Endocyste in diesem Zustande weisslich und undurchsichtig ist, so erscheinen sie in dem lebenden Stocke als weissliche Keile, an Spiritusexemplaren bei durchfallendem Lichte betrachtet, dunkler als die angrenzenden Zoöcien.

Nicht alle steril gewordenen oder vielmehr gebliebenen Zoöcien bleiben aber auf der Stufe der Keil zoöcien stehen, sie verwandeln sich mitunter in eine Zoöcienform, die ich als Thurmzoöcien bezeichnen möchte (Taf. IV, Fig. 7 und Fig. 4. o. f.).

Die zcllig gebliebene Endocyste des hinteren proximalen Theiles der Oberseite beginnt nämlich zu wuchern und bildet eine grosse, schlauchartige Auftreibung, deren Liingsachse senkrecht gegen die Unterlage steht. Die Ectocyste wird natürlich hierdurch ebenfalls aufgebläht, verdickt sich ziemlich stark und das junge Zoöcium bekommt eine von dem typischen Zoöcium ungemein abweichende Gestalt. Der Thurnauswuchs kann ungemein lang werden, er ist oft 3 oder 4 Mal so hoch als das Zoöcium, das ihn erzeugte, lang ist. Er gliedert sich, soweit mir bekannt, niemals von der IIöhlung des Zoöcium durch eine Scheidewand ab, kann also nicht als ein besonderes Individuum angeschen werden. Die Ectocyste des Thurmes bleibt stets ohne Kalkeinlagerungen, und auch die Stacheln des proximalen Theiles des Zoöcium bleiben unverkalkt, dagegen erhalten die Seiten- und Hinterwände desselben Einlagerungen von Kalksalzen, und zwar finden sich in ihnen ausser den normalen Kalkplatten (Fig. 7 a a ) auch noch andere weiter nach oben gelegene zartere $(b b)$, welche weiter auf die Ober- 
seite des Zoöcium hinaufreichen. Solche Thurmzoöcien fallen an dem frischen Stocke sofort in die Augen. Sie erscheinen dem blossen Auge als krystallhelle, stramm aufgerichtete Zäpfchen, welche man anfänglich ohne nähere Untersuchung als etwas dem Thierstocke selbst Fremdes anzusehen leicht geneigt ist.

Indessen scheinen sich nicht nur keilförmig gebliebene Endzoöcien solcher Längsreihen, die von dem Aussenrande des Stockes verdrängt wurden, in Thurmzoöcien zu verwandeln, auch die, solchen Keilzoöcien angrenzenden älteren, noch rectangulär gebliebenen Zoöcien scheinen sich so metamorphosiren zu können, so z. B. das Zoöcium $f$ auf Fig. 4. Ja sogar ganz normal gebildete, mit Deckelapparat versehene Zoöcien treiben mitunter Thurmauswüchse an ihrer Oberseite. In der Leipziger zoologischen Sammlung befindet sich z. B. ein leider getrocknetes Exemplar von Fl. membranacea, welches zahlreiche, iber den ganzen Stock in quincunxartiger Vertheilung ausgebreitete Gruppen von Thurmzoöcien mit ungemein langen Thürmen zeigt. Die Thurmzoöcien sind hier bis auf den Auswuchs ganz normal gebaut und besitzen einen Deckelapparat. Ich bin geneigt, zu glauben, dass ler thurmartige Auswuchs nicht gleich an der Knospe entstanden ist, dass wir es hier vielmehr mit Zoöcien zu thun haben, die ursprünglich denselben entbehrten und normale Zoöcien darstellten, dann aber ihr Polypid verloren und anstatt ein solches neu zu bilden - ein Vorgang, lor, wie wir später sehen werden, ungemein häufig vorkommt - zu Thurmzoöciell sich transformirten.

Es würde dies ein Vorgang sein, welcher einigermaassen zu vergleichen wäre mit der periodisch wiederkehrenden Verlängerung der Zoöcien von Aethea argillacea, wie Sмıтт sie beschrieben hat. 1) Allerdings kommt es bei letzterer Species nicht nur zu einer Verlängerung des einmal fertig gebildeten Zoöcium, sondern auch zu ciner Neubildung des Deckelapparates an der Spitze des verlängerten Theiles und zur Neubildung eines Polypiden innerhalb desselben.

Was die Dimensionen der einzehnen Zoöcien betrifft, so lässt sich durchaus nichts Bestimmtes angeben, da dieselben ungemein variiren.

Im Allgemeinen sind die primären Zoöcien und die denselben zunächst liegenden bedeutend kleiner als die später entstandenen. Die Länge des oberen der auf Taf. IV, Fig. 3 abgebildeten primären Zoöcien betrug 0,41 Mm., die des längsten gestreckten Zoöcium $h$ auf Fig. 4 dagegen 1,15 $\mathrm{Mm}$., seine Breite 0,12 Mm. Die auf Figur 6 abgebildeten

1) Öfvers. af K. Yet.-Akad. Förhandl. 1865, p. 29, Tab. IV, Fig. 18. 
Zoöcien kann man ohngefähr als von normaler Länge betrachten. Das Zoöcium $f$ auf dieser Figur ist $0,77 \mathrm{Mm}$. lang und $0,25 \mathrm{Mm}$. breit. Ein Vergleich der Figuren 3, 4, 5, 6 und 8 auf Taf. IV, welche sämmtlich in 22 facher Vergrösserung dargestellt sind, wird das über dic wechselnde Grösse Gesagte auf den ersten Blick bestätigen.

Nachdem wir nun im Allgemeinen die verschiedenen Modificationen betrachtet haben, denen die Form der Einzelzoöcien im Laufe des Wachsthumes eines Stockes unterliegen kann, wende ich mich zur genaueren Darstellung des Knospungsprocesses selbst.

Derselbe ist in neuerer Zeit ausführlicher von Suтt beschrieben worden. Ich schalte hier die Darstellung des ausgezeichneten schwedischen Forschers in extenso ein, da dieselbe, weil in schwedischer Sprache abgefasst, nicht allen Zoologen ohne weiteres zugänglich ist.

Sмıтт 1) sagt: "Der Entwicklungsrand (von Fl. membranacea) zeigt . . . . von innen nach aussen, wie ein Zoöcium nach dem andern sich entwickelt.... Dieser ganze Rand ist also zu betrachten als eine Knospe der Colonie (des Thierstockes) als eine Gesammtknospe, welche lurch Theilung sich in die einzelnen Zoöcien differenzirt und entwickelt. Dieselbe ist eine ausgebreitete Anschwellung längs des Randes der ganzen Colonie und besteht aus Fettkörpern, welche in eine Haut eingeschlossen sind.

Wir müssen wohl schon hier ihren Inhalt als Fettkörper ansehen, da wir keinen Unterschied entdecken können zwischen ihnen und den kleinen losen lichtbrechenden Körnern und Blasen, welche in der Leibeshöhle des ausgebildeten Zoöcium schwimmen, und welche, wie wir weiter unten sehen werden, nur dazu dienen können, die Organe $\mathrm{zu}$ reproduciren, welche in den Knospen, die wir hier vor Augen haben, neu gebildet werden. Die Gesammtknospe breitet sich mehr und mehr aus, ihre Theilung zeigt sich zuerst als eine Falte der Haut zwischen deren beiden Blättern sich bildet eine dem Aussehen nach hornige durchbrochene Zwischenwand. Durch diese verticalen, fast parallelen Theilungswände entstehen die ersten Anlagen zu den werdenden Zellreihen, welche gegen das Centrum der Colonic radial gestellt sind. Die Gesammtknospe ist auf diese Weise getheilt worden in neben einander liegende, abgeplattete Röhren. Wenn die Entwicklung von Organen im Inneren des bleibenden Thierhauses an der Basis der Röhren ihren Anfang genommen hat, theilen sich diese, jede für sich, durch Querwände, welche auf dieselbe Weise entstehen, wic die vorhin beschriebenen Längswände der eben neu begründeten Thierhäuser. « 
Surt nimmt also an, es gäbe einen Zeitpunkt, wo der äusserste Rand des ganzen Stockes, resp. ein grösserer Theil desselben umgeben ist von einer grossen, ungetheilten Knospe, in welcher erst nachträglich und zwar vom peripherischen Rande aus Scheidewände auftreten, welche die von den sämmtlichen, am weitesten nach der Peripherie zu gelegenen fertigen Zoöcien gemeinsam gebildete Gesammtknospe in je einer Zoöcienlängsreihe entsprechende Abschnitte zerlegen.

Ein Vorgang, wie der von Surt geschilderte, muss dem unbefangenen Beurtheiler schon aus rein theoretischen Gründen etwas unwahrscheinlich vorkommen. Einerseits würde es nämlich eine höchst auffallende und gänzlich einzig dastehende Thatsache sein, dass eine Anzahl von Individuen einer so hoch organisirten Thiergruppe sich zusammenthun, um gemeinschaftlich eine Knospe hervorzubringen. Wir können uns sehr wohl denken, dass eine von e inem Individuum erzeugte Knospe in mehrere Einzelindividuen zerfältt. Der umgekehrte Vorgang erscheint als völlig unvereinbar mit unserer jetzigen wissenschaftlichen Auffassung des Individuums. Die einzigen bekannten Fälle, wo zwei Individuen sich vereinigen, um ein drittes zu bilden, sind die geschlechtliche Copulation und die Conjugation, mit diesen beiden Vorgängen hat aber die Knospung der Bryozoen auch nicht das Mindeste gemein.

Andererseits muss man festhalten, dass in dem die Gesammtknospe nach Smiтts Anschauungen erzeugenden Stocke doch auch bereits radiale Zoöcienl:̈ngstreihen existiren, und dass es vollkommen unbegreiflich erscheint, weshalb in der ganz ungegliederten Gesammtknospe die Radialscheidewinde am peripherischen Rande gerade an solchen Stellen auftreten, dass sie centripetal fortwachsend genau auf die Scheidewände der präexistirenden Zoöcienlïngsreihen des Stockes treffen.

Die Untersuchung der mir zu Gebote stehenden Exemplare hat mich denn auch zu einer Auffassung des Knospungsvorganges kommen lassen, welche von der Smitt'schen einigermaassen abweicht.

Ich habe mich zunächst niemals überzeugen können, dass zu irgend einer Zeit der Entwicklungsrand besteht aus einer Gesammtknospe, welche ihre Entstehung mehreren mehr central liegenden Zoöcien verdankt.

Betrachten wir den Rand eines mässig wachsenden Stockes, so finden wir, dass derselbe gebildet wird von noch unfertigen Zoöcien. Wenn in denselben aberhaupt schon die Anlage' des Polypids vorhanden ist, so ist die Mündung des Zoöcium doch noch nicht durchgebrochen, und das Polypid kann also noch in keinen Verkehr mit der 
Aussenwelt treten. Aber auch die kleinsten Zoöcien, welche ubrigens, wie aus dem oben Gesagten hervorgeht, immer von zwei etwas weiter entwickelten nach rechts und links begrenzt werden, sind scharf gegen die anliegenden abgegrenzt. Ein jedes unfertige Zoöciun besteht aus einem einfachen parallelopipedischen Sacke, dessen Wandung von einer sehr zarten durchsichtigen Ectocyste und einer aus deutlichen, zelligen Elementen gebildeten Endocyste gebildet wird. In dem Stocke, den wir jetzt betrachten, d. 'h. in einem mässig wachsenden, sind die Zoöcien der Randzone zwar oftmals bedeutend kleiner, niemals aber sehr bedeutend länger als die Zoöcien, denen sie entsprossen sind, und zwar sitzt jede Zoöciumknospe der Randzone mit ihrem hinteren proximalen Ende dem Vorderende eines Zoöcium der nächstinneren Zoöcienquerreihe auf; nur selten liegen zwei Zoöcienknospen dem Vorderende eines älteren Zoöcium an (Taf. IV, Fig. 3 rechter Hand). Ilier haben wir es also sicher mit einem Gebilde zu thun, welches durchaus keine Aehnlichkeit hat mit einer Smitt'schen Gesammtknospe. Wir erkennen nur eine Randzone scharf gegen einander abgegrenzter liandzoöcien, welche so gleichnässig an ihrem distalen Ende wachsen, lass der Rand des Stockes scharf abgeschnitten erscheint.

lst nun das Wachsthum sämmtlicher Randzoöcien so weit fortgeschritten, dass die längsten Zoöcienknospen der Randzone die für diesen Theil des Stockes normale mittlere Zoöcienlänge überschritten haben, so beginnt die Endocyste an der Stelle, welche dem normalen Ende des übermässig gewachsenen Zoöcium entsprechen würde, nach innen zu eine Falte zu bilden, welche senkrecht gegen die Längsachse des Zoöcium steht. Die Falte bildet sich gleichzeitig an der oberen und unteren Wand, sowie an den Seitenwänden; die Ränder der Falte wachsen gegen einander, treffen sich in der Mitte und verschmelzen hier. Es hat sich also ziemlich nahe dem Vorderende des betreffenden \%oöcium eine aus zwei Blätlern der Endocyste gebildete Scheidewand gebildet, welche das Lumen des Zoöcium quer durchsetzt, und den vordersten Abschnitt des ursprunglich einfachen Zoöcium abtrennt: aus dem übermässig verlängerten Zoöcium ist ein normal grosses Zoöcium mit einer Knospe an seinem vorderen Ende geworden. Die Wände der Falte secerniren in das Lumen der Falte hinein jede eine Chitinlamelle, die beiden Chitinlamellen legen sich an einander, wenn die Ränder der Falte sich treffen, treffen sich auch die Chitinlamellen, und verschmelzen. Die eine bildet nun die Ectocyste der Vorderwand des jetzt in zweite Linie gerückten Mutterzoöcium, die andere die Ectocyste der Hinterwand der Knospe. Auf Tafel V, Fig. 12 ist ein Zoöcium abgebildet, von dem sich eben eine Knospe abschnurt. Die 
Falte ist bei $a$ deutlich sichtbar. Jede Knospe entsteht also durch eine einfache Abtrennung des Vorderendes ihres Mutterzoöcium.

Etwas anders verhält sich die Sache bei einem in starkem Wachsthume begriffenen Stocke, und zwar sind es offenbar vornehmlich derartige Stöcke, an denen Surt seine Beobachtungen gemacht hat. Hier ist die noch unfertige Zoöcien enthaltende Randzone viel breiter, erst in der zehnten oder zwölften Querreihe finden wir Zoöcien mit völlig entwickelten Polypiden und mil normal ausgebildeten Kalkeinlagerungen in der Ectocyste. Indessen haben bereits sämmtliche Zoöcien mit Ausnahme derjenigen der äussersten Randzone ihre definitive Begrenzung erhalten. Ob die einzelnen Zoöcien auch nach ihrer Abgrenzung noch um ein Weniges wachsen können, ist bei der grossen Variabilität der Zoöciendimensionen schwer zu constatiren, erscheint mir aber wahrscheinlich. Die Zoöcien der ïussersten Randzone haben bereits ihre Normalbreite erlangt und sind scharf abgegrenzt gegen die Zoöcien der anliegenden Längsreihen, ihre Länge übertrifft aber die Normallänge der Zoöcien dieses Theiles des Stockes um ein ganz Bedeutendes, mitunter um das 3 fache. Als terminales Ende einer jeden Zoöcienläıgsreihe erscheint somit ein langer parallelopipedischer Schlauch von viereckigem Querschnitte, an dessen proximalem Ende, d. b. an der Ilinterwand eine ungemein kleine Anlage für ein Polypid zu erkennen ist. Während nun ein jeder solcher Schlauch an seinem Vorderende weiter wächst, gliedert sich sein hinterster Abschnitt durch eine auf die oben geschilderte Weise entstehende Scheidewand zu einem gesonderten Zoöcium ab. Das Vorderende wächst aber so stark, dlass, so oft sich auch dieser Abschnürungsprocess am Ilinterende wiederholt, das ungegliederte Vorderende doch iquivalent bleibt mehreren Zoöcien.

Ein Stück eines solchen Randes ist auf Taf. IV, Fig. " 3 abgebildet. Jede der Zoöcienlängsreihen I und Il endet in einen langen Schlauch, die ursprüngliche Zoöcienreihe III aber in zwei derartige Schliiuche, da dadurch, dass von dem Zoöcium III $a$ zwei jüngere Zoöcien entspringen, die ursprünglich einfache Reihe dichotom getheilt wurde. Durch $b$ wird die letzte deutliche Zoöcienquerwand jeder Zoöcienreihe bezeichnet. $\Lambda \mathrm{n}$ ihrer Vorderseite befindet sich eine noch sehr kleine Polypidknospe. Das Vordertheil eines jeden Schlauches ist undurchsichtig (im Leben weisslich), der hinterste Theil dagegen durchsichtig, und zwar bei den längsten Schläuchen durchsichtiger als bei den kürzeren, wie z. B. bei 4. Dieses Durchsichtigwerden der Wandungen zeigt, dass der hintere Theil des betreffenden Zoöcium im Begriff steht, sich als ein gesondertes Einzelzoöcimm durch eine Falte abzugrenzen. Der durchsichtige Theil ist 
gegen den undurchsichtigen durch eine ziemlich scharfe, hier durch $a$ bezeichnete Linie abgegrenzt; auf diesem Punkte bildet sich die Querscheidewand. An dem Rande eines stark wachsenden Stockes finden wir also allerdings unfertige Zoöcien, Knospen, welche äquivalent sind mehreren gewöhnlichen Zoöcien. Der ganze Rand ist aber keineswegs eine grosse ungetheilte Knospe, an deren Erzeugung mehrere ältere Zoöcien Theil genommen haben, eine Gesammtknospe nach Surtr, sondern ein Complex scharf gegen einander abgesonderter Knospen, von denen allerdings jede mehreren hintereinander liegenden Zoöcien äquivalent ist, aber als das peripherische Ende einer bestimmten Zoöcienlängsreihe erscheint. Die Knospe 1 muss man also als den Descendenten des Zoöcium I, die Knospe 2 als den des Zoöcium II ansehen. Das Zoücium I $a$ hat allerdings eine Knospe erzeugt, welche mehreren Zoöcien äquivalent ist, später in mehrere sich gliedern wird, aber nur dieses eine Zoöcium hat an der Erzeugung dieser Knospe Antheil, nicht zugleich auch die nebenan gelegenen. Der Entwicklungsrand von Fl. membranacea ist keine Gesammtknospe im Smitt'schen Sinne, sondern ein Complex von Knospen, welche jede als der Descendent eines bestimmten, weiter nach innen zu gelegenen Zoöcium zu hetrachten ist. Eine jede solche Knospe segmentirt sich nachträglich in mehrere Einzelzoöcien, und ich schlage für sie den Namen »Gros sknospe ( vor. 1)

Surтt ist zu seiner Ansicht offenbar durch den Umstand gebracht worden, dass im Falle eine neue Zoöcienlängsreihe eingeschaltet werden soll, eine solche Grossknospe an ihrem vorderen Ende sich gabelt, bereils ehe ihr hinteres ungegabeltes Ende sich in einzelne Zoöcien segmentirt hat.

Betrachten wir die bei der Einschiebung einer neuen Zoöcienlängsreihe eintretenden Erscheinungen zunächst wieder an einem in mässigem Wachisthume begriffenen Stocke z. B. dem auf Taf. IV, Fig. 3 abgebildeten.

Das Zoöcium $c$ hat an seinem Vorderende durch Abschnürung anfänglich e in e ungemein breite Knospe $d$ erzeugt. Diese Knospe war aber ebenfalls eine Grossknospe, die zwei Zoöcien äquivalent war, die aber nicht hinter, sondern neben einander liegen. Diese Grossknospe $d$ hat sich durch eine nachträglich entstehende Längsscheidewand in die zwei Einzelzoöcien getrennt, und zwar ist diese Längsscheidewand nicht von der an das Mutterzoöcium $c$ angrenzenden Hinterseite der

1) Das Wort "gross" soll natürlich in dieser Zusammensetzung eine ganz andere Bedeutung haben, als $\mathbf{z}$. B. in dem Wort "Grossamme". 
Knospe ausgegangen, sondern von dem freien Vorderrande. Die Knospe hat sich also zunächst gegabelt ehe sie definitiv in zwei getrennte Zoöcien zerfiel. Aber auch hier ist die Grossknospe das Product des Knospungsprocesses, der Wucherung e in es Mutterzoöcium, also keine Gesammtknospe im Surts'schen Sinne.

Aehnliche Erscheinungen finden wir nun auch bei einem stark wuchernden Entwicklungsrande nur noch viel schärfer ausgeprägt. Betrachten wir das Zoöcium IV $c$ auf Fig. 5 der Taf. IV, so sehen wir, dass die Randknospe, die Grossknospe, welche sich von ihm vorn abgeschnürt hat (No.6), an ihrem Vorderende durch eine von dem freien Rande ausgehende Längsscheidewand $c$, welche nicht bis zur Hinterwand $b$ der Grossknospe reicht, gegabelt erscheint. Das Vorderende der Gesammtknospe bifurcirt sich also, bildet sich aus zur Anlage von z we i Zoöcienlängsreihen, ehe das Hinterende, welches offenbar die Anlage für ein einziges Zoöcium bildet, sich an seinem Vorderende abgeschlossen hat. Die Grossknospe No. 6 entspricht also in ihrer Gesammtheit ohngefähr ॐ Einzelzoöcien; bliebe der Stock auf diesem Wachsthumsstadium stehen, und gliederten sich die vorhandenen Grossknospen, ohne weiter an Grösse zuzunehmen, in die Zoöcien, zu denen sie die Anlage enthalten, wie dies der Stock, dessen Rand in Fig. 6 abgebildet ist, gethan hat, so würde der proximale Theil der Knospe sich durch eine Querscheidewand abgliedern ohngefähr in der Höhe des unteren Endes der Längsscheidewand $c$, und jeder der beiden Aeste des vorderen distalen Knospenendes würde ohngefähr ein normales und noch ein rudimentäres Randzoöcium abgeben.

Der eben geschilderte Vorgang läst es uns auch begreiflich erscheinen, wie ein Zoöcium, das an seinem Vorderende zwei jüngere Zoöcien trägt, an seinem Vorderende schon selbst gegabelt erscheinen kann, wie z. B. das Zoöcium III $a$. Die Zoöcien III $a$, Ill $b$, IIIc und die Knospen 3 und 4 bildeten zu einer gewissen Zeit eine ungetheilte Grossknospe und die Längsscheidewand der Knospen 3 und 4 trat auf, ehe die Querscheidewände zwischen IIl $a$ und III $b \mathrm{u}$. $c$ sich gebildet hatten.

In Allgemeinen liaben also die Vorgänge der Knospung bei Fl. membranacea in gewisser Beziehung ungemein viel Aehnlichkeit mit den bei der Theilung von Pflanzenzellen vorkommenden. Auch in unserem Falle kann man, genau genommen, nicht sagen, dass ein Zoöcium $a$ das Mutterzoöicum der an seinem Vorderende abgeschnürten Knospe $b$ ist, sondern man muss sagen, dass beides Tochterindividuen eines früheren gemeinsamen Mutterindividuums sind. Nur hat sich bereits das mehr centripetal gelegene Tochterindividuum weiter ausgebildet als das weiter peripherisch gelegene. 
Ich fasse die geschilderten Erscheinungen der Knospung noch einmal kurz zusammen: Ein unfertiges Zoöcium, eine Knospe wuchert und dasjenige Stück, um welches die Knospe die Dimensionen überschreilet, welche das definitive Zoöcium haben soll, wird durch eine Querscheidewand abgeschnitten. Ist das Wachsthum des Stockes mässig, so geschieht diese Abschnürung sehr bald, nachdem die Knospe die normale Zoöciumgrösse überschritten hat. Ist das Wachsthum des Stockes dagegen stark, so wächst die Knospe (welche ich jetzt Grossknospe nenne) zu einer sehr langen Röhre heran, ehe sie sich durch Bildung von Querscheidewänden in ihrem hinteren Ende zu gliedern beginnt, während übrigens ihr Vorderende noch immer fortwächst. In der Idee entsprechen die einzelnen Zoöcienlängsreihen einem Kreisausschnitte, werden also nach der Peripherie zu breiter. Wird das peripherische Ende einer solchen Längsreihe bei fortgesetztem Wachsthume so breit, dass ein Zoöcium es nicht mehr ausfüllen kann, so wird durch Dichotomie des Vorderendes der Knospe dieselbe in zwei nebeneinander liegende Knospen getrennt, von denen jede nun die Basis einer neuen Längsreihe bildet.

Diese Dichotomie kann vor sich gehen an einer Knospe, die kürzer oder ebenso lang als die Normallänge eines Zoöcium ist, oder an einer Grossknospe.

Wenden wir uns nun zur Betrachtung der histologischen Beschaffenheit der jungen Knospen.

Surt schildert den Entwicklungsrand von Fl. membranacea als eine Ausanmlung von Fettkörper, umliült von einer Haut; auch die Knospen der anderen Bryozoen betrachtet er als iihnlich gebildet. Dem gegenüber ist von Glaparéde, und beiliufig auch von Reiciert constatirt worden, dass die Wandung derselben stets aus einer zarten Ectoeyste und einer deutlich zelligen Endocyste besteht.

Es ist mir übrigens nicht ganz klar geworden, welcher von diesen beiden eben genannten Hauptbestandtheilen der Wandung Smitr als die "Haut" bezeichnet. Ich bin beinahe geneigt, zu glauben, dass er die Ectocyste anfänglich ganz übersehen hat und die zellige Endocyste „Haut« nennt, wenigstens wird eine solche $\Lambda$ uffassung einigermassen begrúndet durch die Aeusserung, die er weiterhin thut: „Die Längsscheidewände der Gesammtknospe zeigten sich anfänglich als eine Falte der Haut, zwischen deren beiden Blättern sich eine dem Aussehen nach hornige, unterbrochene Zwischenwand bildet.

Betrachten wir eine Grossknospe, - diese zeigt diese Verhältnisse am deutlichsten, - so finden wir sie gebildet von einem hohlen, schlauchartigen Körper mit viereckigem Querschnitte, der von ohen 
nach unten ein wenig abgeplattet ist und sich an seinem Vorderende ein wenig abflacht, so dass er hier wie ein einseitig geschärfter Meissel erscheint. Die Begrenzung der Grossknospe nach aussen wird an ihr im ganzen Umfange gebildet von einer sehr dünnen chitinösen Cuticula, welche an den Seitenwänden verschmilzt mit der Cuticula der nebenliegenden Knospen (Taf. VI, Fig. 5 a.).

Auf diese Cuticula folgt nun zunächst nach innen eine einfache Lage deutlicher Cylinderepithelzellen (b), welche aber nur an der Oberseite mit der von ihr secernirten Cuticula fest zusammenhängt. Die sie bildenden Zellen sind ziemlich lange, im Querschnitt unregelmässig polygonale Cylinderepithelien, welche einen deutlichen Kern mit stark lichtbrechenden Kernkörperchen enthalten (Taf. VI, Fig. 14). An Spiritusexemplaren weichen die einzelnen Zellen seillich ein wenig auseinander. Diese Zellschicht ist an der Oberseite der Knospe sowie an den Seitentheilen von mässiger Dicke, der Längendurchmesser der Zellen übertrifft den Querdurchmesser nicht sehr $\left(b, b^{\prime}\right)$, dagegen verlängern sich die Epithelzellen der Unterfläche $\left(b^{\prime \prime}\right)$ ganz bedeutend. Sic werden hier zu langgestreckten Parallelopipeden oder Säulen. Der Kern liegt ohngefähr in der Mitte. Die Längsachse sämmtlicher Epithelzellen steht nicht senkrecht auf der Guticula, sondern ist sehräg nach hinten gerichtet (Taf. VI, Fig. 15).

Nach innen liegt dieser Epithelschicht eine zweite, nur in jungen Knospen deutlich als solche zu erkennende Zellschicht auf (Taf. VI, Fig. 5 u. 15, c.). Dieselbe besteht, wie man auf Längsschnitten deutlich sehen kann, aus spindelförmigen Zellelementen, welche sich mit ihren spitzen Enden zwischen einander einkeilen und mit ovalen Kernen in der Mitte ihrer Längsausdehnung versehen sind. Die Längsachsen der Spindelzellen laufen parallel der Längsachse der Knospe.

An der Innenseité dieser zweiten Spindelzellschicht haften an der oberen und den Seitenwänden rundliche oder unregelmässig geformte Haufen runder, scharf begrenzter, ungemein stark lichtbrechender Körner. Diese Körnerhaufen ragen frei in das Lumen der Knospe vor (Taf. VI, Fig. 5 u. $15, d$, u. Fig. 6).

Die Wandungen der jungen Knospe bestehen also 1) a us einer inneren Spindelzellsehicht mit anliegenden Körnerhaufen; 2) einer äusseren Cylinderepithelschicht, und 3) einer von der letzteren secernirten Guticula.

Der Innenraum der Knospe wird theilweise erfüllt von einer feinkörnigen lockeren, ich möehte sagen wolkigen Substanz, welche ich als einen durch Alkohol hervorgebrachten Niederschlag von Eiweissstoffen aus der Leibesflüssigkeit anzusehen geneigt bin. 
Dies ist der Bau einer ganz jungen Knospe, und zwar auch nur ihres distalen Endes; weiter nach hinten zu verändert sich das Bild ein wenig. Die Cylinderepithelzellen der Wandung platten sich weiter nach dem proximalen Ende zu ein wenig ab, besonders die der Unterseite verkürzen sich, die einzelnen Zellen rücken auseinander, die Zellgrenzen werden undeutlicher (Taf. VI, Fig. 13), die Kerne jedoch bleiben deutlich erkennbar. An dem hintersten Theile einer Grossknospe, also an demjenigen, der zunächst als ein gesondertes Einzelzoöcium sich abschnüren soll, z. B. an dem Stück $a b$ der Knospe 1 auf Taf. IV, Fig. 5 haben sich die Verhältnisse noch weiter verändert. Die Endocyste hat an der Oberseite des Zoöcium die für die Chilostomen bereits mehrfach beschriebene netzartige Beschaffenheit angenommen, d. h. die scharfen Zellgrenzen der Cylinderzellen sind ganz verschwunden, die Zellkerne sind weit auseinander gerückt und liegen jeder für sich in einem mehr oder weniger deutlichen Häufchen protoplasmatischer Substanz, welche durch Ausläufer mit einander verbunden sind (Taf. VI, Fig. 16), indessen ist die Substanz der Endocyste nicht gänzlich aus den Maschen dés Netzes verschwunden, sie bildet vielmehr ein ungemein zartes, homogenes Häutchen, auf welchem die einzelnen die Zellkerne umgebenden Zellterritorien als nach innen vorspringende Verdickungen erscheinen. Die Elemente der Spindelzellschicht sind beinahe ganz verschwunden, vielleicht ist anzunehmen, dass ein Theil der die Zellterritorien verbindenden Ausläufer aus ibnen sich gebildet hat. Die Endocyste.stellt also hier eine Verschmelzung der ursprünglich scharf getrennten Zellen der Knospenwandung dar. Nur in den binteren oberen Ecken der Knospe, welche sich knopfartig aufzublähen beginnen, zeigen sich die Elemente der Cylinderepithellage noch in ihrer fruheren, scharf begrenzten Form.

Diese knopfartigen Auftreibungen sind, wie man leicht erkennt, die Anlagen der beiden Stacheln. Die Körnerhaufen sind während der ganzen rückschreitenden Metamorphose als Zellelement der Zoöciumwandungen intact geblieben; zu ihnen treten mitunter noch grosse, scharf begrenzte, von stark lichtbrechender Substanz gefüllte Blasen oder Körner. Einen Kern kann man an diesen nicht erkennen (Taf. VI, Fig. 16, a.).

Etwas abweichend ist das Aussehen der Endocyste an der Unterseite der Zoöcienknospen.

Hier persistirt die Spindelschicht bedeutend länger als solche; sie bildet eine dünne membranöse Ausbreitung, in der man die Spindelzellen mit ihren Kernen noch deutlich erkennen kann, besonders finden sich in den jüngsten abgeschnürten Zoöcien, in deren oberen Wand 
die Spindelzellschicht schon lange verschwunden ist, zwei deutliche Spindelfaserzüge, welche parallel mit den Seitenkanten des Zoöcium auf der Unterfläche derselben sich hinziehen. Dieser aus der Spindelzellschicht entstandenen Gewebsschicht (Taf. Vl, Fig. 18,c) liegen die metamorphosirten Bestandtheile der Gylinderepithelschicht nach aussen zu auf. Sie erscheinen jetzt als rundliche blasige Zellen, welche theils vereinzelt, theils in Haufen zusammenliegend gegen die Ectocyste zu vorspringen. Taf. VI, Fig. 17. zeigt die Unterfläche eines Theiles eines solchen Zoöcium von aussen dargestellt. Fig. 18 ist ein Längsschnitt. $a$ ist die Ectocyste, von der die Endocyste sich losgetrennt hat, $b$ sind die blasig gewordenen Cylinderepithelzellen, $c$ ist die Spindelfaserschicht. Die Kerne der Cylinderepithelien sind ungemein deutlich zu erkennen.

Die regressive Metamorphose der einzelnen Bestandtheile braucht nun nur ein klein wenig in der eben angedeuteten Art und Weise fortzuschreiten, um die gesammte Endocyste so erscheinen zu lassen, wic dieselbe in dem anatomischen Theile dieser Arbeit beschrieben wurde.

Nur an einigen wenigen Stellen der Seitenwände behält die Epithelschicht ihr ursprüngliches Ansehen. Dies ist dort, wo sie über die Rosettenplatten wegläuft. Die Rosettenplatten bilden sich schon sehr zeitig, lange ehe die Verkalkung der Ectocyste beginnt. Die birnförmigen Rosettenplatten der Querwände, resp. ihre Poren entstehen höchst wahrscheinlich dadurch, dass einzelne Zellen der beiden Blätter der Endocystenfalte, welche die jungen Knospen von ihrem Mutterzoöcium abgliedern, kein Chitin absondern, die zwischen den beiden Blättern der Falte sich bildenden Chitinblätter also von Anfang an durchbrochen bleiben, und durch die so entstandenen Poren treten die Epithelzellen der Vorderwand des Mutterzoöcium in directe Verbindung mit den Epithelzellen der Hinterwand der Knospe. Diese Epithelzellen gehen nun keine regressive Metamorphose ein, sondern bleiben als die Zellpfröpfe der Rosettenplatten bestehen.

$\mathrm{Da}$, wo zwei nebeneinander liegende Zoöcienlängsreihen durch das secundäre Auftreten einer Längsscheidewand ausgehend von dem Vorderende einer Grossknospe sich von einander trennen, kann man sich die Entstehung der Poren der Rosettenplatten der Seitenwände auf ähnliche Weise stattfindend vorstellen. Anders ist es bei zwei Zoöcienlängsreihen, welche nicht aus einer gemeinsamen Grossknospe entstanden sind. Hier muss man eine Resorption der ursprünglich gebildeten Cuticula annehmen.

Die Seitenstränge entstehen ziemlich zeitig. Es sind wahrscheinlich locale Ausbildungen der Spindelzellschicht der Unterfläche der Knospe. 
Die weitere Ausbildung, welche dic Zoöeien nun erfahren, besteht einmal in einer Verdickung und Verkalkung der Eetoeyste der Seitenund Querwände, in der Ausbildung der Stacheln und in dem Auftreten des Deckelapparates und der Parietalmuskeln. Da aber die Bildung des Deckelapparates genau zusammenhängt mil der Entwicklung des Polypiden innerhalh des Zoöeium, und die Entwickelung der Parietalmuskeln besser im Zusammenhange mit der Entwicklung der übrigen Muskeln hesprochen wird, so sehe ich von der Schilderung der letzteren beiden Vorgänge vorläufig ab.

Die Verkalkung der Ectoeyste betrifft nicht die Eetocyste in ihrer ganzen Dicke, sondern nur in einer mittleren Sehicht derselben werden Kalksalze abgelagert. Die Kalkeinlagerungen treten anfänglich als feinkörnige Flecke auf, von denen je einer darstellt die Anlage für eines der 4 Gerüststüeke des ausgewachsenen Zoöcium. Jieselhen sind zunächst nur klein und liegen weit auseiander, wachsen aber allmälig durch Anlagerung neuer Substanzen ihrer Peripherie, bis sie beinabe zusammenstossen und ihre definitive Gestalt angenommen haben.

Dass es wirklich die mittelste Sehicht der Eetocyste ist, welehe verkalkt, kann man am leichtesten an den Stacheln erkennen.

Die Stacheln treten auf, nachdem das Zoöeium sieh, wie wir oben sahen, ringsherum abgegrenzt hat, und als ein einfacher parallelopipedischer Sack erseheint. Sie erseheinen zunächst als kurze, rundliche Auftreibungen der Ectocyste an den oberen und hinteren Ecken des Zoöcium, ausgekleidet von der Endocyste, welehe hier die deutlich zellige Struetur ihrer Epithelschicht sich 'lange bewahrt, auch dann noch, wenn dieselbe auf der ganzen ührigen Oberseite des Zoöcium bereits versehwunden ist. Auf Taf. V, Fig. $6(s p)$ sind die Anlagen der Stacheln noch ungemein klein, stärker sind sie schon in den Fig. 7 al)gebildeten Zoöcium, und aul dem in Fig. 8 dargestellten älteren Zoöeium erscheinen sic hercits als starke, lange, oben abgerundete, stumpf kegelförmige Auftreibungen. Auf Taf. VI, Fig. 2 ist ein bezüglich seiner ;iusseren Gestalt definitiv ausgebildeter Stachel dargestellt, der aber noch keine Spur von Verkalkung zeigt. Die Wandungen desselben orseheinen im optischen Quersehnitte.

Ausgekleidet ist seine Höhlung von einer dünnen, netzartigen Endocyste $d$, auf diese folgt nach aussen zu eine feine Chitinschicht, welche wir bis in die Spitze des Stachels verfolgen können $(c)$, nach aussen von dieser und zwar scharf gegen sie alggegrenzt, sieht man eine dicke Schicht $b$, welche aber nicht bis zur Spitze des Stachels reicht, sondern ein Stutck vorher aufhört. Sie unterscheidet sich von 
der Schicht c durch das stärkere Lichtbrechungsvermogen. Wiederum nach aussen von $b$ finden wir denn die starke Ghilinschicht $a$, welche wie die Schicht $c$ bis an die Spitze des Stachels reicht, scine ganze äussere Bekleidung bildend. Nur die Schicht $b$ ist es nun, in welcher sich die Kalksalze ablagern. Da sie nicht bis zur Spitze des Kegels reicht, bleibt die Stachelspitze stets unverkalkt, und das Kalkgerüste des Stachels erhält die oben beschriebene Form eines oben offenen abgestutzten Hohlkegels, wie man auf Taf. IV, Fig. 1 u. 2, und Taf. VI, Fig. 3 abgebildet findet.

Wenden wir uns nun zur Entwicklungsgeschichte des Polypids innerhalb des Zoöcium.

Sobald eine Knospe sich durch Bildung einer Querwand von seinem Mutterzoöcium abgeschnürt hat, zeigen sich an ihrer Hinterwand die ersten Anlagen der Polypidknospe, und zwar isŁ es völlig gleich, ob die Knospe ein einziges Zoöcium darstellt, oder eine Grossknospe. Die Knospe 2 auf Fig. $\ddot{3}$ der Taf. IV zeigt bei $b$ eine deutliche Polypidknospe, obgleich das Zoöcium $a b$ an seinem Vorderende noch durchaus nicht abgeschlossen ist. Die Anlage des Polypids erscheint zunächst als eine Wucherung der Zellschicht der Endocyste in der Mitte der Hinterwand der Knospe, und zwar in dem Winkel, den die Hinterwand mit der oberen Wand macht.

Bald ordnen sich die Bestandtheile des regellosen Zellhaufens in zwei deutlich gesonderte Schichten, und wir sehen nun einen rundlichen Körper, bestehend aus einer äusseren einschichtigen Zellschicht, welche sich scharf absetzt gegen die das Innere des Körpers bildenden Zellen. Letztere beginnen nun ebenfalls sich zu ordnen und sich an die äussere Zellschicht als eine zweite innere Zellschicht anzulegen, welche einen kleinen centralen Hohlraum umschliesst (Taf. VI, Fig. 23). Die Zellen ähneln sehr kurzen Gylinderepithelzellen und sind mil doutlichen Kernen versehen. An ihrer oberen und hinteren Seite hängt die so gebildete Knospe fest zusammen mit der Endocyste, und zwar höchst wahrscheinlicher Weise mit der Spindelzellschicht, wenngleich sie ihre Entstehung offenbar einer Wucherung der Epithelschicht verdankt.

Die Knospe beginnt nun zu wachsen, sie streckt sich in die Länge (Taf. IV, Fig. 5, 2 bei $b$ ) und plattet sich seitlich ab. Die Zellen ihrer beiden Schichten vermehren sich und bilden sich zu längeren Gylinderzellen aus. Ein Querschnitt durch eine solche Knospe zeigt nun ein Bild ähnlich dem auf Taf. VI, Fig. 21 dargestellten. Ein spaltförmiger, genau in der Symmetriecbene des Zoöcium liegender Hohlraun $a$ wird umschlossen von zwei dicht aneinander liegenden Zellenschichten $b$ u. $c$, 
welche aber scharf gegen einander abgegrenzt sind. Die cben angezogene Figur ist übrigens nach dem Querschnitte einer etwas ältern Knospe angefertigt, aber besonders ihr oberer Theil kann sehr gut zur Erläuterung des eben geschilderten Stadium dienen.

Nun beginnt eine Veränderung der äusseren Zellschicht. Die Elemente derselhen verkleinern sich an dem distalen vorderen Ende der Knospe, platten sich ab und heben sich hier von der inneren Zellschicht los, eine kleine nach vorn spitz zulaufende Dute bildend, deren obere Fläche der Endocyste des Zoöcium dicht anliegen. Die äussere Zellschicht bildet also jetzt einen rings geschlossenen birnförmigen Sack, welche den von der inneren Zellschicht gebildeten ringsgeschlossenen Sack umschliesst und sich nur an dem Vorderende von ihm abhebt. Der ä u s s e r e S a ck is t, wie wir zum bessern Verständniss des Folgenden vorausgreifend sagen wollen, die Anlage der Tentakelscheide und desäusseren Epithels des Darmtractus, der inner Sack bildet die Anlage der Tentakeln resp. ihrer Zellbekleidung und des inneren drüsigen Epithels des Darmtractus.

Zunächst verändert nun der innere Zellsack seine Gestalt. Es bildet sich auf dem untern Theile seiner Seitenflächen jederseits eine horizontale längliche Einsenkung in welche der äussere Zellsack sich mit hineinsenkt. Auf Taf. VI, Fig. 24 $B$ sehen wir diese Einsenkung bei $a$ von der Seite, auf Fig. 21 bei $d$ im Querschnitte. Etwas später weichen nun die beiden Blätter des inneren Zellsackes, welche bis jetzt ziemlich nahe aneinander lagen, oben ein wenig auseinander, die Höhlung wird etwas gerăumiger in ihrem oberen Theile und der bis jetzt geschlossene innere Sack öffnet sich an seiner oberen Fläche mit einer in der Symmetrieebene des Zoöcium liegenden Spalte (Taf. Vl, Fig. $24 A s p$ ), welche bald auch auf seine Vorderseite herabgreift.

Der äussere birnförmige Zellsack umschliesst jetzt also einen inneren an seiner Oberseite längsgespaltenen Sack.

Die beiden Längseinsenkungen von denen eben gesprochen wurde, bilden sich nun zu Falten aus, welche in der Mitte der Längsausdehnung der Polypidknospe in querer Richtung gegeneinander wachsen. Sie stossen schliesslich auf einander und verschmelzen, so dass ihre oberen und unteren Blätter miteinander sich verbinden (Taf. VI, Fig. 22). Von dem inneren Zellsacke wird hierdurch eine längs seiner Unterfläche verlaufende Röhre abgegliedert, welche aber durch zwei Oeffnungen, von denen die eine am Hinterende der Knospe, die andere am Vorderende gelegen ist, mit seiner Höhlung in Verbindung steht. Dies ist die Anlage des Darmtractus mit Mund- und Afteröffnung. Die Afteröffnung 
mündet anfänglich noch in die von den oberen Hälften der Seitentheile des inneren Zellsackes begrenzte Höhle, bald aber setzt sich die Abschnürung des Darmtractus bis an das distale Ende der Knospe fort und die Afteröffnung mündet nun nicht mehr in die Höhlung des inneren Zellsackes, sondern nur in die des äusseren, dessen einzelne Zellen nun uberall klein geworden sind und sich abgeplattet haben. Wollen wir uns nun die Form der ursprünglich den einfachen inneren Zellsack bildenden Zellschicht auf diesem Stadium einigermassen vergegenwärtigen, so können wir sagen, dieselbe habe die Gestalt eines Trichters, dessen oberer weiterer Theil seitlich stark zusammengedrückt worden ist, und dessen unterer dünner Theil so gebogen worden, dass er der einen schmalen Seite des zusammengedrückten Theiles dicht anliegt. Die untere Mündung des Trichters stellt dann die Afteröffnung dar, die Uebergangsstelle des weiteren Theiles des Trichters in den engeren die Mundöffnung, der enge Theil den Darm und der weite Theil die Anlage der Tentakelkrone sowie eines Theiles des Oesophagus. In Figur $25 B$ sehen wir die Abschnürung der Darmanlage vollendet. Einen Querschnitt einer Polypidknospe auf diesem Stadium der Entwicklung ist in Fig. 22 abgebildet. Innerhalb des äusseren Zellsackes $c$ liegt das Darmrohr $b$ mit seinem deutlichen Lumen $a$; dasselbe ist ganz geschlossen auch auf seiner Oberseite und die unteren Blätter der sich entgegenwachsenden seitlichen Falten des inneren Zellsackes $b$ sind bereits ganz verschmolzen, die oberen Blätter $b^{\prime}$ dagegen lassen noch eine Spalte erkennen, an ihren oberen freien Rändern zeigen die seitlichen Blätter des innern Zellsackes aber schon knopfartige Ausbuchtungen $t$ die Anlagen der Tentakeln. Diese entstehen wie eben angedeutet als Wucherungen der freien Ränder der oberen Spalte des inneren Zellsackes; man kann an ihnen sehr bald einen äusseren einschichtigen Zellbelag von einer inneren Füllungszellmasse unterscheiden. Die Längsachsen der Tentakelanlagen stehen senkrecht auf der Symmetrieebene der Knospe, die Tentakeln stehen also in zwei bilaterel symmetrisch angeordneten Reihen einander gegenüber, wie aus Fig. $2: 5 A$ und dem Querschnitte Fig. 22 deutlich zu ersehen.

Dass zunächst nur wenige Tentakeln sich anlegen und neue dann erst allmälig hinzutreten, wie Snitt und Claparède gesehen haben wollen, das habe ich nicht beobachten können. Ich sah stets, bein ersten Auftreten von Tentakelanlagen, 16, 17, oder 18 Stück gleichzeitig erscheinen, nur kann man dieselben bei Betrachtung der Knospe von oben in dem Stadium, wo sie sich anzulegen beginnen, nicht sämmtlich schen. Die Tentakelanlagen sind nämlich angeordnet, rings um den ganzen Rand, der durch die Spaltung des innern Zellsackes 
an seiner oberen und vorderen Fläche entsteht. Eine Linie, die den Mittelpunkt der Basen der sämmtlichen einzelnen Tentakeln verbindet, ist also nicht einfach zusammengedrückt hufeisen- oder U-förnig, sondern die anscheinend freien Enden des Ilufeisens krümmen sich aus der Fläche des Hufeisens nach unten und schliessen hier zusammen: die Anlagen der vordersten, am weitesten nach dem distalen Ende der Polypidknospe gelegenen Tentakelanlagen kommen also unter die weiter nach hinten $\mathrm{zu}$ entstehenden $\mathrm{zu}$ liegen und können von oben nicht gesehen werden. Die Tentakelanlagen $b$ auf Fig. 25, $B$ liegen nach unten von der Tentakelanlage $c$, und sind daher auf Fig. $25, A$ nicht zu sehen, weil eben die Tentakelanlagen $c$ sie verdecken.

Der äussere Zellsack hatte sich bis jetzt wenig verändert, nur war er ein wenig spitzer und grösser geworden und seine zelligen Bestandtheile hatten sich abgeplattet und verkleinert. Jetzt beginnt er sich faltenartig in die zwischen Anlage der Tentakelkerne und Darmtractus bestehende Spalte einzusenken, die Falten der beiden Seiten verschmelzen miteinander und der untere hierdurch röhrenartig ahgegliederte den Darmtractus umschliessende Theil des äusseren Zellsackes wird nun definitiv zum äusseren Epithelium des Darmtractus, während der Rest die Tentakelscheide allein bildet.

Die Mundöffnung liegt excentrisch in dem von dem oberen Theil der beiden Seitentheile des inneren Zellsackes gebildeten Trichter, dessen Rand von den Tentakelanlagen umgeben ist. Die vordersten am meisten distal gelegenen Tentakeln sind bedeutend weiter von der Mundöffnung entfernt, getrennt von ihr durch eine weite Fläche, auf dieser erhebt sich an dem distalen Rande der Mundöffnung ein querer Wulst (Fig. 26, $f$ ). Er bildet die Abgrenzung des Oesophagus gegen die Tentakelkrone und bildet sich, wie wir später sehen, zu einer Falte aus, deren Lumen einen Theil des Ringkanales bildet, in den die Höhlung der Tentakeln mündet. Morphologisch entspricht dieser quere Wulst vollkommen derjenigen Erhehung auf der intratentaculären Leibeswand von Pedicellina, welche Alluas als Epistom gedeutet hatte, und der Raum zwischen ihr und der Basis der am meisten distal gelegenen Tentakeln der intratentaculären Leibeswand selbst. Ueberhaupt gleicht eine Polypidknospe von Fl. membranacea auf diesem Stadium ganz ungemein einer Pedicellina, die bilateral-symmetrische Anordnung der Tentakeln, die intratentaculäre Fläche, der einfache Darmtractus ohne Blindsack sind Zilge, die wir bei ausgewachsenen Thieren nur bei den Entoprocta finden, und auf einem noch jüngern 
Stadium mündet ja sogar auch der Darm innerhalb des Randes desjenigen Gebildes, das sich zur Tentakelkrone entwickeln soll. 1)

Von dem Magen gliedert sich nun an seinem vorderen Ende ein dünnwandiger Theil zunächst der Afteröffnung ab und erscheint als Rectum (Taf. VI, Fig. 26 u. 27, R). Während dieser Vorgänge nimmt die ganze Polypidknospe an Grösse zu und der vordere dütenartige Theil der Tentakelscheide wächst nach vorn. Auch die Tentakeln wachsen in die Länge (Fig. 26 A). Die Spitzen der nach hinten und seitlich von der Mundöffnung gelegenen Tentakeln bleiben noch gegeneinander gerichtet, während die nach vorn von der Mundöffnung liegenden, ihre Längsachse bereits parallel der Symmetrieebene geordnet haben. Diese rücken nun allmälig an die Mundöffnung und den letztere am analen Rande abgrenzenden Wulst heran, das Homologon ter intratentaculiren Leibeswand bei Pedicellina verschwindet, und allm:ilig verliert die Tentakelkrone ihre zusammengedrückte Gestalt und weitet sich zu einem rundlichen Becher aus, dessen Wandungen von den Tentakeln gebildet werden, welche immer länger wachsen und ihre Lingsachsen, die zum Theil bis jetzt senkrecht auf der Symmetriebene der Knospe gestanden hatten, parallel mit derselben richten (Taf. VI, Fig. 27, B).

Bis zu dem in Fig. 25 abgebildeten Stadium lag die Polypidknospe dicht an der Hinterwand des Zoöcium an, von da an beginne sie allmälig in der Symmetrieebene des Zoöcium vorzurücken. Ihr Hinterrand entfernt sich also von der Ilinterwand des Zoöcium und es werden (in Theil der Zellen der Endocyste (und zwar wie ich vermuthe ihrer Spindelzelllage), welche der hinteren Seite der Polypidknospe anhingen, ausgezogen zu spindelförmigen Fasem mit deutlichen in der Milte jeder Faser erkennbaren Kernen. Dies ist die Anlage des grossen Retractors (Taf. VI, Fig. 26 und $27, m$; Taf. V, Fig. 6, $m$ ).

Die Tentakelscheide wichst, je mehr die Polypidknospe in dem Zoöcium vorrückt, immer weiter nach vorn, bis sie die Stelle erreicht hat, wo sie später durch die Mündung mit der Aussenwelt in Verbin-

1) Man ist gewölınlich geneigt, die hufeisenförmige Anordnung der Phylactolaemententakeln als ein Zeichen der höheren Ausbildung dieser Bryozoenabtheilung anzusehen. Die Art und Weise, wie die Tentakelkrone sich bei unserem Thier entwickelt, lässt diese Anschauung als etwas weniger berechtigt erscheinen. Die definitive Anordnung der Tentakeln bei den Phylactolaemen ähnelt vielmehr der Anordnungsweise der Tentakeln der Chilostomen in einem Jugendzustande. In dem auf Taf. VI, Fig. 25, $B$ abgebildeten Stadium kann man die Tentakeln auffassen als seordnet in einer geschlossenen einmal nach innen eingebogenen Linie innerhall deren excentrisch der Mund liegt. 
dung treten soll. - Hier verbreitert sie sich dann und geht in die Substanz der Endocyste ïber (Taf. V, Fig. 6, Tsch).

Ist das Wachsthum der Polypidknospe ohngefähr bis zu dem Stadium gelangt, welches auf Taf. VI, Fig. 24 abgebildet ist, so haben ihre Dimensionen so zugenommen, dass nun die grosse Curvatur des Darmtractus an die Endocyste der Unterfläche des Zoöcium zu liegen kommt, und es beginnt dort, wo das äussere Epithel des Magens die Spindelzellschicht der Endocyste berührt, eine Verwachsung dieser beiden Schichten. Rüekt nun das Polypid weiter vor, so wird ein Theil der Spindelzellschicht, der zunächst mit dem Magen verwachsen ist, von der Epithelzelllage der Endocyste abgehoben, bleibt aber an seinen Rändern durch Ausläufer noch mit dem übrigen Theil der Spindelzellschicht in Verbindung. Es ist dies die Anlage der Funicularplatte.

Alle Theile des Polypids sind nun so ziemlich angelegt und erhalten durch ein einfaches weiteres Wachsthum ihre definitive oben beschriebene Gestalt (Taf. V, Fig. 7 u. 8).

Die Längsachsen der Tentakeln lagern sich nun parallel der Längsachse des Zoöcium und die endliche Differenzirung des eigentlichen Magens in einen Pylor- und Cardialtheil nebst Blindsack, erfolgt durch das Auftreten des letzteren als einer zunächst kleinen, dann aber immer mehr sich streckenden Aussackung des mittleren Theiles des Magens, welche sich bald seitlich von der Symmetrieebene des Zoöcium lagert Fig. 7 u. 8, st).

Es bleibt noch übrig zu besprechen die Entstehung der Parietalmuskeln, der Parietovaginalmuskeln, der Parietovaginalbänder und des Deckelapparates.

Die Parietalmuskeln treten verhältnissmässig ziemlich spät auf. Erst wenn ein Zoöcium ohngefähr das auf Taf. II, Fig. 8 dargestellte Stadium erreicht hat, sehen wir sie plötzlich vorhanden, ohne dass es gelungen wäre, ihre allmälige Bildung Schritt für Schritt zu verfolgen. Anfangs sind sie weit zarter als später, zeigen aber stets einen deutlichen Kern.

leh bin geneigt sie zu betrachten als entstanden aus Elementen der Spindelzellschicht der Endocyste, welche sich selbstständig entwickelt und an ihrem mittleren Theile von der Endocyste abgehoben haben, während ihre Endpunkte in Verbindung mit derselben blieben. Nehmen wir an, dass ursprünglich das eiṇe Fnde der eine Parietalmuskelfaser bildenden Spindelzelle an der Endocyste der Oberseite des Zoöcium lag, das andere aber in der Endocyste einer Seitenfläche, so würden wir durch einen Vorgang, wie ich ihn so eben andeutete, wirklich Muskelfasern erhalten, welche von Wand zu Wand verlaufend, 
den Hohlraum des Zoöcium quer durchsetzen. Aehnlich denke ich mir die Entstehung der Parietoraginalmuskeln und der Parietovagialbănder. Letztere erscheinen schon auf einer früheren Stufe der Entwicklung als schmale bandartige, aus spindelförmigen Elementen bestehende Ausläufer der Tentakelscheide (Taf. V, Fig. 7 u. $8, \operatorname{lp} v)$.

Der Deckel a ppara t beginnt sich zu bilden, wenn die Tentakelscheide, welche entsprechend der in ibr vorgehenden Ausbildung der Tentakeln sich zu einem geräumigen Sacke ausgeweitet hat, mit ihrem Vorderende bis zu ihrer definitiven Ansatzstelle vorgerückt ist. Der vordere Theil der Tentakelscheide erscheint alsdann als eine solide, flach ausgebreitete, mehrschichtige Zellmasse (Taf. V, Fig. $7, x^{\prime}$ ), deren vorderer Rand von einer in der Substanz der Cuticula sich zeigenden feinen halbmondförmigen Linie begrenzt wird. Sie setzt sich durch einen scharfen Rand $x^{\prime \prime}$ gegen den hohlen Theil der Tentakelscheide ab. An den Enden der verdickten Linie op zeigen sich stärkere Zellensammlungen $x$, an welche sich die nun plötzlich auftretenden Deckelmuskeln ansetzen. Ich glaube mir nun die Bildungsweise der Mündung, so vorstellen zu dürfen, dass dieselbe entstehe durch eine horizontale Spaltung des mittleren Theiles der compacten Zellmasse und eine Resorption der Substanz der Cuticula längs der halbmondförmigen Linie $O p$. Hierdurch bildet sich eine horizontal liegende Einstülpung der Wandung des Zoöcium, welche durch einen unterhalb des Deckels liegenden Spalt von aussen zugänglich ist. Die zelligen Wandungen dieser Einstülpung secerniren eine ungemein feine Cuticula, welche bald an den Rändern der Spalte in Verbindung tritt mit der Cuticula der Oberseite des Zoöcium. Die Wände dieser Einstülpung liegen vorläufig noch dicht auf einander und ihr Hohlraum ist auf diesem Stadium noch durch eine Scheidewand $\left(x^{\prime \prime}\right)$ getrennt von der Höhlung der Tentakelscheide. Die Zellensammlungen $x$ stellen dar die Matrix für die beiden an den Enden der verdickten Linie $O p$ auftretenden Einstülpungen der Ectocyste, welche die nach innen in das Lumen des Zoöcium vorspringenden Enden des Deckelapparales bilden. Bei weiterer Vergrösserung der Tentakelscheide schwindet die Scheidewand $x^{\prime \prime}$ zum Theil und der Rand der so entstandenen Oeffnung wulstet sich zum Diaphragmakegel auf.

Dass der Durchbruch der Mündung wirklich in der eben beschriebenen Weise vor sich geht, davon habe ich mich im Detail allerdings nicht bei Fl. membranacea, sondern bei einer anderen hierzu geeigneteren Bryozoe, bei Alcyonidium hispidum überzeugt.

Ueber die Art und Weise, wie die einzelnen Zellen der ursprïng- 
lich in allen ihren Theilen gleichmässig gebildeten inneren Zellschicht der Polypidknospe zu den so different gestalteten Epithel- und Wimperepithelzellen der Tentakeln und des Darmtractus sich ausbilden, darüber kann ich keine näheren Angaben machen. Die homogene Lamelle, welche die Stütze der Wandungen der Tentakeln und des Darmtractus bildet, betrachte ich als eine Art Sekret, entstanden zwischen den beiden ursprünglichen Zellschichten der Polypidknospe.

Die eben gegebene Darstellung der Entstehung des Polypids in dem Zoöcium stimmt in den allgemeinen morphologisehen Zügen ziemlich genau überein mit der Surтt'schen Schilderung dieser Vorgänge ${ }^{1}$ ), so wie auch mit Ciaparéde's ${ }^{2}$ ) Darstellung desselben Vorganges bei Serupocellaria und Bugula. lch kann aber nicht mit CAPARède die Tentakelscheide als eine einfache Einstülpung der Endocyste des Zoöcium nach innen und die Anlage der Polypidknospe als eine einfache Blase auffassen. Es ist dieselbe, sowie sie zur Blase wird, eine zweischichlige Blase und die Tentakelscheide tritt erst sehr spät in Verbindung mit dem Theil der Endocyste des Zoöcium als dessen Einstülpung nach innen sie beim ausgebildeten Thiere erscheint.

Das Polypid, dessen Entwicklung innerhalb des Zoöcium wir eben verfolgt haben, ist aber kein dauernder Insasse desselben, dessen Lebensdauer übereinstimmt mit der Lebensdauer des Zoöeium. Wir linden über den ganzen Stock kleinere Gruppen fertig ausgebildeter Zoöcien zerstreut, welche ihre Polypide verloren haben und anstatt derselben nur die sogenannten »dunklen oder braunen Körper « verschiedener englischer Autoren, die »Keimkapseln « Surt t's entbalten. Diese Thatsache ist für eine grosse Anzahl von Chilostomen und Ctenostomen lïngst bekannt. Guaparène bemerkt sehr richtig, dass aber die Zoöcien, welche keine Polypide mehr enthalten, durchaus nicht abgestorben seien, das beweist schon der Umstand, dass sie, wie wir gleich sehen werden, durch eine neue Knospung ihrer Endocyste ein neues Polypid in sich erzeugen können. A bgestorben sind dagegen die ursprünglich in ihnen, als sie noch Knospen waren, gebildeten Polypide, nicht resorbirt. Surt hat den Vorgang des Absterbens der Polypide völlig richtig erkannt und auch abgebildet, leider ist seine Beschreibung des Vorgangs aber zu kurz und namentlich seine Abbildungen zu klein gewesen, als dass sie einen völlig überzeugenden Eindruck gemacht hätten. Ich will daher ein wenig näher auf die Sache èngehen.

Das Zoöcium $A$ auf Taf. V, Fig. 1 enthält ein völlig normal gebil-

1) Öfver's. af k. Vet. Akad. Förhandl. 1865. No. 1.

2) Zeitsch: f. wiss. Zool. Vol. XXI. p. 114 u. ff. 
detes Polypid, auf der Höhe seiner Entwicklung. Das Zoöcium B zeigt dagegen ein Polypid, an welchem sich bereits die ersten Spuren des künftigen Zerfalls zeigen; dasselbe ist ganz ungewöhnlich tief in sein Zoöcium zurückgezogen, dies Oesophagus berührt die Hinterwand des Zoöcium und die grossen Retractorenfasern sind zu ganz kurzen und dicken Fasern zusammengeschrumpft. Die Seitenstränge sind theilweise zerstört und die Zellpfropfen der Rosettenplatten haben sich an einigen Stellen nach innen mit einer homogenen Lamelle bekleidet und sich so als gesonderte Polster abgeschlossen $(r s p l)$.

Das Zoöcium $C$ zeigt den Zerfall des Polypids bereits viel weiter fortgeschritten. Die Tentakelkrone ist hier vollkommen verschwunden, desgleichen der Oesophagus, die Tentakelscheide erscheint nur noch als ein strangartiger Anhang eines zweigelappten Sackes, dessen linker Lappen, wie man leicht erkennt, dem Cardialtheile, der rechte Lappen hingegen dem Blindsacke des Magens entspricht. Derselbe wird begrenzt von einer festen homogenen Membran, welche ich als aus der homogenen Stützlamelle dnrch Verdickung entstanden betrachte, und enthält die in der Auflösung begriffenen Reste der Zellauskleidung des Magens, sammt den in ihnen enthaltenen braunen Pigınenten. Er wird festgehalten an einer bestimmten Stelle des Zoöcium durch die Funicularplatte, welche durchaus nicht der Auflösung anheim gefallen ist, sondern sich vielmehr weiter ausgebildet und verzweigt zu haben scheint.

In dem Zoöcium $D$ ist das Polypid zusammengeschrumpft zu einem von einer festen (chitinösen?) Hülle umgebenen Körper, der als letzte Spur seiner frühern Bildung eine schwache ${ }^{\circ} \mathrm{Zweilappung}$ zeigt. Sein Inhalt besteht aus einer feinkörnigen, unorganisirten. Nasse. Zwischen der Form, welche der » braune Körper « in dem Zoöcium $C$ zeigt bis zu dem in dem Zoöcium $D$ kann man in den polypidlosen Zoöcien eines Stockes alle möglichen Uebergänge und Variationen finden (Taf. N, Fig. 2, 3, 4, a). Auf Taf. V, Fig. 10 ist ein solcher körper stärker vergrössert abgebildet. Wir sehen in seinem Inneren eine merkwürdige Zeichnung, die an die Zeichnung einer Diatomeenschale erinnert, und wirklich ist es auch eine. Ich habe mich auf das evidenteste uberzeugt, dass die meisten »dunklen Körper « bei unserer Species Reste der zuletzt von den Polypiden aufgenommenen Nahrung enthalten. Ich habe nicht nur Diatomeenschalen, sondern auch Radiolariengerüste, Nesselkapseln, Spongiennadeln u. s. w. in ihnen gefunden. Dieser letztere Umstand beweist klar und deutlich, dass wir es hier wirklich in den "braunen Körpern " mit einem Producte des Zerfalls der Polypide zu thun haben. Ich kann also für unsere Species die 
Ansicht Glaparìde's, die braunen Körper seien "Ansammlungen eines Secrets, die sich mit einer feinen Membran umgeben ", nicht theilen, und glaube auch nicht, dass dieselbe sich für andere Species als richtig erweisen wird. Dagegen kann ich mit Claparède auf das völligste ubereinstimmen in seiner Verwerfung der Surts'schen Ansicht, die braunen Körper seien "groddkapslar ", " Keimkapseln " aus denen bei manchen Species die jungen Polypidknospen entständen, welche man so häufig zugleich mit den braunen Körpern in den völlig ausgebildeten Zoöcien trifft, bei anderen dagegen sogar Eier. Die Glaparéde'sche Widerlegung und Kritik der Surt'schen Keinkapsel-Theorie 1) ist so ausführlich, dass ich auf eine solche mich hier nicht einzulassen brauche, und sollte ja noch ein Zweifel erhoben werden können gegen die Kraft der.Claparène'schen Argumente, so muss der Umstand, dass bei Fl. membranacea in sehr viclen Fällen fremde kieselige oder kalkige Körper in diesen » Keimkapseln « liegen, diesen Zweifel gründlich beseitigen.

Die » Keimkapseln « oder »braunen Körper" entstehen bei Fl. membranacea durch den Zerfall der Polypide und eine Art Encystirung des grösseren Theiles der Zerfallsproducte.

Die Zoöcien verlieren also zu Zeiten die anfänglich von ihnen durch Knospung erzeugten Polypide, und es treten alsdann in ihnen Gebilde auf, die man bis vor kurzem allgemein als Polypidknospen ansah, als die Anlage eines neuen Polypides, welches in dem leergewordenen Zoöcium die Stelle des ursprünglichen Polypides einnehmen sollte.

Wie entstehen nun diese jungen nouen Polypidknospen? Sмrт nimmt an, wie sich schon aus dem Ebengesagten ergiebt, dieselben entstünden aus den Keimkapseln. Diese Ansicht ist von Claparède widerlegt worden, merkwürdiger Weise erklärt aber dieser so genaue Forscher das Vorhandensein dieser neuen jungen Polypidknospen auf eine Art und Weise, welche meiner Ansicht nach ebensowenig eine Bestätigung finden kann, als die von ibm beseitigte Surt'sche Theorie, zum wenigsten kann ich für Fl. membranacea (und für Alcyonidium hispidum) diese Ansicht nicht theilen.

Glaparède glaubt nämlich - im Anschluss an seine Annahme die "braunen Körper " seien" ein Secret - diejenigen Gebilde, welche Grant, Farre und Suitr für junge Polypidknospen gehalten haben, seien die Producte der regressiven Metamorphose der ursprünglich in den Zoöcien enthalten gewesenen Polypide. Seiner Meinung nach wurden die genannten Forscher wdadurch irre geleitet, dass der sich

1) Zeitschr. f. wiss. Zool. XXI. p. 147. 
rückbildende Nahrungsschlauch die gleichen Stadien durchläuft wie eine neu sich bildende Endknospe (resp. deren Polypid) nur in entgegengesetzter Reihenfolge «. Schon aus theoretischen Gründen scheint mir diese Ansicht wenig für sich zu haben. Ein Beispiel, dass irgend ein Organismus, sei er nun ein ganzes Individuum oder nur ein Organ, ladurch untergeht, dass er, nachdem er den Höhepunkt seiner Ausbildung nach Durchlaufung einer Reihe von Entwicklungsstadien crlangt hat, nun wieder umkehrt und diese EntwickJungstadien in umgekehrter Ordnung durchläuft, ist meines Wissens im ganzen Bereiche der organischen Welt nicht vorhanden.

Es ist wahr, dass man bei manchen Bryozoen nur sehr selten den Polypid im Zerfall begriffen findet, während man sehr häufig junge Knospen und braune Körper findet, dies kann für mich aber nur beweisen, dass der Vorgang des Zerfalls der Polypiden bei diesen Species sehr schnell vor sich geht, nicht, dass er nicht stattfindet. Für Fl. membranacea habe ich aber alle möglichen Stadien des wirklichen Zerfalles der Polypiden und seine Verwandlung in einen braunen Körper beobachtet. Bei Alcyonidium hispidum endlich ist das wirkliche Verhältniss noch viel klarer. Hier verlieren die einzelnen Zoöcien ebenfalls ihre Polypide sehr häufig durch Zerfall, lange aber ehe die Polypide ihre charakteristische Form verloren haben und zu »braunen Körpern " geworden sind, beginnt die Endocyste der Oberseite der Zoöcien durch Knospung nach innen ein neues Polypid zu erzeugen. In ein und demselben Zoöcium finden wir sehr häufig ein im Zerfall begriffenes Polypid, das aber noch seine ursprüngliche Natur deutlich erkennen lässt, zusammen mit einer jungen neuen Knospe, welche sich durch nichts unterscheidet von den Polypidknospen in den Zoöcienknospen am Rande des Stockes. Hier wird also das neue Polypid genau so wie das alte durch eine Knospung der Endocyste des Zoöcium nach innen erzeugt, und ganz dasselbe Yerhältniss finden wir auch bei unserer Species, bei Fl. membranacea.

Nur in einem Punkte ist das Auftreten der zweiten Polypidknospe bei dieser Species verschieden von dem Auftreten der ersten in der Zoöcienknospe. Während nämlich die erste Polypidknospe auftritt in dem Winkel, den die Hinterwand der Knospe nit ihrer Oberwand bildet, entsteht die zweite in dem fertigen Zoöcium in der Mitte der Oberwand. Nun liegt in vielen Fällen auch der durch den Zerfall des Darmcanales entstandene braune Körper in der Mitte des Zoöcium, dadurch kommen junge Knospen und "brauner Körper « oft in nahe Berührung. Diese nahe Berührung ist aber eine durchaus accidentelle und weist durchaus nicht auf eine Beziehung zwischen den beiden Gebilden hin. Auf 
Taf. V, Fig. 2-5 sind 4 völlig ausgebildete typische Zoöcien abgebildet, welche ihre Polypide verloren haben und nun im Begriff sind, ein neues zu knospen $(k n)$. Die Knospe liegt, wie schon gesagt, bei allen diesen ziemlich in der Mitte der Oberseite in grösserer oder geringerer Nähe des braunen Körpers. Die Polypidknospe in der Figur 2 erscheint als ein einfacher Zellhaufen, an dem sich die iusseren Zellen eben zu einer zusammenhängenden Schicht zu ordnen beginnen, in Figur 3 hat sich bereits der innere und der :iussere Zellsack gebildet. In Figur 4 zeigt die Knospe bereits Tentakeln und Tentakelscheide (Tsch), während der braune Körper $(a)$ noch sehr gross ist und auch die grossen Retractoren $(m)$ des früheren Polypides noch deutlich erkennbar sind, und in Fig. 5 ist das junge Polypid bereits in allen seinen wesentlichen Zugen entwickelt und die Tentakelscheide ist in Verbindung getreten mit der früheren Mündung. Das letztere scheint übrigens nicht immer der Fall zu sein. In Fig. 4 scheint sich bei op' ein neuer Deckelapparat, eine neue Mündung zu entwickeln für das junge Polŷpid. Diese Neubildung des Deckelapparates habe ich übrigens nur einmal, eben an dem abgebildeten Zoöcium beobachtet. Beiläufig sei hier noch bemerkt, dass das Auftreten eines Deckelapparates an der Zoöciumknospe nicht eine Funetion - im mathematischen Sinne - des Auftretens des Polypides in dem Zoöcium zu sein scheint. Ich habe einmal ein Zoöcium gefunden, welches kein Polypid und keinen "braunen Körper " enthielt, überhaupt derartig abortirt war, dass es kaum wahrscheinlich erscheint, es habe je ein Polypid besessen, welches aber einen rudimentären Deckel besass. Derselbe erschien als eine an der Stelle, wo sonst der Deckel sich befindet, erscheinende ungemein kurze, quere, etwas gebogene Verdickung der Ectocyste, von deren Enden einige wenige Muskelfäden entsprangen und sich an der Leibeswand jederseits ansetzten. -

Ich muss also festhatten

1) dass die ausgewachsenen Polypide von Fl. membranacea häufig durch wirklichen Zerfall, - nicht durch Resorption - zu Grunde gehen, ohne dass dadurch die Lebensthätigkeit ihrer Zoöcien beeinträchtigt würde;

2) dass die sogenannten »braunen Körper « oder "Keimkapseln « die Producte des Zerfalls der Polypide, kein Secret der Endocyste, sind;

3) dass die "braunen Körper " nichts zu thun haben mit dem Auftreten derjenigen Gehilde in Innern des Zoücium, welche Surrt und die alteren Forscher als neue kleine Polypidknospen, Claparide dagegen als Producte der regressiven Metamorphose des Polypids ansieht; 
4) dass die fragliehen Gebilde wirklich neue kleine Polypidknospen sind, welche als nicht aus den » Keimkapseln « herrühren, sondern dureh eine Knospung der Zoöeienendoeyste nach innen auf dieselbe Weise entstanden sind, wie die ursprünglich in diesen Zoöeien vorhanden gewesenen Polypide.

\section{Erklärung der Abbildangen.}

\section{Flustra membranacea (Lin. Sol.).}

\section{Tafel TV.}

Fig. 1 u. 2. 145/1. Halbschematische Abbildung eines der Symmetrieebene halbirten Zoöcium mit seinem Polypid in Fig. 1 mit hervorgestulpter; Fig. 2 mit eingezogener Tentakelkrone. Ec. Ectocyste. En. Eindocyste. Sp. Stacliel. Op. Deckelfalte. T. Tentakeln. Tsch. Tentakelscheide. N. Gangliou. Oes. Oesophagus. W. Bewimperte vordere Zone desselben. C. Cardialtheil des Magens. St. Eigentlicher Magen. St $t^{1}$. Blindsack des Magens. $P$. Pylortheil des Magens. $R$. Rectum, $R^{1}$. Letzter Abschnitt des Rectums. RM. Grosser Retractor. Md. Mündung des Zoöcium. pvm. Parietovaginalmuskeln. lig. $p v$. Parietovaginalbänder. $p m$. Parietalmuskeln. opm. Deckelmuskeln. d. Vorderes Diaphragma der Tentakelscheide. $F l$. Seitenstränge. $x$. Funicularplatte (Colonialnervensystem der übrigen Autoren). rspl. Rosettenplatten.

Fig. 3. 22/1. Ein junger Stock; die beiden primären Zoöcien sind durch einen rothen Punkt, die sterilen Zoöcien durch rothe Kreuze bezeichnet; die punktirten rothen Linien deuten die Reilıenfolge an, in der die einzelnen Zoöcien aus den primären und aus einander entstanden sind.

Fig. 4. 22/1. Ein Stück eines älteren Stockes. $c$ u. $f$ Thurmzoöcien.

Fig. 5. $22 / 1$. Ein Stück des in starken Wachsthum begriffenen Randes eines Stockes; der Rand wird von Grossknospen gebildet.

Fig. 6. 22/1. Ein Stück des Randes eines Stockes, der sein Wachsthum eingestellt hat.

Fig. 7. Ein Thurmzoöcium. A. von der Seite gesehen; B. seine Umrisse von oben.

Fig. 8. 22/1. 2 primäre Zoöcien von oben gesehen; die punktirten Kreise deuten die von ihnen ausgehenden Knospen an.

\section{Tafel V.}

Fig. 1. 100/1. Eine Gruppe von 4 Zoöcien, von unten gesehen. In dem Zoöcium $A$ ist das Polypid auf dem Höhenpunkte seiner Entwicklung. Die Buchstaben haben dieselbe Bedeutung wie bei Fig. 1 auf Taf. I. $m$. Sphincter 
der Tentakelscheide; $n$. Längszeichnung des Oesophagus, ausgehend von dem Ganglion $N$. Im Zoöcium $B$ ist der Polypid ungewöhnlich weit zuriickgezogen und beginnt abzusterben. $m^{1}$. Längsmuskeln der Tentakelscheide, welche in die Parietovaginalmuskeln übertreten. Im Zoöcium $C$ hat sich das Polypid in einen grossen wbraunen Körper" verwandelt $\{a\}$. Im Zoöcium $D$ ist derselbe zu einem kleinen Ḱlumpen zusammengeschrumpft.

Fig. 2. 100/1. Ein völlig erwachsenes Zoöcium, welches scin Polypid verloren hat und dureh Knospung seincr Endocyste nach innen ein neues zu erzeugen beginnt. Kn. Junge Zoöcienknospe. Op. Deckel. Das Ganze von oben gesehen.

Fig. 3. 100/1. Ein ähnliches Zoöcium von unten geschen. Kn. Weiter vorgeschrittene neue Polypidknospe. a. "Brauner Körper"*.

Fig. 4. 100/1. Ein ähnliches Zoöcium von oben gesehen. Die neue Polypidknospe $k n$ ist noch weiter vorgeschritten. $O p^{1}$. Zweiter, sich neu bildender Deckel. $y$. Zwei kleine warzenartige Auftreibungen der Ectocyste. $k$. Körnerhaufen der Endocyste. $x$. Leistenartige Verdickung der Ectocyste, bezeichnend die Ansatzlinie der Parietalnuskeln.

Fig. 5. 100/1. Ein ähıliches Zoöcium von unten geschen. Polypidknospe noch weiter entwickelt.

Figg. 6. 7. 8. 100/1. 3 junge Cystidknospen mit Polypidknospen. Fig. 6 zeigt die jüngste, Fig. 8 die älteste. $s p$. Stachel. $m$. Grosse Retractoren. st. Blindsack des Magens. Op. Anlage des Randes der Deckelfalte. $x$. Matrix der in das Zoöcium vorspringenden Ecken der Deckelfalte. $x^{1}$. Verdickung der Endocyste, in welcher sich die Zoöcienmündung anlegt. $x^{2}$. Grenze derselben gegen die Höhlung der Tentakelscheide. opm. Deckelmuskeln. lig. pv. Parietovaginalbänder.

Fig. 9. 100/1. Ein ausgewachsenes Zoöcium von unten gesehen, das Polypid ist hervorgestreckt, so dass man innerhalb des Zoöcium nur Magen und Rectum erblickt. rspl. Rosettenplatten mit ibren Zellpfröpfchen. $f l$. Seitenstränge. $f p l$. Funicularplatte, $a$. Längsstränge der Spindelzellschicht der Unterfläche der Endocyste.

Fig. 10. 200/1. Ein brauner Körper, in dessen Inneren Reste der zuletzt von dem Polypid verschluckten Nahrung sich vorfinden.

Fig. 11. 145/1. Verdickter Theil der Deckelfalte Uer Ectocyste (Deckel).

Fig. 12. $57 / 1$. Ein junges Zoöcium, an dessen vorderem Rande sich eine Kinospe durch die Falte abschnüıt.

\section{Tafel VI.}

Die Erklärung der Bedeutung der einzelnen Buchstaben findet sich im Text.

rig. 1. 200/1. Vordertheil des Oesophagus und Basaltheil der Tentakelkrone mit Nervencentrum $(N)$ von Flustra foliacea.

Fig. 2. 200/1. Ausgewachsener, aber noch nicht verkalkter Stachel.

Fig. 3. $57 / 1$. Halbschematische Darstellung des Kalkskeletts eines normalen Zoöcium nebst einem Theile der Skelette von 4 anliegenden Zoöcien.

Fig. 4. 570/1. Eine Rosettenplatte. 
Fig. 5. 100/1. Querschnith dureh den vorderen Theil einer Grossknospe.

Fig. 6. 570/1- Körnerhaufen der Endocyste.

Fig. 7. 570/1. Zellen des inneren Epitheliums des Pylortheiles des Magens.

Fig. 8. 570/1. Desgleichen aus dem Cardialtheile des Magens.

Fig. 9. 145/1. Querschnitt durch den Oesophagus.

Fig. 10. 1800/1. Querschnitt eines Tentakels.

Fig. 11. 1800/1. Ein Stiick einer quergestreiften Muskelfaser des grossen Retractors mit Kern.

Fig. 12. 570/1. Ein Stück Funicularplatte.

Fig. 13. 570/1. Zellschicht der Endocyste am hinteren Theile einer Grossknospe.

Fig. 14. 570/1. Desgleichen am vordersten Theile.

Fig. 15. 570/1. Querschnitt der Leibeswand eines Zoöcium am mittleren Theile einer Grossknospe parallel ihrer Längsachse.

Fig. 16. 570/1. Nelzförmige Endocyste einer älteren Knospe.

Fig. 17. 570/1. Endocyste der Unterseite einer älteren Cystidknospe von aussen gesehen.

Fig. 18. 570/1. Querschnitt dureh die Unterseite der Leibeswand einer älteren Knospe parallel ihrer Längsachse.

rigg. 19. 20. 570/1. 2 Stücke der Seitenstränge'.

liigg. 21. 22. 450/1. Querschnitte durch 2 Polypidknospen.

Figg. 23. 24. 25. 26. 27. 145/1. Entwicklung einer Polypidknospe. A. Ansicht von oben; $B$. Seitenansicht. 
IV.

Ueber die Morphologie der Bryozoen.

dont on trouvera l'exposé dans cet ouvrage, ne devront
être considérés que comme de simples opinions que je
propose, dans l'intention d'avertir de ce qui me paraît
être, et de ce qui pourrait effectivement avoir lien.e
Lamarck, Philosophie zoologique I. p. XX111.

Inr Grossen und Ganzen kamn man die augenblicklich hei den meisten Zoologen herrschende Ansicht über die Morphologie der Bryozoen und besonders der Bryozoa ectoprocta, von welchen letzteren hicr zunächst ausschliesslich die Rede sein soll, ausdrücken in dem Satze : "Die Bryozoen bilden Thierstöcke; die diese zusammensetzenden einzelnen Individuen sind in vielen Fällen polymòrph."

Noch vor kurzer Zeit würde diese Definition ganz im Allgemeinen für alle Bryozoen güllig gewesen sein, denn auch mehrere Arten der Bryozoa ectoprocta bilden Thierstöcke; die Untersuchungen von KEFERstein, Craparede und Kowalewsky haben uns aber belehrt, dass es in dieser Abtheilung auch Arten giebt, deren einzelne Individuen als solche leben und nicht zu Thierstöcken zusammentreten. Diese erzeugen zwar auch neue Individuen durch Knospung; diese Knospen bleiben aber nicht im Zusammenhange mit dem Mutterthiere, sondern fallen ab und führen nun getrennt ein selbstständiges Leben. Diese Arten fasst man jetzt in die Gattung Lox os o ma Keferst. zusammen und sieht gewöhnlich das Verhältniss, in dem diese Gattung zu den übrigen Bryozoen steht, als ähnlich an demjenigen, in welchem eine Süsswasser-Hydra zu einer beliebigen Campanularie steht.

Nur ein Forscher theilt augenblicklich diese Ansicht nicht; es ist HAECKEL. ${ }^{1}$ ) Dieser sielit die Bryozoen grösstentheils nicht als Thierstöcke, sondern als »Buschpersonen « an. Nur die sogenannten Bryozoa articulata betrachtet er als wirkliche Thierstöcke. Auch HAECKEL sieht selbstverständlich die Bryozoenstöcke als einen Complex von Einzelwesen an, welcher durch die Knospung eines primären, auf geschlechtlichem Wege erzeugten Einzelwesen entstanden sind, also mit Ehrenberg

1) HaEckel »generelle Morphologie". Vol. I. p. 324, 325, 328. 
zu reden als einen natülichen Stanmbaum; dagegen hält er dic Einzelwesen, welche diesen Stammbaum bilden und als welche er ansieht das einzelne Zoöcium samnt seinem Polypid nicht für äquivalent den Einzelwesen z. B. eines Campanularienstockes, er hält sie nur für Individuen vierter Ordnung, nicht für Individuen fünfter Ordnung, sieht daher den ganzen Bryozoenstock als ein einziges Individuum 5. Ordnung an, als eine »Person «. Ein ungegliederter Bryozoenstock ist also z. B. morphologisch gleichwerthig einer einzigen Annelide und die ihn zusammensetzenden Einzelwesen je einem Annelidensegmente. Bei einem gegliederten Bryozoenstocke dagegen sieht er schon jedes einzelne Astglied als ein Individuum : 3 . Ordnung, als eine »Person " an, der ganze Stock ist ihm daher ein wirklicher Thierstock, eine Corme. Diese HAEGKEL'sche Ansicht näher zu discutiren erscheint hier nicht möglich, da zugleich eine Kritik seiner ganzen Biontentheorie damit verbunden werden müsste. Indessen zeigt gerade der Umstand, dass er durch dieselbe genöthigt wird, den gegliederten Bryozoenstock in eine andere Individuenordnung zu stellen, als den ungegliederten, recht deutlich, wic künstlich das ganze Gebäude ist. Für unsere Zwecke ist es vollkommen gleichgültig, ob wir das Einzelwesen des Bryozoenstockes als ein Individuum 4. oder 5. Ordnung ansehen; es genügt uns, hier zu constatiren, dass НАвскеL zu denjenigen Forschern gehört, welche als Einzelwesen des Bryozoenstockes das Zoöcium als Polypid ansehen.

Die im Anfang charakterisirte herrschende Ansicht über die Morphologie der Bryozoen hat sich sehr langsam entwickelt, zugleich mit dem Begriffe des.Thierstockes und des Polymorphismus. Die einzelnen Phasen dieser Entwicklung sind ziemlich schwer zu verfolgen und zwar deshalb, weil die Bryozoen erst sehr spät als eine besondere Classe von den übrigen »Polypen " abgetrennt worden sind und ihr von den Schema der übrigen Thierstöcke mannigfach abweichender Bau, zumal bei der unvollkommenen Erkeuntniss Organisation der Einzelwesen, den ältern Forschern stets ein gewisses Räthsel geblieben ist.

Bekanntlich waren es hauptsächlich Pexsonel und Jussieu, welche die bis zu ihrer Zeit zu den Pflanzen gerechneten »Zoophyten " von diesen entfernten und ihre thierische Natur nachwiesen. Von dieser Zeit an finden wir drei verschiedene Ansichten uber die Morphologie des Zoophytenstockes: einmal (und zwar ist dies die verbreitetste Ansicht) werden die Zoophyten als wahre Thiere, als ein Complex thierischer Einzelindividuen angesehen und die sogenannten Polyparien, die festen Gerüste derselben als eine Art Schale, zu welchen die einzelnen Polypen in demselben Verhiltnisse stehen, wie die Mollusken zu ihren Schalen, also den damaligen Ansichten entsprechend, als Bewohner der 
Polyparien. Das Verhiluiss zwischen l'olyp und P'olyparium wird also als völlig gleich denjenigen aufgefasst, in welchem wir jetzt einen unbicolen Wurm zu seiner Röhre stehend uns denken. Die geschlechtliche Vermehrung wird bei dieser Auffassung von dem Wachsthum durch Knospung gar nicht scharf getrennt; man nimmt an, dass innerhalb des Stockes sich Knospen " gemmae " bilden, welche theils in der Substanz des Thierstockes liegen bleiben oder sich seiner Aussenfläche direct anlegen - dann vergrössert sich der Stock - oder sich von ihm trennen und nun neue Stöcke auf die erstere Art durch Erzeugung von mit ihnen in Zusammenhang bleibenden Knospen bilden.

Dieser Ansicht steht eine zweite gegenüber, die hauptsïchlich von Pallas und Linné vertreten wird. Diese wird gewöhnlich als cin Rückschritt angesehen. Die Zoophyten werden als ein Mittelding zwischen Thier und Pflanze betrachtet, nur die äussersten Enden der Aeste, die Polypenköpfe, sollen wirkliche Thicre sein, die Stämme dagegen Pflanzen, weil sie nach Art der Pflanzen wachsen. Die Art und Weise, in welcher diese berühmten Forscher ihre Auffassungsweise ausdrücken, ist unsern jetzigen Ansichten nach sicherlich eine höchst unglückliche, ich glaube jedoch, dass die Auffassungsweise selbst ein grosser Fortschritt war. PALlas besonders will dadurch sicher weiter Nichts ausdrücken, als dass man die Polyparien nicht ansehen darf als die blossen Wohnungen der Polypen, sondern als integrirende Leibestheile derselben. Er hat erkannt, dass das Wachsthum der Polypenstöcke ein anderes ist, als das der übrigen Thiere, dass sie wirklich knospen und, da man die Fähigkeit der Knospung damals lediglich den Pflanzen zuschrieb, so wird er naturgemässer Weise dahin geführt, die Polyparien als Pflanzen anzusehen. Dies tritt besonders an der folgenden Stelle ${ }^{1}$ ) hervor: "hanc meridiano sole clarioren, in plerisque zoophytis indolem (d. h. die in intermediäre Natur der Zoophyten zwischen Thier und Pflanzen) in eorum quibusdam non agnoscere nec Reaumurius nec sagacissimus Ellisius nequiverunt; sic cnim prior pro vegetante animali Tubulariam gelatinosam aquarum dulcium descripsit, et alter disserte dicit Sertularias non esse cellulas et domicilia, sed exuvias, cutem, zoophyti.«

Eine dritte, höchst eigenthümliche Ansicht ist die von Schweigger. Dieser sieht die Korallen und mit ihnen auch die Flustren, Cellularien. u. s. w. nicht als einen Complex von Einzelthieren an, sondern betrachtet den ganzen Stock als ein einziges Individuum mit vielen Mundöfnungen. 
Diese so sehr verschiedenen Ansichten uber die Natur der Thier. stöcke bestanden eine geraume Zeit neben einander und ziemlich langsam entwickelten sich die Ansichten über die Morphologie de: einzelnen Abtheilungen der Bryozoen, welche man noch nicht als cine Zusammengehörige Classe aufzufassen geneigl war, innerhalh, derselben.

Eigentlich sind es nur die grösseren, mil festeren Gerüsten versehenen marinen Formen, über deren Morphologie wir einige Andeudungen finden. Auch bei diesen Thieren wurden die Polypide stets als die eigentlichen Einzelthiere angesehen, welche in dem Stocke nur wohnen und mit ihren Wolnnungen in gar keiner oder doch nur schr loser Verbindung stehen. Basten und Jussiev wollten beide beobachte haben, dass die Polypide der Flustren ihre Gehäuse willkürlich verlassen. 1) Laun sok sagt (histoire naturelle des aninıaux sans vertèbres II, p. 73) in Betreff der "polypes à polypier", in welche Abtheilung (r) die meisten Bryozoen rechnet: "Le polypier est tout à fait distinet des animaux qu'il contient, comme le guêpier l'est des gućpes qui l'habitent." Ja derselbe Forscher ging noch viel weiter; er sagt uber dic Flustren 1. c. p. 154: „ll parait que les polypes de ces polypiers ne communiquent point les uns avec les autres, n'ont point de corps commun, distinct de celui des individus, et ne constituent point des animaux composés. " Seine Ansicht, wie er sich die Entstehung der netzartigen Flustrenstöcke denkt, finden wir 1. c. p. 156 : „On a observé sur les cellules des Flustres, de petites bulles (so bczeichnet der Verfasser offenbar die Ooecien) qui paraissent être les vésicules gemmifères de ces polypes. Ces bulles, après s'ètre détachées, tombent sans doute sur le plan de position à côté des autres cellules «; er sieht also die Flustren und überhaupt die krustenförmig ausgebreiteten Bryozoenstöcke als ein ganz zufälliges organisch nicht zusammenhängendes Aggregat von Einzelthieren (den Polypiden) mit ihren Schalen (den Zoöcien) an. Die Cristatellen, Alcyonellen, Serialarien und seine Cellarien (eine Anzahl von chilostomen und ctenostomen Bryozoen-Gattungen nebst einigen Hydroidpolypen umfassend) sieht er dagegen als wirklich zusammengesetzte Thiere an.

Die eben geschilderten morphologschen Auffassungen sind gänzlich incommensurabel mit unseren jetzigen wissen schaftlichen Ansichten.

1) Schon Grant vermuthet sehr richtig, dass diese Beobachtung so zu deuten ist, dass diese beiden Forscher, die an den Wänden der Gefässe aus den schwärmenden Larven der Flustren sich entwickelnden jungen Thiere für Polypide angesehen haben, welche ihre Zoöcien verlassen und sich dort festgesetzt haben. 
Grant 1) war es vorbehalten den Grund zu legen zu einer richtigeren Würdigung und der Morphologie dieser Thierclasse. Er fasst das Zoöcium als cinen integrirenden Theil des Bryozoenorganismus auf; er kennt die Zusammensetzung desselben aus einer weicheren inneren und einer härteren äusseren Schicht, nicht das Polypid allein fasst er als das eigentliche Thier auf, sondern betrachtet dasselbe nur als den Complex der Respirations- und Verdauungsorgane. Zoöcium + Polypid bildet für ihn das Einzelthier des Stockes, dessen Wachsthum durch Knospung er vollkommen richtig erkennt. Dieser Anschauungsweise, zu welcher sie ubrigens meist ziemlich selbstständig kommen, schliessen sich Farre ${ }^{2}$ ), Thompson ${ }^{3}$ ), Milne Edwards ${ }^{4}$ ) und Ehrenberg ${ }^{5}$ ) an; besonders die beiden letzteren vertreten diese Anschauung sehr scharf und ihnen nebst Tномpsov verdanken wir ja auch die Feststellung der Thatsache, dass die Bryozoen eine gesonderte Analöffnung besitzen, sowie die hierauf gegründete Abtrennung der Bryozoen als einer eigenen Classe. Zu dieser durch die eben erwähnten epochemachenden Arbeiten festgestellten Auffassungsweise bekannte sich 1851 auch Leuckart. Ibm, dem Schöpfer des Begriffes des Polymorphismus, verdanken wir aber die wiehtigste Erweiterung derselben, nämlich die Feststellung der Thatsache, dass die Avicularien und Vibracularien der Chilostomen als zum Zweek der Hervorbringung abweichender Leistungen abweichend entwickelte heteromorphe Individuen anzusehen sind, "gleichwerthig den übrigen Einzelwesen des Stockes. ${ }^{6}$ ) Diese Ansicht, ubrigens schon von var Benedex ${ }^{7}$ ), wenngleich undeutlich geahnt, wurde auch von Alexander Bracy in seiner Arbeit "das Individuum der Pflanzen in seinem Verhältniss zur Species « 1853. p. 86 anerkannt und vertheidigt, von Fritz Müru.er ${ }^{8}$ ) auf die Stammglieder der Vesiculariaden ausgedehnt und auch von Sмiтт ${ }^{9}$ ) angenommen und erweitert. Sie bildet einen integrirenden Theil unserer jetzigen morphologischen Auffassungsweise der Bryozoen. Die durch die eben erwähnten neue-

1) The Edinburgh New Philos. Journal. 1827. p. 407.

2) Philosophical Transactions 1837. p. 387.

3) Zoological Researches and Illustr. 1830.

4) Annales des Sc. naturelles 1836. p. 5.

5) Beiträge z. physiol. Kenntniss d. Corallenthiere im Allgem. u. bes. des rothen Meeres. 1834.

6) Ueber den Polymorphismus d. Individuen oder die Erscheinungen d. Arbeitstheilung i. d. Natur. 1851. p. 17.

7) Recherche sur l'anatomie la physiologie et le développement des bryozoaires qui habitent la côte d'Ostende. Mém. de l'Acd. de Belgique. XVIII. p. 22.

8) Troschel's Archiv f. Naturgesch. XXVI. 1860. p. 311.

9) Sмiтt Upsala Univ. Ârsskrift 1863. 
ren Forscher begrundete Anschauungsweise des Bryozoenstockes ist wohl diejenige, welche augenblicklich noch unter den Zoologen die grösste Anhängerzahl besitzt: „ihr zufolge ist - fassen wir sie kurz zusammen - der Bryozoenstock ein Complex von einzelnen Individuen, welche durch Knospung mehr oder weniger direct hervorgegangen sind aus einer auf geschlechtlichem Wege erzeugten frei schwimmenden Larve, welche sich festsetzte und in das primäre Einzelthier verwandelte. Als Einzelindividuum wird angesehen das Zoöcium und Polypid. Bei einzelnen Abtheilungen wird der Thierstock polymorph und das Einzelthier tritt in diesem Falle ansser seiner typischen Gestalt noch als Aricularium, Vibracularium, Ooecium, Stachel, Stammglied oder Wurzelfaser auf. Das Polypid des normalen Einzelthieres wird angesehen als der Complex der Respirations- und Verdauungsorgane. Auch kann eine unvollkommene Abgrenzung der Einzelindividuen gegen einander vorkommen (z. B. bei Lophopus). "-

Dieser Ansicht steht eine zweite entgegen, die neueren Ursprungs ist: Alzmax, der classische Monograph der Süsswasserbryozoen, ist ilır Vater. $\left.{ }^{1}\right)$

Der Grundgedanken dieser zweiten Ansicht ist der, dass der PoIynorphismus der Individuen nicht eine Eigenthümlichkeit einzelner Abtheilungen der Bryozoen sei, sondern allen ohne Ausnahme zukomme. Als Einzelthier des Stockes wird nicht aufgefasst Zoöcium + Polypid, sondern Zoöcium und Polypid werden jedes für sich als ein besonderes Individuum angesehen, das letztere als der durch Knospung entstandene Descendent des ersteren. Ax.lyan fasst diese Verbailinisse bei den Süsswasserbryozoen noch etwas complicirter auf: er sieht den frei schwimmenden, bewimperten Embryo als cin ungeschlechtliches Einzelthier an, welches durch linospung in seinem Innern ein anderes Einzelthier, das Polypid, erzeugt. Ob er dieses Letztere als ein geschlechtliches oder ein ungeschlechtliches Thier betrachten soll, daruber ist er nicht ganz mit sich im Reinen, denn er ist unentschieden, ob er den am vorderen Ende des Funiculus befindlichen Hoden als blosses Organ des Polypids - er betrachtet den Funiculus als zum Polypid gehörig - oder. als ein besonderes von dem Polypid durch Knospung erzeugtes Individuum betrachten soll. Entscheidet man sich für die erste Ansicht, so erscheint das Polypid als ein geschlechtliches und zwar männliches Individuum, nimmt man dagegen die letztere an, so ist das Polypid ein ungeschlechtliches, männliches Individuum, den Hoden knospendes geschlechtloses Individuum. Das Ovarium sieht er mit 
völliger Sicherheit als ein von dem aus dem frei schwimmenden Enıbryo entstandenen ungeschlechtlichen Individuum lurch Knospung erzeugtes geschlechlliches weibliches Individuum an. Wir haben also seiner Ansicht nach zwischen den folgenden beiden Auffassungen zu wihlen :

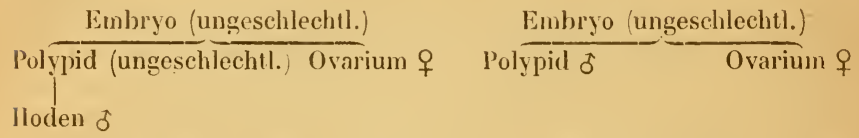

Beide Auffassungen stimmen darin überein, dass der Embryo, d. h. das primäre Zoöcium und überhaupt die Zoöcien resp. bei den Species mit verschmolzenen Zoöcien das Coenoecium und die durch Knospung an ihm entstandenen Polypide als Einzelthiere angesehen werden. Ein directer Beweis für die Berechtigung einer solchen Anschauungsweise wird übrigens nicht beigebracht und die ganze Entwicklung der Bryozoen als ein Generationswechsel betrachtet.

Dieser Ansicht schloss sich Leuckart bei Gelegenheit der Besprechung der Allyax'schen Monographie 1859 in seinem Jahresberichte ${ }^{1)}$ theilweise an, die oflenbar extremen Ansichten Allmax's mildernd. Er betrachtet nur das Polypid und das Zoöcium als besondere Individuen, sieht dagegen den Eierslock und den Hoden als blosse Organe an und vergleicht höchst treffend das Verhältniss von Polypid und Zoöcium mit dem, in welchem der Scolex und die Blase bei einem Cysticercus stehen.

Auch Sutr ${ }^{2}$, wenngleich mit einigen Reserven, ist nicht abgeneigt, der Allmas'schen Ansicht sich anzuschliessen.

Reichert in seiner neuesten Arbeit ${ }^{3}$ ) bringt ohne von den Bestrebungen seiner eben hier citirten Vorgänger Kenntniss zu haben oder wenigstens zu nehmen, dieselbe Theorie als etwas ganz Neues vor. Er sieht das Polypid (sein Bryozoid) ebenfalls als einen Descendenten des Zoöciums, (seiner Brutkapsel), an und vergleicht den Vorgang der Entstehung desselben innerhalb des Zoöciums mit der Entstehung der medusoiden Geschlechtthiere in den Brutkapseln der Campanularien. Einen eigentlichen Beweis für die Richtigkeit seiner Anschauung bringt er ebenfalls nicht und bemerkt nur, dass er zu dieser Annahme gedrängt würde durch die merkwürdige secundäre

1) Jahresbericht für 1857. p. 50 des Sep.-Abdr.

2) loeo citato.

3) Vergl. Anatom. Untersuchungen über Zoobotryon pellucidus (Еннвхв.) а.d. Abh. d. Kgl. Akad. d. Wiss. z. Berl. 1870. 
Art der Entstehung des Polypides innerhall des Zoöcium, welche in keiner Weise sich vergleichen lasse mit der Entstehung des Darmapparates bei irgend einem andern Thiere. In seinen Schlussbenerkungen erhalten wir einen kurzen Abriss seiner Auffassung des Bryozoenbaues überhaupt. Es ist aber ungemein zu bedauern, dass dieser eine Fülle der anregendsten Gedanken enthaltende Abschnitt so sehr schwer geniessbar wird durch die dunkle philosophische Ausdrucksweise des Verfassers.

lch glaube, Reichert's Auffassung der Bryozoen, wenn ich sie anders richtig verstanden habe, ungefähr folgendermassen darstellen zu können: Der Individuenstock der Bryozoen besteht aus einer Anzahl von einzelnen Individuen, welche einen sehr verschiedenen Entricklungsgrad zeigen und auf ungeschlechtlichem Wege durch Knospung entstanden sind.

Als die am höchsten entwickelte Form erscheint das Bryozoid (unser Polypid), welches durch "generatio gemmifera per intersusceptionem (Einschachtelung) « hervorgegangen ist aus der nächst niederen Individuenform der Brutkapsel (unserem Zoöcium), und welches auch durch seine histologische Zusammensetzung seine höhere Ausbildungsstufe kundgiebt. In ihm tritt nämlich ausser der "protozootischen" Substanz auch noch Epithelialgewebe auf. Die eben erwihnte niichst niedere Form, die Brutkapsel, zeigt nur noch protozootische Sibstanz, welche sich jedoch stellenweise zu contractilen Fasern (unsern Muskeln) ausbildet. Hier schliesst er die Avicularien und Vibracularien an und, offenbar als noch niederere Individuenform, die Stammglieder der Vesiculariaden, weil ihnen ja, die Muskeln fellen. Als unterste Ausbildungsstufe des Individuums betrachtet er die einfach aus "protozootischen Schliuchen« bestehenden Fortpflanzungsorgane. Alle diese verschiedenen Individuenformen sieht er als verschiedene Modificationen eines und desselben Grundplanes an. Die eigenthümliche Form des Bryozoenstockes wird dadurch hervorgebracht, dass Brutkapsel, Bryozoid und Fortpflanzungsindividuen, eventuell atch die Avicularien, zusammentreten zur Bildung des ssogenannten Bryozoenkopfes" (des Einzelthieres im Sinne der älteren Auffassung) und dass diese Einheit 2 ter Ordnung entweder direct durch ihre Aggregation den Bryozoenstock bildet (Brutkapselstock), oder sich dem andern "Hauptbestandtheile des Individuenstockes dem Bryozoenstamme gegenüberstellt und erst mit diesem zusammen den Bryozoenstock bildet (Stammstock).

Im Allgemeinen ist diese Auffassungsweise vollkommen mit der Allmax'schen übereinstimmend und die einzelnen Abweichungen der- 
selben werden dadurch hervorgebracht, dass Reichert seinen Betrachtungen eine Vesiculariade, einen "Stammstock", zu Grunde gelegt hat. Er betrachtet die Entwicklungsweise der Bryozoen aber nicht als einen Generationswechsel.

Meine eigene Ansicht ${ }^{1}$ ) über die Morphologie der Bryozoen schliesst sich eng an die Allyav-Reicuert'sche an, ungefähr mit denselben Reserven, welche Letckirt in seinem Jahresberichte gemacht. Ich habe miclı in keiner Weise überzeugen können, dass die Fortpflanzungsorgane der Bryozoen wirklich als gesonderte Individuen zu betrachten wären. Wenn man sieht, wie z. B. bei Membranipora pilosa der grösseste Theil des hinteren Hohlraumes des Zoöcium ausgefült ist mit Bildungszellen von Spermatozoen, welche der Endocyste mehr oder weniger fest anhaften, und sich bald überzeugt, dass diese Bildungszellen ursprünglich niemals ein genau begrenztes Ganze bilden, so kann man sich unmöglich entschliessen, dieses lockere Aggregat als das Homologon eines besonderen Individuums zu betrachten. Auch der Eierstock ist keine durch Wucherung der Endocyste entstandene Neubildung, wie das Polypid, die Eier scheinen mir vielmehr aufgefasst werden zu müssen als directe Umwandlungsproducte von Zellen der Endocyste. Wir haben hier genau dieselben Verhältnisse, wie bei vielen marinen Anneliden, bei welchen ja auch die Genitalproducte als metamorphosirte Elemente der Leibeswand erscheinen.

Dagegen sehe ich ebenfalls das Polypid als gesondertes Individuen an, welches durch knospung nach innen von einem andern Individuum, dem Zoöcium, erzeugl worden ist. Hierfür spricht, wie schon Reichert sehr richtig bemerkt, die Entstehungsweise desselben, deren ganze ligenthümlichkeit noch schärfer hervortritt in der von mir weiter oben gegebenen Darstellung der Knospung des Polypids bei Flustra membranacea. Indessen würde der blosse Umstand, dass die Entstehung eines Jarmes abweicht ron der aller übrigen Därme, noch nicht hinreichen, ım nachzuweisen, dass der hesagte Darm nun wirklich kein eigentlicher Darm ist. Auch der Unstand, dass es Zoöcien oder Homologa von solchen giebt, welche ohne Polypid dauernd existiren, reicht nicht lin, zu beweisen, dass das Polypid wirklich ein besonderes Individuum ist. Dieser Beweis wird meiner Ansicht nach vielmehr dadurch geliefert, dass auch in denjenigen Zoöcien, in welchen ursprünglich ein Polypid entstand, das letztere kein integrirender Bestandtheil des

1) Ich kann nicht umhin, an dieser Stelle auf das dankbarste anzuerkennen, wie ungemein viel die Durchsprechung meiner Ansichten mit Herm Prof. R. L.evcrart zur klärung derselben beizutragen hat. 
Organismus ist, dass das Zoöcium ganz gut ohne dasselbe bestehen kann, ja dass es bei den Chilostomen und Ctenostomen Regel zu sein scheint, dass die Polypide zeitweilig untergehen und durch neue, durch Knospung der Endocyste nach innen entstehende ersetzt werden.

Ein Beispiel, dass ein Thier den ganzen Complex seiner inneren Organe periodisch verliert und dann wieder ersetzt, kennen wir nicht. Zwar haben DaLyel (dessen Angaben ich übrigens nur aus dem von Brons in seinen "Glassen und Ordnungen des Thierreichs " Vol. 2, p. 399 gegebenen Resumé kenne) und Semper (wissenschaftl. Resultate etc. 1 Vol. Holothur. p. 201) gezeigt, dass die Holothurien ihren Darm, ihre Geschlechtsorgane etc. ausstossen und dann reproduciren können, dieser Fall ist aber gänzlich von dem unsrigen verschieden. Bei den Holothurien haben wir es mit einer Reproduction von Organen zu thun, welehe abgestossen worden sind in Folge einer Art pathologischen Processes, welcher eintritt, wenn die Thiere sich unter ungünstigen iussern Verhältnissen befinden oder injurïrt werden, bei den Bryozoen dagegen mit einem offenbar ziemlich regelmässig wiederkehrenden Untergehen des betreffenden Organencomplexes des Polypids und einer ebenso regelmässigen Neubildung desselben. Dasselbe wie für die Holothurien gilt auch für die von M' Itosn beobachtete Abstossung und Neubildung des Rüssels bei einigen Nemertinen, z. B. den Ommatopleiden (cf. Leuckart, Jahresber. f. 1868 u. 1869, p. 322 d. Arch.).

Jedes Einzelthier der früheren Auffassung besteht also meiner Ansicht nach aus zwei Individuen, dem Zoöcium und dem Polypid, welche aber nicht neben einander leben, sondern von denen das letztere in das erstere eingeschachtelt ist, wie der Cysticer'cus-Kopf in die CysticercusBlase. 1 )

REICHERT ist nun geneigt, „als Grunḋform aller aus dem Knospungsprocess hervorgehenden Elemente des Stockes einen einfachen, nach den specifischen Leistungen verschiedenartig gestalteten cylindrischen oder sphäroidischen Hohlkörper « zu betrachten. Dies ist sicher durchaus richtig und muss eigentlich schon a priori angenommen werden, da wir uns nicht denken können, dass innerhalb ein und derselben Thierclasse die Individuen sich nach zwei oder mehreren typisch verschiedenen Grundplanen entwickeln, so heteromorph sie auch in ihrer äussern

1) Ich muss hierbei bemerken, dass ich mich in der Leuckart'schen Auffassung des Generationswechsels bei den Cestoden völlig anschliesse und ihn als einen 3 gliedrigen betrachte, den Scolex also als ein selbstständiges Individuum als einen Descendenten des in die Cysticercus-Blase sich metamorphosirenden 6hakigen Embryo ansehe. ef. LEvckant sdie Blasenbandwürmer und ihre Entwicklung. « 
definitiven Gestalt sein mögen. Als Grundform haben wir anzunehmen einen ringsum geschlossenen, aus einer oder mehreren Zellschichten gebildeten Sack. Auch das Polypid ist auf einer gewissen Entwicklungsstufe einfach als ein solcher Sack angelegt, wie ich in dem vorigen Aufsatze ausführlich gezeigt habe.

Dagegen ist fest $\mathrm{zu}$ halten, dass nun nicht alle Variationen, welche im weitern Lauf der Entwicklung diese Grundform eingeht, gleich sehr von einander verschieden sind, sondern dass wir, ähnlich wie wir hei den Hydroidpolypen zwei primäre Hauptmodificationen der ursprünglichen Grundform finden, die hydroide und die medusoide Individuenform, auf welche wir zunächst in erster Linie alle secundären Modificationen des Hydromedusen-Individuums, als da sind: Deckstücke, Schwimmglocken, Geschlechtsstücke, Taster und Magenpolypen zurückführen können, ebenso auch zwei primäre Hauptmodificationen der Grundform, des Bryozoenindividuums, unterscheiden können, auf welche in erster Linie alle vorkommenden Individuenformen zurückzuführen sind, um erst, insofern als sie zu einer von diesen beiden primären Hauptmodificationen gehören, in zweiter Linic sich dem allgemeinen Bryozoenbauplane unterzuordnen. Ich will diese beiden Hauptmodificationen küntighin als die cystide und die polypide Individuenform bezeichnen, oder sie kürzer als Cystide und Polypide unterscheiden. Dieselben sind nicht allein morphologisch und genetisch, sondern auch functionell verschieden.

Das Schema eines Cystids ist ein Sack, dessen Wandungen aus einer mehr oder weniger complicirt gebauten, ein- oder mehrschichtigen Gewebslage gebildet wird, in oder an der sich meist Muskelfasern entwickeln. Die äussere Fläche des Sackes, die wenigstens zeitweilig regelmässig von einer deutlichen Epithelialschicht gebildet wird, hat die Fähigkeit, Cuticularsubstanz abzuscheiden. Die am häufigsten vorkommende Gystidform ist das Zoöcium im Surtт'schen Sinne. Die Cystide entstehen entweder direct durch einfache Metamorphose aus der geschlechtlich erzeugten freischwimmenden, bewimperten Larve, oder durch die Knospuug anderer Cystide nach a us en.

Die Function des Cystids besteht in dem Schutze des Polypids nach aussen und in der Besorgung der Erhaltung der Art, durch geschlechtliche sowohl, als auch durch ungeschlechtliche Fortpflanzung. Alle Knospungsvorgänge innerhalb des Stockes gehen von der Endocyste der Gystide aus, und auch die Genitalproducte, sowohl männliche als weibliche, entstehen an bald mehr, bald weniger scharf umschriebenen Stellen der Innenfläche der Endocyste durch directe Metamorphose einzelner Formelemente der letzteren. 
Das Schema des Polypids ist ein von der Innenfläche der Endocyste eines Cystids seinen Ursprung nehmender Zellcomplex, der sich sehr bald zu einem geschlossenen Sack ausbildet und alsdann durch eine nachträglich sich bildende Oeffnung des anfangs ringsum geschlossnen Cystids in Verbindung tritt mit der Aussenwelt und für diesen Verkehr meistens besondere Organe entwickelt. Die am häufigsten vorkommende Polypidform ist das Polypid im Alluan'schen Sinne. Bei den Bryozoa ectoprocta ist das Polypid stets der Descendent eines Cystids und zwar entsteht es stets durch Knospung der Innenfläche der Endocyste nach innen.

Die Function der Polypide ist der Verkehr mit der Aussenwelt. Das Polypid ist es, welches die Nahrung aufnimmt und verdaut. Seine Tentakeln besorgen die Athmung, und auch die Gefühlswahrnehmungen werden zunächst von ihm vermittelt und erst von ihm auf das Cystid übertragen. Cystide und Polypide stehen also bei den Bryozoen in einem ganz andern Verhältniss zu einander, als dic medusoiden und hydroiden Individuen des Hydroidpolypenstockes. Ueberall, wo wir innerhalb desselben Entwicklungscyclus bei letzterem hydroide und medusoide Individuen auftreten sehen, bilden sie jedes für sich ein Glied des bei diesen Thieren meist 3 gliedrigen Generationswechsels. 1) Die lyydroiden Individuen besorgen die ungeschlechtliche Fortpflanzung, die medusoiden dagegen die geschlechtliche; bei den Bryozoen aber besorgen die Cystide beide, sowohl die ungeschlechtliche, als die geschlechtliche Fortpflanzung; die Polypide sind bei den ectoprocten Bryozoen wenigstens stets steril.

Der Hauptwerth der Unterscheidung der beiden Hauptmodificationen der ursprünglichen Individuengrundform bei den Hydroidpolypen besteht nun offenbar darin, dass uns durch dieselbe ein Einblick gewährt wird in das Verhältniss, in welchem diejenigen Coelenteratenformen zu einander stehen, in deren Entwicklungscyclus nur eine der beiden Individuenhauptmodificationen vorkommt und welche bald nach dem hydroiden, bald nach dem medusoiden Schema gebaut sind z. B. des Verhältnisses, in welchem eine cryptocarpe Meduse zu einer Actinie steht. Denselben Vortheil scheint mir auch die Unterscheidung der beiden Individuenhauptmodificationen bei den Bryozoen zu gewähren. Durch dieselben wird uns ebenfalls ein Einblick eröffnet in das Verhältniss, in welchem einzelne aberrante Bryozoenformen zu den typischen Bryozoenformen stehen.

1) Die drei Glieder sind z. B. bei einer Campanulariade : 1) der aus dem Embryo entstandene Hydroidpolyp; 2) die Brutkapsel (ebenfalls ein hydroides Individuun); 3) das medusoide Geschlechtsthier, resp. die sich loslüsende Meduse. 
Wir kennen, soweit unsre jetzigen Kenntnisse reichen, keine Bryozoenspecies, in deren Entwicklungscyclus blos cystide Individuen vorkommen. Dagegen kommen cystide Individuen vor, welche eine Zeit lang ein isolirtes, frei bewegliches Leben zu fübren im Stande sind. Es sind dieses die frei schwimmenden, bewimperten Larven. Dieselben sind theilweise sehr einfach gebaut, z. B. die Larven der phylactolaemen Bryozoen. Andere dagegen sind schon höher entwickelt, mit einer Mundöffinung und besondern Sinnesorganen (Augen) versehen, wie \%. B. die Larven einiger chilostomen Bryozoen; einzelne, welche man als Cyphonauten bezeichnet, besitzen sogar einen deutlich differenzirten Darmcanal mit Mund- und Afteröffnung. Aber auch diese letzteren sind nur cystiden Individuen äquivalent, denı ih. Darmcanal steht durchaus in keiner Beziehung zu den Polypide des primären Zoöciums, welches durch directe Metamorphose aus ihnen entsteht, wie SchNeIDER ausfuhrlich nachgewiesen hat.

Dagegen giebt es Bryozoenspecies, in deren Entwicklungscyclus, wie mir scheint, nur polypide Individuen vorkommen, oder in denen wenigstens die polypiden Individuen nicht derartig in die cystiden Individuen eingeschachtelt sind, wie wir es bei den gewöhnlichen typischen Bryozoen zu finden gewohnt sind. In beiden Fällen sind die Polypide dann nicht steril, sondern erhalten Geschlechtsorgane. Diese Bryozoen sind es, welche ich unter dem Namen Bryozoa entoprocta zusammenzufasser vorgeschlagen habe. 1) Ich glaube mich überzeugt zu haben, dass der Becher einer Perlicellina lediglich einem polypiden Individuum entspricht, und nicht einem Cystide mil eingeschachteltem Polypide. Ich vergleiche die Leibeswand einer Pedicellina nicht mit der des Zoöciums einer chilostomen Bryozoe, sondern mit dem äussern Epithel des Darmcanales eines Polypids. Ilierfür spricht ungemein der Umstand, dass bei den Pedicellinen auch wirklich, soweit ich es zu erkennen vermochte, kein ausseres Epithel des Darmeanals.vorhanden ist, und dass innerhalb der weichen Leibeswand sich keine Musculatur entwickelt. Auch stehen die Tentakeln von Pedicellina in einem durchaus andern Verhälınisse zu der Leibeswand, als dies bei einer chilostomen Bryozoe der Fall ist; dass es ferner Stadien giebt, in denen ein junges Polypid einer chilostomen Bryozoe auch in seinen gröbern morphologischen Verhïltnissen ungemein Aehnlichkeit hat mit einer Pedicellina, habe ich schon bei Gelegenheit der Besprechung der Entwicklung des Polypids von Flustra membranacea ausführlicher nachzuweisen versucht. Die Leibeshöhle einer Pedicellina entspricht dann aber durchaus nicht

1) Zeitschr. f. wissensch. Zoologie, Vol. XX. p. 34. 
demjenigen Raume, welchen die früheren Forscher gewohnlich als Leibeshöhle einer chilostomen Bryozoe ansahen, sondern man muss sio parallelisiren mil dem Ringcanal, welcher den Rand der Mundöffnung umgiebt und in den die Höhlungen der Tentakeln münden, besonders, wenn man sich denselben erweitert denkt, dadurch, dass das :iussere Epithel des Darmcanales ein wenig abgeholsen ist von der homogenen Lamelle, die den Darmcanal stützt; ich sehe den Becher einer Pedicellina als ein polypides Individuum an, welches mit Genitalorganen versehen worden ist. Der Stiel und die Stolonen von Pedicellina sind dagegen vielleicht aufzufassen als cystide Individuen, eine vorliufis allerdings noch unbewiesene Vermuthung, für welehe übrigens der Umstand spricht, dass in die Zusammensetzung ihrer Wandungen eine deutliche Muskelschicht eingeht.

Im Pedicellinenstock hätten wir also noch cystide und polypide Individuen; dagegen hat hier das Polypid die Function der geschlechtlichen Fortpflanzung übernommen und zu diesem Zwecke einen Genitalapparat erhalten, der ebensovicl complicirter ist, wie der Genitalapparat der Cystide der gewöhnlichen Bryozoen, als die Polypide uberhaupt dic Cystide an Complication des Baues ubertreffen; den Cystiden d. h. den Stolonen und Stielen bliebe aber dann die Fähigkeit der ungeschlechtlichen Fortpflanzung, der Knospung.

Bei Loxosoma hingegen finden wir offenbar in dem ganzen Entwicklungseyclus nur die polypiden Individuen. Das Polypid ubernimmt beide: die geschlechtliche und die ungeschlechtliche Fortpflanzung und für das ganze Thier von Loxosoma gilt meiner Ansicht nach genau dasselbe, was ich eben über den Becher der Pedicellinen gesagt habe.

Ich verhehle mir ubrigens gar nicht, dass unsere Kenntniss der Entwicklungsgeschichte von Pedicellina und Loxosoma noch lange nicht weit genug fortgeschritten ist, um als Bestätigung meiner eben vorgebrachten Ansicht dienen zu können, und dass, so lange dies nicht geschehen, letztere nur als eine Vermuthung angesehen werden darf, deren Annahme oder Widerlegung ich vorläufig andern Forschern überlassen muss.

Wenden wir aus nach dieser Abschweifung wiederum zur Morphologic der ectoprocten Bry̧ozoenstöcke. Der so höcht eigenthümliche Hahitus derselben wird nun dadurch hervorgebracht, dass im Allgemeinen die Gystide und Polypide zu einander in einem ganz absonderlichen und ungewöhnlichen Verhältnisse stehen. Reıchert hat dies sehr wohl erkannt und in einer allerdings etwas dunkeln Form ausgesprochen. Er sagt (I. c. p. 314): odie Individuenstöcke der Bryozoen sind vor Allem durch die bekannte Vereinigung der den cyclischen Lebenslauf des Ge- 
schöpfes abschliessenden Elemente, zur Form des Bryozoenkopfes charakterisirt. « In schlichteren Worten kann man diese merkw üdige Thatsache ungefähr folgendermassen ausdricken : dic eine Individuenhauptmodification des Bryozoenstockes, das Polypid, ist stets ein Abkömmling der andern, des Cystids, ist aber mit dem letzteren viel inniger verbunden, als dies sonst gewöhnlich mit 2 Individuen im Thierreich der Fall zu sein pflegt; das Polypid ist in das Cystid eingeschachtelt und der Bryozoenstock ist also nicht ein directes Aggregat von einer Anzahl von cystiden und polypiden Individuen, wie z. B. der Siphonophorenstock ein Complex von medusoiden und hydroiden Individuen ist, sondern je ein Cystid und Polypid treten zunächst in eine ganz besonders innige Vereinigung, in welcher das letzlere sich zu den ersteren wie ein blosses Organ verhält; dieser Complex von Polypid und Cystid bildet nun eine höhere Einheit und erst diese ist es, aus welcher der Bryozoenstock direct sich zusanımensetzt. Diese secundäre Einheit aus 2 primären bestehend nennt Reichert den "Bryozoenkopf «. Diese Bezeichnung hat für die Vesiculariaden ihre Berechtigung, da bei dieser Abtheilung diese Bryozoenköpfe wirklich als seitliche terminale Endigungen des Stockes erscheinen, da sie die Fähigkeit, neue Cystide durch Knospung zu erzeugen, verloren haben. Im Allgemeinen erscheint er aber bei der bei weitem überwiegenden Mehrzahl der Bryozoenstöcke als unstatthaft, da bei diesen ein Unterschied zwischen Stanmgliedern und » Bryozoenköpfen " nicht vorhanden ist, der Stock vielmehr lediglich aus „Köpfen " besteht und diese sich jetzt in keiner wenn auch noch so oberflächlichen Weise mit den Polypenköpfen der Hydroidpolypenstöcke vergleichen lassen. Ich schlage daher vor, die Bezeichnung »Bryozoenkopf " durch den Ausdruck »Pol y p oc y s tid « zu ersetzen, und definire das letztere als »den Complex eines cystiden Individuums mit einem in dasselbe cingeschachtelten polypiden Descendenten ". Mein Polypocystid entspricht also dem Einzelindividuum der álteren Auffassung. Nebenbei sei hier noch bemerkt, dass meiner Ansicht nach gar kein Grund vorliegt, die beiden älteren Ausdrüicke »Polypid « und „Zoöcium«, wie Rerchert es thul, durch die Ausdrücke » Bryozoid " und »Brutkapsel " zu ersetzen.

Während also der so höchst eigenthümliche Bau aller ectoproclen Bryozoenstöcke auf denı regelmässigen Vorkommen der beiden Individuenhauptmodificationen des Cystids und des Polypids innerhalb desselben Stockes und auf dem Zusammentreten derselben zu einer höheren Einheit, dem Polypocystid, also auf einem zwar durchgreifenden, aber versteckten Dimorphismus sïmmtlicher Elemente des Stockes beruht, werden die so ungemein mannigfaltigen und zierlichen äusseren Verschiedenheiten, welche die Bryozoenstöcke zeigen und auf welche bis 
jetzt hauptsächlich die Classifieation der Bryozoen gegrundet wurde, hervorgebracht durch einen in zweiter Linie auftretenden Polymorphismus der Cystide nnd Polypide an und für sich.

Die gewöhnlichste Form, in welcher das Cystid auftrill, ist das Zoöcium. Das Zoöcium in seiner einfachsten Form ist, wie eben gesagt, ein ringsum geschlossener Sack, der aus einer weichen, ein- oder mehrschichtigen Gewcbslage besteht, in oder an der sich Muskelfasern entwickeln, welche eine Verengerung seines Hohlraumes bewirken können. Die äussere Fläche des Sackes secernirt Cuticularsubstanz, welche bald als blosses Secret auftritt (Cristatella), bald gallertig bleibt (Lophopus), meist aber zu einer Chitin-Guticula erhärtet, welche entweder stets chitinös bleibt (die meisten Phylactolaemen und Ctenostomen) oder theilweise verkalkt (die meisten Chilostomen und alle Cyelostomen). Das einzelne Zoöciumerzeugt in der Regel durch Knospung nach innen auf einmal nur ein einziges Polypid, ein Nährthier. Mitunter treten aber an dem Zoöcium gleichzeitig 2 (Larve von Alcyonella fungosa) oder mehrere Polypide auf. Das Cystid wächst in diesem Falle ganz bedeutend, ohne sich durch Scheidewändẻ abzutheilen $\mathrm{d}$. $\mathrm{h}$. ohne also durch Theilung in Tochtercystide sich zu gliedern, und wir sehen dann den ganzen Stock aus einem mehr oder weniger gelappten oder verästelten grossen $\mathrm{Cy}-$ stide bestehen, an dem eine ganze Reihe von Polypiden sich vorfinden. So ist es bei Lophopus, bei den Alcyonellen und Plumatellen, bei denen keine Scheidewände zwischen den zu jedem Polypid gehörigen Regionen des Cystids sich vorfinden. Ein Stock von Lophopus insbesondere verhälı sich also zu einem aus gesonderten Polypocystiden zusammengesetzten Bryozoenstocke genau so, wie sich ein Triaenophorus oder eine Ligula zu einer aus deutlich getrennten Proglottiden bestehenden Bandwurmkette verhält. Bei ersteren deutet ja ebenfalls nur eine undeutliche Einschnürung, bei Ligula sogar nur die vielfache Wiederholung der Geschlechisorgane im Imnern des gemeinschaftlichen Körpers eine Zusammensetzung aus mehreren Gliedern an, während bei einer gewöhnlichen Taenia die Trennung der einzelnen Proglottiden scharf durchgefuhrt ist.

Von der Form, in welcher das Cystid bei Lophopus vorkommt, bis zu den getrennten Zoöcien der Chilostomen giebt es übrigens eine ganze Reihe von Uebergängen. Während man wirklich darüber stréiten kann, ob man das Cönöcium von Lophopus als ein grosses Cystid oder als einen Gomplex mehrerer verschmolzener Cystide ansehen soll, liegt schon z. B. bei Plumatella die Auffassung viel näher, das Cönöcium als einen Complex unvollkommen von einander abgegrenz- 
ter Zoocien aufzufassen. Scheidewände treten hier auch wirklich schon vereinzelt auf, bei Fredericella ist schliesslich die Trennung der einzelıen Zoöcien scharf durchgeführt.

Bei allen bis jetzt herangezogenen Arten sind übrigens die Zoöcien noch sämmtlich im Besitze aller der den Cystiden zukommenden specifischen Functionen ; sie besorgen dic Abgrenzung des Stockes der Aussenwelt gegenüber, vermitteln den Schutz der Polypide und übernehmen sämmliche Functionen der Fortpflanzung, sowohl die Erzeugung neuer Cystide durch Knospung nach aussen, als auch die von Polypiden durch Knospung nach innen und die Ilervorbringung von Genitalproducten nebst dem Schutze der jungen Brut. Sämmtliche im Stocke vorkommende Cystide treten unter der Form des wirklichen Zoöciums auf und nur die primären Zoöcien sind gewölınlich ein wenig von dem Normaltypus des Zoöciums der betreflenden Species abweichend. In andern Fällen hingegen tritt eine Arbeitstheilung ein und einzelne Cystide werden zu besondern Functionen besonders modificirt. Dies ist vornehmlich bei einigen Chilostomen, Ctenostomen und Vesiculariaden der Fall.

Bei einigen Chilostomen wird zunächst der Schutz oder die Nahrungsbeschaffung ') für die ganze Colonie, sowie die Brutptlege besonderen metamorphosirten Cystidformen übertragen. Ich erinnere zunächst an Flustra foliacea. Bei dieser Species finden wir unter den flächenhaft an einander gereihten Gystiden, von denen die meisten sich zu wirklichen Polypocystiden entwickeln, einzelne, welche sich zuAvicularien ausbilden. Diese Avicularien haben im Allgemeinen noch ganz die Gestalt der typischen Zoöcien und erzeugen ganz ebenso, wie diese letzteren nene Gystide durch Knospung an ihrem Vorderende. Das Verhalten der Avicularien bei Flustra foliacea und einigen Verwandten liefert daher den Beweis, dass auch die Avicularien andrer Chilostomen, welche nicht in die Reihe der Polypocystide eingeschaltet sind, z. B. die von Bugula und Scrupocellaria u. s. w. als wirkliche eystide Individuen anzusehen sind, wenngleich sie die Fähigkeit, neue Cystide zu knospen, verloren haben. Die Brutpllege wird bei Flustra foliacea von dem vorderen Theile des typischen Zoöciums übernommen, welches nachträglich durch Abgrenzung ron den übrigen Theile des Zoöciums und durch

1) d. h. die indirecte Nahrungsbeschaffung; es wird ja angenommen, dass die Function der $\Lambda$ vicularien nicht allein in der Entfernung und $\Lambda$ bhaltung von fremden Gegenständen von der Oberfläche des Stockes besteht, sondern dass dieselhen auch in ihren Bereich kommende Organismen, z. B. kleine Würmer, fassen und festhalten, bis sich dieselben durch Verwesung auflösen. Hierdurch wird in unmittelbarer Nähe der Polypide das Wasser mit fein vertheilter organischer Substanz geschwängert, welche tetztere dann dem Polypide zur Nahrung dient. ef. Busk, quaterl. Journ, Micr. Sc. 1854. p. 26. 
Wachsthum nach oben sich zu einem Oöcium ausbildet. Hier trennt sich also dureh einen Vorgang, den man eigentlich mehr als eine Theilung, denn als eine eigentliche Knospung ansehen kaun, ein Theil des Zoöcium als Brutbehälter ab. Da der abgetrennte Theil aber doch auch nach oben wuchert, so haben wir hier schon den Anfang einer ausserhalb der gewöhnlichen linearen Richtung vor sich gehenden lateralen Ǩnospung, durch welehe sterile Seitenglieder des Stockes erzeugt werden. Dies ist bei vielen Chilostomen der Fall, in besonders hohem Grade bei der Familie der Cellulariaden. Ilier schliessen sich die Polypocystide direct an einander an; ihre Reihe ist nicht unterbrochen dureh metamorphosirte Gystide, dagegen treten regelmässig seitlich an den meisten Polypoeystiden dureh Knospung nach aussen cystide Individuen auf, welche dazu bestimmt sind, die functionen zu übernehmen, welche wir bei Flustra foliacea von innerhalb der Reihe der gewöhnlichen Zoöcien licgenden Cystiden ausgeübt sehen: Es treten seitlich gestellte Avicularien, Vibracularien und Oöcien auf. Diese verlieren jetzt aber die Fähigkeit, neue Cystide zu knospen, und bilden sterile Seitenglieder des Stockes. Als eine weitere sterile Cystidenform treten bei vielen Chilostomen auch noch die sogenannten Wurzelfäden hinzu. Diese sind als zum Zweck der Befestigung des Stockes resp. zu seiner Verstärkung modificirte Cystide anzusehen.

Bei einigen Gyclostomen werden in die Reihe der gewöhnlichen Zoöcien die sogenannten Oöcien eingesehoben. Diese Oöcien sind aher ganz verschieden von den bei den Chilostomen vorkommenden. Nach den Untersuchungen von Surt scheint es mir sicher zu stehen, dass wir es hier nicht blos mit Individuen zu thun haben, welche der Brutpflege vorstchen, sondern mit solchen, welehe wirklich Embryonen erzeugen. $\left.{ }^{1}\right)$ Unsere Kenntniss der Entwicklungsgeschichte der Cyclostomen ist aber noch eine ungemein geringe und wir müssen daher vorläufig annehmen, - da wir durchaus Nichts davon wissen, dass auch von den wirklichen Zoöcien bei diesen Thieren Genitalproducte crzeugt werden - dass wir es in den Oöcien der Chilostomen mil besonders modificirten Cystiden zu thun haben, welehe ausschliesslich die Erzeugung von Genitalproducten vermitteln, dagegen keine Polypide erzeugen und also als Geschlechtsthiere anzuschen sind. Ob diese gesehlechtliche Fortpllanzung hier auf parthenogenctischem Wege vor sich geht oder nicht, können wir augenblicklich nicht entscheiden, vorläufig spricht der Anschein dafür.

1) Die Annahme, von Hıncks und Smitr, dass die Embryonen auch bei manchen Chilostomen durch Knospung im Inmeru der Oöcien entstehen, glaubte ich als widerlegt betrachten zu dïrfen. cf. Zeitschr. f. wissensch. Zool. Vol. XX. p. 6. 
Bei den Crisiaden haben wir also hndividuen, welche ausehliesslich die geschlechtlichen Funetionen übernehmen; bei den Vesiculariaden ist dies ander's. Ilier ist die Arbeitstheilung nach einer andern Richtung hin ausgebildet; bei ihnen finden wir Cystide, welche ausschliesslich neue Cystide knospen, dagegen weder Polypide noch auch Genitalproducte erzeugen; es sind dies die Stammglieder. Die von diesen letzteren geknospten Cystide entwickeln sich dagegen grösstentheils zu wirklichen Polypocystiden, welehe die gesehlechtliche Fortpflanzung und die Brutpflege besorgen, die übrigen, welehe sich nieht zu Polypocystiden entwickeln, werden zu Wurzelfasern; die Anlage eines Polypoeystids und eines Wurzelfadens sind bei den Vesiculariaden einander so gleich, dass gerade hierdureh der Beweis geliefert wird, dass auch die Wurzelfäden als wirkliche cystide Individuen anzusehen sind.

Die erste Individuenhauptmodification des Bryozoenstockes, das Cystid, kommt also, soweil wir jetzt wissen, bei den ectoprocten Bryozoen in folgenden secundären Modificationen vor:

1) Als einfaches Zoöcium.

2) Als Coenoccium d. h. als ein sehr grosses, einem Complex von vielen gewöhnlichen Zoöcien äquivalentes Zoöcium.

3) Als Avicularium (wir werden gleich sehen, dass übrigens nur einige Avieularien in toto blosse Cystide darstellen, andre dagegen als Polypocystide erscheinen).

4) Als Vibracularien.

5) Als Oöcien bei den Chilostomen d. h. als Brutbehälter.

6) Als Oöeien bei den Grisiaden d. h. als Geschlechtsthiere.

7) Als Stammglicder bei den Vesieulariaden.

8) Als Wurzelfäden.

Gewöhnlich nahm man bis jetzt an, dass die zweite Individuenhauptmodifieation des Bryozoenindividuums nur in einer einzigen Forn auftrete, nähmlich als das gewöhnliche Polypid in Allyax'schen Sinne. Ich glaube mich jedoch überzeugt zu haben, dass dasselbe bei den ectoprocten Bryozocn in 2 verschiedenen secundären Modificationen vorkommen, nämlich einmal, wie schon gesagt, als gewöhnliches Polypid, und damn als jener Gefühlsborsten tragender "peculiar body " (cf. Busk, l. c. p. 28), der sich in den Avicularien ciner Anzahl von Cellulariaden vorfindet. Ich habe oben gesagt, die Avicularien seien ebenso wie die Oöcien, Vibracularien und Wurzelfäden sterile Individuen. Dies ist im Allgemeinen unbestreitbar; sie sind, mit Ausnahme der eben erwähnten Fälle, wo sie den Zoöcien längsreihen eingeschaltet sind, wirklich nicht im Stande, durch Knospung nach aussen Cystide zu erzeugen. 
Dagegen hat die Entstehungsweise jenes "peculiar hody im Innern eines Avicularium, z. B. bei Bugula flabellata, Bicellaria ciliata, eine solche Aehnlichkeit mit den Auftreten einer jungen Polypidknospe innerhalb) einer Zoöcienknospe, und das Verhältniss des fertigen Fühlknopfes zu dem Avicularien-Cystid ist so ungemein ähnlich dem, in welchem ein wirkliches Polypid zu seinem Zöcium steht, dass ich nicht umhin kanı, anzunehmen, dass der "peculiar body« wirklich einem Polypide äquivalent sei.

Ein Avicularium, welches ein solches Fühlorgan einschliesst, entsteht anfänglich z. B. bei Bugula flabellata als cin kculenförmiger Auswuchs des Zoöcium, der offenbar eine $\mathrm{Cy}$ stidknospe darstellt. Dieser plattet sich zunächst in der einen, der Mundungsarea des Zoöcium zugekehrten Seite ab und wächst danı an seiner Spitze, bis sie ungefälır die Gestalt des vollendeten Avicularium mit angezogenem Unterkiefer erlangt hat; es bildet sich nun die Scheidung von Ober- und Unterkiefer; letzterer wird beweglich und kann nun durch Muskeln, welche sich in der Höhle des Kopfes entwickelt haben, gegen den Oberkiefer hin und her bewegt werden. Durch die Trennung von Oberund Unterschnabel wird aber nicht etwa die Höhle des Kopfes nach aussen hin er-

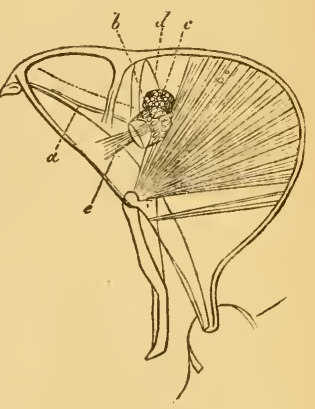

Fig. 2 . offnet, dieselbe ist vielmehr durch eine Membran (cf. den Holzschnitt, a) geschlossen, welche zu deu Oberschnabel und dem Kopfe ziemlich genau dieselbe Stellung einnimmt, welche der Gaumen bei einem wirklichen Vogelkopfe inne hat, besonders wenn man sich denselben so nach hinten und unten verlängert denkt, dass er die Speiseröhre quer verschliesst und direct in die innere Fläche des Unterkiefers auskleidende Schleimhaut ubergeht. Auch die Sehne der grossen Schliessmuskeln des Unterkiefers scheint mir nicht, wie Busk angiebt, diese Membran zu durehbohren, sondern unter derselben an die Innenfläche des Unterkiefers hinzulaufen. Noch bevor die Trennung des Untersehnabels erfolgt ist, hat die zu dieser Zeit noch deutliche polygonale Epithelialzellen zeigende Schlussmembran durch Wucherung nach innen einen Zellknopf hervorgebracht. Diesen Körper bezeichnet Busk als " peculiar body", Smitr dagegen als »Ganglion des Avieulariums «. Dieser Zellknopf differenzirt sich sehr bald in einen von einer festeren äusseren Membran eingeschlossnen napfförmigen 
Korper $(b)$ und einen ihm aufliegenden zelligen Knopf $(c)$, weleher durch Stränge (die Nerven Suıт's) mit der Endocyste des Avicularium verbuulen ist $(d)$. Die Oeffnung des napfförmigen Körpers ist der Schlussmembran zugewendet und die feste äusscre Membran geht direct an ihren Rändern in die Schlussmembran über. Die Höhlung des napfförmigen Körpers öffnet sich nun nach aussen, indem sich in der Schlussmembran eine Oeffnung bildet, genau so, wie die Höhlung der Tentakelscheide durch das Durchbrechen der Mündung des Zoöcium sich nach aussen öffnet. Die Höhlung des Kopfes wird in unserm Falle aber ebensowenig selbst eröffnet durch diesen Vorgang, als in letzterem Falle die Iöhle des Cystids; ebenso wie die Tentakelseheide fest mit den Rändern der Mündung zusammenhängt, hängt auch der Rand des nappfförmigen Körpers mit den Rändern der Oeffnung der Schlussınembran zusammen. Die Oeffnung der Ietzteren hat zu dem Kopfe des Aviculariun genau dieselbe Lage, wie die Choanen eines wirklichen Vogelkopfes zur Schädelkapsel. Im Grunde der Höhlung des napfförmigen Körpers entwickelt sich nun ein Bündel Fühlborsten, welche durch die Oeffnung
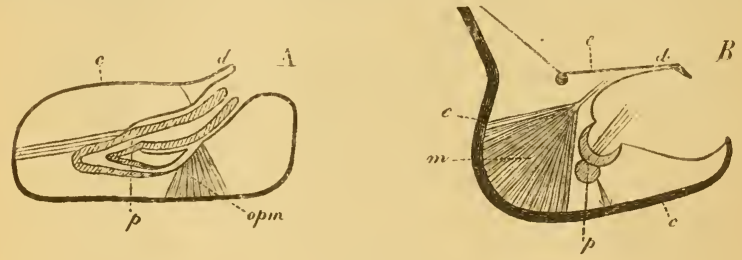

Fig. 23.

A. Ein Zoöcium mit seinem Polypid. c. Cystid. p. Polypid. d. Deckelfalte. B. Ein Avicularium mit seinem Fühlkuopfe. c. Cystid. p. Polypid (Füblknopf). d. Deckelfalte (Unterkiefer). m. Schliessmuskeln.

ler Schlussmembran nach aussen hervorragen, genau so, wie die Tenlakeln ${ }^{1}$ ) cines halb ausgestreckten Polypids aus der Oeffnung des Verschluss-Diaphragma's.

Die eben geschilderte Structur des Fühlknopfes sowie seine Lagerung zu den übrigen Theilen des Aviculariencystids scheint mir ungemein dafür zu sprechen, dass wir es wirklich in demselben mit einem rudimentären Polypide zu thun haben, welches die Fähigkeit verloren hat, die Nahrungsaufnahme und die Assimilation der Speisen zu vermitteln und nur noch Gefuhlswahruchmungen besorgt. Dass auch die Lage des Fühlknopfes innerhalb des Aviculariencystids wirk-

1) Natürlich liegt es mir gänzlich fern, diese Fühlborsten etwa als wirklich den Tentakeln homolog anselien zu wollen. 
lich der des Polypids und Zoöciums entspricht, wird durch einen Blick auf die beigefügten schematischen Figuren sofort klar werden. Der Unterkieler des Avicularium entspricht hierbei genau der Deckelfalte des Zoöcium einer Chilostome, die Schlıssmembran dem Verschlussdiaphragma. Dass übrigens der Fühlknopf auch ähnlich wie das Polypid etwas hervorgestulpt werden kann, scheint mir aus den Busk'schen Abbildungen deutlich hervorzugehen. Die mit einem Fühlknopfe versehenen Avicularien sind also meiner Ansicht nach nicht als einfache Gystide, sondern als wirkliche Polypocystide anzusehen.

Die am höchsten entwickelte Polypidform kommt, wie schon oben gesagt, bei den entoprocten Bryozoen vor. Bei Pedicellina entspricht der Becher einem Polypid, nicht einem Polypoeystid; bei Loxosoma ist das ganze Thier einem Polypide äquivalent. Wir künnen also folgende Polypidmorlificationen unterscheiden :

1) das Polypid der ectoprocten Bryozoen;

2) den Fülılknopf der Avieularien einiger Chilostomen.

3) das Polypid der entoprocten Bryozoen.

Untersuchen wir nun kurz zum Schluss, ob wir den Entwicklungseyclus der Bryozoen im Allgemeinen mit AlLmas als einen Generationswechsel auffassen dürfen. Ich glaube dies nicht. Die Allax'sche Auflassungsweise hat dadureh ihre Berechtigung für ihre Vertheidiger, lass diese das Ovarium und den Testis als gesonderte von dem ungeschlechtlichen Zoöcium geknospte Individuen ansehen; alsdanı fältt der Entwicklungscyelus der Bryozoen wirklieh in den Bereich des Steenstritp'schen Generationswechsels, d. h. wir haben es alsdann mit einer ungeschlechtlichen, aus dem befruchteten Ei entstandenen Generation zu thun, welche auf ungeschlechtlichem Wege eine geschlechtliche Generation erzeugt, diè selbst nun wieder ungeschlechtliche Nachkommen erzeugt. Bei dieser Auffassung gehört aber auch das Polypid zu den fortpflanzungsfahigen Individuen, denn dasselbe wird, wie wir schon oben sahen, entweder als ein männliches Geschlechtsthier oder als ein ein männliches Geschlechtsthier knospendes ungeschlechtliches Thier angesehen. Da ich mich der Ausuas'schen Ansicht in Betreff der Geschlechtsthiere, wie schon oben erläutert, nicht ansehliessen kann, so fällt für mich auch die Möglichkeit weg, die Erscheinung unter den Begriff des Generationswechsels zu subsummiren. Dass durch das Auftreten zweier heteromorpher Individuen-Ilauptmodificationen an und für sich ein Generationswechsel nicht hervorgebracht wird, ist klar, und zwar hier um so weniger, da die eine derselben, die polypide, immer steril ist, meiner Auffassung nach auch bei den Phylactolimen, da ich 
den Funiculus, an dem hier die Spermatozoen sich bilden, nicht als zum Polypid, sondern zum Cystid gehörig anzusehen mich berechtigt glaube. Es erhellt hieraus sofort, dass, wie übrigens schon oben beiläufig bemerkt wurde, die beiden heteromorphen Individuenhauptmodificationen der Bryozoen zu einander in einen ganz andern genetischen Verhiltniss stehen, als die hydroiden und medusoiden Individuenformen bei den IIydroidpolypen. Diese letzteren bilden da, wo sie innerhalb desselben coelenderaten Entwicklungscyclus vorkommen, immer die mit einander abwechselnden Glieder eines Generationswechsels, beide sind also fortpflanzungsfähig; bei den ectoprocten Bryozoen hingegen werden sämmtliche Fortpflanzungsfunctionen von den Cystiden übernommen. Das Cystid knospt neue Cystide nach aussen und Polypide nach innen und erzeugt innerhalb seiner Wandungen Genitalproducte, Eier und Samen. Der Kreislauf der Entwicklung wird also lurch die Cystide abgeschlossen. Die polypiden Individuen, sowie die sterilen Cystide, z. B. die Wurzelfasern und die Vibracularien sind für die Erhaltung der Art ohne jede Bedeutung; es sind sterile Seitenglieder, die lediglich zur Erhaltung des individuellen Lebens des Stockes beitragen. Auch die Entwicklungsweise der entoprocten Bryozoen geht nicht auf dem Wege des Generationswechsels vor sich, nicht einmal hei Pedicellina, denn die aus dem Ei der letztern entstehende Larve ist, soweit uns die vorliegenden Beobachtungen zu urtheilen erlauben, als ein Polypid und nicht als ein Cystid anzusehen und wird selbst wieder zu einem Geschlechtsthier.

Nur bei einer einzigen Abtheilung der Bryozoen können wir eine Art Generationswechsel beobachten: Es sind dies die Vesiculariaden. Auch bei diesen wird allerdings, wie bei allen ectoprocten Bryozoen die Summe der Functionen der Fortpflanzung von den Cystiden allein besorgt; die cystiden Individuen aber zerfallen, wie wir oben sahen, wieder in zwei verschiedene Abtheilungen, von denen die eine die Stammglieder, lediglich die ungeschlechtliche Fortpflanzung, die Knospung der Zoöcien besorgt, die andere hingegen, die Zoöcien, die geschlechtliche Fortpflanzung, die Erzeugung von Eiern und Sperma. Sollten nun, wie mir übrigens höchst wahrscheinlich dünkt, aber noch nicht durch directe Beobachtung bewiesen ist, die aus den Eiern entstandenen Embryonen sich durch directe Metamorphose in primäre Stammglieder umwandeln, so hätten wir es bei diesen Thieren allerdings mit einem wirklichen Generationswechsel zu thun: der Embryo verwandelt sich in ein Stammglied, dieses knospt Zoöcien, diese erzeugen Fier und Spermatozoen, durch deren Zusammentreten ein Embryo entsteht, der wieder einem Stammgliede homolog ist. Dieser 
Generationswechsel wäre also ein zweigliedriger. Aehnlich würden die Verhältnissse auch bei Crisia sein, wenn wirklich, wie nach unsern jetzigen Kenntnissen nicht ganz unwahrscheinlich ist, nur die Oöcien Geschlechtsthiere darstellen, die eigentlichen Zoöcien aber ungeschlechtlich wären, unter der Voraussetzung, dass der Embryo sich direct in ein ungeschlechtliches Zoöcium verwandelt. Hier lïge ebenfalls ein zweigliedriger Generationswechsel vor. Ich mache ubrigens ausdrücklich darauf aufmerksam, dass sowohl bei den Vesicularien, als auch bei Crisia das wirkliche Vorhandensein eines solchen Generationswechsels noch nicht endgültig constatirt worden ist.

Ich kann diese kurze Besprechung der Morphologie der Bryocoen nicht beschliessen, ohne im Allgemeinen die histologischen Ansichten zu berühren, welche in Betreff dieser Thierclasse von zwei bedeutenden Forschern, von Suitr und Reicuert aufgestellt worden sind.

In seinem Aufsatze »On Hafsbryozoernas Utveckling Och Fettkroppar. Öfvers. af K. Vet.-Akad. Förhandl. 186.5. No. I. « sucht Suitr nachzuweisen, dass bei allen Fortpflanzungsvorgiingen der Bryozoen der »Fettkörper« eine grosse Rolle spielt, der Triger aller dieser Erscheinungen ist. Unter dem Namen »Fettkörper« versteht Surr, um mit Claparède zu reden, die flottirenden, zellartigen Körper der Leibeshöhle überhaupt, und erklärt diesen Ausdruck für gleichbedeutend mit der Bezeichnung "Lymphkörperchen ", "floatings cells " etc. Bildet sich eine neue Knospe, so entsteht sie nach Sмiтt zunächst als eine Ansammlung von Fettkörpern an dem vordern Ende des Mutterzoöcium; entstelit ein Ei z. B. bei Lepralia Peachii durch „Knospung der Endocyste nach innen ", so ist es eine Fettkörpermasse, die zun̋̈clıst an der Stelle aufIritt, wo wir spiiter das Ei finden. Die Spermatozoen entstehen aus einer Ansammlung von Fettkörpern an dem proximalen Ende der Zoöcien, kurz alle neu sich bildenden Gewebstheile sollen dadurch entstehen, dass Fettkörper sich aus der Leibesflussigkeit an einer bestimmten Stelle absetzen und dort ein neues Gebilde, also gleichsam durch Anschwemmung, hervorbringen. Schon Cuaparkide hat sich gegen diese histogenetische Auffassung ausgesprochen und für die Bildung neuer Cystidknospen nachgewiesen, dass dieselben nicht aus Depositen der Leibesflüssigkeit, sondern durch Wucherung und Vermehrung der histologischen Elemente der Endocyste des Mutterzoöciums entstehen. Dieser Glaparède'schen Ansicht muss ich mich völlig anschliessen. Für die Cystid- und Polypidknospen von Flustra membranacea habe ich weiter oben meine Auffassungsweise ausführlich 
dargelegt, aher auch bei allen andern Bryozoen, welche ich zu untersuchen Gelegenheit hatte, habe ich niemals die Ueberzeugung gewinnen können, dass man wirklich gezwungen wäre, für die Entstehung irgend einer Knospe oder eines Organs auf die Smitr'sche Theorie zurückzukommen. Mir scheint es vielmehr bedeutend wahrscheinlicher, dass die in der Leibesflüssigkeit der Cystide schwimmenden Körperchen lediglich als Lymphkörperchen anzusehen sind, und dass dieselben mit der Gewebsbildung durchaus Nichts zu thun haben. Ein grosses Verdienst hat sich aber Surt ; ganz abgesehen von der wirklich erstaunlichen Fülle von neuen Beobachtungen, mit denen er die Wissenschaft bereicherte, dadurch erworben, dass er zu zeigen versuchte, wie allen Fortpflanzungsvorgängen bei den Bryozoen ein gemeinsamer Zug eigen ist. Ilierin stimme ich ihm, wenigstens was die ectoprocten Bryocoen betrift, völlig bei. Aber nicht der offenbar sehr heterogene Elemente umfassende Surtr'sche Fettkörper ist das Sulsstrat aller Fortpflanzungserscheinungen der Bryozoen, sondern diese werden hervorgebracht durch cine Wucherung und Umbildung der Elemente der Endocyste der Cystide. Die Endocyste der Gystide besteht stets aus wenigstens einer mehr oder minder regressiv metamorphosirten Zellschicht. In den Fällen, wo die Zellgrenzen undeutlich werden, bleiben stets wenigstens die Zellkerne bestehen, und an diese knüpft offenbar in diesen Fillen die Neubildung von wirklichen neuen Zellen an.

Die histologischen Ansichten von Reicherт ${ }^{1}$ ) erstrecken sich nicht, wie die Suıt'schen, auf die Histogenese, sondern beziehen sich lediglich auf die Gewebe des fertigen Thieres und zwar leider auf diejenigen einer einzigen Species des Zoobotryon pellucidus. Die bei der Untersuchung dieses Thieres von Reicnert gewonnenen Resultate werden olne Weiteres auf alle Glieder der so mannigfaltig gebauten Classe der Bryozoen übertragen, und bilden zugleich die Hauptgrundlage der Reichert'schen Ansichten über die Systematik der Bryozoen. Eine eingehende Würdigung der letzteren gehört nicht in den Bereich der gegenwärtigen Arbeit, und ich begnüge mich daher, an dieser Stelle kurz darauf hinzuweisen, wie sehr es allen Principien einer naturlichen Classification widerspricht, allein nach den histologischen Verhältnissen einer Thiergruppe den ihr im System zukommenden Platz bestimmen zu wollen, selbst bei der Voraussetzung, dass die histologischen Verhältnisse bei allen Gliedern der in Bezug auf ihre Stellung im System

1) ef. Vergleichende anatomische Untersuchungen über Zoubotryon pellucidus Ehrenberg;. Aus den Alhandlungen d. K. Akad. zu Berlin, 1869. 
zu untersuchenden Thiergruppe wirklich gleichartig sind. Eine solche Classification wird immer eine eben so künstliche sein, als eine aul die äussere Aehnlichkeit oder Unähnlichkeit einzelner Organe des Thierleibes gegründete. Indessen triftt die oben gemachte Annahme, dass die histologischen Verhältnisse, wenn sie zur Grundlage der Feststellung der systematischen Stellung derselben dienen sollen, wenigstens im Grossen und Ganzen im Bereich der ganzen Gruppe übereinstimmend sein müssen, für die Classe der Bryozoen durchaus nicht zu.

Eine Reihe von Publicationen hat den Nachweis zu liefern gesucht, dass einzelne Abtheilungen der Bryozoen in ihrem histologischen Baue sehr von einander abweichen und gezeigt, dass der Bau derselben ein durchaus anderer ist, als Reichert ihn bei Zoobotryon pellucidus gefunden haben will. Letzterer hat aber einfach die von ihm an einer Species gemachten Beobachtungen verallgemeinert und die in fruheren Arbeiten über den histologischen Bau anderer Glieder der Bryozoenclasse gemachten Angaben einfach als nicht bewiesen angesehen, ohne eine Widerlegung der grösstentheils nicht widerlegten und daher den allgemeinen Gebrauche nach augenblicklich noch als richtig angenommenen Thatsachen zu versuchen. Dass auch dieses Verfahren durchaus nicht übereinstimmt mit den Grundsätzen, welche für eine jede unparteiische und ohne Voreingenommenheit geführte wissenschaftliche Forschung geltend sein müssen, braucht wohl nicht erst besonders hervorgehoben $\mathrm{zu}$ werden. Hierzu kommt noch, dass Reicnert lediglich die bei dem erwachsenen Thiere vorhandenen histologischen Verhältnisse in Rechnung zieht, und auch bei der Untersuchung dieser viele neue Methoden der Histologie als lediglich zu Täuschungen führend und Artefacte hervorrufend von der Hand gewiesen hat. Besonders hält er gehärtete Exemplare für vollkommen ungeeignet, um die Structur der Gewebe an ihnen zu untersuchen. Dass Reichert hiermit zugleich einen guten, ja vielleicht den grössten Theil der neueren Resultate der Histologie iuberhaupt als auf Täuschung beruhend streicht, liegt auf der Hand. Reichert sagt (l. c. p. 301): "Die mikroskopische Untersuchung des Zoobotryon pellucidus hat zu dem Ergebniss geführt, dass am Aufbau des Bryozoenstockes, abgesehen von den zu Skeletttheilen (Ectocyst, elastische Stützlamelle der Spannbänder und des Bryozoids) erhärteten Excreten nur zwei histologische Substanzen verwendet sind : 1. das in der histologischen Form des Epithels auftretende Gebilde, welches im Bereiche des Bryozoids (Darmcanal mit den Tentakeln) angetroffen wird und 2. das eigenthümliche, an einzelnen Stellen durch Contractionsfähigkeit ausgezeichnete Gewebe, aus welchem der Endocyst, die Retractoren und 
die weiche Substanz der Spannbänder der Brutkapsel, ferner das communale Bewegungsorgan, endlich der zweite weiche Hauptbestandtheil des Bryozoids gebildet sind. Gewebe, die sich mit den so charakteristischen, histologischen Elementen des Nervensystems, des Muskelsystems, des Bindesubstanzgerüstes oder mit dem Blute höherer Thiere vergleichen lassen, kommen bei Zoobotryon pellucidus nicht vor; auch sind dieselben bei keinem Bryozoon mit genügender Sicherheit nachgewiesen«. Das Gewebe No. 2 nennt Reichert die "protozootische Substanz «; dieselbe soll im Leben festweich, pellucid, farblos, entweder völlig homogen oder feinkörnig granulirt sein. An ihr ist auch nicht die geringste Spur einer Zeichnung zu entdecken, die auf Zellkörper oder deren Bestandtheile, wie z. B. Zellkerne zu beziehen wäre; in ihr treten Vacuolen und Körncheneinlagerungen auf. Dieselbe kann contractile Stränge bilden (die Muskeln aller übrigen Forscher), sie liefert Excrete, Cuticulargebilde u. s. w. Reiciert sagt ferner (l. c. p. 320) von den Bryozoen im Allgemeinen: "Meine Untersuchungen haben ergeben, dass die Bryozoen zu einer Entwicklungs- und Differenzirungsstufe thierischer Organisation gehören, bei weleher die charakteristischen Gebilde des Nervensystems, des Muskclsystems, ferner Blut- und Bindesubstanzgebilde höherer Thiere nicht vorkommen, und die vielmehr durch die "protozootische Substanz " ausgezeichnet ist. « Er theilt ferner die niedrigsten wirbellosen Thiere mit Rücksicht auf den innern Bau in zwei Gruppen : bei der ersten soll die Wand des thierischen Ilohlkörpers ausschliesslich durch die protozootische Substanz gebildet werden, hei der zweiten tritt auch noch das Epithel hinzu, obschon die protozootische Substanz im Gesammthau des Körpers als Hauptbestandtheil anzusehen ist. Zu dieser zweiten Gruppe rechnet Reichert die Bryozoen.

Ob die Reicuent'schen Ansichten über den Bau von Zoobotryon allgemeine Annahme finden werden, muss vorliufig dahin gestellt bleiben. Dagegen muss ich constatiren, dass nach den bis jetzt vorliegenden Untersuchungen cine ganze Reihe von Bryozoen einen histologischen Bau zeigen, der durchaus Nichts gemein hat mit dem von Reiciert der Bryozoenclasse überhaupt zugeschriebenen. Zunächst kommt bei den phylactolämen Bryozoen überhaupt ein Gewebe, welches sich unter den Begriff der protozoolischen Substanz von Reiciert subsummiren liesse, durchaus nicht vor. Ueberall baben wir es bei diesen Thieren mit aus deutlichen Zellen oder Zellderivaten bestehenden Geweben zu thun. Die Kerne der ursprünglichen Zellelemente blciben wenigstens stets auch dann bestehen, wenn, wie $z$. B. bei den innern Wimpernepithel der Endocyste, die Grenzen der einzelnen 
Zellen verschwinden. Die Muskeln der Phylactolämen können nicht als blosse Stränge einer contractilen Substanz angesehen werden, sondern als wirkliche Muskelfasern, da wir bei ihnen, wenigstens ganz sicher bei den grossen Retractoren in jeder Muskelfaser eine innere, contractile Substanz, eine äussere elastische Hülle und einen deutlichen Kern unterscheiden können. Dass Nervenfasern an diese Muskeln herantreten, ist allerdings nicht nachgewiesen; ein solcher Nachweis ist jedoch auch für die Feststellung der musculösen Natur irgend eines Gebildes nicht unungänglich erforderlich. Als Muskelfaser muss angesehen werden ein jedes contractile Element, bei welchem eine äussere elastische Hülle als Antagonist wirkt gegen die contractile innere Substanz des Gebildes und durch seine Elasticität nach Aufhören der Contraction die einzelnen Elemente der contractilen Substanz wiederum zurückführt in ihre ursprüngliche Gleichgewichtslage. Wegen genauerer Angaben über den histologischen Bau muss ich auf (lie Arbeiten von Allmax ${ }^{1}$ ) und Ifvatт ${ }^{2}$ ) verweisen, deren Angaben zu bestitigen ich selbst in meiner Dissertation ${ }^{3}$ ) Gelegenheit hatte. Dass ich ebenfalls die Endocyste der Zoöeien der chilostomen Bryozoen nicht als aus protozootischer Substanz bestehend ansehen kann, geht wenigstens für Flustra membranacea aus den von mir im vorhergehenden Alsschnitte gemachten Angaben hervor; auch Claparède stimmt mil mir hierin überein, wenigstens beschreibt or Kerne in der Endocyste von Bugula und Scrupocellaria. $\left.{ }^{4}\right)$ Auch für eine Ctenostome für Vesicularia cuscuta schildert er die Endocyste der Zoöcien als aus einer deutlichen Zellschicht bestehend. Dass auch die Gewebe der entoprocten Bryozoen bis jetzi, als aus deutlichen Zellelementen bestehend, angesehen wurden, geht aus Kowalewsky's ${ }^{5}$ ) Arbeit über Loxosoma und aus denen von UlıanıN ${ }^{6}$ ) und mir $^{7}$ ) selbst iiber Pedicellina echinata hervor. Eine Widerlegung dieser símmtlichen Angaben wird daher nothwendig sein, um der Reicuert'schen Ansicht über die Ilistolngie der Bryozoen allgemeine Geltung zu verschaffen.

Leipzig, den 3. Mai 1871.

1) A Mionograph of the Freshwater-Polyzoa. 1856.

2) Hyatr, Observ. on Polyzoa ete. Proceed. of the Essex Inet. Vol. IV

3) Archiv für Anatomie. 1868. p. 465.

4) Zeitschr. f. wiss. Zoolog. Vol. XXI.

5) Mémoires de l'Aead. imp. de St. Petersbourg. Vol. X. Nr. 2.

6) Bulletin de la Soc. Imp. des Naturalistes de Moscou. 1870.

7) Zeitsehr. f. wiss. Zool. Vol. XX. p. 1. 



\title{
BEITRÄGE
}

\author{
ZUR
}

\section{KENNTNISS DER BRYOZOEN}

VON

\section{DR. HINRICH NITSCHE,}

PROFESSOR AN DER UNIVERSITÄT LEIPZIG.

III. HEFT.

MIT DREI TAFELN.

V. Ueber die Knospung der Bryozoen.

\section{LEIPZIG,}

VERLAG VON WILHELM ENGELMANN.

1876. 
Abdruck aus der Zeitsehrift für wissensch. Zool. XXV. Suppl.-Bd. 3. Heft. 


\title{
FESTSCHRIF'
}

\author{
SR. EXCELLENZ
}

HERRN GEHEIMRATH UND PROFESSOR

\section{DR. JOHANN FRIEDRICH VON BRANITT}

\author{
ZUR FEIER
}

SEINES FÜNFZIGJÄHRIGEN DOCTORJUBILÄUMS

AM 24. JANUAR 1876

\section{GEWIDMET}

VON DEM ZOOLOGISCHEN INSTITUTE

DER

K. UNIVERSITÄT ZU LEIPZIG. 

V.

Ueber die Knospung der Bryozoen.

\section{A. Ueber die Knospung der Polypide der phylactolaemen Süsswasser- bryozoen.}

(Tafel XXIV u. XXV, Fig. 1-3.)

Die Knospung bei den Bryozoen, oder richtiger gesagt, bei den "Bryozoa ectoprocta ${ }^{1}$ ) geht, wie man schon bei ganz oberflächlicher Betrachtung leicht erkennen kann, bei verschiedenen Formen in verschiedener Weise vor sich, und wenn man blos die allgemeinsten Verhältnisse in Betracht zieht, so kann man zwei verschiedene Hauptmodificationen derselben unterscheiden.

Fassen wir die Natur der Bryozoen in der Weise auf, wie Allman und Levckart dies schon fruher gethan, eine Ansicht, die ich später ausführlicher $\mathrm{zu}$ begründen und festzustellen mich bemüht habe, $d . \mathrm{h}$. jedes »Einzelthier " der früheren Autoren als »Polypocystid «, als ein Doppelthier bestehend aus dem " Cystid " und dessen in letzteres eingeschachtelten Descendenten dem „Polypid", so können wir zwei verschiedene Arten von Stöcken, resp. Stockformen bei den Bryozoen unterscheiden, je nach der Art und Weise wie die Cystide sich verhalten.

Bei den Einen, z. B. bei allen Ghilostomen und Cyclostomen etc., zerfällt jeder Stock in eine gewisse Anzahl von Polypocystide, von denen jedes bis auf geringe Communicationsporen von dem anderen abgeschlossen ist, und sein eigenes Polypid enthält, bei den Anderen, z. B. bei den phylactolaemen Süsswasserbryozoen, hingegen kann man den Stock auffassen als bestehend aus dem übermässig vergrösserten, ge-

1) Vergl. Carus, Handbuch der Zoologie, I, p. 794. 
wachsenen, primären, dem Ei entschlüpften Cystid, an welchem eine grosse Anzahl von Polypiden durch Knospung nach innen entstanden sind, und in welchem es nur hier und da zur Abschliessung getrennter Polypocystide gekommen ist. Auch in den Fällen, in welchen, wie bei Fredericella, einer phylactolaemen Bryozoe, der Habitus des erwachsenen Stockes dem einer chilostomen Bryozoe mit getrennten Polypocystiden ganz ungemein nahe kommt; ist dennoch die Entstehungsweise dieses Stockes ganz ähnlich der, welche wir bei den übrigen phylactolacmen Bryozoen vorfinden, unterscheidet sich dagegen lurchaus von der, die bei den erst erwähnten Formen vorkömmt.

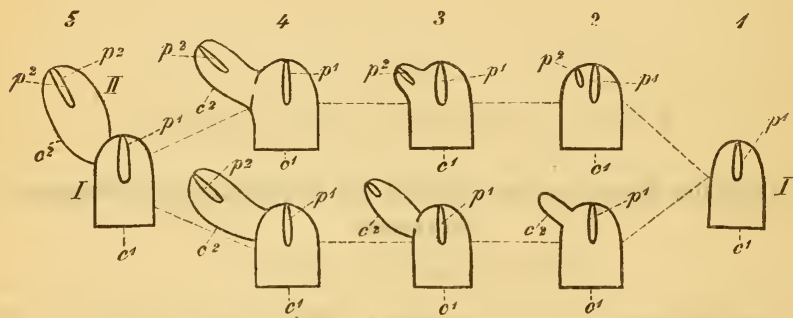

Diese hier angedeutete Verschiedenheit der Entwicklungsweise lässt sich am besten an dem obenstehenden Schema klar machen. Als Ausgangspunct aller Knospung haben wir ein einfaches Polypocystid I mit seinem Cystid $c^{1}$ und seinem Polypid $p^{1}$ hinzustellen. Indem dieses $\mathrm{zu}$ knospen beginnt, verwandelt es sich allmälig in den primären, aus zwei Polypocystiden bestehenden Stock, wie ihn die Fig. 5 aufweist, in welcher das neugeknospte Polypocystid II mit seinem Gystid $c^{2}$ und seinem Polypid $p^{2}$ eingezeichnet ist. Das Schema 5 kann nun aber aus dem Schema $\mathcal{l}$ auf zwei verschiedene Weisen hervorgehen. Einmal (vergl. die unteren Figuren 2, 3, 4) beginnt das Cystid $c^{1}$ zu wachsen und bildet zunächst ein Tochtercystid $c^{2}$, das anfänglich noch in offener Verbindung mit der Leibeshöhle der Mutter (Fig. 2 u. 3), bald gegen diese sich abschliesst. Erst nachträglich beginnt dieses Cystid $c^{2}$ an seiner Innenseite das Polypid $p^{2}$ zu erzeugen. Im anderen Falle aber (vergl. die oberen Figuren 2, 3, 4) beginnt das Cystid $c^{1}$ zunächst dicht nehen dem primären Polypid $p^{1}$ eine zweite Polypidknospe $p^{2} \mathrm{zu}$ bilden, und erst wenn diese einen gewissen Punct der Ausbildung erreicht hat, beginnt der in ihrem Umkreise gelegene Theil des Cystids zu wuchern und sich auszustülpen, und zwar entweder lediglich um in dem auf diese Weise vergrösserten primären Gystide auch Raum für die immer weiter sich 
entwickelnde und heranreifende Polypidknospe zu schaffen, oder um sich (Fig. 4) gegen das primäre Cystid abzugrenzen und ein eigenes zweites Cystid $c^{2}$ zu bilden. Das Polypid II kann also aus dem Polypid I auf zwei ganz verschiedenen Wegen entstehen, und wir können diese beiden Knospungshauptmodificationen als die Knospung mit voraneilendem Cystid und die mit voraneilendem Polypid unterscheiden. Unter die erste Abtheilung im weitesten Sinne gehört ebenfalls die bei den Vesiculariaden vorkommende Art und Weise der Knospung, nur mit dem Unterschiede, dass hier die C y st i d knospung ihr Maximum erreicht. Die primäre Gystidknospe ${ }^{1}$ ) erzeugt keine Polypide, sondern diese nehmen stets nur in lateral an diesem, wiederum in verschiedene "Stammglieder" sich abtheilenden, primären Cystide entstehenden Cystiden ihren Ursprung.

Im Allgemeinen muss man daher jede Untersuchung über die Knospung der Bryozoen in zwei Theile zerlegen, erstens : wie entsteht an dem Muttercystid das Tochtercystid? und zweitens: wie entsteht an dem Cystid das Polypid? Erstere Frage habe ich in einer früheren Arbeit ${ }^{2}$ ) eingehend für Flustra membranacea erörtert, und zu gleicher Zeit auch die Vorgänge der Entstehung des Polypids einer genaueren Betrachtung unterworfen. Dagegen blieb die Frage unentschieden, in welcher Weise die verschiedenen Schichten des Muttercystids an dem Aufbau der verschiedenen Schichten, in die man das Polypid histogenetisch und morphogenetisch zerlegen kann, theilnehmen. Die Schuld hiervon trïgt der Umstand, dass die verschiedenen Schichten der Endocyste bei den erwachsenen Chilostomen so schwer von einander zu trennen sind, dass man dieselben auf das allerleichteste ubersieht. Für die Süsswasserbryozoen, speciell die allein meiner Untersuchung zugänglichen phylactolaemen Formen ist nun aber diese Frage ganz leicht zu lösen, da einmal die einzelnen Schichten des Cystids an der Stelle wo die Knospen sich bilden, sehr deutlich zu erkennen sind, andererseits das Polypid sich ebenfalls leicht auf ein einfaches Schema reduciren lässt.

Bei den phylactolaemen Süsswasserbryozoen besteht die Leibeswand (Endocyst, Allm.) des nicht immer in einzelne streng getrennte Zooecien geschiedenen grossen Cystids 1) aus einer äusseren Zellschicht, 2) einer mittleren Stützlamelle mit Muskelbeleg, die wir als Tunica muscularis bezeichnen wollen und 3) aus einer inneren Wimperzellschicht, welche den Innenraum des Cystids begrenzt. Die Entwicklungsgeschichte

1) Vergleiche meine Ausführungen Zeitschr. f. wissensch. Zool. XXI, p. 493.

2) Zeitschr. f. wissensch. Zoologie. XXI, p. 416-418. 
weist späterhin nach, dass auch hier wie úberall die innere und die äussere Zellschicht das Wichtigste ist, während die Tunica muscularis das Nebensächliche, erst späterhin in übrigens nicht näher erforschter Weise Entstehende ist.

Folgt man der Allman-Leuckart'schen Auffassung, der ich mich angeschlossen habe, derzufolge Cystid und Polypid selbstständige Individuen darstellen, so kann man möglicher Weise, nämlich bei Annahme einer Aehnlichkeit im Bau des Cystids mit einem Coelenteraten resp. einer Gastrula, die Schicht 1 als Ectoderm, die Schicht 3 als Endoderm bezeichnen. Dies ist natürlich gänzlich unstatthaft wenn man das Polypid als den Eingeweidecomplex des Cystids betrachtet; alsdann bleibt die Schicht 1 allerdings in ihrer Bedeutung als Ectoderm bestehen, die Tunica muscularis aber mit der Schicht 3 erscheint alsdann als der Hautfaserplatte entsprechend, während Epithel des Polypids und Darmmusculatur die Darmfaserplatte und die epitheliale Auskleidung des Darmcanales das Darmdrüsenblatt darstellt.

Um zu einer richtigen Auffassung der Schichtenbildung des Polypids zu gelangen, betrachten wir am besten das eingezogene Polypid Wir sehen, dass rings un die Oeffnung, welche von aussen in die Höhlung der zuriirkgezogenen Tentakelscheide führt, die gesammte Leibeswand in die Tentakelscheide übergeht. Der Grund des Tentakelscheiden-Sackes ist von zwei Oeffnungen, der ein wenig höher liegenden Afteröffnung und der Mundöffnung, durchbohrt. Um die Mundöffnung erhebt sich ein Kranz von Tentakeln, von denen die bei weitem grössere, seitlich und analwärts von der Mundöffnung liegende Zahl zweizeilig auf zwei rechts und links vom Munde sich vorfindende grossen primären Tentakeln, den sogenannten Armen des Lophophors angeordnet ist. Die Arme sowohl des Lophophors, als auch die einzelnen Tentakeln sind hohl und communiciren mit einem Ringcanal, welcher den Schlund umgiebt, und an den Basen der Arme des Lophophors in directer, offner Verbindung mit dem Innenraume des Cystids steht. Zwischen Mund und Afteröffnung verläuft der Darmcanal in Form einer mehr oder weniger modificirten, hinten in einen langen Blindsack ausgezogenen Röhrenschlinge. Die Spitze dieser Röhrenschlinge ist durch einen Strang, den Funiculus, an irgend einer Stelle der Leibeswand des Cystids befestigt, und ausserdem ist sowohl die Tentakelscheide als der Darmeanal mit der Cystidwandung durch die Parietovaginalbänder (vergl. das Schema in meinen Beiträgen zur Anat. und Entwicklungsgeschichte der phylactolaemen Süsswasserbryozoen. Arch. für Anat. u. Physiol. 1868, p. 467) und die eigentliche, aus einzelligen Fasern bestehende Musculatur verbunden. Ausserden haben wir noch das Central- 
nervensystem zu erwähnen. Dieses liegt innerhalb des Ringcanales des Lophophors und besteht (vergl. I. c. Taf. III', Fig. 28) aus einem am Rande des Epistoms gelegenen im Querschnitt nierenförmigen Centralganglion, von welchem in jeden Arm des Lophophors ein langer Strang abgeht ${ }^{1}$ ).

Wir können nun ganz leicht erkennen, dass die homogene Stützlamelle die mittlere Schicht dieser sämmtlichen Organe bildet, und an bei weitem den meisten Stellen ebenfalls mit Muskelfasern belegt ist. Sie geht an den Rändern der Einstülpungsöffnung direet in die Tunica museularis des Cystids über (vergl. Taf. XXV, Fig. V den schwarzen Strich). Gehen wir ferner auf die Zusammensetzung der deutlich zelligen Schichten des Polypids näher ein, so erkennen wir, dass dureh die Einstülpungsöffnung die äussere Zellschicht des Cystids sich direct in die sehr dünn werdende Zellauskleidung des Tentakelscheidensackes fortsetzt, und dass diese selbe Zellschicht ferner die gesammte äussere Fläche der Arme des Lophophors überzieht; an der Innenseite der Tentakeln wandelt sie sich in ein Wimperepithel um, das ganz direct wieder in das Wimperepithel des Oesophagus übergeht. Letzteres setzt sich alsdann direct fort in die epitheliale Auskleidung des Darmtractus, und an der Afteröffnung des Enddarmes geht es wiederum in die innere Auskleidung des Tentakelscheidensackes über. Wir haben es daher hier mit einem continuirlichen, sehr merkwürdig ausgebauchten, aber völlig in sich geschlossenen Zellsacke zu thun, welcher an der Einstülpungsöffnung des Cystids direet in dessen Eetodermlage ubergeht. Dies ist

1) Von dem wirklichen Vorhandensein eines Schlundringes habe ich mich neuerdings nicht wieder zu überzeugen Gelegenheit gebabt. Dagegen kann man an jeder lebenden Colonie von Cristatella mucedo mit leichter Mühe die Nervenstränge in den Lophophorarmen beobachten, und mit absoluter Sicherheit constatiren, dass auch von dem Innenrande derselben Nerven abgegeben werden für die Tentakeln an der Innenseite der doppelthufeisenförmigen Tentakelkrone. Ich möchte bei dieser Gelegenheit bemerken, dass erst in diesem Frühjahr Cristatella mucedo, deren Statoblasten allerdings schon früher von mir gesehen worden waren, durch die Herren Studiosen Reichenbach und HatscheK in "Schimmels "Teich" zu Leipzig aufgefunden wurde, und zwar in sehr grosser Anzahl und herrlichen bis $\uparrow$ Fuss langen Stöcken. Dieselben leben meist an den Stengeln und der Unterfläche der älteren Nymphaeenblätter, deren eines einmal gegen 30 Colonien trug. Dieselben Herren haben ferner durch längere Versuche auch ein Verfahren ausfindig gemacht um gute Präparate von diesem Thier herzustellen. Es besteht darin, dass man das, auch unter dem Druck eines Deckgläschens die Tenkelkronen weit hervorstreckende Thier auf dem Objectträger und unter dem Deckglase in einem grösseren Gefäss mit Wasser allmälig matt werden lässt, alsdann das Thier unter dem Deckglase durch Osmiumsäure tödtet und nach einer kurzen Härtung in Alkohol mit BEALEschem Carmin färbt. 
keine erschlossene, sondern durch die directe Lntersuchung des erwachsenen Thieres auf das leichteste nachweisbare Thatsache. Dieser Gesammt-Zellsack ruht direct auf der homogenen, an vielen Stellen mit Muskelfasern belegten Stutzmembran, und nach aussen von dieser folgt nun die zweite äussere Zellschicht. Diese steht an der Einstülpungsöffnung in Verbindung mit der inneren Wimperzellschicht des Cystids, bekleidet gleichmässig die der Höhle des Cystids zugewandte Fläche der Tentakelscheide, geht über auf die Parietovaginalbänder, setzt sich durch die an der Basis der Arme des Lophophors gelegenen Oeffnungen direct in die Höhlung des Lophophors und sämmtlicher Tentakeln fort, und bekleidet natürlich auch die nach der Höhlung des Lophophors gekehrte Fläche der Nervenstränge. Sie geht ferner continuirlich auf den Darmcanal über, und bildet dessen äusseres Epithel, sie bekleidet die Oberfläche des Funiculus und steht an den Stellen wo Parietovaginalbänder und Funiculus dem Cystid sich inseriren, in directer nochmaliger Verbindung mit der inneren Zellschicht des Cystids. Fernere directe Verbindungen zwischen der letzteren und dem äusseren Tentakelnscheidenepithel sowie mit dem äusseren Epithel des Darmcanales werden durch die langen, einkernigen Spindelzellen hergestellt, welche die Elemente der Parietovaginalmuskeln und der grossen Bewegungsmuskeln des Polypids bilden. Das Nervensystem besteht aus einem inneren grosszelligen Kern und einer aus platten Zellen bestehenden äusseren Hülle. Diese Verhältnisse sind auf dem Schema Taf. XXVI, Fig. V u. VI deutlich dargestellt, nur sind Muskeln, Parietovaginalbänder und Funiculus weggelassen. Es ist ferner auf diesem Schema der mit dem Ectoderm des Cystids in Verbindung stehende Zellsack blau, die Tunica muscularis resp. die Stützmembran schwarz, und der mit dem inneren Epithel des Cystids zusammenhängende Zellsack roth colorirt. Die eigentliche nervöse Substanz des Ganglion ist blau, die Hülle roth dargestellt worden, ein Verfahren, welches erst weiter unten durch die Knospungsgeschichte ihre Begründung finden kann.

Ich will nun in dem Folgenden die Frage zu lösen versuchen, wie entsteht an dem Cystid das Polypid und in welcher Weise nehmen die Schichten des Gystids an der Bildung der Polypidschichten Antheil?

Die Resultate dieser meiner jetzt folgenden Darstellung geben nun aber nicht etwa etwas Neues; ich habe in meiner vorläufigen Mittheilung ${ }^{1}$ ) bereits gezeigt, dass Metscunikofr es war, dem das Verdienst zukommt, die wichtigsten Thatsachen in scharfen Umrissen festgestellt zu haben. Ich sagte in dieser vorläufigen Mittheilung: »aber bereits ehe diese

1) Sitzungsber. d. Naturf. Gesellsch. zu Leipzig, 1. Jahrg. 1874, p. 62. 
Angaben (in Betreff der Bildung des Polypids bei den Seebryozoen) publicirt wurden, hatte Metscinıкoff ${ }^{1}$ ) der Petersburger.Academie eine wahrhaft lakonische vorläufige Mittheilung üher die Entwicklung der Alcyonella gemacht - dieselbe wurde erst vicl später in Deutschland bekannt - welche einen ganz bedeutenden Fortschritt auf diesem Gebiete darstellt. Nicht allein wurde durch diese Arbeit, wie Nitscue späterhin nachwies ${ }^{2}$ ), das Räthsel, warum man bei den phylactolaemen Bryozoen keine Oeffnung zum Austritte der Embryonen entdecken konnte, auf die einfachste Weise gelöst, sondern in den letzten Zeilen dieser Mittheilung sind auch in Betreff der Art, wie die Polypide an der jungen Larve d. h. dem primären aus dem Ei entstandenen Cystide knospen, so genaue Mittheilungen niedergelegt, dass weitere über diesen Gegenstand eigentlich überflüssig erscheinen könnten.

Der ganze Wortlaut dieser Mittheilungen ist folgender : mDie beiden Zooiden entwickeln sich wie gewöhnliche Knospen, wobei die beiden Keimblätter einen grossen Antheil nehmen. Das obere Blatı dient zur Bildung der Epidermis des Tentakel- und Darmepithels und höchstwahrscheinlich auch zur Erzeugung des bei dem Embryonen sehr grossen Nervenganglions. Das untere Blatt bildet dagegen die Muskeln des gesammten Körpers sowie das innere Epithel nebst Genitalien. «"

Ich bin nun im Stande diese Angaben bis in das Detail hinein zu bestätigen und die Berechtigung, meine gleichlautenden Angaben über diesen Gegenstand zu publiciren und hier in vorläufiger Mittheilung zu erwähnen, begründet sich lediglich darauf, dass 1) meine Untersuchungen nicht an den primären embryonalen innerhalb der Larve entstehenden, sondern an später am Stocke sich entwickelnden Polypiden gemacht worden, dass 2) die Anwendung der Schnittmethode es mir gestattete so deutliche Bilder zu bekommen, dass jede cinzelne Zelle mil der Camera lucida gezeichnet werden konnte, dass 3) ich im Stande bin genaue Angaben über die Formung des Polypids aus der Knospenanlage zu machen; Angaben welche in der МетsснмікоғF'schen vorläufigen Mittheilung vollkommen fehlen. Auch ist dieser vorläufigen Mittheilung bis jetzt noch keinerlei ausführlichere Mittheilung gefolgt, in deren Erwartung ich die demnächst zu publicirenden Angaben und Zeichnungen beinahe zwei Jahre im Pulte habe ruhen lassen.«

Ausser den eben erwähnten Angaben Метschxiкоғf's habe ich keine weitere Literatur zu berücksichtigen, da alle anderen älteren Angaben in Betreff der Süsswasserbryozoen in keiner Weise auf die Frage

1) Mélanges biologiques T. VII. p. 675 .

2) Zeitschr. f. wissensch. Zoologie. XXII, p. 467. 
eingehen, wie aus den Schichten des Mutterthieres sich die Schichten des Polypids entwickeln, und die neueren Arbeiten über Bryozoenknospung nicht an Phylactolaemen, sondern an Gyclostomen und Chilostomen, d.h. an, wie meine eigenen Untersuchungen mir gezeigi haben, weniger zu der genaueren Erforschung der Knospungsvorgänge geeigneten Formen, angestellt worden sind. -

Die Beobachtung der Entstehung der ersten Polypidanlage an dem Cystid ist am leichtesten an den secundären Polypidknospen zu machen, die an dem sogenannten Embryo der phylactolaemen Bryozoen sich entwickeln nachdem dasselbe sich bereits festgesetzt und in den jungen Stock verwandelt hat. Was zunächst den Embryo selbst betrifft, so entwickelt er sich, wie МетschnıкоғF an oben citirtem Orte nachgewiesen hat, und wie ich selbst ${ }^{1}$ ) bestätigen konnte, nicht frei in der Leibeshöhle des Mutterthieres, sondern in einem inneren Ooecium. Die (Taf. XXV, Fig. 1) gegebene Wiederholung des von mir vor einigen Jahren veröflentlichten Holzschnittes stellt einen noch in diesem Ooecium eingeschlossenen Embryo dar. Derselbe entspricht ohngefähr dem von Allman $\left.{ }^{2}\right)$ auf Taf. XI, Fig. 33 dargestellten. Man sieht auf meiner Zeichnung genau die Falte $\left(F\right.$ u. $\left.F^{1}\right)$ welche, wie Mrtschnikoff gezeigt hat als eine Art Kragen an dem ursprünglich einfach sackförmigen Embryo auftritt und den Theil der Leibeswand schützt, von welchem die Tentakelscheide der primären beiden Polypide $(P)$ sich durch die Oeffnungen $(0)$ invaginirt. Ist der Embryo nun später durch die Oeffnung des Ooecium, - also wie ich bereits fruher zu zeigen suchte, ohne Eröffnung der eigentlichen Innenhöhle des Cystids - nach aussen gelangt, so schwimmt er eine Zeit lang frei herum und setzt sich dann fest. Bei dieser Fixirung geht er aus dem eben kurz beschriebenen Stadium in das Stadium des primären Stockes (Fig. 3) uber. Bei dieser Verwandelung verliert er die Falte. Die Modalität dieses merkıürdigen Vorganges ist noch nicht bekannt. Sie wird aber durch Vergleich der Figuren 1, 2 u. 3 sehr klar. Die Leibeswand des jungen Stockes geht nämlich ausschliesslich hervor aus dem von der Falte bedeckten Theile des Embryonalkörpers, also aus dem in Fig. 1 zwischen den Buchstaben 0,0 u. $b, b$ gelegenen Theile.

Dieser ist es der wächst, während die Falte sowohl als der vom Grunde $b$ der Falte bis zu dem durch $c$ bezeichneten hinteren Pole des Enbryo verlaufende Theil der Leibeswand des primären Cystids regressiv metamorphosirt wird. Die Einstulpungsöffnungen der beiden primären

1) Zeitschr. f. wissensch. Zoologie. XXII, p. $467 \mathrm{ff}$.

2) A Monograph of the Fresh-Water Polyzoa. 
Polypide, dié in Fig. I nahe bei einander liegen, rücken durch stärkeres Wachsthum der zwischen ihnen liegenden Leibeswand des Gystids auscinander (Fig. 2) und kommen schliesslich bei dem jungen Stocke (Fig. 3) auf die diametral entgegengesetzten Enden desselben zu liegen. Die Falte, die anfänglich (Fig. 1) nach vorn den Embryonalleib umschloss, wird nach hinten umgeschlagen, und überdeckt jetzt den im Wachsthum gegen das Vorderende zurückgebliebenen hinteren Pol der Larve (Fig. 2). Schliesslich wird (Fig. 3) die ganze hintere Hälfte der Larve mitsammt der Falte in das Innere des jungen Stockes hineingestulpt, und geht einer regressiven Metamorphose wahrscheinlich durch Verfettung entgegen. Die in der Figur 3 noch bestehende Einstülpungsöffnung entspricht also mit ihrem Rande $b b$ ohngefähr einem im Embryo Fig. 1 rings um den Embryonalkörper durch die Buchstaben $b b$ gedachten Kreise; der Punct $c$ des letzteren Embryo entspricht dagegen dem gleichbezeichneten der Figur 3. Aber auch diese Einstülpungsöffnung schwindet schliesslich und es liegt nun der regressiv metamorphosirte Rest der hinteren Hälfte des Embryonal- resp. Larvencystids als ein bald resorbirter Klumpen von zerfallenden Zellen im inneren der Höhle des jungen Gystids. An diesem hat bereits früher die Ausbildung der Cuticula, der sogenannten Ectocyste begonnen. Aber die Ausscheidung dieses anfänglich gallertigen und glashellen Secretes findet nicht statt an dem Theil des Embryonal- resp. Larvenkörpers der früher die Wimpern getragen hat, sondern an dem gleich von Anfang an wimperlosen. Der wimpertragende, d. h. das äussere Blatt des faltenartigen Kragens und der hintere Theil des Embryo ist ja ganz zu Grunde gegangen.

Bereits ehe diese regressive Metamorphose eines Theiles des primären Gystids vor sich geht, hat die Bildung von vier neuen Knospen begonnen. Der junge Stock (Fig. 3) liegt in derselben Weise einem Nymphaeenblatte oder einem anderen in Wasser befindlichen Körper auf, wie die Zeichnung dem Papiere. Er kann nun durch eine Ebene, welche durch die Symmetrieebene beider Polypide gelegt wird, in zwei völlig symmetrische Hälften getheilt werden. An der Stelle, wo diese Ebene das Gystid schneidet, und zwar an der dem Oesophagus der primären Polypide zugewendeten Seite entstehen die neuen Polypidknospen; man kann hier ganz deutlich sehen, dass sie wie Metschniкoff angiebt, aus den beiden primären Schichten der „Endocyste« des jungen Stockes entstehen. Die Beobachtungen und Zeichnungen, auf welche icb diese Darstellung gründe, sind bereits alt; ich habe sie nicht von neuem controlirt. Aber meine Zeichnungen lassen über dic Richtigkeit der Beobachtung keinen Zweifel zu, besonders da sie einer Zeit entstammen, in welcher ich von der tieferen Bedeutung dieser Vor- 
gänge noch gar keine Vorstellung hatte. Ich erwähne sie hier nur, weil an der Larve die Vorgänge wegen der Durchsichtigkeit der Gewebe leichter zu constatiren sind als an den erwachsenen Stöcken. Wie es mit der Tunica muscularis steht, das kann ich für die jungen Formen nicht angeben. Dagegen habe ich mich auf Schnitten der an den erwachsenen Stöcken von Alcyonella und Cristatella auftretenden Polypidknospen überzeugt, dass an der Stelle wo die Knospen entstehen, die Tunica muscularis durchbrochen wird. Die späterhin auftretende Tunica muscularis des Polypids stammt also nicht direct von der Tunica muscularis des Cystids ab. Fig. 1 u. 6 auf Taf. XXIV, stellen zwei der eben erwähnten Schnitte dar. Am schwierigsten ist das Verhältniss der einzelnen Schichten der Knospe zu den Schichten des Cystids bei Cristatella festzustellen, weil hier die äussere Zellschicht des Gystidleibes eine ganz besonders starke Metamorphose erfahren hat. Es sondern hier die Zellen dieser Schicht (Fig. 6, a) an ihrer Oberfläche nicht eine einfache Cuticula ab, sondern sie stellen eine Art Becherzellen dar, die ganz ungemein hoch werden. In ihrem Inneren finden sich grosse starklichtbrechende durchaus homogene Klumpen, die, wie ich vermuthe, durch Ruptur der äusseren Zellwandung nach aussen hervortreten und dann als höchst merkwürdig gestaltete flaschenförmige Secretballen der Oberfläche des Thieres ansitzen und die Ectocyste vertreten 1). Es scheint nun dass diese grossen Zellen immer wieder ergänzt werden durch kleinere Zellen, die zwischen ihrer Basis der Tunica muscularis direct aufliegen, und diese den jungen Zellelementen der Endocyste noch näher stehenden Zellen scheinen es zu sein, welche übergehen in die innere Schicht der Knospe. Eine deutliche Einstülpungsöffnung ist auf der Aussenfläche von Cristatella n icht zu sehen. Dagegen kann man ganz genau erkennen, dass die innere Epithelialauskleidung des Cystids direct übergeht in die äussere Zellschicht der Knospe, und dass an der Stelle, wo die Knospe mit der Wand des Cystids zusammenhängt, niemals ein Zusammenhang beider ZelIschichten der Knospe stattfindet, beide vielmehr durch eine scharfe Demarcationslinie von einander getrennt sind. Ich kann ferner auch nicht sagen, ob wir es bei der Bildung der inneren Zellschicht der Knospe des Cristatellapolypids wirklich mit einer typischen In vagination des Ectoderms zu thun haben oder nicht, vielleicht mit einer

1) Ich muss sehr bedauern, hier nicht die Angahen von Hvatr über diese Puncte, resp. über die Knospung berücksichtigen zu können. Das Exemplar der betreffenden Arbeit, die mir durch die Güte des Verfassers zuging, ist mir abhanden gekommen, und in Leipzig kein Exemplar der Proceedings des Essex Institutes aufzutreiben. 
zapfenähnlichen Wucherung derselben, in der sich späterhin erst die innere Knospenhöhle durch Auseinanderweichen der Zellen ausbildet.

Viel klarer liegen die Verhältnisse bei Alcyonella; breitet man das einer Einstülpungsöffnung der Tentakelscheide zunächst gelegene Stück der Cystidleibeswand eines älteren Stockes aus, so dass man auf die äussere Fläche der von ihrer Cuticula (Ectocyste) befreiten Leibeswand (Endocyste) sieht, so erkennt man an der Stelle, wo eine junge Knospe wie die im Schnitt No. 1, Taf. XXIV dargestellte, - liegt, deutlich eine Einsenkung des hier bedeutend weniger als bei Cristatella metamorphosirten Ectoderms. Ich habe diese Einstülpung auf den verschiedenen Schnitten, die ich (Taf. XXIV, Fig. 1, 2 u. 3) abgebildet habe, durch $h$ bezeichnet. Es stellt dieselbe aber nicht eine runde Einsenkung dar, sondern einen länglichen Spalt, der späterhin senkrecht gegen die sich ausbildende Symmetrieebene des jungen Polypids zu stehen kommt.

Wir haben also wie dies überhaupt bei allen ectoprocten Bryozoen der Fall zu sein scheint, als erste Anlage des Polypids einen zweischichtigen Zellsack mit einer inneren Höhle $(I)$. Die diese zunächst begrenzende Zellschicht (Fig. 1, 2, $a^{\prime}$ ) stammt bei den Phylactolaemen her von dem Ectoderm $(a)$ des Cystids, und bleibt mit ihm dauernd im Zusanmenhange; die äussere Zellschicht der Knospe $c^{\prime}$ geht dagegen direct über in die innere Zellauskleidung des Cystids $c$.

Vergleicht man nun diese Knospenanlage mit dem Schema des erwachsenen Polypids, wie ich es oben auf Grund der anatomischen Befunde darstellte, so tritt sofort die Vermuthung nahe, dass wir in den beiden Zellschichten der Knospe die beiden Zellschichten des erwachsenen Polypids vorgebildet haben, und diese Vermuthung erweist sich hei genauerer, übrigens nur an Schnitten resp. Spaltpräparaten von Knospen ausführbaren Untersuchung als völlig richtig. Der Rest dieser Arbeit ist nun lediglich gewidmet der Darstellung, wie durch Faltenbildung und Faltenconcrescenz aus der Knospenanlage sich die definilive Form des in seinen wesentlichen Bestandtheilen bereits vorgebildeten Polypids entwickelt.

In dieser Darstellung wird man aber Lücken finden, die ich hier sofort klar bezeichnen will: es ist nir nicht gelungen die Bildung des Funiculus, der Tunica muscularis und der grossen Muskeln ganz festzustellen. Die Tunica muscularis ist plötzlich da, ohne dass ihre Herkunft von dem einen oder dem anderen, oder vielleicht beiden Blättern der Knospe nachzuweisen wäre. Desgleichen ist der Funiculus als ein der Oralseite der jungen Knospe anliegender, einerseits mit dem Epithel des Magensackes, andererseits mit dem Epithel der inneren Zellschicht des Cystids zusammenhängender Zellstrang ebenso plötzlich vorhanden, ohne 
dass seine Entstehung nachzuweisen wäre. Er liegt zunächst der äusseren Wandung der Knospe dicht an, und sein Insertionspunct an dem Cystid liegt nahe der Einstülpungsöffnung des Ectoderms, rủckt aber schliesslich durch Wachsthum der zwischenliegenden Leibeswand immer weiter von dieser ab. Schon früh (Fig. 3 Fun.) kann man eine Anschwellung an demselben erkennen. Ob diese die Anlage der Statoblasten, oder die Bildungsstätte der Genitalproducte darstellt, weiss ich nicht; ersteres scheint mir aber das Wahrscheinlichere.

Was die Muskeln des Polypids, d. h. die Parietovaginalmuskeln und die grossen Bewegungsmuskeln betriff, so bin ich zwar nicht zu ganz scharfer Feststellung der Einzelvorgänge bei ihrer Bildung gelangt, dagegen glaube ich die allgemeinen Züge derselben feststellen zu können. Es braucht wohl nicht noch einmal gegenüber Reichert besonders betont zu werden, dass hier von Strängen einer "protozootischen Substanz in keiner Weise die Rede sein kann. Jedes Element dieser Muskelstränge stellt ein e mit einem deutlichen Kern versehene langausgezogene Zelle dar, wie dies auch bei den übrigen Bryozoa ectoprocta der Fall ist. Es sind diese Muskeln nun einfache Elemente der äusseren Zellschicht der Knospe, welche ursprünglich in dem Winkel gelegen waren, wo diese mit der inneren Zellauskleidung des Cytids zusammenhängt. Durch das Wachsthum des Cytids, welches jederzeit die Neubildung von Polypiden begleitet und welche den nöthigen Raum schafft für die weitere Entfaltung der letzteren, werden nun diese Zellen spindelförmig ausgezogen. Es stimmt diese Angabe auch mit den Ansichten von Metscunikoff. Ueber die Bildung der Parietovaginalbänder weiss ich nichts zu berichten.

Es sei hier ferner gleich eine hesondere Eigenthümlichkeit der Knospungsverbältnisse der Phylactolaemen erwähnt, welche in der weiteren Darstellung nicht wohl untergebracht werden kann und soviel mir bekannt bei den anderen Bryozoen nie vorkommt. Es ist die Thatsache, dass in sehr vielen Fällen, sowohl bei Cristatella als bei Alcyonella nicht e in sondern $\mathrm{z}$ we i Polypide aus derselben Knospenanlage hervorgehen. Dies ist z. B. in Fig. 3 der Taf. XXIV dargestellt. Aber die zweite Knospe ist hier nicht ganz ausgezeichnet, sie steht aber nicht etwa im Zusammenhange mit dem Funiculus, wie man bei oberflachlicher Betrachtung der Abbildung vermuthen könnte, sondern dieser läuft hinter ihr weg. Eine solche secundäre Knospe entsteht an der primären Knospenanlage bäufig schon sehr früh. Besonders ist dies bei Cristatella der Fall, wo oft zwei noch ganz junge Knospen, ähnlich wie die von Alcyonella auf Tafel XXIV, Fig. 1 dargestellte, von einer und derselben Einstülpungsstelle ausgehen, so dass man anfänglich eine tief 
nierenförmig eingeschnittene Knospe zu sehen meint, die mit der convexen Seite der Leibeswand des Thieres ansitzt. Ebenso wie bei der Entwicklung des Embryo, resp. der Larve zu dem jungen Stocke die beiden Polypide auseinanderrücken, ebenso geschieht dies bei der Weiterentwicklung der beiden oben beschriebenen zusammenhängenden Knospen, die man anfänglich, wenn sie beide ziemlich gleichaltrig sind, wie bei Cristatella, wohl gut als Doppelknospe bezeichnen könnte.

Ehe ich zur weiteren Darstellung der Knospung schreite, muss ich noch bemerken, dass Alcman die einzelnen Stadien auf seiner Tafel XI eigentlich recht gut abgebildet hat. Nur hat die Durchsichtigkeit der Knospen ihn verhindert die Reliefverhältnisse ihrer Aussenseite genügend zu würdigen, und erst diese, verbunden mit der Schnittoder richtiger gesagt Spaltungsmethode ist im Stande uns einen richtigen Begriff von den Vorgängen zu geben. Was die von mir sehr häufig ausgeführten Spaltungen der Knospen betriff, so möchte ich bernerken, dass zu der scheinbar schwierigen Ausführung derselben weiter nichts gehört als ein wenig Geduld. Ich habe dieselhe auf dem Objectträger unter einer Gundlach'schen Präparirloupe mit einem gewöhnlichen feinen Scalpell an Osmiumsäure- und Alkoholpräparaten vorgenommen. Die Knospe darf dabei nicht in einem zu grossen Flüssigkeitstropfen liegen, sonst weicht sie dem Messer zu leicht aus und wird auch leicht durch die Bewegung, welche entsteht wenn das Messer mit der Flüssigkeit in Berührung tritt und diese sich an ihm hinaufzieht, verschoben. Am besten wählt man ein, auf einem guten Schleifstein nach jedem Schnitt wieder zu schleifendes, Messer mit convexer Schneide, welches alsdann nach Art eines sogenannten Wiegemessers geführt wird. Man schneidet nämlich nicht aus freier Hand, sondern setzt die Mitte der Schneide zunächst auf den Objectträger auf und führt dann den Schnitt aus, indem man die Spitze des Messers durch Heben des Heftes senkt ohne die Mitte der Schneide von der Unterlage zu entfernen. Ich führe dieses Verfahren deshalb ausführlich an, weil dasselbe sich zu Schnitten und Spaltungen aller derjenigen minutiösen Objecte sehr gut verwerthen lässt, welche sich wegen der Schwierigkeit, sie in einer Einhettungsmasse wiederzufinden, nicht wohl mit dem Rasirmesser schneiden lassen.

Die äussere ganz grobe Gestaltveränderung der Knospen ist von Allman Taf. XI, Fig. 10, 11, 12 u. 13 wie gesagt gut wiedergegeben. Die ursprünglich knopfförmig in das Innere des Cystids vorragende Knospe (Taf. XXIV, Fig. 1) nimmt auf dem Längsschnitt bald eine lang flaschenförmige Gestalt an (Fig. 2); man darf sich aber den Querschnitt dieser Knospe nicht etwa an jeder einzelnen Stelle drehrund denken; 
die Knospe wird vielmehr bald so zusammengedrückt, dass der kürzeste Durchmesser ihres Querschnittes in die Medianebene fällt. Dies ist besonders in noch etwas späteren Stadien stark ausgeprägt und wird in der Fis. 12 von Alluan, sowie in der von mir Taf. XXIV, Fig. 7 gegebenen Abbildung ausgedrückt. Der ursprüngliche Hohlraum der Knospe stellt genau wie bei den chilostomen Bryozoen die Anlage des Hohlraums der Tentakelscheide und des Darmtractus dar. Der der Anheftungsstelle der Knospe zunächst liegende Theil wird zu ersterem, letzterer geht aus dem hinteren Theile des Hohlraumes hervor. Getrennt werden diese beiden Anlagen, indem sich jederseits an der Knospe eine Furche bildet, welche beide Blätter derselben nach innen gegen einander zu einstülpt. Man muss sich den Vorgang ähnlich denken, wie wenn man einen zweischichtigen hohlen Gumniball in beide llände nähme und nun mit dem Finger jederseits so lange drückte, bis sich die beiden Fingerspitzen, getrennt durch die vierfachen Wandungen des Balles, gegeneinanderlegten. Es ist dies derselbe morphologische Vorgang, den ich Zeitschr. f. wiss. Zool. XXI. Taf. III, Fig. 22 bei Flustra membranacea auf einem Längsschnitt dargestellt habe. Derselbe ist auch sehr gut von Allman Taf. XI, Fig. 12 gezeichnet worden, und zwar in seinem Beginne. Man muss sich aber nicht denken, dass direct eine ganz tiefe Furche sich bildet, diese wird erst später deutlich, anfänglich schiebt sich jederseits nur eine wuchernde der iusseren Knospenschicht entstammende Zellleiste gegen die Medianebene vor und trennt das schlingenförmige Darmrohr, resp. dessen Epithelialauskleidung von dem Hohlraum der Tentakelscheide ab. Erst späterhin trennt sich diese Zellleiste in zwei Blätter, die Einstülpungen treffen aufeinander und versehmelzen. Es ist dann ein Stadium erreicht, welches auf Taf. XXIV, Fig. 8 abgebildet und das mit Weglassung der gleichzeitig erfolgenden Bildung der Arme des Lophophors schematisch auf Taf. XXVI, Fig. II dargestellı ist. Wir erhalten oben einen hohlen zweischichtigen Sack, dessen Wandungen die Anlage der Tentakelscheide darstell, an den sich nach unten wie ein hohler Henkel (ich entnehme dies gute Bild dem Horer'schen Referate über die Korotnıefr'sche Arbeit über die Knospung von Paludicella, eine Arbeit, die übrigens wohl auf einem sehr unvollständigen Verständniss der wirklichen Vorgänge beruht) der Darmcanal anschliesst; derselbe besteht nach aussen aus einem der äusseren Knospenschicht entstammenden dünneren Epithel und einer inneren grossen dicken Zelllage, dem eigentlichen Darmepithel. Der Darm communicírt mit zwei Oeffnungen, der Mund- und Afteröffnung, mit dem Hohlraum der Tentakelscheide. Sowohl an jungen Alcyonellenstöcken (Taf. XXV, Fig. 3), als an Cristatellenstöcken (XXIV, Fig. 11) ist 
die den Darm einer jeden jungen Knospe in zwei symmetrische Seitenhälften theilende Medianebene dieselbe wie die Medianebene des nächsten älteren Polypids, oder läuft derselben wenigstens parallel. Es ist ferner bei den jungen Alcyonellastöcken sowohl wie bei den Cristatellastöcken das Einzelindividuum immer gleich gerichtet. Die älteren Polypide, welche die beiden mittelsten Längsreihen des langgestreckten Stockes von Gristatella bilden, wenden sich (vergl. das Schema, Taf. XXIV, Fig. 11) immer der Analseite zu, und das gleiche kann man Taf. XXV, Fig. 3 bei Alcyonella sehen; die beiderseitigen jungen Knospen wenden alsdann ebenfalls wiederum ihre Analseite dem nächst älteren Thiere zu; aber insofern ist bei den jungen Alcyonellastöcken eine verschiedene Anordnung der Individuen wie bei Cristatella, als bei ersteren, wenn einmal die secundären Knospen $\left(\boldsymbol{K} n^{\prime \prime}\right)$ sich gebildet haben, zwischen diese und das Mutterthier die dritte $\left(\boldsymbol{K} n^{\prime}\right)$ eingeschoben wird (Taf. XXV, Fig. 3), während bei Cristatella die jungsten Knospen die äusserste Randzone des Stockes einnehmen und die Individuen von innen nach aussen zu immer jünger werden (Fig. 11, Taf. XXIV).

Es ist nun noch die Bildung des Lophophors und des Nervensystems zu besprechen.

Ich habe in meiner Darstellung der Tentakelbildung an den Knospen von Flustra membranacea ${ }^{1}$ ) gezeígt, dass die Tentakeln dieses Thieres und, wie ich jetzt hinzusetzen kann, auch anderer Bryozoen mit später kreisförmigem Lophophor, nicht gleich anfänglich in einem Kreise, sondern in einem nach dem After zu offenen Halbkreise entstehen. Ich babe ferner diese Anordnung verglichen mit der Anordnung der Tentakeln bei den phylactolaemen Bryozoen. Diese letztere Anschauung ist aber nicht haltbar. Die Tentakeln der Phylactolaemen sind, was ihre Entstehung betriff, gar nicht ohne Weiteres mit den Tentakeln der »Infundibulata von Gervals zu vergleichen. Es erscheinen dieselben vielmehr als secundäre Bildungen an den beiden Armen des Lophophors, und diese letzteren sind es, welche zunächst entstehen und gewissermassen als zwei primäre grosse Tentakeln betrachtet werden können. Gleichzeitig mit der Abschnürung des Darmcanals, oder richtiger gesagt, noch ehe dieselbe vollständig geworden, entsteht nämlich rechts und links an der Knospenanlage (vergl. Taf. XXIV, Fig. 7 u. 8) eine Einstülpung in der Nähe der Afteröffnung. Diese Einstülpungsötfnung ist auf den beiden Figuren mit $E$ bezeichnet. Hierdurch wird ein hohler Zapfen jederseits in die Höhle der Tentakelscheide vorgetrieben, der als $L^{\prime}$ auf beiden Figuren bezeichnet, deutlich durch die immer dünner wer-

1) Zeitschr. f. wissensch. Zoologie. XXI, p. 44 u. 45. 
denden Wände der Tentakelscheide durchschimmert. Auf dem Schnitte Fig. 3 ist derselbe ebenfalls $(L)$ ganz deutlich. Dies sind die Anlagen der Lophophorarme, und ihre Höhlung die Höhlung dieser. Diese innere Höhle der Arme steht also anfänglich in ganz weiter offener Communication mit der Höhle des Cystids und communicirt niemals mit dem Oesophagus oder dem Darm, ebensowenig wie die Höhlung der Tentakeln irgend eines Bryozoon. Die Vermuthung Reichert's ${ }^{1}$ ), dass eine solche bei Zoobotryon pellucidus bestände, ist also völlig falsch. Die innere Zellschicht der Knospe giebı die äussere Zellbekleidung der Lophophorarme, während die innere dünne, übrigens bei Cristatella ganz sicher zu erkennende Epithelialauskleidung der Lophophorhöhle von der äusseren Zellschicht der Knospenanlage geliefert wird. Die Lophophorhöhle des erwachsenen Thieres beschränkt sich aber nicht auf die Höhlen der beiden Arme, sondern läuft als ein geschlossener Ringcanal um den Mund herum. Dieser Canal entsteht, indern von den beiden seitlichen Einstülpungsöffnungen der Lophophorarme eine Rinne (Fig. $8 L F$ ) nach der Mundseite der Knospe zu sich bildet. Diese Rinne der Aussenseite der Knospe erscheint in dem Hohlraum der Tentakelscheide als eine erhabene Leiste, welche den Mund umzieht (Taf. XXIV, Fig. $4 L^{\prime \prime}$ ). Vor dem Munde stossen bald die Rinnen, resp. Leisten jeder Seite zusammen. Auf gespaltenen älteren Knospen erscheint daher auf der Mundseite eine Einbiegung der beiden Blätter (Fig. $4 L F$, schematisch auf Taf. XXVI, Fig. IV). Durch spätere Vertiefung dieser Rinne und durch Verwachsung ihrer Ränder wird dann der Ringcanal ausgebildet. Auf den Schenas Taf. XXVI, Fig. V u. VI ist diese Verwachsung nicht eingezeichnet, um besser die ursprüngliche Communication der Tentakelhöhle mit der Leibeshöhle des Cystids zu zeigen. Die Gestalt, welche der gesammte Lophophor bei einer älteren Knospe, die noch keine Tentakeln zeigt, annimmt, geht am besten aus der Vergleichung der Fig. 4 u. 5 auf Taf. XXIV und dem Schema IV auf Taf. XXVI hervor. Fig. 5 stellt einen Querschnitt durch die auf Fig. 4 abgebildete Knospe an der durch $\mathrm{X}$ bezeichneten Stelle dar. Alle diejenigen Theile der Teutakelkrone eines erwachsenen Thieres sind jetzt angelegt, welche übrig bleiben würden, wenn man sämmtliche Tentakeln an ihrer Basis abschnitte.

Bei weiterer Entwicklung der Knospe wird nun einmal durch Differenzirung der einzelnen Theile des anfangs einfach schlingenförmigen Darmes, dieser seiner definitiven Gestalt näher gebracht (Taf. XXIV, Fig. 10), andererseits bilden sich die Tentakeln. Diese beginnen zunächst an der vor dem Munde, d. h. an seiner abanalen Seite gelegenen

1) Vergl. anatomische Untersuchungen über Zoobotryon pellucidus Ehrenberg. 
Lophophorleiste sich zu bilden, und zwar als einfache Ausstülpungen der beiden Blätter dieser Anlage. Die Höhlung der Tentakeln steht also in directer Verbindung mit der Höhlung des Lophophors, und jeder Tentakel besteht aus einer inneren dünnen Zellauskleidung, die der äusseren Schicht der Knospenanlage entstammt, und einer äusseren Zellbekleidung, von der sich späterhin die Wimperzellbekleidung der Tentakeln auf der dems Munde zugewendeten Seite differenzirt. Diese äussere Zellbekleidung entstammt mitsammt der inneren Zellschicht der Tentakelscheide und dem Darmepithel der inneren Schicht der Knospe 1). Erst späterhin bilden sich die weiteren Tentakeln heraus, und zwar zunächst die, der äusseren Tentakelreihe der hufeisenförmignen Tentakelkrone entsprechenden; von ihnen entstehen wieder die der Basis der Lophophorarme zunächst gelegenen zuerst und sind bereits deutlich entwickelt (Fig. 10), wenn die der Spitze mehr genäherten erst als kleine hogige Ausbuchtungen des Lophophorrandes erscheinen. Am spätesten bilden sich die Tentakeln an den einander zugewendeten Kanten der Lophophorarme. Auf Fig. 9 der Taf. XXIV fehlen diese noch vollkommen. Man kann aber an derselben Figur noch deutlich die beiden Einstülpungsöffnungen der Lophophorarme $(E)$ erkennen. Es sind dies die beim erwachsenen Thier persistirenden Communicationsöffnungen der Lophophorhöhle mit der Hölıle des Cystids, die ich in meiner Dissertation beschrieben habe ${ }^{2}$ ). Bei Alcyonella ist es hiufig, dass das Polypid seine Tentakelkrone bereits zu einer Zeit vorstreckt, wenn ihm diese letzteren Tentakeln noch fehlen.

Es bleibt noch ubrig die Entstehung des Nervensystems resp. die von mir erkannte Bildung des grossen Ganglion zu beschreiben. Der wesentliche Theil desselben entsteht, wie MeтschnгкоғF völlig richtig angedeutet hat, a us dem inneren Blatteder Knospenanlage, a us demselben, a us demebenfalls die innere Auskleidung des Darmes sich bildet. Dieser Vorgang ist ungemein leicht zu verstehen, wenn man zunächst die Schemata II, IIl u. IV auf Taf. XXVI vergleicht. Ehe noch die beiden Hälften des Ringcanals des Lophophors sich vereinigt haben, entsteht zwischen den Armen des Lophophors und

1) An dieser Stelle muss ich einschieben, dass diese meine Angaben ganz genau übereinstimmen mit denen neuerdings von REPIACHовғ (Ztschr.f. w. Zool. XXV) gemachten über die Tentakelbildung von Tendra zostericola. Dieser hat unter Anleitung von Meтschniкоpf das Wesentliche der Tentakelbildung sehr richtig erkannt, und muss ich mich seiner Ansicht vollig anschliessen, dass wirklich bei der Bildung der Tentakeln beide Blätter betheiligt sind, und die innere Zellauskleidung der Tentakeln (meine Füllungszellmasse) dem äusseren Blatte der Knospe entspringt, auch bei den marinen Bryozoen.

๖) Archiv f. Anat. u. Physiol. 1868, p. 486. 
auf ihrer dem Munde zugewendeten Seite eine Einstülpung der Leibeswand der Knospe; diese Einstulpung ist aber gerade entgegengesetzt gerichtet, wie die Einstulpungen und Falten, die wir bis jetzt gesehen haben. Ihre Höhlung communicirt nicht mit der Höhlung des Cystids, sondern mit der Höhlung der Tentakelscheide. Dies ist auf Taf. XXIV, Fig. 3 ganz ungemein deutlich bei $N$ zu sehen. Die Ränder dieser Einstülpung wachsen nun wie die Ränder der Medullarrinne eines Wirbelthierembryo gegen einander, und wie in letzterem Falle eine hohle Röhre von der dorsalen Leibeswand des Thieres abgeschnürt wird, so wird hier eine hohle Blase von der Wand des Polypids abgeschnürt.

In unserem Falle ist aber die Wandung, an der diese Abschnurung vor sich geht, zweischichtig. Es besteht daher die Blase aus zwei Blättern, von denen das innere ursprünglich zusammenhing mit der äusseren Zellbekleidung der Lophophorarme, die äusseren dagegen mit dem inneren Epithel derselben, und dem äusseren Epithel des Darmtractus. Es stellt nun diese innere Blase, die anfänglich hohl ist, bald aber solid wird, die innere Masse des Ganglion, die eigentlichen Nervenzellen dar, während dagegen die äussere das Neurilemm bildet. Die beiden Schemata III u. IV sind nun aber weiter nichts, als farbig ausgeführte Darstellungen der beiden auf Fig. 3 u. 4 der Taf. XXIV dargestellten Schnitte, welche genau Zelle für Zelle mit der Camera lucida gezeichnet sind. Auf Figur III ist die Spalte, durch welche sich die Schlinge des Darmes von der Basis der Tentakelscheide abgeschnüt hat, der Deutlicbkeit wegen übertrieben. In Fig. 3 der Taf. XXIV wird diese Spalte blos durch die Grenze der beiden Zellschichten von denen die eine nach ihrer künftigen Bestimmung als Neurilemm $(N l)$, die andere dagegen in ihrer Eigenschaft als äusseres Epithel der concaven Seite der Darmschlinge mit $A D$, als äussere Zellschicht der Knospen, aber zugleich als $c^{\prime}$ bezeichnet ist. In Fig. 4 ist die Abschnürung des Ganglion bereits der Vollendung nahe. Nur an der Stelle $x$ hängt noch seine innere Blase mit dem Epithel des Oesophagus zusammen, und an dieser Stelle fehlt daher dem Darmeanal vorläufig noch seine äussere Epithelbekleidung. Auf dem Schema V u. VI habe ich diese Abschnürung vollendet dargestellt. In Fig. 8 der Taf. XXIV ist die sehr grosse Anlage des Ganglion durch $N$ angedeutet.

Wie die Arme des Centralnervensystems, die sich in die Lophophorarme hinein erstrecken, sich bilden, ist mir unbekannt geblieben. Denkbar wären zwei Möglichkeiten, dass nämlich entweder eine Rinne als Fortsetzung der medianen das Ganglion liefernden Einstülpung sich auf der inneren Fläche eines jeden Lophophorarmes bildete, und durch Verwachsung dieser Ränder und Abschnúrung der so ent- 
standenen Röhre die Stränge aufträten, oder dass sie durch Auswachsung der ursprünglichen Ganglienblase in zwei lange Hörner entständen. Aber dieses sind reine Vermuthungen.

Thatsache bleibt nur, dass die innere Zellschicht des Ganglion aus derselben Knospenschicht entsteht, aus der auch die innere Zellauskleidung des Darmes und das äussere Epithel der Tentakeln sich differenzirt ${ }^{1}$ ). Als wesentlichen Punct meiner gesammten Darstellung möchte ich nochmals betonen, dass auch für die Bryozoen in einigen Puncten genauer als bisher, bei der Knospung, die Bildung eines neuen Individuums, resp. (für den der die Individuennatur des Polypids nicht anerkennt) die Bildung eines wichtigen Organcomplexes durch einfache Faltung und Faltenconcrescenz einer mehrblättrigen Anlage nachgewiesen worden ist.

\section{B. Ueber den Bau und die Knospung von Loxosoma Kefersteinii Claparède.}

(Taf. XXV, Fig. 4-20, Taf. XXVI, Fig. VII-XIII.)

Im Jahre 1862 publicirte Keferstein die Beschreibung einer der Pedicellina nahe stehenden Bryozoe, welche zu St. Vaast als Schmarotzer auf Capitella rubicunda vorkommt, und taufte sie Loxosoma singulare (3). Dieses sonderbare Thier war zuerst an derselben Localität von CLAPARÉdE entdeckt worden. In seiner etwas späteren Publication (4) nahm dieser Forscher den einmal von Kefersterv gegebenen Namen an und vervollständigte dessen Angaben. Eine neue Species desselben Genus, die allerdings manche Abweichungen zeigen sollte, publicirte im Jahre 1866 Kowalewsky unter der Bezeichnung Lox. neapolitanum (8). Er hatte dieses Thierchen zu Neapel auf den Röhren von Phyllochaetopterus gefunden. An derselben Localität fand CLaparède später auf den Stöcken von Acamarchis eine neue bedeutend grössere Species, welche er Loxosoma Kefersteinii taufte (11). Eine genauere Beschreibung der bei die-

1) Ich möchte hier noch darauf aufmerksam machen, dass auch bei den infundibulaten Bryozoen die Bildung des Nervencentrums in ähnlicher Weise vor sich geht. Ich habe bei der Knospung von Flustra membranacea (Ztschr. f.w.Zool. XXI, Taf. III, Fig. 26) ein Organ abgebildet, das ich als ein Analogon des Epistoms der Pedicellina gedeutet habe. Ich glaube nicht mehr dass die nach aussen gegen den After zu von diesem Organ gebildete Furche einen Theil des späteren Ringcanales bildet, vielmehr scheint mir diese Furche, die besonders in der Profilansicht der Fig. $26 B$ sehr deutlich ist, und die mit dem Innenraum der Tentakelscheide communicirt, die Anlage des Ganglion ist, eine Vermuthung, die ich bei der Untersuchung der gleichen Bildung bei Alcyonidium hispidum bestätigt gefunden habe. Die gleiche Bildung ist übrigens bereits von Allman (Taf. XI, Fig. 8) an den Knospen von Paludicella gezeichnet worden. 
sem Thiere vorkommenden Knospung gab derselbe Forscher im Jahre 1870 (13). Ueber die geschlechtliche Fortpflanzung von Loxosoma singulare waren schon früher von KefERsteis gelegentlich einige weitere Bemerkungen gemacht worden (9). Fügen wir hinzu, dass Levckart (10) und ich (12) selbst unabhängig von einander die von KowaLEwsKY und KEFERSTEiv beschriebenen Loxosomalarven mit dem von Busch beschriebenen Cyclopelma longociliatum (1) identificirten, und dass ich selbst (12) die verwandtschaftlichen Verhältnisse der drei Genera Pedicellina, Loxosoma und Urnasella schärfer betonte, inden ich sie zu der Gruppe der Bryozoa entoprocta zusammenfasste, so haben wir die gesammte Literatur, welche sich ausdrücklich auf unser Genus bezieht, erschöpft.

Ausserdem kommt aher das Genus Loxosoma in mancherlei Verkleidungen in der Literatur vor. Die erste kenntliche Abbildung von Loxosoma, die überhaupt publicirt wurde, rührt von Norman (2) her, der seine auf Phascolosomen schmarotzende Species als »tentacular appendages« des Phascolosoma, oder wie er selbst glaubte, eines neuen Echinoderms "Strephenterus" beschrieb. Leuckart (5) nahm sehr bald sowohl den Strephenterus als Phascolosoma und die "Tentakeln " als solitäre Bryozoen in Anspruch. Hlatte er selbst doch zu Treport solche Thiere auf Phascolosomen schmarotzend gefunden. Indessen stimnte der Habitus des von ihm gefundenen Thieres nicht ganz mit dem von Loxosoma, und er zweifelt daher in seiner kurzen Notiz an der Identitat der Phascolosomaparasiten mil Loxosoma. Eine mir von meinem verehrten Lehrer Herru Prof. Levckart freundlichst gestatteten Einsicht seiner damals gemachten Zeichnungen, erlaubt mir aber bei unserer jetzt vorgeschrittenen Kenntniss des Genus Loxosoma die bestimmte Behauptung auszusprechen, dass Levckart es hier doch mit wirklichen Loxosomen $\mathrm{zu}$ thun hatte.

Ausserdem gehört, wie auch Levckart (7) zunächst nachwies, die von van Beneden sen. und Hesse (6) beschriebene Tristomide Cyclatella annelidicola zu den Loxosomen, und es ist der abweichende Habitus, den das Thier in der Abbildung zeigt, wohl auf die bekannte schematisirende Zeichenweise Hesse's zu schieben.

Die in den eben erwähnten Publicationen beschriebenen Species bilden als das Genus Loxosoma eine böchst natürliche Gruppe. Allerdings geht dies nicht sofort aus den vorhandenen Literaturangaben hervor, da Kowalewsky seinem Loxosoma Neapolitanum eine der Mundöffnung der Pedicellina entsprechende Einfuhröffnung für die Nahrungsstoffe abspricht. Schon früher (12) glaubte ich mich aber berechtigt, darauf hinzuweisen, dass diese Angabe wahrscheinlich auf einem Irrthume beruht, und eine gütige mündliche Nlttheilung Herrn Kowalewsky's 
selbst setzt mich in Stand zu versichern, dass auch er sich dieser Ansicht sehr zuneigt. Lassen wir daher diese Angabe bei Seite so können wir unsere augenblicklichen Kenntnisse über den Bau von Loxosoma in folgenden Sätzen zusammenfassen:

Loxosoma ist eine kleine solitire Bryozoe, welche aus einem kurzen drehrunden Stiel und einem in diesen ohne scharfe Abgrenzung ubergehenden eigentlichen Körper, dem Kelche besteht. Der Stiel ist von einer mehr oder weniger senk recht gegen seine Längsachse stehenden Fussfliche begrenzt. Mit dieser heftet das Thier sich an fremde Gegenstände an. Der Kelch zeigt, wenn das Thier ungestört ist, einen nach aussen gebogenen Rand. Eine durch ihn gelegte Ebene steht aber nicht senkrecht gegen die Längsachse des Thieres, sondern schneidet sie unter einem Winkel von vielleicht $30-450$. Das gesammte Thier ist bilateral symmetrisch gebaut. Die Symmetrieebene steht senkrecht, sowohl auf der Fussebene als auf der Kelchrandebene. Der Rand des Kelches wird umstanden von einer paarigen Anzahl von Tentakeln, welche kurz sind, meist mit ihren Spitzen etwas nach innen gekrimmt erscheinen, und auf der Innenseite Wimpern tragen. Dieselben können nicht eingezogen sondern nur mit sammt dem Kelchrande nach innen eingeschlagen werden. Dieser schliesst sich alsdann uber den eingeschlagenen Tentakeln wie ein mit Zugschnüren versehener Sack. Die peripherische Zone der Leibeswand nach innen von den Tentakeln ist gleichfalls mit Wimpern hedekt. Der intratentakulare Raum wurde früher meist als Schlund bezeichnet, und es stammt daher die Angahe, dass bei unserem Thiere der After den Schlund durchbohre. Es ist dagegen, wie ich schon fur Loxosoma Neapolitanum nachzuweisen suchte, sicher, dass derselhe nur dem Intratentakulärraume hei Pedicellina entspricht. In diesem liegen in der Symmetrieebene an der tieferen Seite der Mund, an der höheren dagegen der After auf einer schornsteinarligen Verlängerung. Ausserdem werden von Glaparède noch Geschlechtsorgane beschrieben, die rechts und links von dem Magen liegen.

Ich habe mich nun etwas näher mit der Anatomie und der Knospung einer Species dieses Genus befasst.

Wenn man im Monat September genauer die grossen Büsche von Zoobotryon pellucidum Ehrbg. betrachtet, welche die Pfähle der Badehäuser vor Santa Lucia in Neapel bekleiden, so findet man einzelne Zweige derselben ungemein reichlich besetzt mit kleinen weissen braungefleckten Kolben, welche lebhaft hin und her schlagen. Eine genauere Untersuchung lässt darüber keinen Zweifel, dass wir es hier mit dem von Glaparède entdeckten Loxosoma Kefersteinii zu thun haben und zwar in dieser Jahreszeit mit nicht geschlechtsreifen Thieren, welche 
aber in regster Vermehrung durch Knospung begriffen sind. Von diesen Thieren sammelte ich im Herbst 1872 eine grosse Menge und lege hiermit die Resultate vor, welche mir die Untersuchung des Baues und der Knospung geliefert hat. Ich bemerke hierbei sofort, dass dic anatomische Darstellung dem mit dem Bau einer Pedicellina Vertrauten nur wenig neue Details bringen wird, dass diese mir aber nicht Selbstzweck war, sondern lediglich die nothwendige Basis um die Vorgänge der Knospung einerseits und das Verhältniss dieser Species von Loxosoma zu dem so merkwürdigen Loxosoma Neapolitanum Kowal. untersuchen zu können.

Die Untersuchungen wurden an Präparaten vorgenommen, welche in absolutem Alkohol conservirt und zum Theil vorher mit Ueberosmiumsäure gehärtet waren. Letztere eigneten sich ganz besonders zur Anfertigung von Schnitt- oder Spaltungspräparaten nach der oben (p. 355) von mir beschriebenen Methode. Ich will die einzelnen Organe in derselben Reihenfolge beschreiben, wie ich dies früher bei Pedicellina gethan habe, um eine Vergleichung beider so nahe verwandten Thierformen zu erleichtern.

\section{Der Stiel.}

Der Stiel, dessen Länge bei jungen Exemplaren verhältnissmässig viel kürzer ist, hat bei den erwachsenen Exemplaren einen Durchmesser von circa $50 \mu=0,05 \mathrm{M}$., bei einer Länge von circa 1,0 $\mathrm{Mm}$. Er ist ebensowenig wie bei Pedicellina ein hohles Organ, sondern durchaus solid. Nach aussen wird er wie der gesammte Körper von Loxosoma mit Ausnahme der wimpernden Flächen der Tentakeln, begrenzt von einer festen, völlig homogenen Cuticula (Taf. XXV, Fig. 5 u. $6 \mathrm{c}$ ). Unterhalb dieser Cuticula liegt an der Fussfläche des Stieles eine Lage grosser dicht aneinanderliegender Zellen (Fig. 8) deren Contouren eine mosaikartige Zeichnung daselbst bilden. Dieselben sind mit einem deutlichen Kern versehen. Ihre Entwicklung ist bei jüngeren Individuen stärker, als bei den älteren. Der Bau der ubrigen Wand des Stieles ist cin völlig gleichmässiger. Nirgends findet sich wie bei Pedicellina an dem oberen Ende des Stieles eine gleichmässig den ganzen Umfang des Stieles einnehmende Zellschicht, sondern wir erkennen eine Anzahl von Längszonen (gewöhnlich acht an der Zahl), die in gleichmässigen Abständen den Stiel umgeben, jede aus einer einzigen Reihe von Zellen mit viereckiger bis spindelförmiger Contour bestehen, und zwischen sich einen Raum lassen, der von mehr oder weniger deutlichen Längsfasern eingenommen wird. Mitunter ist nur eine, mitunter mehrere Längsfasern eingeschaltet. Von Zeit zu Zeit sieht man diese Längsfasern, die wahrscheinlich muskulöser Natur sind, anschwellen, und sie sind dann mit 
einem Kern versehen. Dieses Verhältniss ist in Fig. 6 in einem Querschnitt, auf Fig. 7 in einer Flächenansicht dargestellt, $a$ bezeichnet die Zellreihen, $b$ die eingeschobenen Fasern mit ibren Kernen $b^{\prime}$. Das ganze Innere des Stieles ist von einer Art Bindegewebe erfüllt, welche aus einer ganz durchsichtigen, wasserhellen Intercellularsubstanz $(d)$, und einer grossen Menge spindelförmiger Zellèn $(e)$ besteht, deren spitze Enden mitunter mehrfach gespalten, mit einander anastomosiren. Ein deutlicher ovaler Kern ist vorhanden in jeder solchen Spindel, dieselben sind aber nicht wie bei Pedicellina auf die periphere, der Musculatur zunächst gelegene Zone des Stieles beschränkt, sondern durchsetzen gleichmässig den ganzen Innenraum, und zwar sind ihre Längsachsen immer der Längsachse des Stieles parallel geordnet.

Da wo der Stiel in den eigentlichen Körper übergeht, convergiren die letzten Spindelzellen nach dem Centrum zu, und setzen sich an die Wand des Magens fest. Ausserdem erstreckt sich ein dem Bindegewebe des Stieles völlig homologes Gewebe in dic Zwischenräume zwischen Magen und Leibeswand hinein und füllt wohl auch das Innere der Tentakeln aus.

Wir sind also im Stande gewesen, in den wesentlichen Zügen die Angaben von Claparéde (11) bestätigen zu können, müssen aber festhalten, dass die Längszonen, die zwischen den Längsmuskelzügen liegen, nicht von blossen Kernen, sondern von wirklichen Zellen herrühren.

Auch kann bei dieser Species die Fussflïche nicht als eine Art Saugnapf angesehen werden. Es müsste dieselbe, um so bezeichnet werden zu können, mit einem besonderen Muskelapparate ausgestattet sein. Dieser fehlt aber bei unserer Species ganz sicher. Es wird die Fussfläche vielmehr in der Jugend den Körpern, an denen das Thier lebt, durch das Secret einer bei den Knospen vorhandenen, aber später schwindenden Drüse, die der von Kowalewsky bei Loxosoma Neapolitanum beschriebenen persistirenden Fussdrüse aequivalent ist, angeklebt.

Der Kelch ist zwar bedeutend dicker wie der Stiel (vergl. Taf. XXV, Fig. 4) dafür aber auch bedeutend kürzer. Seine grösste Länge beträgt bei meinen ausgewachsenen Exemplaren ohngefähr $0,35-0,4 \mathrm{Mm}$. Seine Gestalt ist wirklich, abgesehen von den Tentakeln, die eines seitlich etwas comprimirten Kelches mit schiefem, nach aussen etwas umgebogenen Rande. Wir betrachten nun seine einzelnen Theile.

\section{Die Leibeswand.}

Die Leibeswand des Kelches besteht, wie bei Pedicellina, aus einer einfachen, platten, polygonalen Zellschicht, welche der von ihr nach aussen secernirten Cuticula dicht anliegt. Bei oberflächlicher Be- 
trachtung von Alkoholpräparaten erkennt man nur die ovalen Kerne. An Osmiumsäurepräparaten kann man aber auch (Fig. 5 A) die Zellgrenzen unterscheiden.

\section{Der Darmcanal.}

Der Darmeanal zeigt genau dieselben Theile wie der von Pedicellina. Man kann an ihm unterscheiden den Oesophagus, den Magen und den Darm, und es zerfällt dieser letztere gleichfalls wieder in Intestinum und Rectum. Am schönsten kann man diese Verhältnisse auf einem Längsschnitt eines erwachsenen Thieres, wie ich denselben auf Taf. XXVI, Fig. 5 abgebildet habe, sehen. Ueber die Deutung der einzelnen Abschnitte, die noch Glaparëde nicht ganz sicher schien, kann weiner Ansicht nach kein Zweifel herrschen, eben wegen der totalen Uebereinstimmung mit deneu von Pedicellina. Die frühere Angabe, der Darm durchbohre den Oesophagus, bezeichnet zwar die richtige Thatsache, dass der After wie bei Pedicellina innerhalb des Tentakelkranzes liegt, aber der Ausdruck beruht doch auf der falschen Voraussetzung, der ganze von den Tentakeln umschlossene Raum entspreche dem Oesophagus.

Die Zellauskleidung des Darmes, welche dicht nach innen der hyalinen Tunica propria anliegt, zeigt sehr verschiedene Beschaffenheit in den verschiedenen Abschnitten. Am deutlichsten ist dies auf Taf. XXV, Fig. $5 \mathrm{zu}$ erkennen. Der runde Mund führt in den, mit nicht sehr hohen Wimperzellen bekleideten, im Querschnitt kreisförmigen Oesophagus, der mit einer beinahe senkrecht stehenden Oeffnung in den weiten sackförmigen Magen mündet. Der dem Stiel zunächst gelegene untere Theil des Magens ist auch noch mit niedrigen Wimperepithelien belegt, dagegen die ganze übrige Wand mit bedeutend höheren, wimperlosen Gylinderepithelien. Dieselben sind auf der oberen Seite des Magens am stärksten, und stellen wohl hier, wie bei Pedicellina Leberzellen dar; wie weit diese Leberzellenzone an den Seiten des Magens herabreicht, zeigt das Schema Taf. XXVI, Fig. VIl. Gegen die Mündung des Oesophagus zu werden sie etwas niedriger. Das Intestinum $(I)$ ist ebenso, wie der diesem zunäclıst gelegene Theil des Euddarmes $(R)$ mit Wimperepithelien bekleidet. Bei einer Flächenbetrachtung sieht man, dass diese Zellen aber eine stark in die Quere gezogene polygonale Form haben. Intestinum und Rectum legen sich an der dem Oesophagus abgewendeten Seite der Leibeswand dicht an, und auch in der Papille, auf der der Anus als kleine runde Oeffnung sich befindet, dem sogenannten Schornstein, liegen Leibeswand und Darmwand dicht an einander. 


\section{Die Tentakelkrone.}

Die Verhältnisse der Tentakelkrone entsprechen ganz genau den von mir bei Pedicellina geschilderten. Das erwachsene Thier hat, wie Claparéne ganz richtig angiebt, 14 bilaterale symmetrisch angeordnete Tentakeln. Dieselben sind ziemlich kurz und umstehen den Kelchrand, in den sie eingeschlagen, aber nicht zurückgezogen werden können. Der Kelchrand kann dann über denselben durch eine Kreismusculatur wie der Rand eines Ziehbeutels so geschlossen werden, dass nur eine ganz kleine Oeffnung bleibt. Von der adanalen Seite der Mundöffnung verläuft eine im Längsschnitt als breite Leiste $(T R)$ erscheinende Falte, rechts und links nach der Stelle zu, wo die Analpapille den Tentakelbasen am meisten genähert ist. Diese begrenzt die, an der Basis der Tentakeln entlang verlaufende Tentakelrinne, welche an der Stelle, wo sie vom Mund durchbohrt ist am breitesten ist, und nach den beiden Enden zu immer schmäler wird. Diese Tentakelrinne wimpert, und steht in Verbindung mit den auf der Innenseite der Tentakeln verlaufenden Wimperepithelzonen, so dass diese letzteren in Verbindung mit der Tentakelrinne einen Zuleitungsapparat darstellen, welcher die in dem Meerwasser suspendirten, feinen organischen Partikelchen dem Munde zufuhrt.

Man kann deutlich erkennen, dass die Wimperzone der im Querschnitt nicht runden, sondern ähnlich wie Pedicellina (cf. 12, Taf. 1ll, Fig. 11) dreikantigen Tentakeln aus drei Reihen von Zellen besteht, von denen die mittlere aus kleineren Elementen zusammengesetzt' ist, als die seitlichen. Die seitlichen Reihen tragen die grossen Wimpern; ob die mittlere Reihe, wie ich fast vermuthe, mit kürzeren Wimpern besetzt ist, konnte ich nicht entscheiden. Die Aussenseite der Tentakeln ist in ihrem Bau der Leibeswand ganz ähnlich und es geht auf sie die Cuticula über.

Zwischen der Tentakelrinne und der Analpapille liegt in der Mitle die intratentakuläre Leibeswand, die der oberen Wand des Magens ganz dicht aufliegt. Auf derselben, welche nach Kowalewsky bei Loxos. Neapolitanum eine Art Brutraum für dic Eier darstellt, findet sich aber wenigstens bei den von mir beobachteten, noch nicht geschlechtsreifen Thieren keine besondere Bruttasche, wie ich eine solche für Pedicellina echinata nachweisen konnte.

\section{Die Genitalorgane und das Nervensystem.}

In meiner vorläufigen Nittheilung sprach ich mich uber diese Genitalorgane folgendermassen aus: "Zwar bin ich fest uberzeugt, dass auch hier wir es mit Thieren zu thun haben, welche Geschlechtsorgane be- 
sitzen, die nach dem Pedicellinentypus gebaut sind; ich kann dies aber nicht streng beweisen, da die sämmtlichen von mir im September zu Neapel gesammelten Thiere sich lediglich ungeschlechtlich fortpflanzten und keine entwickelten Genitalien zeigten. Eine genaue Untersuchung ergab) dagegen, dass auch hier in ähnlicher Lagerung wie bei Pedicellina paarige, birnförmige, mit Zellen gefüllte blasenartige Organe vorkommen, die ich als Genitalanlagen zu deuten mich berechtigt halte. Eine Bruttasche, wie sie bei Pedicellina bekannt ist, fehlte, und es soll ja auch nach Kowalewsky der ganze intratentaculäre Raum als solche fungiren."

Diese Angabe grundet sich auf die Beobachtung, dass bei jungen Individuen quer vor dem Intestinum zwischen Magenwand und Leibeswand eine stabähnliche Zellmasse aufliegt, welche in der Mitte dünn und an den beiden Enden verdickt ist (Fig. 19 GA). Auch an erwachsenen Thieren sieht man auf dem Längsschnitt (Fig. 5 GA) eine Zellmasse liegen, die dem Mitteltheil des bei den jungen Thieren eben geschilderten Stranges entspricht, und bei genauer Betrachtung kann man auch die Seitentheile an unverletzten Exemplaren als grosse mit Zellen gefültte Blasen erkennen. Manchmal sieht man dem Rectum zu noch jederseits eine bei weitem hellere Blase liegen. Diese Organe entsprechen in ihrer Lagerung direct den Genitalorganen von Pedicellina, und ich stehe daher nicht an, sie als Genitalanlage in Anspruch zu nehmen. Sollte sich später herausstellen, dass diese Species auch ein Zwitter ist, so würden wohl die ersteren Blasen als Ovarien, die letzteren als Testikel sich ausweisen.

Diese Zeilen waren niedergeschrieben, ehe die weiter unten genauer zu besprechende Arbeit von Herrn Prof. Sснмптr in meine Hände kam und die Vermulhung, die ich ausgesprochen, zur Gewissheil erhob.

Vom Nervensystem kann ich weiter nichts aussagen, als dass auf Längsschnitten (Taf. XXV, Fig. 5) ein Körper in der Medianebene sichtbar ist, welcher unterhalb der Tentakelrinne der Magenwand aufliegt und wohl bei Untersuchung von frischen Exemplaren als dem Ganglion von Pedicellina entsprechend sich herausstellen dürfte. Wenigstens entspricht seine Lage ziemlich dem von mir bei Pedicellina genau nachgewiesenen Ganglion.

\section{Die Bildung der Knospen.}

Die geschlechtliche Fortpflanzung eines Loxosoma ist bis jetzt nur von Kowalewsky (8), Keferstein (9) und wie wir weiter unten sehen werden von 0 . Scumidr (15) beobachtet worden, wenngleich die auf geschlechtlichem Wege entstandene Larve, wie oben bemerkt wurde, 
sogar wahrseheinlich viel früher als das ausgewachsene Thier selbst bekannt wurde.

Dagegen haben sämmtliche Forscher, welche sich genauer mit unserem Thier beschäftigten, die seitlichen Knospen desselhen beschrieben, und auch Herr Prof. Scнnid hat diese Knospung gesehen, aber als eine besondere Art der geschlechtlichen Fortpflanzung in Anspruch genommen. Indem ich es mir nun vorbehalte, diese letzteren Angaben weiter unten genauer zu erörtern, lasse ich dieselben für den Augenblick bei Seite und führe hier nur die in meiner vorläufigen Mittheilung enthaltenen Angaben, unter alleiniger Berücksichtigung der vor dem Erscheinen der letzteren Arbeit gemachten Angaben über die Knospung von Loxosoma näher aus.

Von diesen letzteren sind, sowie es sich um die genauere Darstellung dieses Gegenstandes handelt, wieder nur die Angaben von CLAPArÈDE zu berücksichtigen. In seiner Mittbeilung über Loxosoma singulare (4) und seiner ersten Mittheilung über L. Kefersteinii (11) hat er die Gestalt der erwachsenen Knospen und besonders ihre Verbindung mit dem Mutterthier nicht richtig erkannt, indem er angiebt oder wenigstens zeichnet, dass dieselben durch die Fussscheibe mit dem Mutterthier zusammenhängen, aber er sagt in letzterer Publication doch schon ausdrücklich: »les gemmes se forment exclusivement en deux points l'un à droite, l'autre à gauche dans le tiers posterieur du corps; c'est aussi en ces deux points là que se fail la gemmation chez le Loxosoma singulare. Le nombre des bourgeons peut s'élever jusque à cinq on six de chaque côté« u. s. f. Diese letzteren Angaben kann ich vollständig bestätigen, desgleichen ist in allen Beziehungen die Verbesserung zu billigen, welche GlapanèDe in seiner zweiten Mitheilung über L. Kefersteinii (13) in Betreff der Anheftungsstelle der Knospe an das Mutterthier und seiner Lage am Körper der Knospe giebt. Ich kann ferner völlig mit ihm übereinstimmen, wenn er sagt »die jungen Knospen stellen blosse Ausstülpungen der Leibeswand vor . .... Da Clapariede aber das parenchymatöse Gewebe im Innern des Mutterthieres und der Knospen übersehen, so sieht er sie als hohle Säcke an und parallelisirt diese Vorgänge bei ihrer Entwicklung völlig denen bei der Entwicklung der ectoprocten Bryozoen. Hierin kann ich ihm nicht beistimmen. Meine eigenen Beobachtungen über den Knospenbildungsprocess haben mir nun folgende Resultate ergeben.

Betrachtet man die Fig. 4 meiner Tafel XXV, so erkennt man auf einem Hydroiden- oder Zoobotryon-Stamme aufsitzend zwei Exemplare von L. Kefersteinii, und zwar stellt Nr. II ein junges im Profil gesehenes Thier, Nr. I ein von der Oralseite gesehenes, völlig erwachsenes dar. 
An ersterem erkennt man zwei seitlich ansitzende Knospen, dagegen waren an dem Original von der letzteren Zeichnung acht Knospen vorhanden, von denen aber nur sieben gezeichnet sind: die eine Knospe rechts wird von der ältesten Knospe verdeckt.

Eine solche grössere AnzahI von Knospen, die auch noch höher steigen kann, ist bei L. Kefersteinii die Regel, während bei den ubrigen Species nur eine geringere Anzahl vorzukommen scheint. Es beginnt ferner dieser Knospungsprocess so zeitig, dass bereits Knospen von der Ausbildung der am Exemplar I mit 1 bezeichneten, also solche, die noch an dem Mutterthier festsitzen, selbst wieder die ersten Spuren einer Knospe zeigen können. Diese ersten Knospenanlagen finden sich zunächst an der e in en Seitenfläche des jungen Thieres oberhalb der Verbindung von Stiel und Kelch. Ist diese erste Knospe schon etwas weiter entwickelt, so beginnt an der entsprechenden Stelle der anderen Seite eine zweite Knospe sich zu bilden, dieser folgt dann eine dritle an der Seite auf der der Knospungsprocess urspringlich begonnen hat, die vierte tritt wieder auf der anderen Seite auf, und so fort; man kann daher häufig an einem und demselben Exemplar sämmtliche Knospenstadien von der ersten Anlage bis zu der erwachsenen, zur Ablösung bereiten Knospe vorfinden. Es stellen hierbei die Knospen der einen Seite die Zwischenstadien zwischen den auf der anderen Seite vorkommenden Entwicklungsstadien dar.

Sobald eine Knospenanlage auch für eine oberflichliche Betrachtung erkennbar wird, erscheint sie als eine ungefähr halbkuglige Hervorwölbung der Körperoberfläche des Mutterthieres (Taf. XXV, Fig. 4 I, 8 u. 6, u. Fig. 13). Bei weiterer Entwicklung hat sie die Gestalt einer, an ciner einzigen Stelle mit der Körperoberfläche des Mutterthieres zusammenhängenden Kugel (Fig. 4. 1. 4 u. Fig. 14), aber nun beginnt, wie dies schon Glaparéde sehr richtig beschrieben, seitlich von dem "Nabel der Anheftungsstelle an das Mutterthier ein Fortsatz herauszuwachsen (Fig. 4 1. 2 u. Fig. 16). Dieser stellt den Stiel der jungen Knospe dar, während die vorher angelegten Theile dem Kelch entsprachen.

Die Knospe nimmt nun allmälig die Gestalt einer Thonpfeife mit einem sehr kurzen Rohre an (Fig. 4. I. 1 u. Fig. 17). Der Grund des Kopfes entspricht dann der Anheftungsstelle der Knospe am Mutterthiere, dem Nabel, der Kopf selbst dem Kelch, der Stiel dem Stiel. Während also später die Achse des Stieles und die des Kelches zusammen eine gerade Linie bilden, stossen bei diesen Knospen die beiden Achsen unter einem stumpfen, anfänglich sogar unter einem rechten Winkel zusammen.

Es handelt sich nun zunächst un die Frage: aus welchem Theile 
des Mutterthieres entsteht die Knospe, und ich kann ganz bestimmt behaupten, dass dieselbe a usschliesslich aus der Leibeswand des Mutterthieres sich bildet. Es geht stets in die Bildung jeder Knospeein 1) ein Stük der polygonalen Zellschicht der mütterlichen Leibeswand, und 2) derdiesem entsprechende Theil der Cuticula des Mutterthieres. Die Cuticula liefert die Cuticula der Knospe, aus der Zellschicht, also aus dem Ectoderm des Mutterthieres sind sämmtliche Organe der Knospe abzuleiten, auch das Epithel des Darmes und das Bindegewebe. Es erscheint diese Behauptung auffallend, wenn man die Matrix der Cuticula des erwachsenen Thieres in Betracht zieht. Diese besteht ja aus flachen, saftlosen, gegen einander kaum deutlich abgegrenzten Epithelzellen, welche durchaus den Eindruck machen, als wären sie sozusagen senil degenerirt, auf ibrem definitiven Entwicklungsstadium angekommen und könuten keine weiteren Veräinderungen eingehen. Indessen ist nichtsdestoweniger das Ectoderm des Mutterthieres wirklich der Mutterboden der knospen, aber nicht in dem oben beschriebenen ausgebildeten oder vielleicht richtiger gesagt bereits rückgebildeten Zustande, sondern in noch jugendlichem, entwicklungsfähigem Stadiun. Es bildet sich die Anlage der jungen Knospen nicht erst an ilteren Thieren, sondern bereits an den Knospen. Es giebt ein Knospenstadium (Fig. 17), auf welchem bereits alle wesentlichen Theile angelegt sind, in welchem aber die Leibeswand noch aus saftigen dicken Epithelzellen besteht. In diesem Stadium grenzt sich nun an den sehon von CLaparède deutlich angegebenen Stellen der beiden Seitenflächen und zwar zunächst an der einen und dann an der andern Seite eine runde Zellplatte in den noch wohl entwickelten Eetoderm ab, und von dieser geht die Entwicklung der Knospen aus. In ilır geht bei weiterem Wachsthum der Knospe, resp. des jungen Thieres nicht die Abplattung und scheinbare Verschmelzung der einzelnen Ectodermzellen, die wir an den übrigen Eetodermzellen beobachten können, vor sich, sondern die Zellen bleiben saftig, ich möchte sagen jugendlich und zu weiterer Theilung fiahig. Ob ursprünglich diese gesanmte Zellplatte von einer Zelle des Ectoderms der Knospenanlage herstammt, das habe ich nicht eruiren können, glaube es aber auch nicht. Auf jeden Fall möchte ich aber betonen, dass sogar, wenn dies nachgewiesen werdeu könnte, es an meinen späteren Ausführungen über die Bedeutung der Knospungsvorgänge nichts ändern könnte. Es ist ganz sicher, dass, mag die Zellplatte ursprünglich aus einer oder mehreren Zellen entstehen, diese einen integrirenden Theil der Leibeswand des Mutterthieres bilden, wie ich dies in der schematischen Fig. VII, Taf. XXVI durch die 
einfache Verdickung der rothen Ectodermschicht bei $Z P$ angedeutet habe. Es entsteht diese Zellplatte keineswegs durch etwaige Anlagerung von einer oder mehreren Zellen, die aus dem Innern des Thieres herstammen, an das Ectoderm; niemals kann man daber in den ersten Stadien bemerken, dass zwischen ihr und der Cuticula etwa noch andere inodificirte Epithelzellen liegen. Ich muss in dieser Hinsicht $\mathbf{C}_{\mathbf{L A}}$ PARÈDE, wie schon bemerkt, völlig beipflichten. Aus dieser jederseits in der Einzahl angelegten Zellplatte, die man gewissermassen einem flachen Stolo vergleichen könnte, entstehen sämmtliche Knospen der betreffenden Seite. Es wird also, wenn aus dieser Zellplatte die erste Knospe sich auszubilden beginnt, nicht das gesammte Zellmaterial zur Herstellung der Knospe verwendet, sondern es bleibt eine laterale Partie zurück, und durch die Weiterwucherung dieser entstehen die übrigen Knospen. Sehr schön kann man dies an Fig. 11 der Taf. XXV sehen. Hier habe ich einen Theil der seitlichen Leibesıand von Loxosoma abgebildet, an welchem man die Kerne $(k)$ der Epithelzellen der Leibeswand deutlich erkennen, die Grenzen der einzelnen Zellen aber nicht sehen kann. Die dunkler gehaltene Partie in der Mitte stellt die stoloartige Zellplatte dar. In dieser kann man bereits die Anlagen von drei verschiedenen Knospen erkennen. Die erste mit I bezeichnete ist so weit entwickelt, dass sie deutlich über die Oberfläche der Mutter hervorragt, ungefähr in der Weise, wie die im Profil, resp. im optischen Längsschnitt gesehene Knospe I der Fig. 13. Dies ist angedeutet durch die um die Zellen herumlaufende, die Basis der Cuticularausstülpung bezeichnende scharfe Contour. Die zweite (II) ist bereits abgegrenzt und besteht aus sechs Zellen, die dritte (III) erst aus zwei Zellen. Im Profil gesehen würde II ähnlich neben der Knospe I liegen, wie die Knospe II der Fig. 13 neben Knospe I. Wenn aber jene sich so weit ausgebildet haben wird als die Nr. I, so ist wieder nicht der ganze Betrag der aus ihrer Wucherung hervorgegangenen Zellen zur Bildung der Knospe III verwendet worden, sondern es ist wieder ein Rest vorhanden, der nun die späteren Knospen erzeugen kann. Ganz ähnlich ist das Bild des flachen Stolo, der in Fig. 12 abgebildet ist. Auch hier sehen wir in ihm eine deutliche bereits weiter ausgebildete Knospe I und einen Complex von anderen Zellen, in dem sich links bei II eine weitere junge Knospe abgrenzt, während die nach unten von der ersten und nach rechts von der zweiten Knospe liegenden Zellen das Restmaterial zur Bildung der ferneren Knospen darstellen.

Es handelt sich nun zunächst um die Frage, wie bildet sich ein im Verhailtniss so complicirt gebautes Thier wie ein Loxosoma aus einer so einfachen Anlage, wie sie dargestellt wird von der einschichtigen eben 
geschilderten Zellplatte. Der erste beobachtbare Vorgang der Knospenbildung ist auf Fig. $10 \mathrm{~A}$ dargestellt. Hier kann man nämlich an dem flächenhaft ausgebreiteten Stolo bemerken, dass eine Anzahl von Zellen, im vorliegenden Fall sechs, sich im Kreise um eine centrale Zelle zu ordnen beginnen. Diese Anordnung scheint kaum wichtig zu sein, hat aber dennoch für die Knospe eine sehr hohe Bedeutung: a u s der in Fig. $10 \mathrm{~A}$ mit $E$ bezeichneten centralen Zelle entwickelt sich späterhin das gesammte Endoderm der Knospe, während das ganzeäussere Blatt, das Ectoderm, aus dem Zellkranze entsteht, der die "Endodermzelle» umgiebt. Dieses Stadium ist übrigens nur schwer zu beobachten, klar ist es nur an den ganz jungen Knospenanlagen, die sich an älteren Knospen vorfinden. Viel häufiger ist das nächstfolgende Stadium Fig. $10 \mathrm{~B}$. Auf diesem hat die ganze Knospenanlage noch immer die Gestalt einer einfachen Zellplatte, aber die ursprünglich einfache centrale Zelle hat sich getheilt und die im Umkreise um dieselbe herumliegenden Zellen, die Ectodermanlage, haben sich ebenfalls vernehrt. Man kann schon an der Beschaffenheit der Zellen die Endodermanlage von der Eetodermanlage unterscheiden, die beiden Zellen der ersteren sind heller und stärker lichtbrechend als die der letzteren.

Dies ist das Bild der ersten Knospenanlage, wenn man die Zellplatte von der Fläche betrachtet, sieht man sie aber im Profil, oder richtiger gesagt in dem optischen Längsschnitt an, so erhält man ein Bild, wie das auf Taf. XXVI in Fig. IX schematisch dargestellte. Es hat sich das Centrum der Knospe bereits über die Oberfläche des Mutterthieres hervorzuwölben begonnen und man erkennt die beiden centralen Endodermzellen, die nun schon deutlich durch ihre hellere Farbe von den Ectodermzellen sich abheben und darum durch die blaue Farbe im Schema characterisirt sind. Am besten kann man die nächsten Vorgänge, so wie ich dieselben aus der Vergleichung der in beliebiger Anzahl zu Gebote stehenden einzelnen Entwickelungsstufen erkannt habe, an den weiteren schematischen Darstellungen Taf. XXVl, Fig. X-XIV erkennen, auf welcher allerdings blos die Entwicklung einer Knospe versinnlicht worden, dagegen die als Stolo fungirende Zellplatte selbst weggelassen ist. Es wölbt sich nämlich jetzt die Knospenanlage immer mehr uber das Niveau der Körperoberfläche des Mutterthieres hinaus, und die centralen Endodermzellen werden von den Ectodermzellen dermassen uberwuchert, dass sie bald von der Aussenfläche der Knospe abgedrängt und in das Innere localisirt werden (Fig.X). Gleichzeitig vermehren sich sowohl die Ectoderm- wie die Endodermzellen durch Theilung. Letztere theilen sich nach $\mathrm{z}$ wei Richtungen, einmal so, dass 
die Theilungsebenen senkrecht gegen die Oberfläche der linospe stehen, andererseits so, dass sie mit dieser parallel laufen. Durch erstere Zelltheilungen, welche schon stattfinden ehe noch die Abdrängung der Endodermzellen von der Knospenoberflïche erfolgt, werden die primären beiden Endodermzellen zunïchst in vier (Fig. 11, I), dann in sechs (Fig. 12, I) und so fort getheilt. Diese 'Theilung geht aber' so vor sich, dass durch dieselbe von der Fläche gesehen immer nur z w ei Zellreihen entstehen. Die Grenze zwischen diesen beiden Zellreihen entspricht der Medianebene der jungen Knospe. Die Zelltheilungen, welche parallel mit der Oberfläche der Knospe erfolgen, lassen daher keinen unregelmässigen Zellkörper, sondern nur zwei senkrecht gegen die Oberlläche gerichtete Zellplatten entstehen, welche neben einander liegen und deren Grenze die Symmetrieebene der Knospe darstellı. Diese Zellplatten, welche aus den beiden primären Endodermzellen, resp. aus der ersten Centralzelle sich bilden, geben die Auskleidung des gesatumten Darmtractus, der intratentaculären Leibeswand und der innern Zellbekleidung der Tentakeln. Man erkennt diese beiden Zellplatten im optischen Querschnitt durch die blaue Farbe auf Schema $\mathrm{X}$ u. Xf deutlich dargestellt. Diesen Schemas entsprechen die Figuren 13 und $14 B$ der Taf. XXV. Wie aus diesen zwei Zeliplatten sich der intratentaculäre Raum nebst Tentakeln und der Darmcanal bildet, geht aus der Vergleichung von Fig. XI, XII, XIII u. VII der Taf. XXVI hervor. Es weichen nämlich diese Zellplatten sowohl da wo sie an dem dem Mutterthiere abgewendeten Knospenpole mit dem Ectoder'm zusammenstossen, als an ihrem entgegengesetzten Rande auseinander, während sie in der Mitte verbunden bleiben. Dadurch wird ein unteres Rohr von eisem oberen abgegrenzl, d. h. der Darmcanal von dem Intratentacularraume. Es bricht aber der Darm vorn und hinten ebenfalls durch, so dass er hier durch After und Mundöffnung mit dem intratentaculären Raume verbunden bleibt. Der Darm stellt also eine holile Schlinge dar, die mit dem Intratentaculärraume durch Mund und After in ganz ähnlicher Weise zusammenhängt, wie der Darm der übrigen Bryozoen mit der Tentakelscheide. Nur ist festzuhalten, dass der Darm der ectoprocten Bryozoen aus z w e Z Zellschichten gebildet wird, während der der endoprocten aus einer einzigen besteht. Ein Medianschnitt durch eine auf dem Stadium Fig. XIII der Taf. XXVI befindliche Knospe würde daher in manchen Beziehungen ein ähnliches Bild geben, wie der Medianschnitt durch ein Alcyonellenpolypid, den ich auf derselben Tafel Fig. II abgebildet habe. Dem schematischen Querschnitt Fig. XIII entspricht das auf Fig. 15 der Taf. XXV abgebildete Stadiun. Hat sich einmal der Darmcanal so weit angelegt, so nimmt er nun durch 
Ausweitung an der Stelle des 'zukünftigen Magens, und Einschnürung seines Lumens zwischen Darm und Enddarm allmälig die Gestalt an, die er im erwachsenen Thier hat und es legt sich durch weitere Ausbildung der Tentakelhöhle der Tentakelapparat an. In Fig. XII u. XIII sehen wir ubber dem Darmcanal eine von Endodernzellen ausgekleidete Ilöhle $(I T R)$, welche dicht unter dem Ectoderm der Knospe gelegen, in der Medianebene in einer Längszone $(y)$ allmälig mit dem Ectoderm verschmilzt. In dieser Längszone öffnet sich nun durch einen Durchbruch diese Höhle nach aussen und stellt den von mir als Intratentacularraum bezeichneten Theil der Leibeswand dar. Die Rander dieser Spalte ( $y$ auf den schematischen Figuren) entsprechen genau den Kelchrande des erwachsenen Thieres. Erst durch diesen Durchbruch kann Mund und After mit der Aussenwelt in Verbindung treten. Aber wenn auch schon lange der Durchbruch erfolgt ist, wie z. B. bei dem auf Taf. XXV, Fig. 16 abgebildeten Stadium liegen die Ränder des Kelches noch fest aneinander und es müssen erst die Tentakeln angelegt sein, ehe sie sich entfalten. Auf Fig. 20 sieht man in einem optischen Längssclinitt, senkrecht gegen die Symmetrieebene, wie die Tentakeln entstehen. Diese werden gebildet durch Wucherung der Spaltränder, und da ihre Aussenseite von der Cuticula des Mutterthieres, die Innenseite von Wimperzellen, ähnlich denen der Tentakelrinne, gebildet werden, so ist anzunehmen, dass sowohl der der Ectodermanlage als der der Endodermanlage angehörige Theil des Kelchrandes an dieser Wucherung sich betheiligt. Die Zahl der Tentakeln der ausgebildeten Knospe beträgt aber im Gegensatz zu dem erwachsenen Thier stets nur 10, und erst später erhält das freie junge Thier die normale Tentakelanzahl, nämlich 14 .

Lange bevor aber der Darm und der Tentakelapparat sich soweit ausgebildet haben, hat einmal die ciussere Forn der Knospe sich weiter entwickelt und stellt nun einen nur an einem Puncte $N$, dem Knospennabel ClaparÈde's, mit dem Mutterthier zusammenhängenden kugligen Körper dar, andererseits hat die Bildung des Mesoderms begonnen. Während auf dem optischen Querschnitt Taf. XXV, Fig. 13 Endoderm und Ectoderm noch nahe aneinander liegen, sind diese beiden Gebilde auf einem späteren Stadium (Taf. XXV, Fig. 14B) durch kleine Zellen voneinander getrennt. Diese bilden die Anlage des merkwürdigen parenchymatösen Bindegewebes, welches die gesammte sogenannte Körperhöhle des erwachsenen Thieres ausfüllt. Mạn kann auf der Flächenansicht solche Zellen bereits bei ziemlich jungen Knospen (Fig. 12 I erkennen; hier liegen jederseils von der Endodermanlage zwei Zellen ( $m s d$, welche wohl als erste Anlage des Mesoderms angesehen werden 
müssen und welche ich nach ihrem Habitus von der Ectodermanlage ableiten möchte; sichere Kriterien zur Entscheidung dieser Frage habe ich nicht gewinnen können. Auf Schema XI, XII u. XIII sind diese Mesodermelemente durch graue Zellen $(M D)$ dargestellt, und es ist uher die weitere Ausbildung des Bindegewebes nur soviel zu bemerken, dass bei fernerem Wachsthum der Knospe die Zellen auseinanderrücken, offenbar durch Ausbildung der Zwischensubstanz, und dass besonders die rechts und links vom Darm liegenden Gruppen sich zu langen ker'nhaltigen Spindelzellen ausziehen, die nach dem Nahel zu convergirend dort mit dem mütterlichen Bindegewebe zusammenhängen (Taf. XX); Fig. 16 u. $17 \mathrm{e}$ ). Ist die Knospe soweit ausgehildet, dass sie abfallt, dann hat sich die Convergenz der Mesodermelemente nach dem Nabul hin verwischt. Es liegt nun eigentlich nahe in diesen Zellen die, nur auf embryonaler Stufe bestehenden Analoga der grossen Retractoren des Polypids der Ectoprocten zu finden. Es muss aher besonders darauf aufmerksam gemacht werden, dass die einschichtige Leibeswand, sowie die ein schichtige Darmwand der entoprocten Bryozoen durchaus nicht ohne Weiteres mit der in der Anlage wenigstens stets deutlich zweischichtigen Cystidwand und der stets zweischichtigen Darınwand der ectoprocten Bryozoen verglichen werden darf. Daher ist auch die "Leibeshöhle« von Loxosoma nicht morphologisch gleichwerthig mit der Cystidhöhle der Ectoprocten, und daher dürfen die fraglichen Fasern vorläufig nicht als Retractorenanlagen in Anspruch genommen werden. Was die Genitalanlagen (Taf. XXV, Fig. 16 u. 19 GA) betrifft, die inmitten der Mesodermelemente liegen, so habe ich nicht sicher constatiren können ob diese aus den Mesodermelementen ihren Ursprung nehmen, ich glaube dies aber.

Wir haben nun nur noch die Bildung des Stieles zu beschreiben.

Betrachten wir die Fig. 14.A der Tafel XXV, so sehen wir an der mit $s t$ bezeichneten Stelle einen kleinen stumpf-eckigen Vorsprung des Profilcontours der Knospe. Dies ist die erste Anlage des Stieles. Dieser wächst als eine einfache Ausstülpung der Leibeswand, in welche viele Mesodermelemente sich hineinziehen, im rechten Winkel gegen die bisherige Längsachse der Knospe aus. Zunächst bildet er nach einiger Zeit einen stumpfen Kegel (Taf. XXV, Fig. $16 \mathrm{ASt}$ ), an dem man sehr schön die acht Ectodermzellreihen, die seine Oberfläche bilden, erkennen kann. Ich muss übrigens bemerken, dass diese Zellen sich unmittelbar anschliessen an die weniger regelmässig geordneten, die Wand des Kelches bildenden, dass diese letzteren aber in der eben citirten Figm $16 A$ nicht gezeichnet sind, um den unter ihnen liegenden Darnıapparat besser hervortreten zu lassen; aber schon jetzt weichen diese 
acht Zellreihen auseinander, um zwischen sich die oben beschriebenen, schon von Claparène erkannten Längsfasern entstehen zu lassen. Ob diese durch Unwandlung vou Ectodermzellen entstehen oder nicht, kann ich nicht nit Bestimntheit entscheiden, glaube aber eher, dass dieselben von Mesodermelementen gebildet werden, welche sich zwischen die auseinanderweichenden Ectodernzellen einschiehen. Auf Fig. $16 \lambda$ kann man diese ersten Spindelzellen deutlich bei $b$ erkennen, ausgebildet sind die später sich zu Längsfasern umwandelnden Spindelzellreihen an Stiele der erwachsenen Knospe Fig. 17.

Im Stiel einer solchen mil seiner Längsachse quer gegen die Längsachse des Mutterthieres gerichteten Larve kann man nun auch ganz deutlich ein Gebilde erkennen, das mit der Fussdrüse, welche KowaLEWSKY von L. Neapolitanum beschreibl, die unverkennbarste Aelınlichkeit hat. Am besten erkennt man sie, wenn man einen senkrecht auf der Medianebene stehenden Längsschnitt durch den Stiel einer linospe macht. Ein solcher ist auf Taf. XXV, Fig. 18 abgebildet. Der Schnit ist gerade durch die Epithelzellreihen des Stieles und nicht durch die Längsfasern gefallen; an der Sohle des Stieles hören diese Zellen auf deutlich zu sein und machen vier grösseren Zellen $(x)$ Platz, welche genau den von Kowalewsky (8. Fig. 1 h) gezeichneten entsprechen, auf dem Schnitte sieht man natürlich nur zwoi. In der Mitle wird aber das Stielende ausgefüllı von einem längeren Schlauche, welcher aus einer homogenen tunica propria besteht und an seinem vom Stielende abgekehrten blinden Ende einen deutlichen Zellbeleg zeigt. An denı weiteren Verlaufe des Schlauches nach dem Stielende zu war eine Zellauskleidung bei meinen gehärteten Praparaten nicht zu sehen. Es ist mir aber unzweifelhaft, dass der obere blinde Theil der von Kowalewsir beschriebenen Drüse, der untere dagegen ihrem Ausfülırungsgange entspricht, und ich glaube, dass am lebenden Thier auch eine Zellbekleidung dieses Ausführungsganges nachweisbar sein wird. Die Mündung des Ausführungsganges ist bei genauer Aufmerksamkeit im Centrum der Sohle erkennbar. Die "Anheftungsorgane" Kowalewskr's scheinen den von mir beschriebenen grösseren Zellen $(x)$ zu entsprechen und könnten vielleicht einzellige accessorische Drüsen darstellen. Beweisen kann irh dies nicht. Diese Drüse ist bei jeder weiter eniwickelten Knospe vorhanden, kann aber schon an sehr jungen festsitzenden losgelösten Thieren nicht mehr nachgewiesen werden. Bei diesen wie bei den ausgewachsenen ist die Sohle des Stieles unterhalb der Cuticula gebildet durch die oben beschriebene dickere Zelllage, welche ich auf Fig. 8 abgebildet habe. Ich bin daher der Ansicht, dass die Knospe von Loxosoma Kefersteinii, sobald sie sich von der Nutter getrennt hat, sich mit 
dem Sekrete der eben beschriebenen Drüse festklebt und alsdann nicht wieder ihren Wohnsitz verändert. Es spriclst hierfür auch der Mangel eines besonderen Muskelapparates der Fussscheibe. Aus welchem Blatte diese Drüse entsteht, konnte ich nicht nachweisen. Dass ein Vergleich dieser bei den übrigen Loxosomenspecies auch im erwachsenen Zustande persistirenden Drüse mit der Pedaldrüse der Gasteropoden (Kowalewsky) oder der Schalendrüse der Mollusken überhaupt (RaY-Lankester) auf einer ganz oberflächlichen Aehnlichkeit und auf einer Art Erinnerung an die früher beliebte systematische Verbindung der Bryozoen mit den Mollusken, resp. den Molluscoïden beruht, brauche ich wohl kaum näher auszufübren.

Bei weiterem Wachsthum der Knospe wird der Winkel, den die Kelchachse mit der Stielachse bildet, immer stumpfer, das Thier streckt sich mehr in die Gestalt des Erwachsenen, und bald löst sich die Knospe von ibrem Mutterboden, um sich mit ihrer Sohle in der Nähe des Mutterthieres zu fixiren. Der Nabel obliterirt bei dieser Gelegenheit und ist schon an den jüngsten angebefteten selbststindigen Thieren nicht mehr erkennbar. Die Stelle, an welcher das Thier also als Knospe angeheftet war, ist bei dem erwachsenen Thier an der analen Seite in der Medianebene, an der Grenze zwischen Stiel und Kelch zu suchen.

Die Dimensionen der grössten von mir beobachteten Knospen betragen in der Länge $0,225 \mathrm{Mm}$. Es entsprechen diese Dimensionen ziemlich den von Kowalewsky für ein erwachsenes kleines Loxosoma Neapolitanum angegebenen, und es wirft dieser Umstand in Verbindung mit der Thatsache, dass eine solche erwachsene Knospe ebenfalls nur zehn Tentakeln hat und eine Fussdrüse besitzt wie L. Neapolitanum, vielleicht ein interessantes Licht auf die phylogenetischen Verhältnisse der Loxosomen. L. Neapolitanum erscheint im Verhältniss zu L. Kefersteinii als ein geschlechtsreif gewordener Jugendzustand, ähnlich wie man die Schizopoden als einen geschlechtsreif gewordenen Jugendzustand der Macruren ansehen kann, oder richtiger gesagt, letztere als die weiter entwickelte Form, in deren Entwicklungscyclus eine uberwundene Phase der phylogenetischen Entwicklung noch als Jugendzustand auftritt. Die letztere Betrachtungsweise empfiehlt sich um so mehr, nachdem wir durch Scпмıт gelernt haben, dass die Fussdrüse nicht nur einem einzigen Loxosoma, sondern bei weitem der Mehrzahl zukömmt. Die mit Fussdrüsen versehenen Loxosomen stellen daher das Gros der Loxosomen auf ihrem gegenwärtigen phylogenetischen Zustande dar, während das Loxosoma Kefersteinii als eine durch Anpassung an eine mehr sedentäre Lehensweise weiter entwickelte Form erscheint, für deren Abstammung von einer kleineren, bit weniger Tentakeln versehenen 
und eine Fussdruse besitzenden Form die Beschaffenheit ihrer Jugendform zeugt.

Soweil meine eigenen Beobachtungen.

Ich muss jetzt zur Besprechung der inzwischen erschienenen Arbeit von Oscall Sснмпт (15) übergehen, welche für das von mir behandelte Thema insofern vonı höchsten Interesse ist, als drei andere Species von Loxosoma einer eingehenden Prüfung unterworfen werden. Es stellt sich durch dieselbe zunächst heraus, dass Herr Prof. Schmot in Betreff des allgemeinen Baues der Loxosomen ziemlich dieselben Resultate bekommen hat wie ich, dass er aber in Betreff einiger Puncte weiter gekomnen ist als ich. Ist es ihm doch gelungen genau die Bildung der Genitalien $\mathrm{zu}$ erforschen und diejenige Vermuthung $\mathrm{zu}$ bestätigen, die ich auf Grund meiner Untersuchungen in der vorläufigen Mittheilung aussprach, dass nämlich Loxosoma Zwitter sei oder, wie ich sagte, genau nach dem Pedicellinentypus gebaute Genitalorgane besitze. Auch ist es ihm gelungen, die geschlechtliche Fortpflanzung, wie KowALEWsKY sie beschrieben, zu sehen, allerdings nur unvollständig. Kann ich daher diese Resultate nur mit der grössten Freude begrüssen, so kann ich mich doch mit einer Reihe der andern Ausführungen des gelehrten Herrn Verfassers nicht ganz einverstanden erklären.

Schuid sagt p. 13: "Welches ist nun die systematische Stellung von Loxosoma. Ich finde gar keine Anhaltepuncte, aber auch nicht, da solche nicht vorhanden, das dringende Bedürfniss, dem Thiere bestimmte jetzt lebende Verwandte zuzuweisen ...... die Anatomie weist ihm keine bestimnte Stelle an. Die Aehnlichkeit mit Pedicellinat ist nach denı nunmehr vorliegenden Detail doch eine zu oberflächliche, un Loxosoma zu einer Bryozoe zu machen".

Dass ich diese Auffassung nicht theilen kann, geht sowohl aus meinen Ausführungen über Pedicellina (12), aus meiner vorläufigen Mittheilung (14) und aus der vorstehenden genaueren Arbeit zur Genüge hervor. Ich gebe $\mathrm{zu}$, dass man wohl daruber streiten kann, ob Loxosoma eine Bryozoe ist, aber nur dann kann dies geschehen, wemn man zugleich die Bryozoennatur von Pedicellina in Frage zieht. Ich bin nämlich der Ansicht, dass das von Herrn Prof. Sсниidт beigebrachte neue Detail, weit entfernt die Oberflächliçhkeit der Aehnlichkeit von Loxosoma mit Pedicellina darzuthun, auch den letzten möglichen Zweifel, ob beide Thiere zusammengehören, gehoben hat, indem el nachweist, dass Loxosoma paarige, zwitterhafte Geschlechtsorgane besitzt. Ich gebe $\mathrm{zu}$, dass die von Scнmid gezeichnete Abbildung ron Loxosoma die Identität der Bildung von Loxosoma und Pedicellina nicht auf den ersten Blick hervortreten lässt, aber jeder Unbefangene, der meine 
genaue Darstellung des Baues von Pedicellina mit der oben von mir gegebenen von Loxosoma vergleicht, und besonders den schematischen Längsschnitt von P'edicellina (12, Taf. XXV, Fig. $2 \mathrm{C}$ ) mit dem Längsschnitt von Loxosoma, wie ich ihn genau nach der Natur gezeichnet, vergleicht, ınuss die völlige Identität beider Bildungen erkennen, und ich kann nur glauben, dass eine Unbekanntschaft nit Ulus sis's sowie meiner früheren Arbeit über Pedicellina Herrn Prof. Scнurnt die oben angeführten Sätze hat schreiben lassen.

Der Behauptung von Herrn Prof. Sснмidт gegenüber, dass keine Aehnlichkeit zwischen Pedicellina und Loxosoma stattfinde, muss ich aber etwas genauer auf den Nachweis einer solchen eingehen, und will dabei zugleich die etwa bei meiner Species nicht mit den Angaben von Herrn Prof. Scнмmт bei seinen Arten stimmenden Bauverhältnisse des erwachsenen Thieres erwähnen.

Zunächst kann ich mich mit den Genus-Characteren, welche Herr Prof. Sснмпт für das Genus. Loxosoma aufstellt, nicht völlig einverstanden erklären. Es wird der Rumpf schildförmig genannt. Diese Bezeichnung mag wohl auf die von Herrn Prof. Schint beobachteten Loxosomen, speciell auf Loxos. Raja, vielleicht auch auf Gyclatella annellidicola (cf. 6, Taf. VIl, Fig. 13 u. 15) passen, sie kann aber, weil auf das sehr characteristische L. Kefersteinii und L. Neapolitanum nicht anwendbar, nicht in die Genusdefinition aufgenommen werden, vielmehr stellt der Rumpf stets eine allerdings mehr oder weniger comprimirte Art Kelch vor. Schildartig sind mir stets nur die Umrisse comprimirter Präparate crschienen.

Dass der obere Theil dieses "Schildes " von den Tentakeln eingenommen wird, ist wiederum keine genaue Bezeichnung der wirklichen Verhältnisse. Vielmehr sitzen, wie ich oben geschildert habe, die Tentakeln dem Kelchrande auf, nur ist dieser bei Loxosoma bedeutend schräger gegen die Längsachse geneigt, als bei Pedicellina. Das von Sснмпт geschilderte Bild erhält man übrigens auch bei meiner Species, wenn man das comprimirte Thier nur in der Vorderansicht betrachtet. Auch muss ich noch bemerken, dass es wirklich schwer ist, ein Loxosoma im Leben von der Seite zn sehen. Am besten erkennt man seinen Profilumriss, wenn man ein gehärtetes Thier in der Medianebene spaltet. Dass sich die Afterölfnung fast central im Tentakelkranze befiudet, kann man ferner ebenfalls für meine Species nicht behaupten. Hier liegt sie vielmehr dem Rande bedeutend genähert, scheint aber, weil an contrahirten Exemplaren der Analschornstein oder die Analpapille gewöhnlich in der Medianebene nach dem Munde zu vorgeklappt wird, allerdings in der Mitte zu liegen. Dass die Anheftung des Thieres 
durch einen saugnapfähnlich erweiterten und mit einem eigenthümlichen Drüsenapparat versehenen unteren Theil des Stieles geschieht, kann man auch nicht ohne weiteres als Gattungscharacter angeben, da die bei weitem grösste Art, das Loxosoma Kefersteinii, eines solchen Drüsenapparates im erwachsenen Zustand ebenso völlig entbehrt, wie einer einen Saugnapf constituirenden Musculatur am unteren Ende des Stieles. Es müsste daher zugefügt werden "wenigstens in der Jugend". Dass ferner bei der geschlechtlichen Entwickelung mit Metamorphose ein Durchbruch der Schwärmlarven durch die Tentakelscheibe stattfindet, sollte doch wohl nicht so olne weiteres von einem Forscher angenommen werden, der soeben im Begriff steht weiter unten nachzuweisen, dass die Geschlechtsorgane mit deutlichen Ausfuhrgängen in Verbindung stehen, besonders wenn die Oeffnungan der gleichgebauten Geschlechtsorgane bei ganz nahe verwandten Formen bereits nachgewiesen worden.

Ueber die Angaben in Betreff des genaueren Baues der von Herrn Prof. Schmid beschriebenen Species kann ich mir, da ich dieselben nicht kenne, natürlich kein Urtheil erlauben, inöchte aber folgende Differenzpuncte $\mathrm{z}$ wischen seinen Angaben und meinen Beobachtungen an einer verwandten Species hervorheben. Ein eigentlicher Ringkragen, der die Tentakeln bedeckt und schützt, existirt ebensowenig als bei Pedicellina. Die Tentakeln werden vielmelır von dem eingeschlagenen Körperrande selbst bedeckt. Unter dem Ringkragen kann bei meiner Species nur der obere Theil der Kelchwandung verstanden werden, welcher auf Taf. XXV, Fig. 5 mit $x$ y bezeichnet ist. Der Sphincter liegt dicht an der Basis der Tentakeln selbst, und verläuft längs dieser in einer Linie, deren Endpuncte in meiner Fig. 5 durch die Buchstaben $x y$ bezeiclinet werden. Was Lage der Tentakeln und ihre Insertion am Kelchrande betrifft, so stimmen die Verhältnisse meines Loxosoma ganz genau mit denen von Pedicellina, und ist auch die Lage des Sphincters und des "Ringkragens" genau dieselbe.

Was die schon von Kowalewsky sehr genau gezeichnete Bindegewebsschicht betrift, so muss ich für meine Species bemerken, dass zwischen den verzweigten Zellen sich eine farblose Gallerte befindet, wie man an Querschnitten, besonders des Stieles, durch Färbung mit Anilinblau leicht nachweisen kann. Ich möchte diese übrigens durchaus nicht ohne weiteres als im lebenden Thier wirklich existirend ansehen. Es kann dieselbe auch ein Gerinnungsproduct einer intercellulären Flüssigkeit sein, obgleich das Vorhandensein der gleichen Gallerte bei Pedicellina dies einigermassen unwahrscheinlich mach. Was die Musculatur betrifft, so habe ich die von Sснмірт angegebene Ringmuskelschicht 
niemals entdecken können. Dass die Längsmuskelfasern innen im Stiel verlaufen, habe ich nicht bei meiner Species beobachtet, vielmehr muss ich die Claparéne'schen Angaben (11) mil den oben gegebenen Einschränkungen völlig aufrecht erbalten.

Die Bemerkung von Herrn Prof. Scmunt, Kowalewsk y habe gesag1, die Tentakeln von L. Neapolitanum bestainden aus drei Reihen Zellen, ist nicht ganz correct. Kowalewskr sagt vielmehr, der Beleg der Innenseite der Tentakeln hestände aus drei Reihen von Zellen, und muss ich diese Angabe für Loxosona Kefersteinii bestätigen. Sollte dies nicht vielleicht auch bei den von Herrn Prof. Scnums beobachteten Formen der Fall sein, und die von ihm beschriebenen kurzen Wimpern auf einer besonderen medianen Zellreihe sitzen?

Der Zellbeleg der inneren Seite der Tentakeln von Loxosoma Neapolitanum und Loxosoma Kefersteinii stimm in Folge dessen genau mit dem Zellbeleg der Innenseite der Tentakeln von Pedicellina wie ich denselben beschrieben habe, uherein (12, Taf. III, Fig. 11). Dass die "Scheibenfurche", wie Herr Prof. Scнmidr sie nennt, bei meinem Loxosoma keine eigentliche Furche, sondern eine von einer nach dem Munde zu immer breiter werdenden Falte begrenzte Rinne ist, die ganz genau der Tentakelrinne von Pedicellina entspricht, sei bier noch besonders hervorgehoben. Die Wandung des Darmes besteht bei unserer Species nicht blos aus einer Zellschicht, sondern auch aus einer deutlichen nach aussen gelegenen Tunica propria, genau wie bei Pedicellina und ich möchte bemerken, dass Herr Prof. Schmid diese (15, Taf. I, Fig. 1) selhst gezeichnet hat. Dass in einer mittleren Zone die Zellen des Magens sehr hoch werden, und eine Leberfunction haben mögen, wie dies aus der bräunlichen oder grünlichen Färbung ihres Inhaltes hervorgeht, ist gewiss unbestreitbar, und Loxosoma stimmt hierin mit Pedicellina genau überein, indessen ist $\mathrm{zu}$ bemerken, dass Herr Prof. Sсницт die Wimpern, die sowohl den Oesophaguszellen, als einem Theil der Magenepithelien und dem eigentlichen Intestinum bei meiner Species aufsitzen und auch bei den anderen wohl nicht fehlen werden, nicht erwähnt. Das Endstuck des Darmes ist nicht blos bäufig gegen das Ende bin eingeschnürt, sondern beide durch diesen constanten Einschnitt getrennte Theile zeigen auch eine ganz andere Anordnung der Zellelemente und sind daher als wirklich getrennte Darmtheile in Anspruch zu nehmen. In allen diesen Puncten stimmt Loxosoma genau mit Pedicellina. Die dem Munddarm zugehörige Drüse (15, Fig. $1 x$ ) hat bei meiner Species und bei Pedicellina kein Analogon.

Dass wirklich die Genitalorgane von Loxosoma genau übereinstimmen mit denen von Pedicellina, lässt sich leicht aus der Vergleichung 
der Angaben von Uluanis ${ }^{1}$ ) und mir in Betreff von Pedicellina und den Scнмит'schen Angaben über Loxosoma nachweisen. In Betreff der Darstellung der topographischen Verhältnisse der Genitalorgane von Pedicellina stimmen bekanntlich die Angaben von UlJaxix und mir recht genau, in Betreff der Deutung differiren wir aber; während Uusaniv das dem Oesophagus genäherte Drüsenpaar als Dotterstöcke, und demgemäss Pedicellina als getrennten Geschlechtes ansiebt, habe ich diese Drüsen, weil sie in sehr vielen Fällen nicht blos eine körnige Masse sondern Spermatozoen in allen Entwickelungsstadien enthalten, als Hoden in Anspruch genommen. Ich habe mich neuerdings noch wiederholt von der Richtigkeit dieser Angaben überzeugt und halte meine Ansicht uber die fraglichen Drüsen um so mehr fest, als es mir gelungen ist, IIerrn Prof. Leuckart, unter dessen Auspicien die Uluanıs'sche Arbeit gemacht wurde, durch meine Präparate von der Richtigkeit meiner Angaben zu uberzeugen ${ }^{2}$ ). Die Genitalorgane von Pedicellina unterscheiden sich von denen der ectoprocten Bryozoen dadurch, dass sie aus zwei Paar Drüsenschläuchen bestehen, von denen die dem Oesophagus näher gelegenen Hoden, die dem Rectum zugewendeten Ovarien darstellen. Die Ausführungsgänge beider Drüsenpaare münden in der Mittelebene des Körpers auf einem am Rande der Bruttasche gelegenen Vorsprung, und der gemeinsame Ausführungsgang ist umgeben von einem unpaaren Drüsenpaquet, das Uluaniv als Schalendrüse, ich selbst einfach als Drüse bezeichnet haben. Die Bruttasche selbst ist weiter nichts, sls eine Aussackung der intratentaculären Leibeswand, in der die Eier ihre Entwickelung durchmachen. Die ectoprocten Bryozoen besitzen dagegen niemals geschlossene Geschlechtsdrüsen mit Ausführungsgängen.

Herr Prof. Scнnid zeigt nun, dass die Genitalien von Loxosoma aus zwei paarigen Eierstöcken bestehen, welche je einen Gang nach der Medianebene, d. h. in die Samenblase senden, und aus einem Paar zweilappiger Hoden, deren Ausführungsgänge ebenfalls in die Samenblase münden. Wir haben also wenn wir die Schalendrüse von Uluaxis, und die Samenblase von Sснмірт, was wohl erlaubt ist, als aequivalent ansehen, genau dieselben Theile aufzuweisen, nur fehlt bei Scнuidr eine Angabe über die Ausmündungsstelle der Genitalien. Die wesentlichen Theile des Genitalapparates von Pedicellina sind also auch bei Loxosoma nachgewiesen. Was die Bruttasche betriff, so fehlt diese nach den bisherigen Angaben bei Loxosoma, auch ist mir, wie schon oben gesagt, niemals gelungen, eine solche zu entdecken, da ich es mit im September

1) Bulletin de la Soc. Imp. des Naturalisles de Moscou 1870.

2) Leuckart. Jahresbericht für 1868 u. 1869 , p. 180. 
gesammelten, nicht geschlechtsreifen Thieren zu thun hatte. Es sollte mich auch gar nicht wundern, wenn dieselbe auch bei meiner Species fehlte, denn wir haben es nach den Angaben von Kowalewsky in Loxosoma mit einem Genus zu thun, bei welchem nur ein $\mathrm{Fi}$ zu gleicher Zeit reif wird. Dieses findet nun innerhalb des Tentakelkranzes auf der intratentaculären Leibeswand seine weitere Entwickelung, eine Stelle, die genau entpricht der Stelle an der die Embryonen von Pedicellina sich ausbilden, nur ist in dem letzteren Falle für die vielen Embryonen ein besonderer Brutplatz eingerichtet. Ob nicht vielleicht aber die "Aussackung des Eierstockes, in der die in der Furchung begriffenen Eier liegen (Sснмıт, p. 12), bei Loxosoma Raja und L. Cochlear eine solche nur von dem Verfasser nicht ganz gewürdigte Bruttasche darstellt, das wage ich nicht zu entscheiden.

Nach diesen und den vorhergehenden Erörterungen muss ich meine Anschauung uber das Verhältniss von Loxosoma und Pedicellina in folgenden Sätzen niederlegen:

1. Ein Einzelthier von Loxosoma stimnt mit einem Einzelthier von Pedicellina in allen wesentlichen Stukeken völlig überein, sowohl was die topographische als histologische Beschaffenheit der einzelnen Organe betrifft.

2. Es unterscheidet sich das Genus Loxosoma von dem Genus Pedicellina nur durch folgende unwichtigere Merkmale:

a. Loxosoma ist ein Einzelthier, wälırend Pedicellina Thierstöcke bildet. Es verhalten sich beide Genera ohngefähr so zu einander, wie eine wirkliche solitäre Ascidie zu einer Clavellina.

$b$. Der Stiel von Loxosoma ist weniger scharf von dem Kelche getrennt als bei Pedicellina, wo das sogenannte Diaphragma diese beiden Körpertheile scharf sondert.

c. Entsprechend seiner Natur als Einzelthier ist Loxosoma häufig (in der Jugend immer) mit einer "Fussdrüse " versehen, welche der Pedicellina, die mit Hülfe ihrer Stolonen sich befestigt, fehlt.

d. Loxosoma als ein nur wenige Eier producirendes Thier hat keine eigentliche Bruttasche, wie Pedicellina, welche gleichzeitig eine ganze Reihe von Jungen innerhalb des Intratentacularraumes birgt. Dass andererseits Loxosoma und Pedicellina nicht ohne weiteres mit den übrigen Bryozoen verbunden werden können, habe ich bereits vor Jahren ausgesprochen und für die fraglichen beiden Genera, sowic für die wahrscheinlich hierher gehörige Urnatella eine eigene Gruppe aufgestellt, welche ich unter dem Namen Bryozoa Entoprocta den sämmtlichen übrigen Bryozoen, die ich als Bryozoa ectoprocta zusammengefasst habe, entgegenstellte. Diese Anschauung ist neuerdings 
auch von Carus in seinem Handbuch angenommen worden, und ich bemerke nochmals ausdrücklich, dass man meiner Ansicht nach zwar über die Berechtigung der Vereinigung der Entoprocta und Ectoprocta in der Classe der Bryozoa im Zweifel sein kann, dagegen unter allen Umständen die Zusammengehörigkeit von Loxosoma, Pedicellina (und Urnatella) anerkennen muss.

Für Jeden, der die eben genatuer ausgefuhrte Verwandischaft von Loxosoma und Pedicellina richtig erkannt hat und weiss, dass Pedicellina sich wie alle ectoprocten Bryozoen durch Knospung fortpflanzt, muss daher die Angabe von Herm Professor Scнмid, bei Loxosoma käme keine ungeschlechtliche Fortpflanzung durch Knospung vor, ungemein auffällig erscheinen; und das Erstaunen muss sich mehren, wenn man erfährt, dass Herr Prof. Sснмidт die längst bekannten und von allen Autoren als Knospen gedeuteten Seitensprösslinge von Loxosoma als geschlechtlich erzeugte, aus Eiern entsprossene Embryonen ansieht. Herr Prof. Sснмит sagt: „Es ist mir geglückt, die Entwicklung dieser vermeintlichen Knospen mit ziemlicher Vollständigkeit zu verfolgen, und es hat sich ergeben, dass eine regelrechte Eientwicklung ohne $\mathrm{Me}-$ tamorphose vorliegt

Je uberraschender diese Behauptung ist, desto mehr sind wir berechtigt nach den Gründen zu fragen, die Herrn Prof. Sснмпт zu derselben berechtigen, und ich muss ehrlich bekennen, dass ich ausser eben der Behauptung, dass dem so sei, keine weiteren diese Ansicht stützenden Angaben gefunden habe. Es fehlt zunächst jeder Beweis, dass wirklich die Seitensprösslinge von einem aus dem Eierstock berstammenden Ei abgeleitet werden müssen. Schon nach Scнмidt bleibt es einfach unentschieden, wie das Ei aus dem Eierstock frei wird, ob durch einen Ausfübrungsgang oder durch Ruptur des Eierstockes; dann soll Schmidts Fig. 10 den Uebertritt eines Eies in eine Art von Kapsel, welche nahe an der Leber liegt, zeigen; ich muss bemerken, dass mir diese Figur das nicht zeigt, vielmehr völlig unverständlich ist, um so mehr, als uns über die Natur dieser Kapsel weiter nichts gesagt wird, als dass sie in der Nähe der Leber liege. Alsdann bildet Sснмпт auf Fig. 11 u. 12 Furchungsstadien von Eiern ab, die cr als weiter entwickelte, zu Seitensprösslingen sich umbildende Eier ansehen möchte, von denen er selbst aber zugiebt, dass es ebensogut Eier sein können, welche die gewöhnliche Entwicklung zu freien Larven durchmachen. Die Furchung soll ferner ablaufen in einer Bucht, dic sich tief bis zur Achse des Körpers erstreckt. Ob diese Bucht nun mit der oben genannten Kapsel identisch ist, ob sie als eine Einsenkung der äusseren Körperbedeckungen erscheint, ob sie ein die Leibessub- 
stanz durchsetzender Canal ist, der aussen eine Mundung hat, davon erfährt man kein Wort. Ersteres scheint mir der Fall zu sein, denn wenige Zeilen später wird oflenbar dieselbe Kapsel oder Bucht als Rinne bezeichnet. Wie nun gar das Ei, resp. der Embryo aul die Aussenfläche des Körpers gelangt, wo er doch sehliesslich, wie die von Sснмidт ausdrücklich anerkannten Figuren von Kowalewsky zeigen, liegt, das ist mit keinem Worte erwähnt. Wir erfahren nur, dass das in der Furchung begriffene Ei die Kapselhaut - uber deren Natur wir gar nichts erfahren haben - vor sich hertreibt, dass diese sich prall an denselben anlegt und später in die Hautbedeckung des Embryos übergenommen wird. Erst nach allen diesen undeutlichen Angaben beginnt dann die eigentliche Beschreibung des Embryo, und von dem Puncte an, wo dieser geschildert wird als eine aus einer Zelllage bestehenden Scheibe, schwindet die Unklarheil und eine verständliche Darstellung der Vorgänge, durch welche diese Scheibe in den dem Aelternthier gleichen Emloryo sich verwandelt, beginnt.

Die eben angeführten Sätze sind wirklich alles, was Herr Prof. Sснмпт vorbringt, um seine Hypothese der Abstanmung der Seitensprösslinge von Eiern zu stützen.

Müssen nun diese so ungemein hinfälligen Gründe schon einen jeden Unbefangenen nachdenklich und misstrauisch machen, so bin ich in Folge meiner eigenen Untersuchungen noch mehr zu solchem Misstrauen berechtigt. Naturlich kann es mir, der nie eine der von Sснмidr beobachteten Species gesehen trat, nicht einfallen zu behaupten, dass die Sache sich bei diesen Species anders verhielte als Herr Prof. Scнmipt es angiebt, dagegen kann ich mit voller Entschiedenheit behaupten, dass die Entwicklung der Seitensprösslinge bei Loxosoma Kefersteinii, welche genau in der Weise sich bilden, wie Scnmidr dies für Loxosoma Raja und cochlear auf Taf. III, Fig. $13-22$ abgebildet hat, keine Entwicklung aus dem Ei, sondern ein Knospungsvorgang ist.

Die Gründe, die mich zu dieser Behauptung bestimmen, sind ausser dem Umstande, dass Herr Prof. Scumidr seine Behauptung, die Seitensprösslinge stammten von Eiern ab, nicht bewiesen hat, folgende:

1. Ich habe hunderte von im Herbst gesammelter erwachsener Loxo-somen untersucht, ohne ein einziges Exemplar mit entwickelten Genitalien gefunden zu haben, und doch waren sie sänmtlich mit Seitensprösslingen überıeich versehen.

2. Ich habe gefunden, dass die Anlage der ersten Knospe sich durchaus nicht erst an den erwachsenen Thieren findet, sondern dass bereits die am Mutterboden noch festsitzenden älteren Knospen selbst wieder eine Knospenanlage tragen, und dass diese nicht 
aus einem Ei hervorgegangen, kann bei der späten Entwicklung der Genitalien wohl mit absoluter Sicherheit behauptet werden.

3. habe ich, wie oben gezeigt, ganz genau den Uebergang der Leiheswandelemente des Mutterthieres, sowohl der zelligen Schicht als der Cuticula, in die entsprechenden Theile der Knospe verfolgen können.

Wie aber Herr Prof. Scнмпт zu seiner Hypothese gekommen ist, scheint mir ebenfalls ganz ungemein klar. Er hat deutlich erkannt, dass bei der Entstehung der Seitensprösslinge drei Keimblätter auftreten; ausgehend nun von dem Gedanken, dass eine solche gesetzmässige Schichtung der Zellen nur bei der Furchung stattfinde, kam er auf die Vermuthung, diese Entwicklung sei eine Entwicklung aus dem Ei und hat nun auf irgend eine Weise wahrscheinlich zu machen gesucht, wie dies Ei nach aussen an die Leibeswand der Mutter gelangt. Diesem Versuche entstanmt die auf ungenügender Basis aufgebaute Darstellung der ersten Abstammung der Zellplatte.

Was die Darstellung betrifft, die Herr Prof. Scnumpt von der Entwicklung des jungen Thieres, nach meiner Ansicht also der Knospe, aus der einschichtigen Zellplatte giebt, so erhellt sofort aus einer Vergleichung unserer beiden Angaben, dass wir in vielen Puncten zu einer ganz gleichen Auffassung gekommen sind. Indessen möchte ich bemerken, dass, vorausgesetzt die Bildung der Seitensprösslinge gehe bei allen Loxosomen in gleicher Weise vor sich, ich mit seinen Angaben und besonders mit den Schlüssen, die er aus den gezeichneten Figuren zieht, mich nicht in allen Puncten einverstanden erklären kann.

Zunächst muss ich hervorheben, dass mir die Figuren 13-22 auf Taf. III nicht ohne weiteres verständlich sind. Sie stellen sämmtlich Stadien dar, die mir aus der Entwicklung von Loxosoma Kefersteinii wohl bekannt sind, aber wären sie dieser Species entnommen, so wären es keine Stadien, die ohne weiteres in der Art miteinander verglichen werden könnten, wie Herr Prof. Scnmid es thut. Er scheint - genau spricht er sich nirgends darüber aus - anzunehmen, dass in sämmtlichen Figuren das obere und untere Ende der Zeichnungen gleiclwerthig ist. Dem könnte ich für L. Kefersteinii nicht beistimmen. Nr. 13, 14 u. 15 würden dann ganz junge kaum über die Oberfliche des Mutterthieres sich hervorwölbende Flächenansichten darstellen. Fig. 16 u. 17 würden ungefähr einem optischen Durchschnitt durch weiter entwickelte Knospen senkrecht gegen die Synmetrieebene entsprechen. Fig. 18 hat am meisten Aehnlichkeit mit einer Ansicht senkrecht auf die Oberfläche einer etwas älteren Knospe, bei welcher eben der Intratentacularraum sich zu öffnen im Begriff steht, und der 
Raum zwischen den beiden medianen Zellreihen würde dann nicht dem Darmlumen, sondern dem Kelchrande entsprechen. Fig. 19 stellte dann wohl sicher wieder einen der oben erwähnten optischen Längsschnitte einer jungen Knospe dar, während Fig. 20 wieder eine Vorderansicht einer Knospe darstellen würde, ungefähr auf einem etwas jüngeren Stadium als dem von mir auf Taf. XXV, Fig. 16 gezeichneten.

Es ist ferner höchst auffallend, dass Herr Prof. Sснмпт niemals genau angiebt, mit welcher Stelle des Leibes seine älteren Knospen mit dem Nutterthier zusammenhängen. Aus der ganzen Darstellung geht aber hervor, dass er annimnt, sie hingen mit der Sohle mit dem Multerthier zusammen. Wenigstens sind alle Figuren so orientirt, dass man annebmen muss, die nach unten gewendeten Enden entsprächen der Anheftungsstelle. Dies wäre nun aber bei L. Kefersteinii sicher nicht der Fall, vielmehr würde, wenn, was sehr wohl möglich wäre, Fig. 22 eine Knospe von L. Kefersteinii darstellte, der Punct, wo diese Knospe an dem Mutterthier ansisse, auf der entgegengesetzten Seite des Papier's liegen. Es ist die Unterlassung einer genaueren Darstellung um so mehr zu bedauern, als Herrn Prof. Schnidt durch die schönen CLAPARÉDE'schen Angaben die Untersuchung dieser Frage nahe gelegt sein musste.

Obgleich daher die Angaben von Herrn Prof. Sснмid über die „zweite geschlechtliche Fortpflanzungsart« sehr positiv sind, und ich bei dem völligen Mangel eines absolut identischen Materials dieselhen nicht direct bestreiten kann, so möchte ich doch glauben, dass dieselben so lange als hypothetisch anzusehen sein dürften, bis die von mir hier angeregten $Z$ weifel durch eine genaue Nachuntersuchung beseitigt sind.

\section{Literatur des Genus Loxosoma.}

1. Busch, W. Beobachtungen über Anatomie und Entwickelungsgeschichte einiger wirbelloser Seethiere. 1851. p. 132, Taf. XVI, Fig. 12-16. (Cyclopelma longociliatum, wahrscheinlich die Larve von Loxosoma.)

2. Norman, A. M. On an Echinoderm new to Science from Ireland. Anuals and Magazine of natural history III. Séries 1861, Vol VII, p. 112-114, Pl. 1X, Fig. 1-4 Erste erkennbare Abbildung von Loxosoma, aber beschrieben als hintere "tentacular appendages" von Strephenterus claviger.)

3. Keferstein, W. Ueber Loxosoma singulare, gen. et sp. n., den Schmarotzer einer Annelide. Zeitschr. f. wiss. Zoologie XII. 1863, p. 131 u. 132, Taf. XI, Fig. 29.

4. Claparède, Ed. Ueber eine wahrscheinlich zu den Bryozoen gehörige Thierform, Loxosoma singulare Keferst. Beobachtungen über Anatomie und EntwickeJungsgeschichte wirbelloser Thiere etc. Leipzig, 1863, p. 105-107, Taf. II, Fig. 6-10. 
3. Leuckart, R. Bericht über die wissenschaftl. Leistungen in der Naturgesch. der niederen Thiere während der Jahre 1861 u. 1862 , p. 47 u. 111. Archiv f. Naturgesch. XIX, 1863, II. Bd. (L. nimmt Strephenterus als ein verstümmeltes Phascolosoma in Anspruch und seine Schwanzanhänge als parasitische Bryozoen, die el selbst auch bei Phascolosomen in Treport gefunden, glaubt aber nicht, dass diese dem Genus Loxosoma zugehören [was sie wirklich thun].)

6. van Beneden, P. J. et Hesse, C. E. Recherches sur les Bdellodes (Hirudinèes) et les Trematodes marins. (Mém. prèsenté à l'Acad. le 8 Novembre 1862.) Mémoires de l'Acad. royale de Belgique. T. XXXIV, 1864, p. 83-84, Taf. XII, Fig. 12-20. (Die Verf. beschreiben unter dem Namen Cyclatella anneliclicola eiı Thier, das sie zu den Tristomidea rechnen, dessen Aehnlichkeil mit Pedicellina und Loxosoma sie aber selbst betonen.)

7. Leuckart, R. Bericht über die Leist. in d. Naturgesch. der niederen Thiere, während des Jahres 1863. p. 91 u. 111 in Archiv f. Naturgeschichte XXX, 1864, II. Bd. (L. niınmt mit Sicherheit Cyclatella als mit Loxosoma identisch in Anspruch.)

8. Kowalewsky , A. Beiträge zur Anatomie und Entwickelungsgeschichte des Loxosoma Neapolitanum sp. n. Mémoires de l'Acad. d. St. Pétersbourg. VII. Sèr., P. X. No. 2, 1866, 10 Seiten mit 1 Taf.

9. Keferstein, W. Bericht über die Fortschritte der Anatomie und Physiologie im Jahre 1866, p. 216. Zeitschrift für rationelle Medicin, 1867. (Im Anschluss an die Beobachtungen Kowalewsky's (8) beschreibt Keferstein die Larve eines Loxosoma.)

10. Leuckart, R. Jahresbericht über die Leist. etc. für die Jahre 1866 u. 1867, p. 340. Archiv f. Naturgeschichte 4868 , Vol. II. (L. nimmt Cyclopelma longociliatum als Loxosomenlarve in Anspruch.)

11. Claparède, Ed. Sur le Loxosoma Kefersteinii, Bryozoaire mou du Golfe de Naples, Annales des Sciences naturelles V Sèr. Vol. $\delta$, p. 28-30, Taf. 6, Fig. 1-3, 1867 .

12. Nitsche, H. Ueber die Anatomie von Pedicellina echinata Sars, Zeitschr. f. wiss. Zool. XX, 1870, p. $72-34$, Taf. II u. III. (N. bespricht die Verwandtschaft von Pedicellina und Loxosoma, nimmt Cyclopelma longociliatum von Busch als Loxosomenlarve in Anspruch und gründet die Gruppe der mendoprocten "Bryozoen.)

13. Claparéde, Ed. Ueber Knospenbildung bei Loxosoma. Zeitschr. f. wiss. Zoologie XXI, 1871, p. 170-171, Taf. X, Fig. 4.

14. Nitsche, H. Ueber den Bau und die Knospung von Loxosoma Kefersteinii, Claparède. Zeitschr. f. wissensch. Zoologie XXV, 1875, p. 451-456.

15. Sснмгdт, 0. Die Gattung Loxosoma. Archiv f. mikr. Anatomie, Bd. XII. 


\section{Allgemeine Betrachtungen.}

Wir ${ }_{6}$ haben bis jetzt einfach die morphologischen Vorgänge bei der Knospung der ectoprocten sowie der endoprocten Bryozoen beschrieben, ohne die Tragweite dieser Beobachtungen zu betonen. Wir wollen jetzt darauf aufmerksam machen, dass dieselben aber wohl geeignet sind einen Beitrag zur Klärung wichtiger zoologischer Tagesfragen zu liefern. Es handelt sich hier um die Gastraeatheorie Ilaeckel's und die Frage nach der "Homologie der Keimblätter«.

In seinem vielbesprochenen Aufsatze über die "Gastraeatheorie «1) sagt Hafckel p. 14: गJedenfalls dürfte durch die nachstehenden Erörterungen schon jetzt der Nachweis geliefert sein, dass die Typentheorie von Cuvier und BAER, welche über ein halbes Jahrhundert hindurch die Basis des zoologischen Systems bildete, durch die Fortschritte der Ontogenie unhalthar geworden ist. An ihrer Stelle errichtet die Gastraeatheorie auf Basis der Phylogenie ein neues System, dessen oberstes Princip die Homologie der Keimblatter und des Urdarmes, und dennächst die Differenzirung der Kreuzachsen und des Coeloms ist«.

Dass eine verinderte Auffassung des Begriffes »Typus « nothwendig wird, sobald man auf dem Boden der Descendenztheorie steht, versteht sich ganz von selbst, und dass diese Veränderung der Auffassung schon stattgefunden hat, ehe die Gastraeatheorie von HAEckel erschien, hat Clats bereits nachgewiesen; desgleichen hat letzterer gezeigt, dass die Veränderungen, welche das System durch die Gastraeatheorie erfahren hat, thatsächlich nicht so bedeutend sind, als es HавскеL darstellt. Es kann indessen kaum geläugnet werden, dass der Versuch Haeckel's als unabweisliche Forderung an jedes neue System festzustellen, dass es uns einen Begriff gehe von unseren, auf die Gesammtbetrachtung der Thiere gegründeten, augenblicklichen Vorstellungen ihres genealogischen Zusammenhanges von hoher Wichligkeit ist, namentlich in einem Zeitpuncte, wo HuxLey ${ }^{2}$ ), der bedeutendste englische Zoologe und Systematiker, sich nicht scheut, auf ein künstliches System zurückzugreifen und die Metazoa nach der Ab-oder Anwesenheit des Darmes in zwei grosse Gruppen zu spalten.

Es ist ferner hervorzuheben, dass durch die scharfe Betonung des

1) Jenaische Zeitschrift VIII, 1874. Die neuere Arbeit von HAECKEL über den gleichen Gegenstand ist mir erst lange nach Abschluss der hier gegebenen Darstellungen zu Händen gekommen, konnte daher nicht mehr benützt werden.

2. Nature No. 267, Vol. XI, p. 101. 
Unterschiedes zwischen den Protozoen und den sämmtlichen übrigen Thieren, und Präcisirung dieser Kluft bei der Bildung der Gruppen der Protozoa und Metazoa ein ganz wesentlicher Fortschritt in unserer Auffassung des Zusammenhanges der thierischen Formen überhaupt gewonnen worden ist. Nur dürfen wir es nicht wie HAEcKeL völlig vergessen, dass die Lehre von der Einzelligkeit der Protozoen von ihm nicht geschaffen, sondern nur wieder belebt worden ist, und dass er früher zu den Gegnern gerade dieser Anschauung gehört hat.

Aber dieser Fortschritt kann auch von demjenigen anerkannt werden, der die Gastraeatheorie verwirft, und diese hat denn auch von Salensky und von Claus, von Metschnikoff und Semper sehr ungünstige Beurtheilungen erfahren. Die Angriffe aller dieser Forscher haben sich gegen die Homologie der Keimblätter gerichtet, und diese ist es auch zunächst über welche die folgenden Zeilen sich verbreiten sollen; diese Ilomologie der Keimblätter ist für die Gastraeatheorie von soleher Bedeutung, dass HA HCKel selbst (p. 14 der Gastraeatheorie) sagt, dass ohne den Nachweis der Homologie der beiden primären Keimblätter bei siimmtlichen Metazoen, die Gastraeatheorie nicht haltbar ist. Je schärfer aber НаЕскеL die Bedeutung der "Homologie der Kcimblätter betont, um so mehr müssen wir uns wundern, dass er weder diese Homologie im Einzelnen durchgehends nachweisen kann oder nur nachzuweisen sucht, noch ïberhaupt eine Definition giebt von dem, was er unter Homologie der Keimblätter versteht. Nur in der Anthropogenie sagt er mehr didaktisch als beweisend : „der Nachweis der Homologie der Keimblatter wird dadurch geliefert, dass sich aus ihnen überall vom Schwamm bis zum Menschen hinauf dieselben Organe entwickeln«.

Wir müssen uns demgemäss an die früheren Publieationen Ilaeckel's und wenn diese nicht ausreichen, an die seiner vertrauten Forschungsgenossen wenden, um die richtige Definition für das Wort "Homologie« zu finden, und zwar wird zu diesem Zwecke am geeignetsten sein, die auf НАЕскEL's früheren Ausführungen in der generellen Morphologie selbst basirende Darstellung dieser Verhältnisse in Gegenbaur's vergleichender Anatomie (Auflage II, p. 78). Gehen wir den dort befindlichen Abschnitt über die "Vergleichung der Organe " durch, so fällt uns zunächst auf, dass mit seiner Annahme »der Homologie der Keimblätter " bei allen Metazoen HaEckel stillschweigend von einem früher von ihm selbst aufgestellten und von Gegenbaur noch 1870 festgehaltenen Grundsatze abweicht. Haeckel und Gegenbaur nehmen nämlich anfänglich nur eine Homologie der Organe innerhalb des Typus an. Dass indessen die Erweiterung des Bereiches, in dem wir nach Homologien forschen dürfen, 
durch die neueren Arbeiten über die Embryologie der Wirbellosen geradezu geboten wird, scheint mir völlig sicher.

Gege NBaUr bezeichnet nun im Allgemeinen »Körpertheile von morphologischer Uebereinstimmung als Homologa, während dagegen die physiologisch übereinstimmenden als Analoga bezeichnet werden müssen«.

Dass in diesem allgemeinen Sinne genommen die Keimblätter homolog sind, zunächst die desselben Thieres untereinander, ergiebt sich von selbst. Das Ectoderm einer Hydra ist dem Endoderm homolog, indem jedes darstellt eine der beiden Hauptschichten, aus denen der ganze Leib des Thieres sich zusammensetzt.

Dass ferner eine allgemeine Homologie im Gegenbaun'schen Sinne zwischen den Keimblättern verschiedener Thiere und verschiedener Thiertypen besteht, lässt sich auch sofort zugeben, sobald man rein morphologisch die Keimblätter als die primären Schichten auffasst, deren Sonderung die Grundbedingung der Bildung jedes Darmthieres ist. Sobald man aber weiter geht und frägt, sind die Keimbläter im engern Sinne homolog, so kann man dies nur dann noch festhalten, wenn mạn zu gleicher Zeit annimmt, dass sämmtliche Furchungszellen als Descendenten der Eizelle gleichwerthig sind. Denn nur dann entsprechen die Keimbläter wirklich der Forderung, die Gegenbaur an speciell homologe Organe stellt, d. h. sie besitzen die gleiche Abstammung. Dass aber die Furchungskugeln nicht gleichwerthig sind bei den meisten Thieren, ist jetzt wohl ziemlich sicher anerkannt, um so mehr, als es scheint, dass auch die früher als nicht zellige Gebilde aufgefassten Dotterballen vieler meroblastischer Eier, besonders der Wurm- und Arthropodeneier, wirklich einen Kern besitzen und lediglich als spät entstehende, mit Deutoplasmaelementen überladene Furchungszellen aufzufassen sind, ein Nachweis, der streng durchgeführt, es nicht mehr gestatten würde die Eier in meroblastische und holoblastische zu sondern, sondern lediglich die Furchungsvorgänge in isochrone und heterochrone zu unterscheiden.

Für die HaEckel'sche Schule sind nun aber die Keimblätter keineswegs homolog, weil sie gleich entstehen, sondern weil aus ihnen Gleiches entsteht. Da man aber, ohne Verwirung anzurichten, einen bereits scharf definirten Ausdruck eben nur in dem einen Sinne gebrauchen darf, so ist es völlig unzulässig, in diesem Sinne von der Homologie der Keimblätter zu reden, man muss vielmehr nur von der Homologie der aus ihnen entstehenden Gebilde reden, und nach dieser forschen. De facto thut dies HaEckel ebenfalls. Von den »beiden primären Keimblättern« ausgehend, sucht er nachzuweisen, 
dass die physiologisch gleichwerthigen Grundorgane der verschiedenen Thiertypen homolog sind, weil sie aus dem gleichen Keimblatte sich bilden.

Der Nachweis aber, dass dieselben Organe aus denselben primitive $n$ Keimblättern entstehen, wie HaEckEL versucht, bringt uns verhältnissmässig wenig weiter. Es wird vielmehr hierdurch lediglich gezeigt, dass wesentlich gleich gelagerte Organe aus gleich gelagerten Embryonalanlagen entstehen, dass also unter ähnlichen Verhältnissen ähnliche Vorgänge des Aufbaues der Organe sich finden, dass speciell die anfänglich nach aussen gelagerten Organe aus dem äusseren Keimblatte entstehen, die inneren aus dem inneren. Es wird dagegen gerade durch die »Homologisirung« der primären Keimblätter eine Gewebsgruppe genetisch zerrissen, welche ein histologisch festgeschlossenes Ganze bildet, wie $z$. B. die Bindesubstanzen.

Die Bedeutung der einschlagenden Fragen liegt aber nach meiner Ansicht gar nicht darin, ob die Organe sich durchgehends aus denselben Keimblättern bilden, sondern ob die einzelnen $G$ ew ebe sich stets aus dem gleichen Keimblatte bilden, dies hat Kleinenberg schon scharf in seiner Monographie der Hydra ausgesprochen.

KLeinenberG sagt p. 84: „Wenn aber als Grundgesetz der Entwicklung feststeht, dass bei allen Thieren, von den Coelenteraten an, die Scheidung des Keimmaterials in zwei concentrische Schichten sich vollzieht, so erhebt sich die weitere Frage, ob überall die Beziehung der beiden Blätter zu den entstehenden Geweben eine identische ist, ob jene Träger der wesentlichen Functionen, die Epithelien, die Musculatur, die Nerven und das Bindegewebe, mit Rücksicht auf die Keimblätter gleichen Ursprungs sind - mit einem Worte nach der Homologie der analogen thierischen Gewebe."

Ich glaube, dass der Ausdruck, den Kleinenberg der wichligen Keimblätterfrage giebt, der völlig zutreffende ist.

Für den Nachweis aber, dass die einzelnen Gewebe der verschiedenen Thiertypen einander homolog sind, dass besonders auch die secundären Keimblätter wirklich, sobald sie einmal differenzirt sind, einen fest bestimmten, unwandelbaren, histologischen Character haben, ist theoretisch der Nachweis nothwendig, dass in allen Fällen obne Ausnahme aus dem gleichen Blatte die gleichen Gewebe entstehen. Dass praktis ch dieser Forderung nicht streng Genüge geleistet werden kann, versteht sich von selbst; aber das können wir verlangen, dass, ehe die "Homologie der Keimblätter( zu einem »Naturgesetz" erhoben wird, der Nachweis gefuhrt wird, dass wirklich die entgegenstehenden Angaben, soweit sie überhaupt von wirklich wissenschaft- 
licher Seite herstammen, berücksichtigt und womöglich widerlegt werden. Sind sie aber nicht widerlegbar, so hat der Nachweis einer einzigen wirklichen Ausnahme mehr Beweiskraft gegen die Lehre von der Homologie der Gewebe bei den verschiedenen Thiertypen, als der gleichzeitige eben so unwiderlegliche Nachweis, dass in hundert andern Fällen wirklich aus denselben Blättern dieselben Organe hervorgehen. Denn um diese letzteren Thatsachen uns zu erklären, genügt eben völlig die Ueberlegung, dass die meist gleiche Lagerung gleieher Gewebe zur Körperoberfläche (nicht etwa zu Rücken- und Bauchfläche etc.) leicht eine gleiche Entstehungsweise der betreffenden Gewebe aus dem Keimmaterial bedingt. Eine ticfere histologische Pridisposition der Keimblätter brauchen wir hierzu durchaus nicht anzunehmen.

Ist die Homologie der Gewebe nun eine wahre, wirklich beweisbare Thatsache, so muss sich zeigen lassen, dass, nachdem einmal der indifferente Zustand der Furchungskugeln überwunden ist, und die Schichten, die wir Keimblätter nennen, sich gebildet haben, denselben in allen Fällen ein bestimmter, jedem einzelnen eigenthümlicher histologischer Entwicklungsgang vorgeschrieben ist. Dies muss sich dann auch nachweisen lassen bei allen am thierischen Körper auftretenden histologischen Neubildungen.

Diese Neubildungen können in drei verschiedene Kategorieen untergebracht werden: 1) die pathologisehen Neubildungen, 2) die ergänzenden Neubildungen, 3) die Neubildung von Individuen durch Wachsthumsproducte. Was die ersteren betrifft, so sind wir in diesenı Falle nicht competent ein eigenes Urtheil zu fällen. Indessen scheint im Grossen und Ganzen die moderne Anschauung dahin zu gehen, dass wirklich die pathologischen Neubildungen bei den höheren Wirbelthieren sich in solchen Grenzen halten, dass sie gut für den Beweis der Lehre von der Homologie der Gewebe verwerthet werden können. Dies stimmt auch mit der Thatsache, dass innerhalb der Gruppe der Wirbelthiere auch bei der Entstehung aus den embryonalen Keimblättern durchgängig die einzelen Gewebe bei den verschiedensten Thierformen aus denselben Keimblättern sich bilden. Die Frage, wie sich die Keimblätter bei der Neubildung verloren gegangener Organe bei den verschiedenen. Thiergruppen, denen dies Regenerationsvermögen zukommt, sich verhalten, ist noch nicht hinreichend aufgeklärt worden. Von den neueren Arbeiten, welche sich mit der Regeneration verloren gegangener Theile beschäftigen, ist zunächst nur die Arbeit von EmLers über die Neubildung des Kopfendes von Diopatra fragilis hier in Betracht zu zichen, und diese weist darauf 
hin, dass allerdings die entsprechenden Gewebstheile des Leibesstumpfes die Neuhildungen aus sich hervorgehen lassen, nicht ein homogenes Blastem, wie Perrier dies hingegen bei der Neubildung der Arme von Comatula annehmen möchte. Wie es sich mit der Neubildung der ergänzenden Theile bei der ungeschlechtlichen Fortpflanzung der Asteriden und Ophiuriden verhält, ist aus den kurzen Notizen von KoWALEWSKY und LüTKEN nicht zu ersehen. Es kann aber nicht genug darauf hingewiesen werden, dass hier ein noch beinahe ganz unbebautes Forschungsgebiet existirt. Desgleichen wäre eine Controlle der herrlichen Versuche Tremblex's über die Hydra wohl endlich einmal an dem Platze. Besonders ist es die Angabe, dass wie Handschuhfinger umgestullpte Polypen mil der nach innen gewendeten Aussenseite, also dem Ectoderm, alle Functionen der früheren Innenseite, des Endoderms verrichten könnten, eine so auffallende, dass dieselbe mit den neueren Hülfsmitteln untersucht, einen wichtigen Beitrag zu unseren Kenntnissen über das Verbältniss der Formelemente zu ihren Functionen zu geben verspräche; auch dann, wenn ihre Resultate lediglich darauf hinausliefen, dass der geniale Forscher hier einmal zu weit gegangen wäre.

Die Neubildung von Individuen durch Wachsthumsproducte, die multicelluläre Fortpflanzung wie ich sie genannt habe ${ }^{1}$ ), geht vor sich auf zweierlei Wegen, durch Theilung oder Knospung. Bei der Theilung geht - mit Ausnahme der an dem Morulastadium eines Thieres mitunter auftretenden " concentrischen Theilung " — ein mit sämmtlichen Grundorganen ausgestattetes Stück des Aelternthieres in die Neubildung des Descendenten ein, was schon daraus hervorgeht, dass wir eigentlich bei diesem Vorgange gar kein Aelternthier und keinen Descendenten unterscheiden können, sondern das gesammte Aelternthier in zwei oder mehrere Descendenten sich spaltet. Hier also hat der Descendent schon seine sämmtlichen Organe vorgebildet erhalten, und die Frage nach der weiteren Ausbildung der ihm noch fehlenden Körpertheile fällt direct nit dem eben angedeuteten Problem der Neubildung verloren gegangener Theile zusammen.

Bei der Knospung hingegen liegen die Verhältnisse nicht so einfach. Die Knospung ist dadurch characterisirt, dass zum Zweck der Neubildung des Descendenten an dem bestehen bleibenden Mutterthier ein Wachsthum eines beschränkten multicellulären Körpertheils beginnt, das nicht direct in den knappen Rahmen der Organe des Mutterthieres hineinpasst. Für den Fall nun, dass die Lehre von der Homologie der Gewebe bei allen Metazoen richtig ist, so muss in allen Fällen ganz ähnlich wie bei

1) Sitzungsber. d. Naturforschenden Gesellschaft zu Leipzig, No. 7, Juli 4875. 
der Theilung dieses Wachsthum gleichzeitig ausgehen von den verschiedenen Hauptschichten des Mutterthieres, das Endoderm derselben muss das Endoderm der Knospe, das Ectoderm deren Ectoderm liefern u. s. f.

Es ist nun unzweifelhaft, dass wirklich in einer grossen Reihe von Fällen der Vorgang in der eben angedeuteten Weise sich abspielt. Es steht fest, dass bei der Knospung von Hydroidpolypen und Medusen das Ectoderm des Mutterthieres das Ectoderm des Descendenten, und das Endoderm das Endoderm liefert. Die Angaben von Kowalewsky über die Knospung von Amauroecium oder richtiger gesagt, uber die Bildung des gewöhnlich als Postabdomen bezeichneten Stolo zeigen ferner, dass an der Bildung desselben sämmtliche Hauptschichten des proliferirenden Aelternthieres theilnehmen.

Aber damit ist nun immer noch nicht bewiesen, dass hier eine wirkliche Prädisposition der Keimblätter zu Grunde liegt, dass dies in allen Fällen so sein muss. Es kann dies vielmehr lediglich daher kommen, dass in allen diesen Fällen die Knospung eine äusserliche ist, und dieses Lagerungsverhältniss des Jungen zum Aelternthiere die einfache morphologische Ursache dieses Verhaltens sei. Bewiesen wäre die häufig angenommene gesetzliche histologische Prädisposition der einzelnen Schichten nur dann, wenn auch in dem Falle, wo die Lagerungsverhältnisse des Descendenten zu dem Stammthiere veränderte sind, die gleichen Vorgänge sich zeigten wie in dem ersten Falle. Wir sind nun über diese Fragen bis jetzt keineswegs im Klaren. Es kommt hekanntermassen eine innere Knospung bei vielen Medusen vor. Erst neuerdings hat uns МетschniкоғF mit einer schönen Arbeit über diesen Gegenstand beschenkt; wir erfahren von ihm, dass die aus der einmal gebildeten Cuninaknospe hervorgehenden Sprösslinge sich auf genau dieselbe Weise bilden, wie sonst überhaupt bei äusserer Knospung einer Meduse an einer anderen, oder an einem Hydrö̈dpolypen. Wie aber die erste in der Höhlung der erwachsenen Cunina liegende entsteht, darüber erfahren wir nichts. Indessen lassen die rein anatomischen Verhältnisse der Qualle es in höchstem Grade unwahrscheinlich erscheinen, dass die erste Knospe ihr Ectoderm von dem Ectoderm des Mutterthieres bezieht, etwa in ähnlicher Weise, wie dies bei der scheinbar inneren Knospung des Scolex an der Cysticercusblase der Fall ist. Bei einer wirklichen inneren genau beobachteten Knospung aber bei der Entstehung der Polypide an den Cystiden der Süsswasserbryozoen, haben MerschniкоFF und ich selbst gezeigt, dass hier aus rein morphologischen Gründen eine durch Einstülpung erfolgende Lagenvertauschung der Schichten vor sich geht, und die äussere Schicht des Cystids in die innere Schicht 
des Polypids, und die innere des Cystids in die äussere des Polypids ubergeht.

Indessen möchte ich auf diese Vertauschung nicht allzuviel Gewicht legen. Es ist, wie schon oben erwähnt, ungemein schwer zu sagen, wie wir die oben genannten und bisher ganz indifferent bezeichneten Schichten des Polypids und Cystids mit denen der übrigen Thiere vergleichen sollen. Nimmt man ohne weiteres die von Leuckart, Reichert, Allman, Salensky und mir vertheidigte Ansicht an, dass das Gystid ein ebenso wie sein Descendent, das Polypid, ein besonderes Individuum ist, so erfolgt sofort systematischer Weise eine Annäherung der Bryozoen an die Coelenteraten, indem dann die Leibeswandung beider nach dem Coelenteratentypus gebaut ist: Ectoderm, Stützmembran mit Musculatur und Endoderm zeigt. Dann aber muss ebenso nothwendig eine Absonderung der endoprocten Bryozoen von den ectoprocten (Pedicellina und Loxosoma) vorgenommen werden, weil diese eine Complication der Organisation in Betreff des Geschlechtsapparates zeigen, welche mit unseren jetzigen Anschauungen über die Grundform des Coelenteratentypus nicht wohl vereinbar ist. Aber schon die Einreihung der ectoprocten Bryozoen bei den Coelenteraten würde bedeutende Schwierigkeiten machen, und vielleicht lediglich dadurch zu lösen sein, dass man den Enddarm mit der Trichterhöhle der Ctenophoren vergliche. Nimmt man aber die Anschauung, dass Polypid und Cystid getrennte Individuen sind nicht an, dann ist der Umkehrung der Schichtenlagerung bei der Knospung keine so fundamentale Bedeutung beizumessen. Dann kann man nit Hülfe der endoprocten Bryozoen die Bryozoen luberbaupt an die Rotiferen, speciell an Stephanoceros und Floscularia anknüpfen. Es erscheint alsdann die innere Schicht der Polypidknospe als Darmdrüsenblatı, die äussere als Darmfaserplatte, während die innere Schicht des Cystids + Muscularis als Hautfaserblatt, und die äussere Schicht desselben als Ectoderm erscheint. Die Bildung des Darmdrüsenblattes aus dem Ectoderm hat alsdann ein Analogon in der Bildung des Darmdrüsenblattes der Larven resp. Embryonen, bei welchen solches durch Einstülpung der einschichtigen durch die Furchung entstandenen Zellblase sich bildet. Allerdings fände ganz ausnabmsweise diese Einstülpung erst zu einer Zeit statt, wo bereits das mittlere Blatt sich differenzirt hat.

Viel bedeutsamer ist dagegen die Thatsache, dass die innere Zellschicht der Polypidanlage - so, und nicht Polypidknospe müssen wir sagen, wenn wir unparteiisch die Frage nach dem morphologischen Werthe des Polypids ausser Acht lassen - auch zugleich die Anlage für das centrale Nervensystem liefert. Wir haben hier den merkwür- 
digen Fall, dass dieselbe Schicht aus sich hervorgehen läst: das Epithel des Darmcanales und die Nervenzelle $n$, eine Thatsache, die, so weit ich sehe, in keiner Weise sich mit der Lehre von der Homologie der Gewebe vereinigen lässt. Denn, dass die von HАEскEL (p. 45 der Gastraeatheorie) angedeutete „frübzeitige Dislocation der Zellen aus einem primären Keimblatte in das andere» nicht als eine wirklich stichhaltige Erklärung angesehen werden kann, ist wohl sonnenklar. Wollen wir so verfahren, dann können wir eben Alles beweisen, was augenblicklich in das Schema unserer idealen Construction des thierischen Körperbaues passt.

Es ist aber hervorzuheben, dass diese Thatsache nicht isolirt dasteht, dass vielmehr ein ganz ähnlicher Vorgang bereits nachgewiesen worden ist, nämlich in zwei Fällen bei der Knospung der zusammengesetzten Ascidien. Kowalewsky hat gezeigt, dass das Nervencent rum bei Didemnium und Amauroecium aus der in nern Zellblase hervorgeht, welche zu gleicher Zeit die Auskleidung des Darmcanals, das Kiemenepithel und die Wandungendes Perithoracalraumes liefert.

Eine gleiche Schwierigkeit für die sichere Feststellung der Homologie der Gewebe ist aber ferner in den Knospungsvorgängen von Loxosoma verborgen. Sehen wir doch, dass hier ein Blatt des Aelternthieres, das Ectoderm, es ist, das die gesammte Anlage der jungen Knospe liefert, und dass erst nachträglich aus dieser Anlage Endoderm und Mesoderm, ersteres allerdings sebr früh, sich herausbildet. Wir sehen also, dass ein neues Thier durch multicelluläre Fortpflanzung entstehen kann, ohne dass sämmtliche Schichten des Mutterthieres an dieser Bildung theilnehmen, dass also das Ectoderm nach seiner definitiven Constituirung als solches keineswegs die Fähigkeit verliert, Gewebselemente, die sonst dem Endoderm, resp. dem Mesoderm angehören, aus sich hervorgehen zu lassen.

So wünschenswerth daher die Feststellung der Lehre von der Homologie der Gewebe im ganzen Bereiche der Metazoen wäre, so kann ich dieselbe doch noch keineswegs als geschehen betrachten, vielmehr zwingt uns die Betrachtung der eben erwähnten, und nach meiner Anschauung sehr wichtigen Thatsachen eine andere Auffassung der Verhältnisse auf.

Nach dieser sind die Keimblätter keineswegs mit einer besonderen histologischen Prädisposition ausgestattete Zellschichten, sondern lediglich die flächenhaft ausgebreiteten Elemente, aus denen die den Metazocnkörper zusammensetzenden, ineinander geschachtelten Röhren sich bilden, Röhren, aus denen wiederum durch Faltenbildung und Congres- 
cenz, sowie durch Spaltung die Organe des definitiven Thieres hervorgehen. Eine aufmerksame Betrachtung der Verbindung in der diese verschiedenen Organe des thierischen Körpers sich befinden, zeigt uns nun, dass in bei weitem den meisten Fällen die gleichen Organe der verschiedenen Thiere gleich gelagert sind zur äusseren Oberfläehe des Thieres. Diese gleiche Lagerung der gleichen Organe, resp. der gleichen Gewebe, ist es, welche bedingt, dass auch in den verschicdensten Thieren die einzelnen Gewebe aus denselben Keimblättern hervorgehen, nicht eine histologische Prädisposition dieser Keimblätter. Wo eine solche gleiche Lagerung nicht stattfindet, ist es auch nicht möglich, die gleiche Entstelıung der betreffenden Organe zu beweisen, so z. B. bei den Genitalien resp. ihren Producten.

Ueber den Werth der eben aufgestellten Anschauung wird die Zukunft entscheiden. Auf jeden Fall glaube ich in der vorstehenden Arbeit einen weiteren Beitrag geliefert zu hahen zur Feststellung der schon von anderer Seite vielfach nachgewiesenen Thatsache, dass nicht nur bei der unicellulären, sondern auch der pluricellulären Fortpflanzung, besonders bei der Knospung, der Bildung der einzelnen Organe, die Bildung von blattartigen Anlagen vorausgeht, mögen dieselben nun, wie bei Alcyonella, direct aus den Keimblättern des Mutterthieres, oder wie bei Loxosoma nur aus einem derselben herstammen. Zugleich holfe ich aber gezeigt zu haben, dass die Bildung des Gewebes nicht durch das ganze Thierreich hindurch nach einem und demselben schon jetzt völlig erkannten Schema vor sich geht. Sollte einmal ein solehes Schema wirklich nachgewiesen werden können, so würde ich der erste sein es mit Freuden zu begrüssen.

\section{Erklärung der Abbildungen.}

Taf. XXIV.

$a$, äussere Zellschicht des Cystids.

$b$, Tunica muscularis.

$c$, innere Zellschicht des Cystids.

$a^{\prime}$, innere Zellschicht der Knospe.

$c^{\prime}$, äussere Zellschicht der Knospe.

$h$, Einstülpungsöffnung der Knospenanlage.

$I$, innere Höhlung der Knospe.

$I^{\prime}$, Höhle der Tentakelscheide.

$I^{\prime \prime}$, Höhle des Darmes.

Tsch, Tentakelscheide.

$L$, Lophophor. 
$L^{\prime}$ Arme des Lophophors.

$L^{\prime \prime}$ abanaler Theil des Lophophors.

$L F$, die Furche, welche bei Bildung des abanalen Lophophortheiles auf der Aussenseite der Tentakelscheide entsteht.

$E$, Einstülpungsöffnung der Höhlung in den Lophophorarmen.

$T$, Tentakelanlagen.

D, Darm.

Md, Mund.

$A$, After.

Oes, Oesophagus.

$E D$, Enddarm.

$M B$, Magenblindsack.

$A D$, äusseres Darmepithel.

$I D$, inneres Darmepithel.

$N$, nervöser Theil des centralen Ganglion.

$\mathrm{Nl}$, Neurilemm.

Fun, Funiculus.

$M$, Retractoren, grosse Bewegungsmuskeln.

Fig. 1-5. Alcyonclla fungosa Pall. spec. 750/1. Mit der Camera lucida gezeichnet.

Fig. 1-4. In der Medianebene halbirte Knospen.

Fig. 1. Eine ganz junge Knospe.

Fig. 2. Eine etwas ältere Knospe.

Fig. 3. Eine Doppelknospe, I die ältere, II die jüngere Anlage. Darm und Tentakelscheide sind getrennt. Der Lophophor ist nur in seinen adanalen Theilen angelegt. Der Funiculus ist ganz deutlich, das Ganglion beginnt sich abzuschnüren.

Fig. 4. Eine ältere Knospe. Die obere Hälfte der Tentakelscheide ist nicht ausgezeichnet, auch fehlt der untere Theil des Darmes, weil er in dem Präparate nicht erhalten war.

Fig. 5. Ein Schnitt durch die Hälfte der vorigen Knospe senkrecht gegen die Medianebene in der Richlung einer in Fig. 4 durch $X$ u. $L^{\prime \prime}$ gelegten Linie.

Fig. 6-11. Cristatella mucedo, Cuv. Fig. 6-10 in den Umrissen mit der Camera lucida gezeichnet.

Fig. 6. 200/1. Medianschnitt durch eine ganz junge Knospe.

Fig. 7. 200/1. Aeussere Ansicht einer etwas älteren Knospe von der Enddarmseite aus. Die durchscheinenden Knospenschichten sind möglichst angegeben, desgl. dic Lophophoranlage, die von der Tentakelscheide umschlossen ist, und nur durchscheint.

Fig. 8. 200/1. Aeussere Ansicht einer ohngefähr gleichalterigen Knospe von der Seite dargestellt. Die Einstülpungsöffnung der Lophophorarme tritt deutlich hervor, auch ist die durch die Bildung des Ganglion bedingte äussere Anschwellung $(N)$ deutlich zu sehen. Die Knospe entspricht ohngefähr einem zwischen Fig. 3 u. 4 mitten innen liegenden Stadium.

Fig. 9. 145/1. Eine noch ältere Knospe, an der bereits die Lophophorarme und der abanale Theil des Lophophors, letzterer schon mit Tentakeln besetzt, deutlich hervortritt, von der Enddarmseite aus gesehen.

Fig. 10. 145/1. Dieselbe Knospe von der Seite gesehen.

Fig. 11. Schematischer Querschnitt durch einen Cristatellastock. 


\section{Tafel XXV.}

Fig. 1-3. Alcyonella fungos a Pall. sp. C, Cystid. P, Polypid. $R$, regressiv metamorphosirtes Polypid. Ooe, Ooecium. $a$, Oeffnung des nach vorn über das Embryonalcystid übergezogenen Faltenringes. $F$, äusseres, $F^{\prime}$ inneres Blatt dieser Falte. $b$, Basis derselben. $c$, hinterster Punct des Embryonalcystids. $K n^{1}$ u. $K n^{2}$, Knospen.

Fig. 1. Aelteres Cystid mit einem regressiv metamorphosirten Polypid und einem Ooecium, in dem ein bereits sehr weit entwickelter Embryo liegt.

Fig. 2. Larve mit zwei Polypiden, im Begriff sich eben festzusetzen, der Faltenring ist bereits nach hinten umgeschlagen, und die Ausstülpungsöffnungen der Polypide sind weit auseinander gerückt, und diese letzteren eingezogen.

Fig. 3. Junger Stock. Das linke primäre Polypid ist ausgestülpt, eine Ectocyste $(E c)$ ist als eine glashelle Gallerte abgesondert, und der hintere Theil des Embryonal- resp. Larvencystids ist in das definitive Cystid hineingerückt, und der regressiven Metamorphose verfallen.

Fig. 4-20. Lox os oma Kefersteinii, Claparède.

Fig. 4. Zwei auf einem Hydroidenstück aufsitzende Loxosomen. I, ausgewachsenes Individuum von der Oralseite gesehen mit acht Knospen, von denen aber nur sieben zu sehen, die Zahlen drücken die Entwickelungsstufe der Knospe aus. II, ein jüngeres Individuum von der linken Seite gesehen, zwei Knospen sichtbar.

Fig. 5. 145/1. Mit der Camera lucida gezeichnetes Spaltungspräparat in der Medianebene. Der Stiel ist nicht ganz ausgezeichnet. c, Cuticula. a, Ectoderm, äussere Zellschicht der Leibeswand, $d e$, bindegewebige Leibessubstanz $(d$, die gallertige Zwischensubstanz, $e$, die spindelförmigen mit einander netzartig verbundenen Zellen). $T 1-7$, die Tentakeln. $T R$, Tentakelrinnenrand. Oe, Oesophagus. $V$, Magen. 1, Darm. $R$, Enddarm auf einer Papille endend, der dicht unter dem Buchstaben $V$ verlaufende Strich deutet die Grenze der verdickten Zellen der oberen Magenwand an.

Fig. 5 A. 590/1. Zellen des Ectoderms mit ihrer deutlichen nach Behandlung des frischen Thieres mit Ueberosmiumsäure hervortretenden Begrenzung.

Fig. 6. 750/1. Stück eines Querschnittes des Stieles. c, Cuticula. $a$, eigentliche Ectodermzellen, welche aber durch die langen Spindelzellen $b$ in acht den Stiel rings umgebende Längszonen auseinandergedrängt sind. $d$, gallertige $\mathrm{Zwischen-}$ substanz.

Fig. 7. Zwei solche Längszonen $a$, mit den dazwischenliegenden Zonen von Spindelzellen, von der Fläche gesehen. Die Kerne sind sehr deutlich.

Fig. 8. Optischer Längsschnitt des Stielendes eines erwachsenen Thieres, um zu zeigen, dass auf der Fussfläche des Stieles die Ectodermzellen sich nur durch die Höhe von denen der Wand des Stieles unterscheiden.

Fig. 9. Spindelzellen des Bindegewebes im Stiel.

Fig. 10-12. Junge Knospenanlagen von der Fläche gesehen. $E$, die Zellen, die sich zum Entoderm umbilden. Die römischen Ziffern bedeuten die einzelnen aus den Knospenanlagen sich bildenden Knospen. $\boldsymbol{K}$, Kerne der Ectodermzellen des Mutterthieres.

Fig. 13-17. 200/1. Junge Knospen in der Seiten- und Analansicht. Die Endodermzellen sind durch tiefern Tuschton ausgezeichnet. $y$, der Ort der, späteren Kelchöffnung. $N$, Nabel. St, Stiel oder Ort des Stieles.

Fig. 13. Zwei junge Knospen in der Seitenansicht, I, die ältere, Il, die ganz junge. 
Fig. 14. Etwas ältere Knospe, $A$, in der Seitenansicht, $b$, in der Analansicht.

Fig. 15. Noch ältere Knospe, an der bereits die Endodermscheibe in den eigentlichen Darmtractus $\left(\boldsymbol{E}^{\prime}\right)$ und die Anlage der intratentaculären Leibeswand $\left(\boldsymbol{E}^{\prime \prime}\right)$ geschieden ist. Der Stiel beginnt zu erscheinen.

Fig. 16. Aeltere Knospe in der Seitenansicht $(A)$ und der Analansicht $(B)$; der Darmcanal und die Tentakeln sind bereits angelegt, desgl. die Genitalanlage $(G A)$, und der Stiel, an dem sich die acht Längszonen von Ectodermzellen zeigen, zwischen denen die Spindelzellen $(b)$ sich einzuschieben beginnen. $e$, die nach dem Nabel zu convergirenden Bindegewebszellen.

Fig. 17. Beinahe ausgewachsene pfeifenähnliche Knospe, die Bezeichnungen wie in Fig. 5 .

Fig. 18. Stielende einer beinahe ausgewachsenen knospe mit der Fussdrüse $(F D)$ und den acces`orischen Drüsenzellen $(x)$ im wirklich hergestellten Längsschnitt (mit der Camera lucida) gezeichnet. $380 / 1$.

Fig. 19. Längsschnitt der Verdauungsorgane einer Knospe senkrecht auf die Symmetrieebene, um die Lage der Genitalanlage $(G A)$ gegen den Magen zu zeigen. $380 / 4$.

Fig. 20. Aeltere Knospe von der Analseite her im optischen Durchschnitt gezeichnet, aber nur die Anlage der intratentaculären Leibeswand und der Tentakeln deutlich gezeichnet.

\section{Taf. XXVI.}

Es ist zunächst hervorzuheben, dass auf dieser Tafel die blauen und rothen Schichten $\mathrm{s}$ ä $\mathrm{mmtlich}$ er Figuren nicht ohne weiteres vergleichbar sind, sondern nur einmal in Fig. I-Vl, andererseits in Fig. VIl-XHI die gleichgefärbten Theile der Figuren gleichen Ursprunges sind.

Fig. I-V. Schematische Darstellung von Längsschnitten durch Knospen und ältere Polypide von Alcyonella. Die Schnitte sind durch die Symmetrieebene geführt. Die blaue Schicht stellt die äussere Schicht der Ectocyste des Cyslids, und die innere Schicht des Polypids dar; die rothe die innere Schicht des Cystids, und die äussere des Polypids. Der dunkele Strich bezeichnet die Tunica muscularis. $o$, Mund. $a$, After. D, Darm. G, Ganglion.

Fig. VII-XIII. Schematische Darstellung von Längsschnitten durch Knospen und durch ein erwachsenes Thier von Loxosoma Kefersteinii senkrecht gegen die Symmetrieebene. Roth das Ectoderm $(E c)$, blau das Endoderm $(E D)$, grau das Mesoderm (M D). 


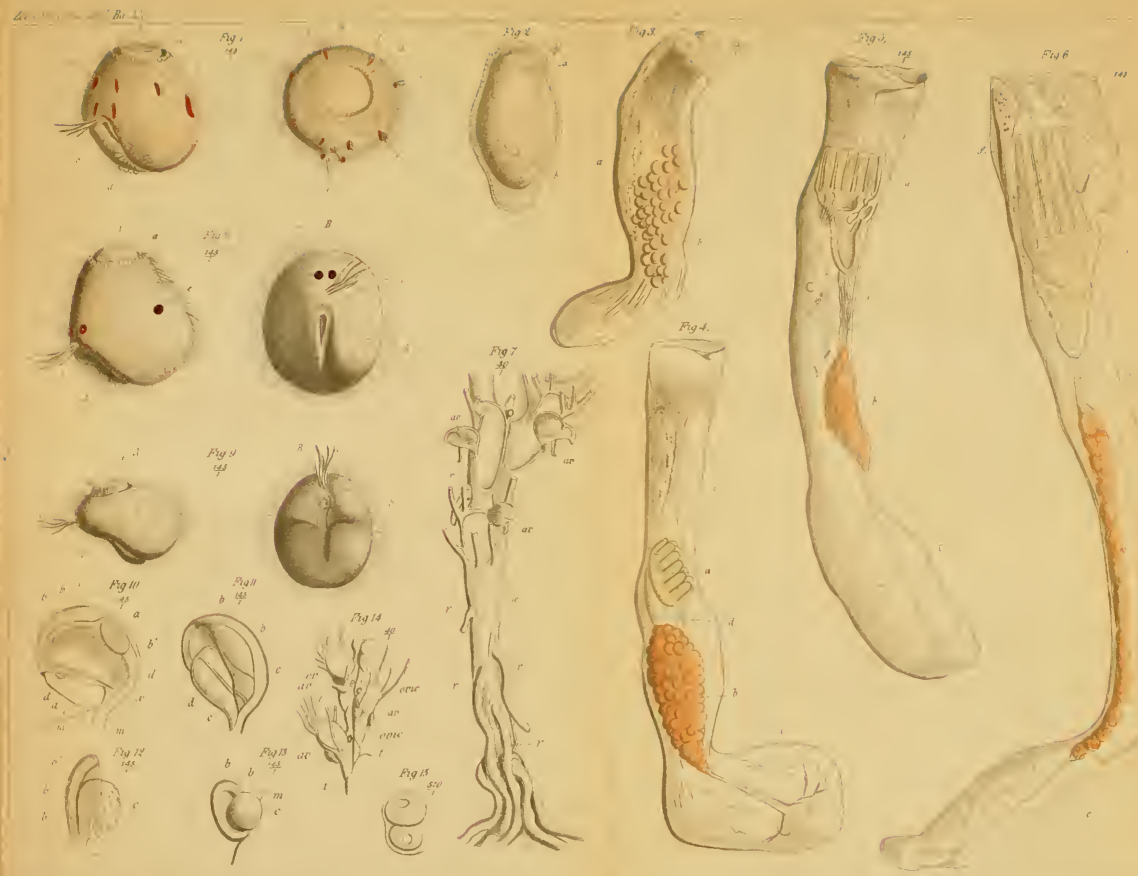





$$
\frac{(w}{3}-11
$$



III
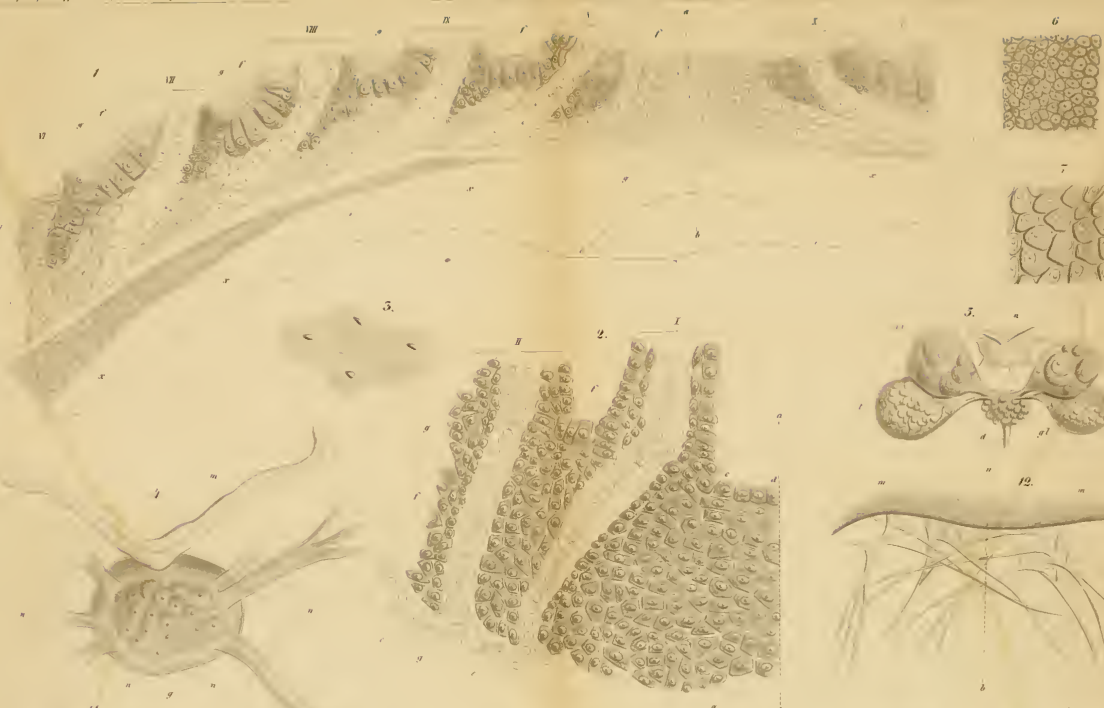
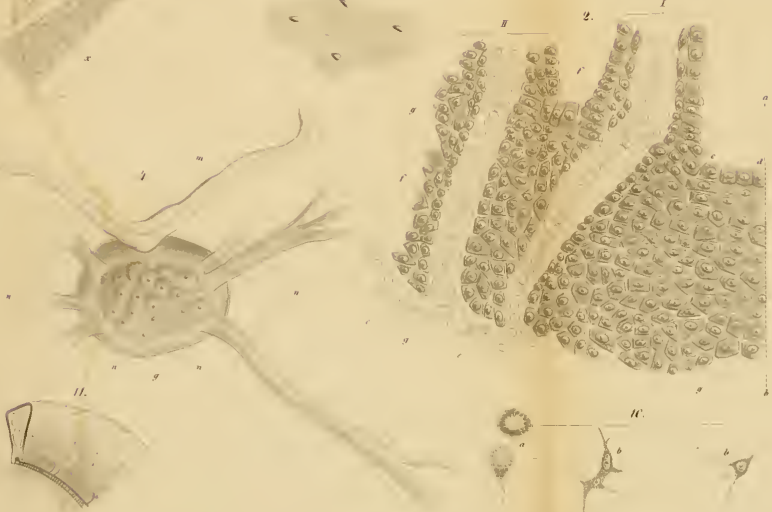

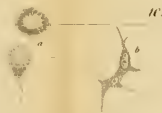

(9)
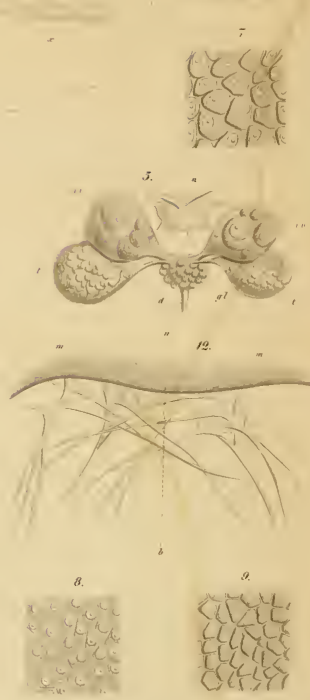


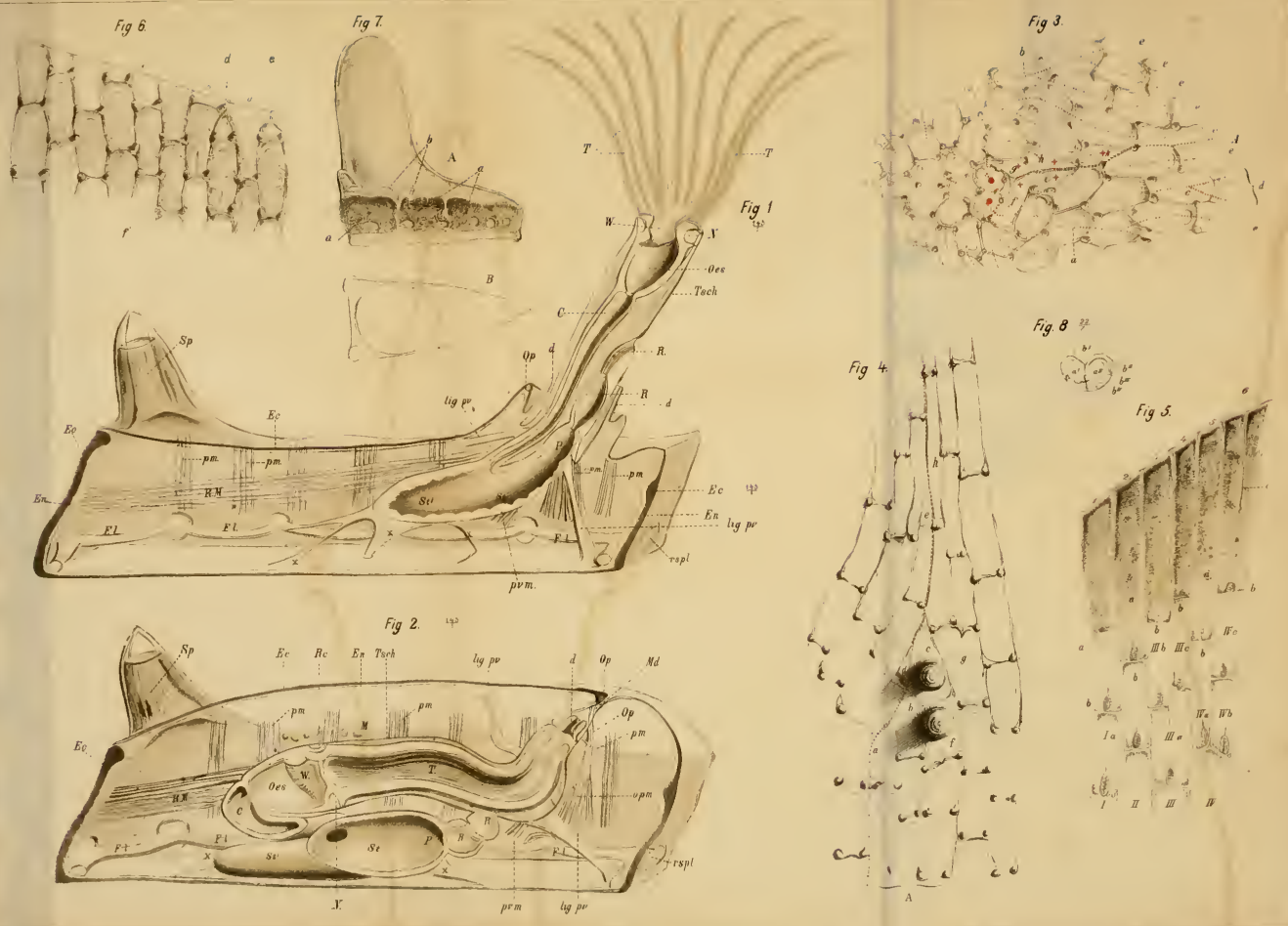

Fig. 8 3?

(4)
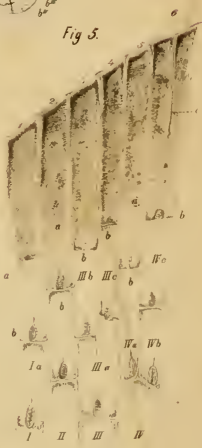



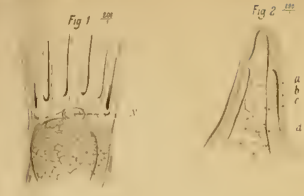

Fig 3 ts
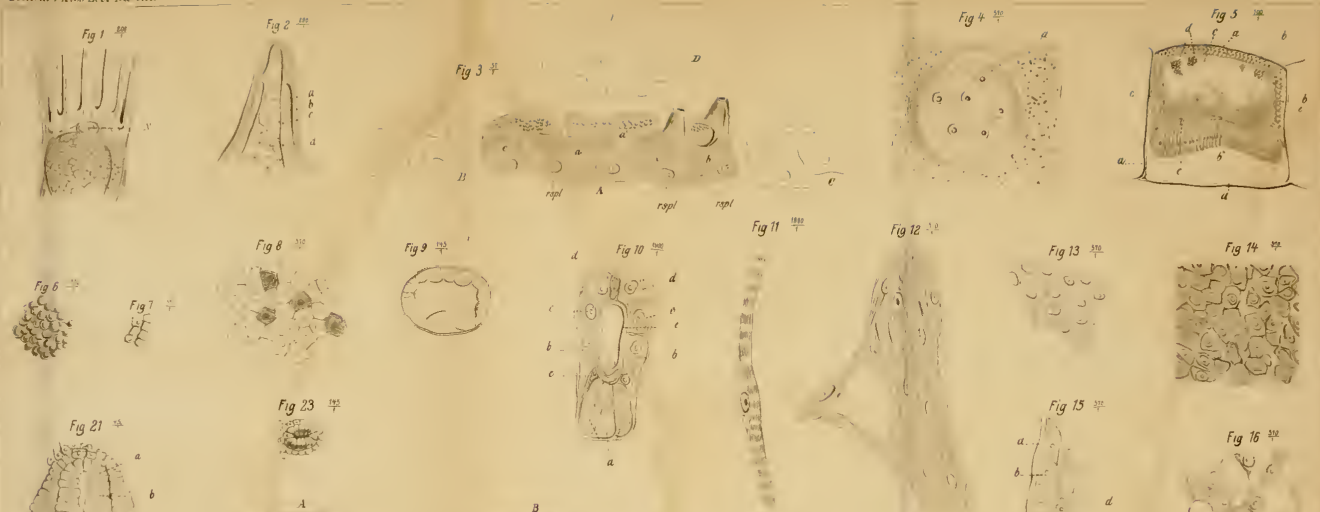

Fig $12:$
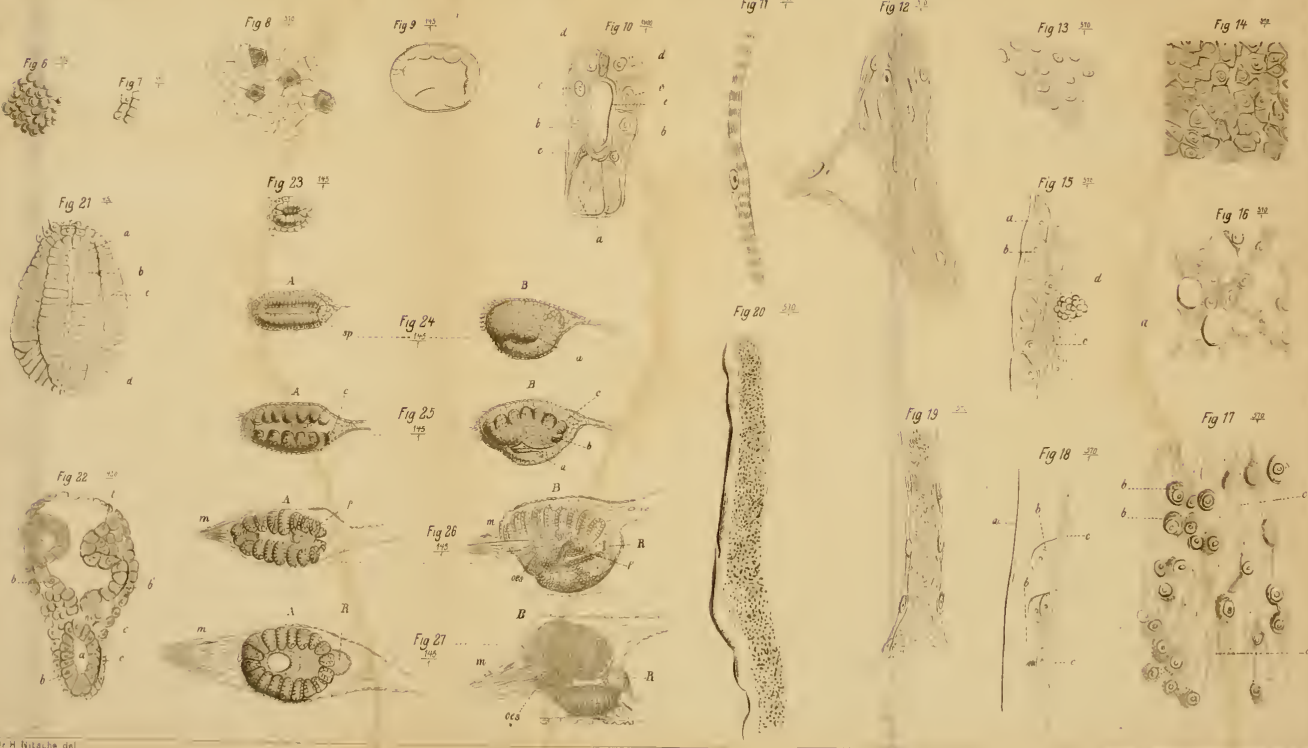


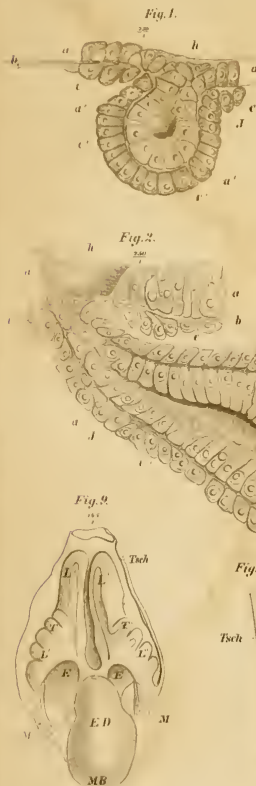

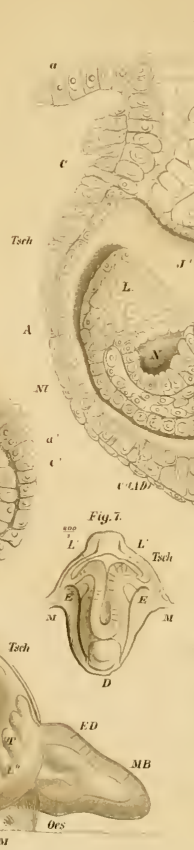

Fing.3.

th

$\cdot$

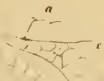

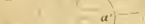

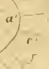

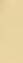

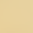




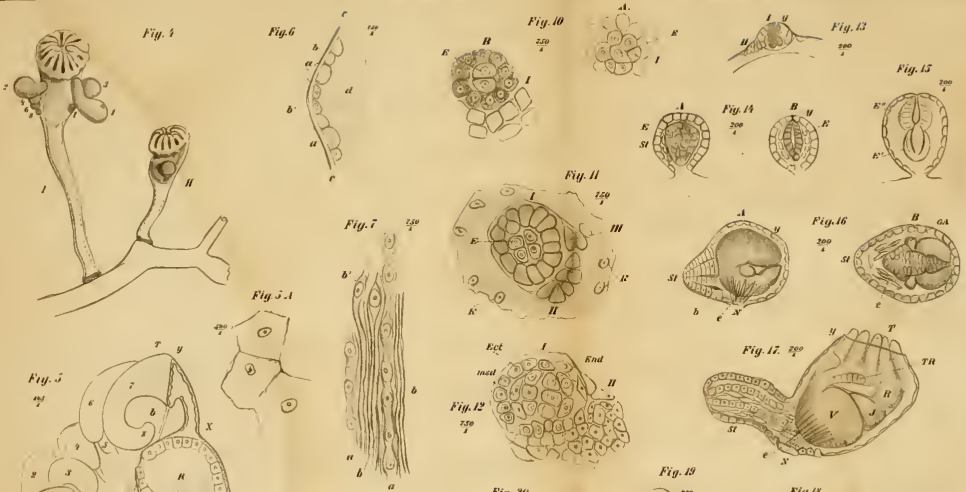

Fig.t.

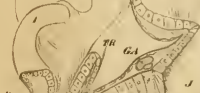

$y$
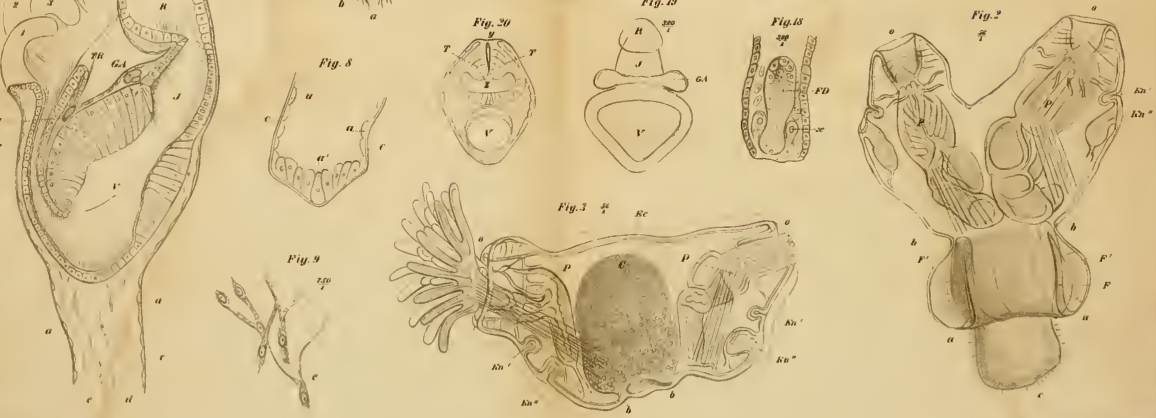


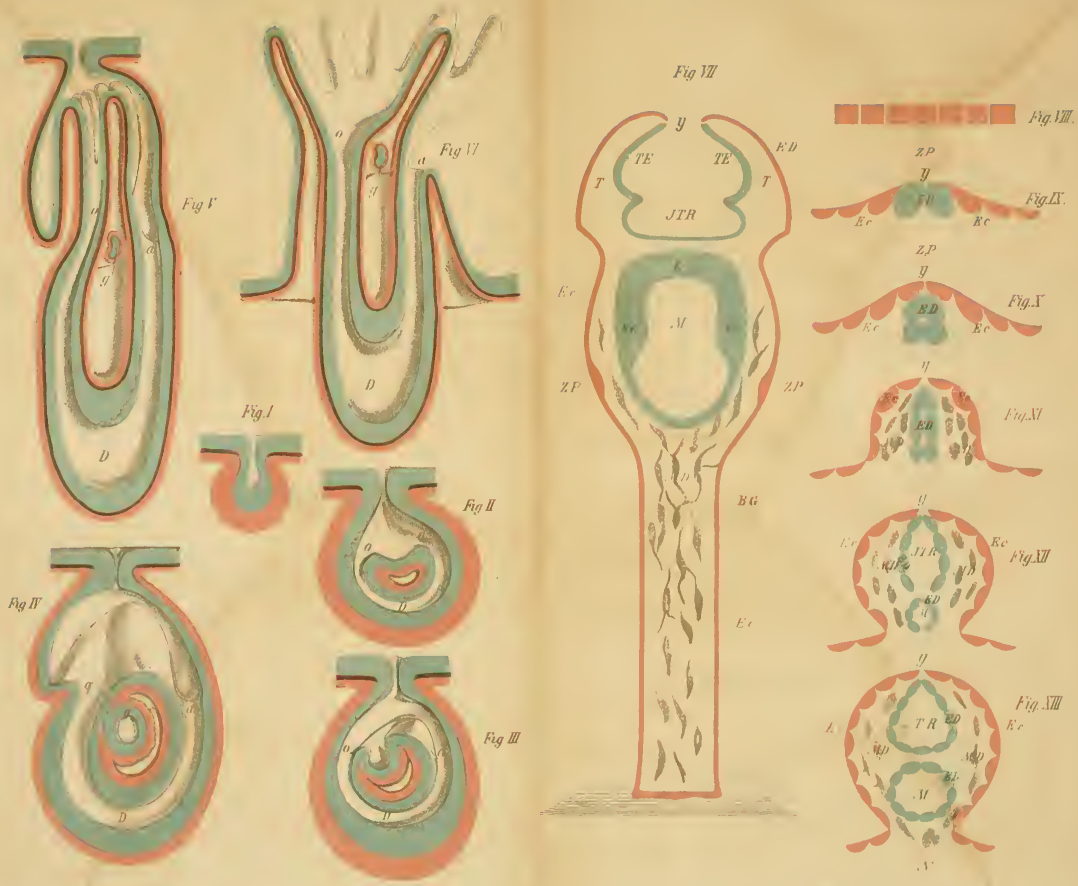








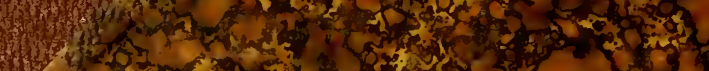

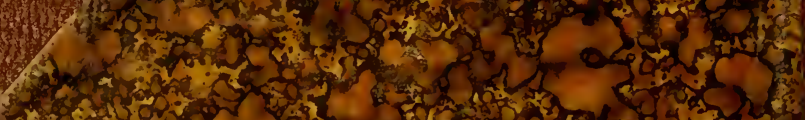

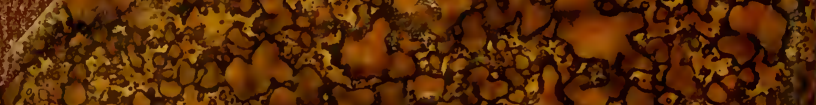

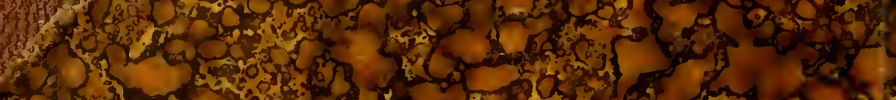

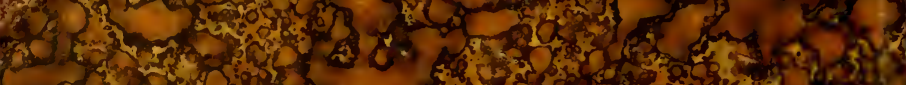

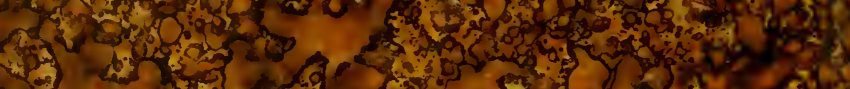
32. 30 .

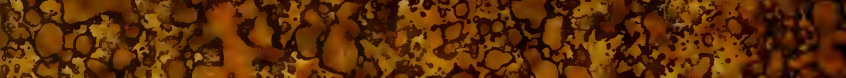

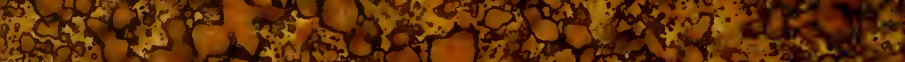
350 .

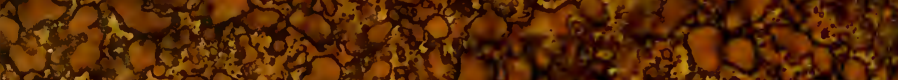

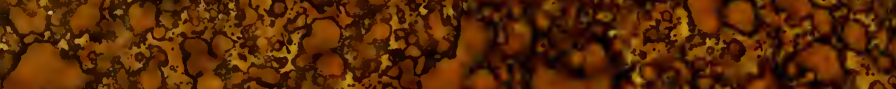

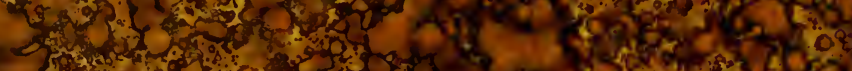

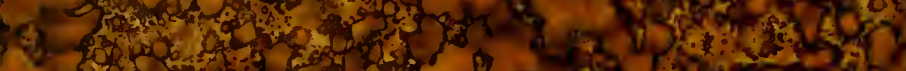

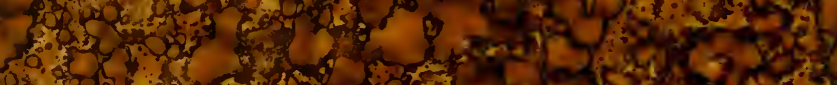

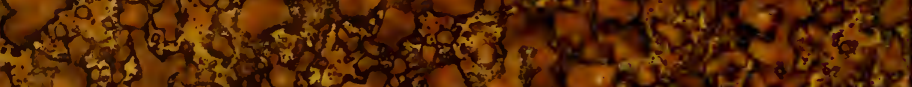

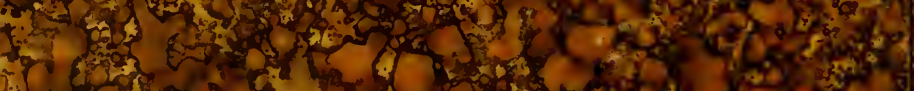

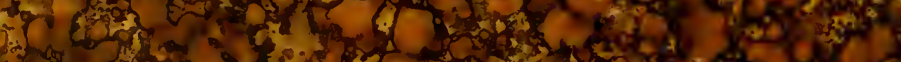
I. 3 . W 20 .

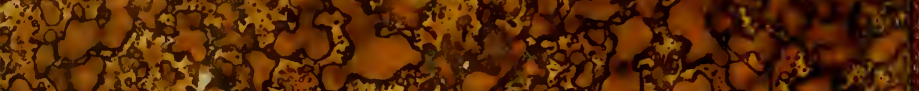
Nof 10

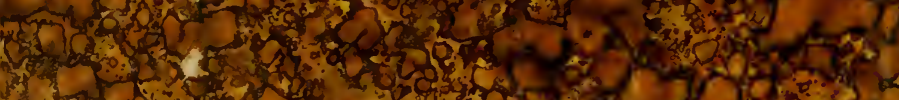

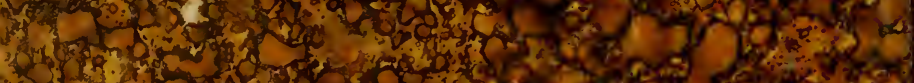

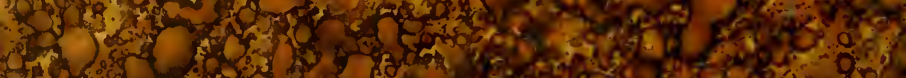

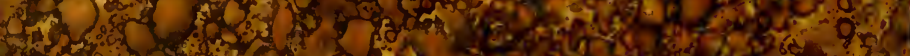

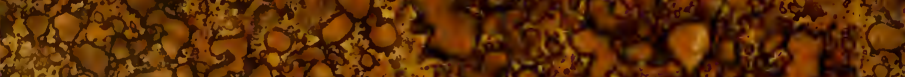

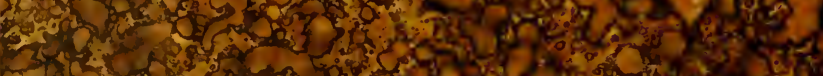

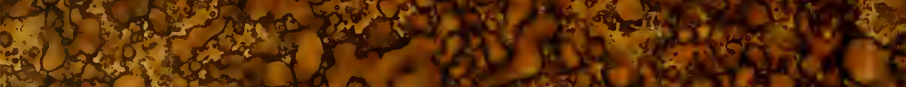

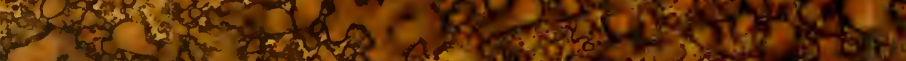

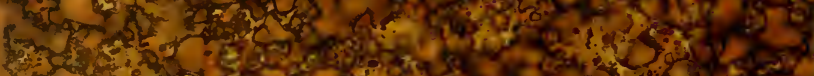

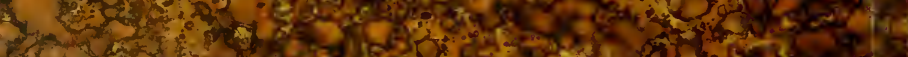

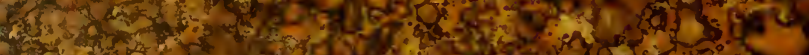

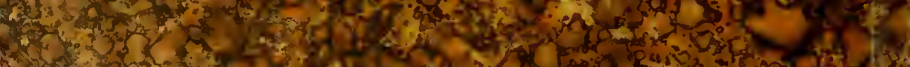

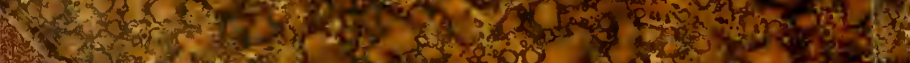

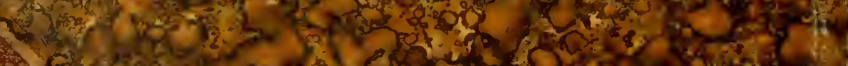

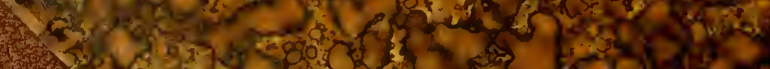

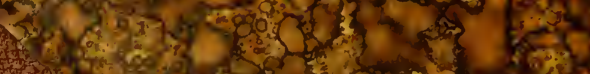

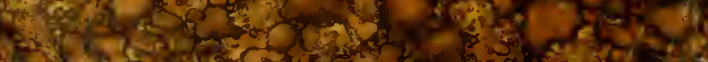

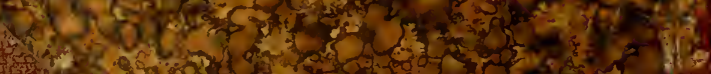

